RENATO NEGRETTI CRUZ

A TEORIA DOS SISTEMAS E A FORÇA NORMATIVA CONSTITUCIONAL DO SISTEMA JURÍDICO SANITÁRIO

Universidade de São Paulo

Faculdade de Direito

São Paulo - 2007 


\section{A TEORIA DOS SISTEMAS E A FORÇA NORMATIVA CONSTITUCIONAL DO SISTEMA JURÍDICO SANITÁRIO}

Dissertação apresentada ao Departamento de Direito do Trabalho e da Seguridade Social da Faculdade de Direito da Universidade de São Paulo para obtenção do título de mestre em Direito do Trabalho.

Orientador: Prof. Dr. Marcus Orione Gonçalves Correia

Universidade de São Paulo

Faculdade de Direito

$$
\text { São Paulo - } 2007
$$


Aos meus Queridos Pais, Vivaldo e Sueli, que não mediram esforços para realizar os sonhos de seus filhos, o meu mais terno e eterno agradecimento!

$\&$

$$
\text { À Aline, }
$$

Em retribuição ao Amor, carinho e apoio incondicionais! 


\section{AGRADECIMENTOS}

Ao Prof. Dr. Marcus Orione Gonçalves Correia, pela orientação atenta e cuidadosa e pela confiança e constante apoio;

Ao Prof. Titular Ignácio Maria Poveda Velasco, pelo apoio institucional no Programa de Pós-Graduação;

À Banca Examinadora do trabalho de qualificação, pelas observações e sugestões criteriosas;

Ao Sr. Alberto e à Sra. Celeste pelo incentivo e carinho fraternais;

Aos amigos Marcelo e Lucyla, pelos livros, pela leitura atenta do trabalho e pelas observações críticas às idéias nele discutidas;

Ao amigo André pela revisão criteriosa e por estar "sempre presente";

À Marli, pela guarda e acolhida filial no Departamento, ao Leandro pela amizade e pelas horas de descontração e à Cida pela atenção e incentivo à finalização deste trabalho;

À Margareth Augusta Bezerra da Silva e à Rosangela Aparecida Ventura Pupo, pela amizade e pelo suporte bibliográfico;

Agradeço ainda ao Aurélio Ribeiro dos Santos e à Agostinha Cardoso Batista pela acolhida na biblioteca e a todos os funcionários da Faculdade de Direito do Largo São Francisco;

Agradeço, finalmente, à Capes (Coordenação de Aperfeiçoamento de Pessoal de Nível Superior), que viabilizou este trabalho por meio de uma bolsa de estudos. 


\section{RESUMO}

Este trabalho, eminentemente bibliográfico, destina-se à revisão da teoria dos sistemas sociais autopoiéticos de Niklas Luhmann e à consideração de seus limites e suas implicações para a compreensão da força normativa constitucional do sistema jurídico sanitário brasileiro. Nesse sentido, são discutidas a diferenciação funcional da sociedade e a função sistêmica do Direito e da Constituição da República Federativa do Brasil de 1988 em generalizar e manter contrafactualmente as expectativas normativas relativas à saúde, indispensáveis para a dinâmica dos processos comunicacionais sociais.

A evolução do sistema sanitário nacional é situada no desenvolvimento do Estado brasileiro e na organização de suas políticas públicas em saúde, durante o século $\mathrm{XX}$, em comparação à conformação dos sistemas de saúde europeus, analisada por Michel Foucault em seus estudos sobre os modelos de Medicina Social e a Crise da Medicina Moderna.

Nesse contexto, a Constituição Federal de 1988 é identificada como o ponto de convergência dos processos comunicacionais da sociedade brasileira no sentido da mais abrangente forma de institucionalização de expectativas normativas, resultante do acoplamento estrutural dos sistemas sociais nacionais, não restritos, de forma alguma, aos seus sistemas jurídico e político.

Incorpora-se, assim, à compreensão do sistema jurídico sanitário a sua crescente complexidade operacional bem como a consideração das expectativas, dos conflitos, do funcionamento dos sistemas que compõe a sociedade brasileira e da função finalística dos programas e princípios constitucionais voltados à implementação dos direitos sociais fundamentais relacionados à saúde.

Palavras-chaves: Sistemas autopoiéticos; sistema sanitário; Constituição; Seguridade Social; direitos sociais; sistema jurídico sanitário. 


\begin{abstract}
This work, eminently bibliographical, is destined to the revision of the theory of Autopoietic Social Systems by Niklas Luhmann and to the consideration of its limits and its implications for the comprehension of the constitutional normative power of the Brazilian legal system as related to sanitation. To this end, the functional differentiation of society and the systemic function of the law and the Brazilian Constitution of 1988 to generalize and maintain contrafactual the normative expectations, which are indispensable to a dynamic of the processes of social communication.

The evolution of the national sanitary system is part of the development of the Brazilian state and in the organization of its public health policies, during the 20th century, in comparison to the European health systems analyzed by Michel Foucault in his studies of the Models of Social Medicine and the Crisis of Modern Medicine.

In this context, the Federal Constitution of 1988 is identified as the convergence point of the communicational processes of the Brazilian society in the sense of a wider form of institutionalization of normative expectations, resulting in the structural connection of the national social systems unrestricted in any manner to the legal and political systems.

We arrive thusly to the comprehension of the legal system of sanitation and its growing operational complexities as well as the consideration of the expectations, conflicts and functioning of systems that compose Brazilian society and the ultimate function of the programs and constitutional principles related to the implementation of fundamental social rights as related to health.
\end{abstract}

Key words: Autopoietic systems, sanitary system, Constitution, Social Security, social rights, legal system as related to sanitation 


\section{SUMÁRIO}

INTRODUÇÃO

\section{CAPÍTULO 1 A TEORIA SISTÊMICA E A AUTOPOIESE SOCIAL}

1.1 Teoria dos Sistemas e os paradigmas científicos

1.2 Principais Características do pensamento sistêmico 20

$\begin{array}{lll}\text { 1.2.1 Pensamento contextual } & 22\end{array}$

1.2.2 Auto-organização: Padrão, Estrutura e Processo 24

1.3 A autopoiese como o padrão da vida 25

1.4 Da autopoiese biológica à autopoiese social 30

1.5 Aspectos gerais da Teoria dos Sistemas Sociais de Niklas Luhmann 34

1.5.1 A distinção entre sistema e ambiente $\quad 40$

1.5.2 Sentido e fechamento operacional do sistema 55

1.5.3 Dupla contingência, programa e diferenciação funcional 61

1.5.4 Acoplamento estrutural e interpenetração 67

$\begin{array}{lll}\text { 1.5.5 Interações, Organizações e Sociedade } & 74\end{array}$

\section{CAPÍTULO 2 O DIREITO COMO SISTEMA SOCIAL AUTOPOIÉTICO 84}

2.1 A posição da teoria sistêmica em face das principais teorias analíticas e $\quad 84$ correntes marxistas do direito

2.2 A autopoiese do Direito 103

2.2.1 Operacionalização e função do sistema jurídico 107

2.2.2 Desdobramentos da autopoiese do sistema jurídico 121

$\begin{array}{lll}2.3 & \text { Críticas ao pensamento sistêmico do direito } & 124\end{array}$ 
2.4 O acoplamento estrutural entre o sistema jurídico e o sistema sanitário

2.4.1 A autopoiese do sistema sanitário

CAPÍTULO 3 O PAPEL DA MEDICINA SOCIAL NO ESTADO 135 MODERNO E AS TENSÕES ENTRE OS SISTEMAS

3.1 Antecedentes históricos da saúde pública 138

3.1.1 Povos antigos

3.1.2 Grécia 141

3.1.3 Roma 142

3.1.4 Idade Média 147

3.2 O impacto da Medicina Social da conformação das políticas de saúde 158

3.2.1 Medicina de Estado - modelo alemão, século XVIII 160

3.2.2 Medicina Urbana - modelo francês, final do século XVIII 164

3.2.3 Medicina dos Pobres e da Força de Trabalho - modelo inglês, século XIX 171

3.2.4 Plano Beveridge e a saúde no Estado de Bem -Estar Social Europeu

CAPÍTULO 4 O SISTEMA SANITÁRIO NACIONAL A PARTIR DA 196 FORMAÇÃO DO ESTADO E DA ORGANIZAÇÃO DA SAÚDE NO BRASIL

4.1 Antecedentes históricos do Brasil-Colônia à Proclamação da República 199

4.2 A República Velha e a conformação inicial do sistema sanitário brasileiro 205

4.3 O sistema de saúde a e sua relação com a previdência entre 1930 e $1964 \quad 220$

4.4 O Movimento pela Reforma Sanitária e as tensões bio-políticas com o 235 modelo biomédico hegemônico do final do século XX

4.4.1 Configuração e crise do modelo biomédico brasileiro 236

4.4.2 O Movimento pela Reforma Sanitária e as tensões entre os sistemas 242 sociais brasileiros em torno de um novo sentido para a saúde pública

4.5 Aspectos gerais da nova organização constitucional do sistema sanitário 249 brasileiro 
CAPÍTULO 5 A FORÇA NORMATIVA CONSTITUCIONAL DO 257 SISTEMA JURÍDICO SANITÁRIO

5.1 A força normativa da Constituição e a teoria dos sistemas 258

5.1.1 Dupla contingência e função sistêmica do direito 259

5.1.2 Constituição, expectativas normativas e os sistemas sociais 262

5.2 A Seguridade Social sob a perspectiva sistêmica do direito 267

5.2.1 Seguridade Social, teoria e interpretação dos direitos sociais 268 enquanto direitos fundamentais e sua função na autopoiese do sistema jurídico sanitário

5.2.2 A incidência e os condicionantes da interpretação constitucional 279 sobre o sistema jurídico sanitário

CONCLUSÃO 


\section{INTRODUÇÃO}

O tema desenvolvido nesta dissertação diz respeito às possibilidades e aos limites da Teoria dos Sistemas Sociais de Niklas Luhmann (1998) para a compreensão da função social desempenhada pelo sistema jurídico sanitário brasileiro e de sua força normativa constitucional na manutenção, como normas jurídicas, das expectativas normativas relacionadas à saúde.

A Teoria dos Sistemas Sociais insere-se no pensamento sistêmico, originário das ciências naturais, mais especificamente no domínio da biologia, no qual se destacaram as pesquisas referentes ao processo de cognição e a ênfase na concepção dos organismos vivos como totalidades integradas, tendo por expoentes os estudos neurofisiológicos de Humberto Maturana e Francisco Varela (1980, 1997, 2005).

O pensamento sistêmico ganhou força, durante o século $\mathrm{XX}$, com os estudos voltados para a compreensão dos sistemas vivos, inicialmente realizados por biólogos organísmicos e, paralelamente, pelos trabalhos acerca dos padrões de comunicação em laços fechados e em redes, desenvolvidos por ciberneticistas de várias áreas, como da matemática, neurociência, engenharia e sociologia. (CAPRA, 1996).

As descobertas relacionadas ao processo de cognição e aos referidos padrões de comunicação levaram ao questionamento das bases do conhecimento humano e a busca de novos fundamentos para o método científico, cujo fator de validação não poderia permanecer restrito à observação de um objeto externo ao ser cognoscente.

A extensão desse questionamento e a adaptação da teoria sistêmica para o campo das ciências sociais são consideradas como traços marcantes da evolução científica interdisciplinar do final do século passado, na medida em que alcançaram as mais diversas áreas do conhecimento como a lingüística, lógica, biologia, física, matemática, cibernética, psicologia, sociologia, ciência política, ética e a ciência jurídica. (ANTUNES, 1989, p. ix).

A efetiva transposição dessa nova teoria sistêmica para o estudo da sociedade como um mecanismo gerador abstrato de uma hipótese teórica explicativa dos sistemas 
sociais é atribuída por diversos autores ao sociólogo alemão Niklas Luhmann. ${ }^{1}$

Como será detalhado no primeiro capítulo, a partir do sentido de autopoiese proposto por Maturana e Varela (1980), Luhmann (1998) procurou reposicionar a sociologia como uma teoria social com pretensões de universalidade.

Propôs, assim, sua Teoria da Sociedade como um modelo teórico alternativo voltado à consideração da complexidade da sociedade moderna, de modo a superar os impasses do método tradicional científico, reduzindo seu distanciamento de discussões transdisciplinares e dos resultados científicos obtidos em outras áreas do conhecimento.

A teoria sistêmica foi então adaptada às ciências sociais como sistemas autoreferenciais de comunicação, repercutindo numa nova forma de entender as relações entre os sistemas sociais que compõe a sociedade e, por conseguinte, a própria função do direito como sistema.

A aplicação de sua Teoria da Sociedade, como um sistema autopoiético, ao estudo do direito foi empreendida por Luhmann (1989a, 1990a, 1992, 1998), sendo posteriormente adotada com novas contribuições por diversos autores como Gunther Teubner (1989b), Celso Fernandes Campilongo (2000b, 2002), Germano Schwartz (2004), dentre outros.

Busca-se, assim, reformular a ciência jurídica com o fim de reestruturar suas premissas científicas de maneira diversa ao idealismo do Positivismo científico natural. Este modelo, como será discutido no segundo capítulo, tornou-se insuficiente para o estudo do direito frente à evolução social e ao aumento de sua complexidade.

A dinâmica da sociedade moderna e das inter-relações entre seus diversos sistemas sociais tornariam impossível sua análise, no sentido técnico tradicional referente à observação e fragmentação do objeto de estudo em partes para se alcançar, no momento seguinte, a sua compreensão como um todo.

O objetivo deste trabalho consiste, portanto, na revisão dessa teoria sistêmica

\footnotetext{
${ }^{1}$ Nesse sentido, apontam Fritjof Capra (1996, p. 172), José Engrácia Antunes (1989, p. x), Gunther Teubner (1989b, p. 737), Germano Schwartz (2004. p. 27), Celso Fernandes Campilongo (2000a, p. 73, 2002, p. 18 e p. 66), Dário Rodríguez Mansilla e Javier Torres Nafarrate (2003, p. 106 e 122), Orlando Villas Bôas Filho (2006a, p. 12 e p. 101), Jean Clam (2006, p. 19), dentre outros autores.
} 
em sua perspectiva jurídica e no questionamento de sua contribuição para a compreensão do sistema jurídico sanitário e de sua força normativa constitucional na garantia do Direito à Saúde tal como previsto na Constituição da República Federativa do Brasil de 1988.

Para tanto, faz-se necessário situar a diferenciação dos sistemas sanitário e jurídico brasileiros sob o enfoque da evolução e organização das ações e serviços estatais de saúde, relacionadas ao próprio desenvolvimento do Estado nacional e às constantes tensões sistêmicas, sobretudo entre os sistemas político e econômico, em torno dos sentidos e das atribuições públicas e da sociedade como um todo em matéria de saúde.

Como foi possível adiantar nesse panorama introdutório, o primeiro capítulo da presente dissertação destina-se à exposição da Teoria dos Sistemas e a conformação do referido pensamento sistêmico como uma possível forma de ruptura do atual paradigma científico, delineando-se, assim, suas linhas gerais, suas origens no campo das ciências naturais e sua adaptação inicial às ciências sociais.

No segundo capítulo é empreendida a crítica ao positivismo científico jurídico e discutidos os limites de sua substituição pela abordagem sistêmica do direito. Nesse intento, a teoria sociológica jurídica de Luhmann (1983) e sua visão autopoiética dos sistemas sociais são discutidas a fim de se chegar à compreensão do funcionamento e da função do sistema jurídico na sociedade moderna.

Empreende-se, dessa forma, a crítica e a releitura das principais idéias relacionadas à visão autopoiética do direito e suas implicações no campo mais específico do sistema jurídico sanitário, sobretudo no "acoplamento estrutural" entre o mesmo e o sistema sanitário brasileiro.

O terceiro capítulo, embora destoe aparentemente da linha mais abstrata da discussão teórica inicial do trabalho, é de suma importância para a compreensão do sistema sanitário brasileiro abordado no capítulo seguinte.

Assim se afigura, pois, ao se tratar do papel da Medicina Social no Estado Moderno e das tensões entre os sistemas, neste terceiro segmento da dissertação são questionados os pressupostos da evolução dos cuidados estatais em saúde e do próprio Direito Sanitário sob os quais se assenta uma respeitável parte da doutrina jurídica nessa 
área. Tal questionamento é empreendido pela confrontação dessa doutrina com os estudos de George Rosen (1979, 1994), Paul Singer, Oswaldo Campos e Elizabeth Machado de Oliveira (1981) e de Michel Foucault (1974, 1979). ${ }^{2}$

Nesse sentido, no terceiro capítulo são discutidas as origens e o desenvolvimento da atuação do Estado em matéria de saúde da população frente à dicotômica visão esboçada, de um lado, por autores que tendem a identificar a Revolução Industrial como o divisor de águas da responsabilização do Estado nessa matéria e, de outro lado, pelos citados pesquisadores da história da Medicina Social e da organização dos serviços sanitários, para os quais essa atuação estatal precede à Revolução Industrial do século XIX não se restringindo a certos grupos de trabalhadores, podendo sim ser situada em diferentes momentos da história contemporânea numa inter-relação política, econômica e social de poder.

Pretende-se, com isso, aferir a pertinência e as potencialidades dessa segunda tese através da contextualização histórica e social dessas relações, desde as antigas práticas de saúde pública, anteriores às revoluções científicas do final do século XVIII, até a conformação de uma nova forma de saúde pública, marcada pelo nascimento da Medicina Social, fundamental para a estruturação e evolução do Estado Moderno.

Dessa forma é traçado o panorama do desenvolvimento histórico e estrutural das principais relações entre o sistema jurídico e os sistemas político, econômico e científico que têm informado a organização das sociedades ocidentais e a atuação do Estado Moderno nas questões relativas à saúde pública de sua população.

Delimitada, neste terceiro capítulo, a abrangência dessas formas européias da atuação estatal em saúde, caracterizadas como estratégias bio-políticas de controle social sobre os corpos por Foucault $(1974,1979)$, passa-se, no quarto capítulo, à discussão de suas potencialidades para a compreensão da diferenciação dos sistemas sociais nacionais, considerando-se as peculiaridades históricas brasileiras.

A partir dessa dinâmica social, sintetizada por Foucault (1979) em seus

\footnotetext{
${ }^{2}$ No que diz respeito à primeira forma interpretativa da atuação do Estado em matéria de saúde a ser questionada, esta é, de certa forma, depreendida dos trabalhos de Sueli Gandolfi Dallari (1987), Paulo Antônio de Carvalho Fortes (DALLARI; FORTES, 1997, p. 187-202) e Marcus Faro de Castro (2003, p. 379-390), dentre outros estudiosos da saúde pública.
} 
modelos europeus de Medicina Social, cumpre no quarto capítulo a sua comparação com a evolução dos sistemas sociais brasileiros em torno da organização do sistema de saúde nacional.

Entende-se de grande relevância a discussão de suas possíveis influências e adaptações à realidade nacional, especialmente, na conformação do sistema sanitário brasileiro e das tensões sistêmicas entre o Movimento pela Reforma Sanitária e o modelo biomédico hegemônico no Brasil ao final do século XX.

Uma vez delimitadas a conformação do sistema sanitário brasileiro e as interrelações entre os diversos sistemas sociais em torno da saúde, sobretudo, no movimento pela redemocratização do Brasil e pela reformulação de seu sistema nacional de saúde, no quinto e último capítulo, a força normativa do sistema jurídico sanitário é, enfim, discutida situando-se a Constituição Federal de 1988 como o centro de convergência dos processos comunicacionais da sociedade brasileira.

A partir da teoria sistêmica e do estudo dos direitos sociais, o sistema jurídico sanitário e sua força normativa são revistos sob a perspectiva da evolução da sociedade brasileira e de seu sistema constitucional de Seguridade social.

Nesse sentido é empreendida a contextualização do sistema jurídico sanitário no âmbito da Seguridade Social, destacando sua inserção na esfera da Ordem Social e dos Direitos e Garantias Fundamentais, enquanto parte integrante de um todo que compreende tanto os direitos fundamentais civis e políticos quanto os imprescindíveis e indissociáveis direitos fundamentais sociais, econômicos e culturais.

De sua inserção na Constituição e da função sistêmica por ela desempenhada em relação a todos os sistemas sociais que compõe a sociedade brasileira é possível se delimitar a força normativa do sistema jurídico sanitário.

Justifica-se, assim, o presente trabalho em razão da importância de se empreender um estudo capaz de situar a autopoiese do sistema jurídico sanitário sob o enfoque funcional dos princípios normativos constitucionais na definição de seus códigos, bem como de sua contextualização no âmbito da Seguridade Social e na dinâmica dos processos comunicacionais circulares e auto-referenciais a esse sistema mais abrangente de proteção social que compõe a esfera constitucional da Ordem Social e dos Direitos e Garantias Fundamentais. 


\section{A TEORIA SISTÊMICA E AUTOPOIESE SOCIAL}

Este capítulo inicial destina-se à releitura das principais idéias relacionadas à teoria dos sistemas e à consideração dos limites e das implicações de sua abordagem autopoiética para a compreensão do funcionamento e estruturação dos sistemas sociais.

A teoria dos sistemas, com as revisões que se pretende destacar, representa a base desse trabalho acadêmico, em razão de suas potencialidades explicativas relacionadas ao Direito à Saúde e sua interpretação constitucional, na qual se destacam os acoplamentos estruturais entre o sistema jurídico e o sistema sanitário brasileiros. Sua escolha parte da reestruturação das premissas científicas em que a construção do saber jurídico, enquanto ciência social, não pode se restringir ao idealizado Positivismo científico naturalista, incompatível com a peculiaridade dos objetos de estudo sociais — suas inter-relações; a impossibilidade de sua análise, no sentido técnico de fragmentação e observação do objeto de estudo em partes, a partir das quais se atingiria a compreensão do todo - e da própria relação subjetiva do observador com tais objetos.

Em que pese a natureza auto-referencial dos sistemas sociais e a impossibilidade de sua total compreensão através de uma observação que thes seja exterior, há que se ressaltar a preocupação de não se reproduzir nesta dissertação qualquer "reducionismo sistêmico" decorrente de sua equivocada consideração meramente funcionalista (restrito a sua função comunicacional interna aos subsistemas sociais autopoiéticos), que privilegiasse tão somente seus mecanismos auto-reprodutivos, operacionalmente fechados ao ambiente.

Pelo contrário, com essa peculiar base teórica, objetiva-se nos capítulos seguintes interpretar algumas das intrincadas relações entre o direito, a busca de melhores condições de saúde e as expectativas sociais a ela relacionadas, especialmente no que diz respeito à capacidade do sistema jurídico em reprocessar não só as demandas externas dos demais sistemas sociais e do ambiente da sociedade em torno da saúde, como seus próprios conflitos internos (suas “antinomias aparentes", seus “conflitos de valores e princípios"). 
Pretende-se incorporar à compreensão do subsistema jurídico sanitário brasileiro sua crescente complexidade operacional que não pode desconsiderar as expectativas e o funcionamento do sistema sanitário muito menos a função finalística dos programas constitucionais para a implementação dos direitos sociais fundamentais relacionados à saúde.

\subsection{Teoria dos Sistemas e os paradigmas científicos}

A teoria dos sistemas desenvolvida no campo das ciências sociais como sistemas auto-referenciais de comunicação por Niklas Luhmann (1998) e, no âmbito jurídico, adaptada por diversos autores como Gunther Teubner (1989b), Celso Fernandes Campilongo (2000b, 2002), apresenta-se como uma extensão, mutatis mutandis, do pensamento sistêmico originado em outras áreas científicas, mais especificamente no domínio da biologia a partir do estudo dos processos de cognição e da ênfase na concepção dos organismos vivos como totalidades integradas, tendo por expoentes os estudos neurofisiológicos de Humberto Maturana e Francisco Varela (1980, 1997, 2005).

Para que se possa compreender a dimensão em que se insere o pensamento sistêmico e sua ruptura com o atual paradigma científico, é preciso, inicialmente, tecer algumas considerações sobre suas origens e o contexto cultural no qual se desenvolveu. ${ }^{3}$

\footnotetext{
${ }^{3}$ A noção de paradigma científico a que nos referimos se relaciona àquela desenvolvida por Thomas $\mathrm{S}$. Kuhn (1989, p. 218), utilizada em sentido mais amplo para designar "toda a constelação de crenças, valores, técnicas etc., partilhadas pelos membros de uma comunidade determinada", correspondendo, em linhas gerais, ao conjunto global de incumbências reconhecidas pelo grupo ou comunidade que pratica a ciência organizada em certos moldes. Em que pese as críticas ao seu uso generalizado e à perda do original sentido, decorrentes de sua transferência para a esfera das Ciências Sociais (ASSIS, 1993), o questionamento proposto por Kuhn (1989) não teve sua importância reduzida enquanto síntese do conjunto de transformações a que o conhecimento científico está sujeito em seu contínuo movimento de (r)evolução. Assim, a despeito das fortes críticas que suas iniciais considerações sobre o tema suscitaram, a pertinência das idéias depreendidas do conceito mais amplo de paradigma teria levado o citado autor a propor o conceito de "matriz disciplinar", tendo em vista diferenciar esse "sentido amplo" do "sentido preciso" e inicialmente proposto de paradigma, de modo que desse novo conceito se podem depreender quatro elementos: (i) generalizações simbólicas; (ii) partes metafísicas do paradigma; (iii) exemplares (que representariam o próprio paradigma em seu sentido preciso), e, por fim, (nem por isso menos importante) (iv) valores. Não cabe ao presente estudo aprofundar a explicação e implicações desses quatro elementos, sendo, por ora, relevante apenas destacar o seu impacto na compreensão do sistema social "ciência", responsável pela "observação de segunda ordem" dos demais sistemas sociais na concretização dos processos sobrecomunicacionais que compõem as operações de observação dos sistemas autopoiéticos (NEVES, 2005, p. 36-38). Nessa específica questão, se insere a noção kuhniana de paradigma, mais especificamente, de seu elemento "valor", posto que, segundo o destaque de Simone Petraglia Kropf e Nísia Trindade Lima (1999),
} 
Segundo Fritjof Capra (1996), a ascensão do pensamento sistêmico introduzido no campo da biologia e posteriormente enriquecido pela psicologia da Gestalt e pela nova ciência da ecologia, com grandes repercussões até mesmo na física quântica situa-se na mudança do paradigma mecanicista para o ecológico, originada no século XX, a partir da década de 20, ocorrida de forma não uniforme em diversos campos científicos, tendo por tensão básica a dicotomia entre as partes e o todo. ${ }^{4}$

A ênfase nas partes tem sido chamada de mecanicista, reducionista ou atomística, ao passo em que a ênfase no todo, de holística, organísmica ou ecológica, sendo que esta perspectiva holística, na ciência do século $\mathrm{XX}$, tornou-se conhecida tecnicamente como sistêmica. (CAPRA, 1996, p. 33).

A importância dessa mudança de paradigma não se resume às ciências biológicas ou naturais, sendo destacada no presente estudo por suas repercussões em toda a base filosófica e analítica que sustenta o pensamento científico ocidental e, por conseguinte, as ciências sociais e jurídicas. Assim, conclui enfaticamente Fritjof Capra

“[...] este último elemento [valorativo] é, para Kuhn, o que confere o sentido de pertencimento dos cientistas a uma comunidade global e específica, garantindo o compromisso profundo destes com uma determinada maneira coletiva de praticar a ciência. A idéia de valores como elementos que legitimam o cumprimento de um conjunto de normas é, portanto, de fundamental importância para compreender-se de que maneira Kuhn concebe a ciência normal como atividade de pesquisa fundada numa sólida rede de compromissos e adesões a um paradigma compartilhado por uma determinada comunidade de praticantes da ciência". Nesse sentido, embora ainda estejamos vivendo um período de transição em que o paradigma mecanicista em sua vertente positivista esteja sendo fortemente questionado, sem, contudo, se ter consolidado um novo paradigma, é justamente pela propositura de novos valores a que, especialmente, o direito está condicionado - do ponto de vista da efetivação dos valores e princípios constitucionais que são inerentes a este trabalho sobre a força normativa do direito social à saúde - que a teoria dos sistemas, desde que readaptada para cumprir essa específica função explicativa, nos afigura como uma "escola de pensamento" (embora não se possa falar da existência de apenas uma única, ou dominante corrente sistêmica) que compete fortemente para esse processo de ruptura.

${ }^{4} \mathrm{O}$ significado do termo Gestalt, em si, é de grande valia para a compreensão de como a ruptura com o paradigma cientifico em discussão se estende pelos diversos campos do conhecimento. Segundo Mapheus Smith (1974, p. 150), trata-se de "palavra alemã que significa forma. Exprime-se, por ela, um todo indiviso e articulado, composto de partes interdependentes. O todo está formado por integração, mais do que por simples adição das partes. Cada parte é um membro do todo e a natureza da parte depende do fato de pertencer ao todo". Ademais, tal conjunto de idéias é muito utilizado no campo da psicologia, como concepção básica da escola psicológica chamada Gestalt. Insere-se, pois, no movimento da Gestalt, que conforme explica Frederich W. Killian (1974, p. 150), corresponde ao "método de estudo dos fenômenos no campo das Ciências Sociais cuja particular aspiração consiste em encontrar nos fenômenos de massa, todos coerentes, funcionais e plenos de sentido, bem como estudar a conduta dêsses todos, e a das partes que o constituíam, e as relações entre as partes e os todos. [...] Como movimento dentro das Ciências Sociais, o método da Gestalt foi iniciado pela primeira vez no campo da Psicologia, à altura de 1895, por Carlos von Ehrenfelds, na Alemanha [...]". 
(1996, p. 41):

\begin{abstract}
A emergência do pensamento sistêmico representou uma profunda revolução na história do pensamento científico ocidental. A crença segundo a qual em todo sistema complexo o comportamento do todo pode ser entendido inteiramente a partir das propriedades de suas partes é fundamental no paradigma cartesiano. Foi este o célebre método de Descartes do pensamento analítico, que tem sido uma característica essencial do moderno pensamento científico. $\mathrm{Na}$ abordagem analítica, ou reducionista, as próprias partes não podem ser analisadas ulteriormente, a não ser reduzindo-as a partes menores. De fato, a ciência ocidental tem progredido dessa maneira, e em cada passo tem surgido um nível de constituintes fundamentais que não podia ser analisado posteriormente. $\mathrm{O}$ grande impacto que adveio com a ciência do século $\mathrm{XX}$ foi a percepção de que os sistemas não podem ser entendidos pela análise. As propriedades das partes não são propriedades intrínsecas, mas só podem ser entendidas dentro do contexto do todo mais amplo. Desse modo, a relação entre as partes e o todo foi revertida. $\mathrm{Na}$ abordagem sistêmica, as propriedades das partes podem ser entendidas apenas a partir da organização do todo. Em conseqüência disso, o pensamento sistêmico concentra-se não em blocos de construção básicos, mas em princípios de organização básicos. O pensamento sistêmico é 'contextual', o que é o oposto do pensamento analítico. A análise significa isolar alguma coisa a fim de entendê-la; o pensamento sistêmico significa colocá-la no contexto de um todo mais amplo.
\end{abstract}

É justamente nesse sentido - a ser discutido em detalhes após a consideração das noções gerais desse novo paradigma sistêmico em vias de se consolidar, mas que já se pode adiantar o seu panorama —, que o sociólogo alemão Niklas Luhmann (1927-1998), em todo o seu trabalho acadêmico de quase três décadas voltado para a construção de uma (nova) teoria da sociedade moderna, buscou reposicionar a sociologia, enquanto ciência, como a teoria da sociedade. ${ }^{5}$

Afasta-se, assim, da sociologia alemã vigente no começo do século XX, cuja identidade esconderia sua relação com a sociedade, em razão de sua inclinação para o objetivismo empirista das ciências naturais, "com sua ênfase na causalidade e na

\footnotetext{
${ }^{5}$ A dimensão da obra de Luhmann é considerada por certos autores como uma "[...] superteoria, com pretensões de universalidade, valer dizer, que reclama aplicabilidade para todo fenômeno social". O que não implicaria, de forma alguma, a exclusão de outras teorias explicativas do fenômeno social, nem mesmo a impossibilidade de um diálogo interdisciplinar entre elas: “[...] Esta pretensão de universalidade não deve ser entendida, no entanto, com a intenção de excluir outras possibilidades de interpretações teóricas que desde a própria sociologia até outras disciplinas; desde a ciência ou outros subsistemas da sociedade possam levantar-se com alternativas. Pelo contrário, a teoria dos sistemas de Niklas Luhmann tem se constituído em diálogo constante com diferentes esforços conceitualizadores provenientes da filosofia, sociologia, lógica formal, do direito, teologia, biologia, física etc." (RODRÍGUEZ; TORRES, 2003, p. 107).
} 
descoberta de leis", centrando sua estrutura conceitual básica numa insuficiente "teoria de entidades sociais, com categorias tais como papéis, interação, intenção e ação social" (BECHMANN; STEHR, 2001, p. 187).

Para Gotthard Bechmann e Nico Stehr (2001, p. 191), além de romper com o referido paradigma centrado na relação "sujeito-objeto", própria da metodologia científica clássica, e de partir para uma visão holística da sociedade, no sentido da histórica dicotomia entre as partes e o todo, Luhmann teria, ainda, se distanciado da "velha tradição européia teórica ontológica" que seria insuficiente "para captar a sociedade moderna em toda sua complexidade", de modo que a unidade deixaria de ser "o ponto de referência definitiva" de sua teoria da sociedade passando a ser destacada a consideração da diversidade e da dispersão das identidades. ${ }^{6}$

A estas profundas rupturas conceituais, como será discutido mais à frente, não ficaram imunes as possíveis formas de se compreender o direito, abrindo-se não apenas novos espaços de saber-poder (FOUCAULT, 1997), que o envolve enquanto prudência, como também a oportunidade de se compreender sua dinâmica, seus limites e suas

\footnotetext{
${ }^{6}$ Sobre a inflexão e ruptura com a tradição européia teórica ontológica por Niklas Luhmann, Gotthard Bechmann e Nico Stehr (2001, p. 191-192) entendem que: “[...] Ele [Luhmann] caracteriza o velho estilo europeu de pensamento pela preocupação com a identificação de unidade sob a diversidade. A sociedade, na visão clássica, consiste de sujeitos de ação cuja unidade fundamental baseia-se na partilha de um entendimento comum. A ontologia refere-se a um mundo existindo objetivamente, separado dos sujeitos que são conscientes de sua existência e capazes de uma representação lingüística não ambígua. Contra isso, Luhmann apresenta um mundo que temporaliza, diferencia e descentraliza todas as identidades. Identidades são produtos de eventos passados. A unidade não mais é o ponto de referência definitivo da teoria. Quando ele relativiza até o esquema ontológico da existência/ não existência como apenas um dos muitos esquemas observáveis, Luhmann ataca as bases de poderosas tradições do pensamento. O paradoxo, de acordo com ele, é que a velha tradição européia emergiu numa sociedade que, hoje, não existe mais, seja em termos de sistema de comunicação ou em termos de formas de diferenciação. [...] [Sendo assim, sua] teoria da sociedade está localizada em dois níveis: no nível semântico ela se distingue da velha tradição européia, enquanto no nível da estrutura social faz-se referência à evolução, diferenciação e ao desenvolvimento da mídia". No mesmo sentido, se posicionam Dário Rodríguez e Javier Torres (2003, p. 125): "A dimensão da qual se depreende que a sociedade seja uma ordem emergente autopoiética deve ser sopesada com todo cuidado, já que contradiz toda a tradição filosófica e sociológica que se sustenta na conceituação do sujeito [...] Desde o momento em que Luhmann opta pela conceituação de autopoiesis, rompe com a tradição de pensamento europeu". Já Rômulo Figueira Neves (2005), ao dissertar sobre Luhmann e a tradição sociológica, embora contemporize com os demais autores acima citados interpretando a teoria luhmanniana como uma "tentativa de superar os déficits da capacidade da tradição sociológica na explicação da sociedade [em sua modernidade e em face da complexidade das novas formas de relações sociais emergentes]", por sua vez, acrescenta que tal distanciamento "não significa que ele [Luhmann] não tenha tido conhecimento e domínio das teorias clássicas, mas sim que a elaboração da teoria dos sistemas sociais não pode ser tributada a um diálogo específico com este ou aquele autor, apesar de ser possível realizar uma análise genética e identificar algumas aproximações com diversos deles" (NEVES, 2005, p.10).
} 
possibilidades relacionadas ao cumprimento de sua função principiológica e valorativa constitucional em face da complexa conformação das relações (comunicacionais) internas à sociedade e desta com seu ambiente. ${ }^{7}$

\subsection{Principais características do pensamento sistêmico}

Antes de se iniciar o detalhamento da visão sistêmica do direito, faz-se necessária a consideração de alguns aspectos gerais das teorias sistêmicas relacionados especificamente ao estudo dos sistemas vivos e dos mecanismos de cognição (teoria biológica do conhecimento) para, em seguida, serem abordadas suas possíveis implicações e desdobramentos no campo das ciências sociais, com especial atenção para a construção de suas teorias sistêmicas sociais.

As origens do pensamento sistêmico podem ser relacionadas às pesquisas desenvolvidas durante todo o século $\mathrm{XX}$ voltadas ao estudo dos sistemas vivos, inicialmente pelos biólogos organísmicos e, paralelamente, pelos ciberneticistas, estes, em sua grande parte, matemáticos, neurocientistas, cientistas sociais e engenheiros, “preocupados com um diferente nível de descrição, concentrando-se em padrões de comunicação, e especialmente em laços fechados e em redes”. (CAPRA, 1996, p. 56).

Um considerável avanço na compreensão dos sistemas vivos, em particular, foi alcançado a partir da formulação de dois questionamentos centrais a esse estudo: "qual é a organização da vida?” e “o que ocorre no fenômeno de percepção?” (MATURANA;

\footnotetext{
${ }^{7}$ As referências a Michel Foucault e às relações entre poder e saber por ele desvendadas em A Arqueologia do Saber (1997), se fazem não no sentido de negar, ou de menosprezar, sua profícua discussão acerca das "verdades científicas" enquanto produtos de um sistema de poder vigente em determinado período. Justamente por considerar tais estudos que denunciam a possibilidade (comprovada historicamente) da validação do conhecimento científico remeter a uma questão de poder, na medida em que este determinaria os enunciados científicos como verdadeiros ou falsos em uma época, é que, justamente, defendemos a necessidade do estudo crítico desse novo paradigma científico sistêmico em vias de consolidação (mais do que sua simples negação ou a sua adesão modista e acrítica), por meio de sua confrontação com a evolução dos direitos sociais, no qual despontam a Seguridade Social e seu subsistema sanitário, de modo a influir, de alguma forma, na disseminação e reelaboração desse conhecimento, reduzindo, consequentemente, o poder e, quem sabe, os riscos sociais, que se concentrariam com a persistência de seu abandono à formulação por teóricos atualmente alheios à luta diária pela concretização dos direitos sociais — tão sujeita às tensões com os demais sistemas sociais como o econômico e o político. Busca-se, assim, aferir as possibilidades de sua utilização como uma teoria de resistência do direito contra os extrapolamentos das próprias fronteiras sistêmicas (alopoises) e as hodiernas tentativas de subversão de sua lógica operativa interna por outros subsistemas sociais que, dessa forma, obstam a sua efetivação.
} 
VARELA, 1980, p. xii).

Tais questionamentos levaram o neurocientista chileno Humberto R. Maturana (1980), com o auxílio de Francisco J. Varela, a desenvolver a concepção de organização circular, denominando-a inovadoramente de autopoiese - termo que passou a ser amplamente difundido nas mais diversas áreas do conhecimento - e, posteriormente, em resposta à segunda questão citada, à formulação da Teoria da Cognição de Santiago. (CAPRA, 1996, p. 87 e 210).

Essa teoria se insere, portanto, no desenvolvimento do estudo biológico do conhecimento, em face da constatação empírica da impossibilidade de se distinguir entre ilusão e percepção em meio a experiências, que levou Humberto R. Maturana (1996, p. 30) à desafiadora afirmação de que "as explicações científicas não explicam um mundo independente, explicam a experiência do observador". 8

Por conseguinte, daí resultou um profundo questionamento dos fundamentos do conhecimento humano e a busca de uma nova base para o método científico, cujo fator de validação não mais se centrasse na observação de um objeto externo.

Assim, a formulação do conceito de autopoiese, já em sua inicial concepção, assumiria uma "radicalidade explosiva" ao questionar uma série de "certezas" com as quais se atua na sociedade contemporânea, propondo a sua reconsideração a partir de uma outra perspectiva possível. Enquanto alternativa para a compreensão da forma e dos limites envolvidos na interpretação da realidade, tal proposta, por si só, se justificaria justamente por ser uma "outra perspectiva possível", e não tanto por um hipotético juízo valorativo, não aferível, que a elegeria como "a melhor" teoria do conhecimento (RODRÍGUEZ; TORRES, 2003, p. 110).

\footnotetext{
${ }^{8}$ Acrescente-se a essa assertiva, na mesma linha da noção kuhniana de paradigma (KUHN, 1989), que para o referido autor, além do aspecto reflexivo do conhecimento construído pelo observador, do ponto de vista de sua própria externalização, uma "explicação é sempre uma proposição que reformula ou recria as observações de um fenômeno, num sistema de conceitos aceitáveis para um grupo de pessoas que compartilham um critério de validação". (MATURANA; VARELA, 2005, p. 34).
} 


\subsubsection{Pensamento Contextual}

A partir do acima citado deslocamento da atenção dos cientistas das partes para o todo, tem-se como primeira característica do pensamento sistêmico o fato de que os sistemas vivos, enquanto totalidades integradas, possuem propriedades essenciais que nenhuma das partes possui.

Afasta-se, portanto, do pensamento sistêmico a crença cartesiana na análise das propriedades das partes para se atingir a compreensão do comportamento do todo em qualquer sistema complexo.

Tal mudança "das partes para o todo" pode ser entendida como uma considerável mudança de objetos para relações. ${ }^{9}$

Ultrapassada a visão mecanicista do mundo enquanto uma coleção de objetos, na visão sistêmica compreende-se que os próprios objetos são redes de relações, inseridas em redes maiores, sendo por tal razão o pensamento sistêmico também denominado pensamento em rede (vernetztes Denken). (CAPRA, 1996, p. 47). ${ }^{10}$

Outra característica, ou "critério", do pensamento sistêmico apontada por Fritjof Capra (1996, p. 46) diz respeito à "capacidade de deslocar a própria atenção de um lado para o outro entre níveis sistêmicos".

Nesse sentido, por toda parte podem ser encontrados sistemas "aninhados" dentro de outros sistemas, sendo que, em geral, diferentes níveis sistêmicos representam níveis de diferentes complexidades.

Não haveria, portanto, uma relação de hierarquia entre esses níveis, mas, sim, de interdependência, sendo que, em cada nível, os fenômenos observados demonstram

\footnotetext{
${ }^{9}$ Embora constitua uma importante questão a ser discutida no decorrer do trabalho, desde já se faz importante destacar que tal mudança não implica em que este novo enfoque relacional deva se restringir a seu aspecto meramente funcionalista, sendo compatível com tal abordagem também o aspecto finalístico de algumas dessas relações, como se pretende desenvolver a seguir.

${ }^{10}$ Os limites e possíveis problemas que surgem da compreensão dos sistemas a partir da idéia de rede serão detidamente considerados ao tratarmos, mais à frente, das críticas a que está sujeita a teoria autopoiética dos sistemas sociais. Nesse sentido, cumpre salientar que a extensão dessa concepção de rede e a substituição das relações hierárquicas por relações de interdependência (não apenas entre os sistemas, mas também no interior de boa parte deles) será em certa medida relativizada ao se tratar da autopoiese dos sistemas sociais, especialmente do sistema jurídico, restringindo-se esta parte inicial do capítulo à descrição da evolução do pensamento sistêmico em suas linhas gerais.
} 
propriedades que não existem em níveis inferiores, as quais são denominadas “propriedades emergentes”, pois surgem nesse nível em particular. (CAPRA, 1996, p. 46).

Essa nova abordagem do pensamento sistêmico implica fortes abalos na estrutura do conhecimento científico, especialmente se for considerada a metáfora do conhecimento, vigente por milhares de anos e até hoje predominante entre os cientistas e filósofos ocidentais, que associa o conhecimento a um edifício. Daí falar-se em "leis fundamentais", "princípios fundamentais", sendo sempre afirmado que o "edifício" da ciência deve ser construído sobre "alicerces" sólidos. (CAPRA, 1996, p. 47). ${ }^{11}$

Contudo, de acordo com Fritjof Capra (1996, p. 58), a nova noção do conhecimento científico vem substituindo a metáfora do conhecimento como um "edifício" pela metáfora da "rede", assim entendida como um conjunto de concepções e de modelos em que nenhuma parte ou propriedade é mais fundamental do que as outras, mas todas resultantes das propriedades das outras partes, sendo a consistência global de suas interrelações determinante da estrutura de toda a "teia da vida".

Cumpre destacar ainda que de tais considerações não se pode depreender, de forma alguma, uma total horizontalização das “inter-relações" sistêmicas, quer sejam biológicas e/ou sociais.

Se esse novo enfoque relacional não permite a sua redução a uma abordagem meramente hierárquica, por sua vez, não implica, de forma contrária, em sua total horizontalização justamente por ser reconhecida a possibilidade de diferenciação sistêmica

\footnotetext{
${ }^{11}$ Sobre a continuidade e a pertinência do emprego de termos como "leis fundamentais" e "princípios fundamentais", tão caros ao Constitucionalismo Social, que, aparentemente, "deveriam" ser abandonadas em face da criticada metáfora do conhecimento como edificio, há que se ter em mente que, pelo contrário, os mesmos serão reafirmados e mantidos neste trabalho levando-se em conta seu distinto significado em direito, uma vez incorporados à sua linguagem e ao seu processo comunicativo auto-referencial, portanto não apenas inseridas na explicação teórica do direito, fruto de sua observação externa e "científica", mas propriamente organizacional e auto-reprodutivo decorrente da diferenciação do próprio sistema jurídico. Assim, ao tratarmos de suas especificidades como, por exemplo, de seu acoplamento estrutural com os demais sistemas sociais, e, do ponto de vista de seu fechamento operacional, da função peculiar desempenhada pelos princípios na interpretação constitucional dos direitos sociais, enquanto "direitos fundamentais", será possível a compreensão do redimensionamento que se pretende dar a essa terminologia, sem deixar de considerar a referida substituição dessa forma de entender a estruturação das inter-relações dos sistemas vivos e sociais (comunicacionais) expressa pela transição da metáfora do conhecimento como edifício (hierarquia) para a da rede, visto que o nível jurídico dos princípios fundamentais, bem como dos direitos e garantias fundamentais de nossa sociedade, corresponderia, grosso modo, a uma espécie de tratamento diferenciado da elevada complexidade social a que o direito não pode se eximir de responder em fase da autopoiese do sistema jurídico brasileiro.
} 
em graus e níveis diversos de complexidade, permanecendo circularmente interligados em contínuas e recíprocas inter-relações.

Uma importante conseqüência dessa visão da realidade como uma rede inseparável de relações consiste na mencionada ruptura do paradigma científico cartesiano, na medida em que questiona a concepção tradicional de objetividade científica até mesmo no campo das ciências naturais, as quais não podem mais prescindir da epistemologia, que, por sua vez, passa a ser parte integral das teorias científicas. ${ }^{12}$

\subsubsection{Auto-organização: Padrão, Estrutura e Processo}

Inicialmente elaboradas e tão logo aprimoradas, nas décadas de 70 e 80, por pesquisadores de vários países e de diversas áreas - Ilya Prigogine na Bélgica, Hermann Haken e Manfred Eigen na Alemanha, James Lovelock na Inglaterra, Lynn Margulis nos Estados Unidos da América do Norte, Humberto R. Maturana e Francisco J. Varela no Chile - as idéias de auto-organização, padrão, estrutura e processo são de grande importância para a compreensão do tema ora tratado, uma vez constituírem as principais características do fenômeno de auto-organização em diversos sistemas, imprescindíveis para a formulação de uma teoria unificada dos sistemas vivos (CAPRA, 1996, p. 79).

A concepção de auto-organização originou-se do discutido reconhecimento da rede como o padrão geral de organização da vida. Nesse sentido, acrescenta Fritjof Capra (1996, p. 134) que o "padrão de organização de qualquer sistema vivo ou não vivo, é a configuração de relações entre os componentes do sistema que determinam as características essenciais desse sistema".

Por sua vez, a estrutura de um sistema consiste na incorporação física dos componentes daquele padrão de organização citado. Segundo Humberto R. Maturana e Francisco J. Varela (2005, p. 54):

\footnotetext{
${ }^{12}$ Cumpre, assim, destacar as seguintes observações de Humberto R. Maturana e Francisco J. Varela (2005, p. 265) no sentido de que "[...] De nossas heranças lingüísticas diferentes surgem todas as diferenças de mundos culturais, que como homens podemos viver e que, dentro dos limites biológicos, podem ser tão diversas quanto se queria. [sendo que] Todo conhecer humano pertence a um desses mundos e é sempre vivo numa tradição cultural". Nesse sentido, pode ainda ser citada a conclusiva afirmação de Fritjof Capra (1996, p. 49): "No novo paradigma, é reconhecido que todas as concepções e todas as teorias científicas são
} 
Entende-se por organização as relações que devem ocorrer entre os componentes de algo, para que seja possível reconhecê-lo como membro de uma classe específica. Entende-se por estrutura de algo os componentes e relações que constituem concretamente uma unidade particular e configuram sua organização.

Trata-se nesse ponto de uma junção entre a tradicional dicotomia entre substância (matéria, estrutura, quantidade) e forma (padrão, ordem, qualidade), que acompanhou toda a história da filosofia e das ciências ocidentais. (CAPRA, 1996, p. 33).

Em outras palavras, quer-se com isso dizer que, ao menos no âmbito dos sistemas biológicos, o padrão de organização se relaciona ao mapeamento abstrato de relações, ao passo em que a estrutura consiste nos componentes físicos efetivos do sistema, ou seja, em matérias, composições químicas, que o integram.

O terceiro componente relacionado à compreensão dos sistemas vivos é denominado "processo vital” por Fritjof Capra (1996, p. 134).

Diferentemente, das máquinas e de outros sistemas fechados, caracterizados por meio de uma estrutura de componentes fixos, num sistema vivo, os seus componentes mudam continuamente através de um fluxo incessante de matéria.

De acordo com os estudos de Ludwig von Bertalanffy (1968, p. 121), biólogo vienense, os sistemas vivos seriam sistemas abertos, pois necessitam se alimentar de um contínuo fluxo de matéria e de energia extraída do seu meio ambiente para permanecerem vivos.

Nesse contexto, se insere a noção de processo vital como a atividade envolvida na contínua incorporação do padrão de organização dos sistemas à sua estrutura dissipativa.

\subsection{A autopoiese como o padrão da vida}

A palavra autopoiese teria sido adotada pelo neurocientista chileno Humberto R. Maturana (1980) como um novo termo técnico para se referir aos resultados de seus

limitadas e aproximadas. A ciência nunca pode fornecer uma compreensão completa e definitiva". 
estudos relacionados à organização característica dos sistemas vivos. ${ }^{13}$

A partir de suas investigações sobre a percepção da cor, o referido neurocientista chileno pode concluir que o sistema nervoso funciona como uma rede fechada de interações, nas quais cada mudança das relações interativas entre certos componentes implica, por conseguinte, numa mudança de suas demais relações interativas ou das relações de outros componentes. Nesse sentido, segundo o próprio Maturana e Varela (2005, p. 183):

Sob esse ângulo, é evidente que o sistema nervoso pode ser definido, no que se refere à sua organização, como dotado de uma clausura operacional. Isto é, está constituído de tal maneira que, quaisquer que sejam suas mudanças, elas geram outras modificações dentro dele mesmo. Assim, seu modo de operar consiste em manter certas relações entre seus componentes invariantes diante das perturbações que geram, tanto na dinâmica interna quanto nas interações do organismo de que faz parte. Em outras palavras, o sistema nervoso funciona como uma rede fechada de mudanças de relações de atividade entre seus componentes.

Tal descoberta levou Maturana (1980) a duas conclusões que lhe permitiram responder os dois questionamentos centrais de seu estudo dos sistemas vivos, anteriormente citados: “Qual é a organização da vida?” e "O que ocorre no fenômeno de percepção?".

Partindo do pressuposto de que essa organização circular do sistema nervoso é a organização básica de todos os sistemas vivos, lhe foi possível concluir, conforme esclarece a esse respeito Fritjof Capra (1996, p. 87), que "os sistemas vivos [...] [estão] organizados num processo circular causal fechado que leva em consideração a mudança evolutiva na maneira como a circularidade é mantida, mas não permite a perda da própria circularidade", sendo esta circularidade global de rede a organização, ou "padrão", básico da vida. Nas palavras do referido pesquisador chileno:

[...] A característica mais peculiar de um sistema autopoiético é que ele se levanta por seus próprios cordões, e se constitui como diferente do meio por sua própria dinâmica, de tal maneira que ambas as coisas são

\footnotetext{
${ }^{13}$ A respeito da centralidade dos estudos de Humberto R. Maturana para a formulação do conceito base de autopoiese convergem diferentes autores: Gunther Teubner (1989a, 1989b), Gotthard Bechmann e Nico Stehr (2001), Fritjof Capra (1996), Celso Fernandes Campilongo (2000a, 2000b, 2002), Niklas Luhmann (1995, 1996), Dário Rodríguez; Javier Torres (2003), Germano Schwartz (2004), dentre outros.
} 
inseparáveis. O que caracteriza o ser vivo é sua organização autopoiética. Seres vivos diferentes se distinguem porque têm estruturas distintas, mas são iguais em organização. (MATURANA; VARELA, 2005, p. 55).

A segunda conclusão a que chegou Humberto R. Maturana foi também de grande importância para completar o seu conceito inovador de autopoiese. Assim, do fechamento circular do sistema nervoso, lhe foi possível extrair uma compreensão inovadora de cognição.

Nessa linha, tem-se que o sistema nervoso não é somente auto-organizador, mas também continuamente auto-referente, sendo que a percepção não pode ser vista como a representação de uma realidade externa, mas deve ser entendida como a criação contínua de novas relações dentro da rede neural. A percepção e a própria cognição não representariam uma realidade exterior, mas sim especificariam uma realidade por meio do processo de organização circular do sistema. Daí porque afirma:

O que dissemos mostra que o funcionamento do sistema nervoso é plenamente consistente com sua participação numa unidade autônoma, na qual todo estado de atividade leva a outro estado de atividade nela mesma, dado que seu modo de operar é circular, ou em clausura operacional. Portanto, por sua própria arquitetura, o sistema nervoso não viola, e sim enriquece, esse caráter autônomo do ser vivo. Começam a tornar-se claros os modos pelos quais todo processo de conhecer está necessariamente baseado na organização como uma unidade no fechamento operacional do sistema nervoso. Daí se segue que todo conhecer é fazer, como correlações sensório-efetoras nos domínios de acoplamento estrutural em que existe o sistema nervoso. (MATURANA; VARELA, 2005, p. 185).

Com base nestes postulados e com a ajuda de Francisco J. Varela, na década de 70, Maturana formulou uma descrição mais completa dessa concepção de organização circular, denominando-a autopoiese (autocriação), a partir da junção dos termos auto, que significa "si mesmo" e se refere à autonomia dos sistemas auto-organizadores, e poiese, que compartilha a mesma raiz grega com a palavra "poesia" e significa "criação", “construção" (CAPRA, 1996, p. 88).

Estabelece-se, assim, uma estreita relação entre autopoiese e teoria do conhecimento. Maturana e Varela (2005), a partir dessa teoria biológica da cognição, desvendam possíveis armadilhas do conhecimento presentes na teoria clássica, sobretudo na disputa histórica entre racionalismo versus empirismo (representacionismo). 
A esse respeito, tem-se, em linhas gerais, que para a corrente racionalista, o conhecimento não poderia partir da imediatez da realidade, senão de um processo eminentemente dedutivo, isento de paradoxos, que se desenvolve por meio de conceitos iniciais e axiomas. Por sua vez, para o empirismo, de maneira radicalmente contrária, prevalece o entendimento de que a realidade é que decidiria o que é verdadeiro ou falso, sendo a verdade, presente nos dados brutos do mundo fenomênico, aclarada através de um método experimental rigoroso. (RODRÍGUEZ; TORRES, 2003, p. 118).

Nesse contexto, a primeira armadilha do conhecer, apontada na crítica ao racionalismo, consiste em se abandonar o conhecimento à ameaça do caos e da arbitrariedade em face da obscura interioridade das possibilidades do pensamento, posto que sobre este não existiria um controle imediato da certeza. Tal postura tende a negar o meio circundante e a supor que o sistema nervoso funciona totalmente no vazio, reduzindo a sua clausura operativa ao "extremo da solidão cognitiva absoluta, ou solipsismo (da tradição filosófica clássica, que afirmava que só existe a interioridade de cada um)". Portanto, se torna incapaz de "explicar a adequação ou comensurabilidade entre o funcionamento do organismo e o de seu mundo" (MATURANA; VARELA, 2005, p. 149$150)$.

A segunda armadilha do conhecimento estaria na crença oposta de que o mundo dos objetos pode dar instruções ao conhecimento, sendo inexistente um mecanismo que permita tal informação. Tal se afigura na medida em que esta posição empirista pressupõe que o sistema nervoso trabalhe com representações do mundo, considerando-o "um instrumento por meio do qual o organismo obtém informações do ambiente, que a seguir utiliza para construir uma representação do mundo que lhe permita computar um comportamento adequado à sua sobrevivência nele" quando, de fato, as pesquisas em neurofisiologia demonstram que o modo de operar do sistema nervoso está determinado, em cada momento, por sua interna clausura operacional, sendo que "a estrutura do meio não pode especificar suas mudanças, mas sim apenas desencadeá-las”. (MATURANA; VARELA, 2005, p. 146-147).

A solução proposta pelos citados autores para esse problema seria a superação de tais contradições aparentes, deixando o plano da oposição para se modificar a própria natureza da pergunta e, dessa forma, reposicioná-la em um contexto mais abrangente, fundado na distinção entre operação/observação. (MATURANA; VARELA, 2005, p. 150). 
Destacam-se, nessa nova abordagem, as interações entre o sistema observado — cujas operações internas se pretende descrever e relacionar às inter-relações específicas desse sistema com seu ambiente e seu acoplamento estrutural com os demais sistemas vivos - e o próprio "sistema observador", como no caso do cientista que se dedica ao "conhecimento" daquele "objeto". ${ }^{14}$

Deve-se frisar que, embora se fale em "observação" e se faça a distinção entre "sistema observado" e "sistema(s) observador(es)" - no caso desses últimos, sistemas psíquico do pesquisador e social científico com que se relacionam —, não se quer com isso reduzir esse modelo ao já criticado positivismo científico naturalista, centrado na completa separação entre sujeito-objeto.

A perspectiva revelada pelos estudos citados aumenta a complexidade em torno da compreensão das possibilidades da compreensão humana. A distinção entre “operação/observação" introduz ao "observador" todo um conjunto de novas inter-relações (internas e externas), posto que o mesmo apresenta-se como um sistema autopoiético próprio que processará os dados (entendidos como estímulos e não os elementos da realidade em si) apreensíveis do seu ambiente (no caso em questão: o sistema observado e suas relações com o entorno), com a peculiaridade de assim atuar a partir dos próprios elementos internos à sua rede neural e ao seu sistema de consciência — lingüístico emergente do sistema metacelular que é o ser humano, sem contar o seu próprio

\footnotetext{
${ }^{14}$ A esse respeito esclarecem Humberto R. Maturana e Francisco J. Varela (2005, p. 150-151): "Na realidade, a situação é simples. Como observadores, podemos ver uma unidade em domínios diferentes, a depender das distinções que fizermos. Assim, por um lado podemos considerar um sistema no domínio de funcionamento de seus componentes, no âmbito de seus estados internos e modificações estruturais. Partindo-se desse modo de operar, para a dinâmica interna do sistema o ambiente não existe, é irrelevante. Por outro lado, também podemos considerar uma unidade segundo suas interações com o meio, e descrever a história de suas inter-relações com ele. Nessa perspectiva - na qual o observador pode estabelecer relações entre certas características do meio e o comportamento da unidade - a dinâmica interna desta é irrelevante. Nenhum desses dois domínios possíveis de descrição é problemático em si. Ambos são necessários para o pleno entendimento de uma unidade. É o observador quem os correlaciona a partir de sua perspectiva externa. É ele quem reconhece que a estrutura do sistema determina suas interações, ao especificar que configurações do meio podem desencadear no sistema mudanças estruturais. É ele quem reconhece que o meio não específica ou instrui as mudanças estruturais do sistema. O problema começa quando passamos, sem perceber, de um domínio para o outro, e começamos a exigir que as correspondências que podemos estabelecer entre eles - pois podemos ver os dois ao mesmo tempo - façam de fato parte do funcionamento da unidade: nesse caso, o organismo e o sistema nervoso. Se mantivermos límpida a nossa contabilidade lógica, essa complicação se dissipará. Tomaremos consciência dessas duas perspectivas e as relacionaremos num domínio mais abrangente por nós estabelecido. Dessa maneira, não precisaremos recorrer às representações nem negar que o sistema nervoso funciona num meio que lhe é comensurável, como resultado de uma história de acoplamento estrutural".
} 
acoplamento estrutural, em termos de sistemas sociais comunicativos, com o sistema científico.

Com os avanços científicos citados, propiciados em parte pela própria cosmologia cartesiana e o desafio de seus limites, atinge-se, paradoxalmente, a sua própria superação. Os subjetivismos e suas decorrentes arbitrariedades que se pretendia afastar da ciência através do método positivista, podem e devem agora ser incorporados ao campo científico como condição (ou elemento) próprio de seu funcionamento cogniscente.

Retomando as distinções entre os três critérios essenciais e interdependentes para a compreensão da teoria dos sistemas vivos e sua repercussão na própria teoria do conhecimento, graças principalmente aos estudos de Humberto R. Maturana e Francisco J. Varela (2005), na síntese proposta por Fritjof Capra (1996, p. 135): “estrutura, padrão de organização e processo vital", conclui-se que o pensamento sistêmico, ao menos em sua origem, relaciona-se ao estudo e diferenciação dos sistemas vivos, às bases biológicas da compreensão humana e na coordenação entre as idéias de autopoiese, enquanto padrão de organização dos sistemas vivos, circular, auto-organizador e auto-referente; estrutura dos sistemas vivos, e processo vital, neste incluídos a dinâmica de suas interações (acoplamentos estruturais) e as demais relações desses sistemas com o seu ambiente.

\subsection{Da autopoiese biológica à autopoiese social}

Apontada como uma "nova revolução coperniciana", a extensão da autopoiese biológica à autopoiese social representou um traço marcante da evolução científica interdisciplinar das últimas décadas, sobretudo a partir dos anos 80, abrangendo as mais diversas áreas do conhecimento como a lingüística, lógica, biologia, física, matemática, cibernética, psicologia, sociologia, ciência política, ética e a ciência jurídica. (ANTUNES, 1989, p. ix).

Sob a perspectiva autopoiética, os fenômenos sociais passaram a ser compreendidos inicialmente de forma atrelada à concepção biológica de sistemas vivos, ou seja, como espécies de metassistemas autopoiéticos de segunda e terceira ordem, construídos a partir de "bio-sistemas" de primeiro grau, reduzindo-se as sociedades humanas a sistemas biológicos de seres humanos interligados. (ANTUNES, 1989, p. ix).

Nesse sentido se apresenta a citada teoria sobre a organização dos seres vivos de 
Humberto R. Maturana e Francisco J. Varela (2005, p. 220) que identifica já em nível celular a configuração de um sistema autopoiético do qual podem emergir outros sistemas de maior complexidade como os organismos e as sociedades, inclusive as humanas, tidos como metassistemas pela agregação de unidades autônomas que podem ser tanto celulares, v.g. o organismo humano, quanto metacelulares, nesta hipótese, as sociedades humanas.

No caso dos fenômenos sociais, a constituição desses metassistemas seria, porém, o resultado de acoplamentos estruturais de terceira ordem, decorrentes da coordenação de condutas entre seus elementos. Diferenciam-se dos acoplamentos de primeira e segunda ordem, que conformam, por exemplo, as células e os organismos vivos respectivamente, em função de uma fenomenologia interna e específica baseada “[...] no fato de que os organismos participantes satisfazem suas ontogenias individuais principalmente por meio de seus acoplamentos mútuos, na rede de interações recíprocas que formam ao constituir as unidades de terceira ordem". (MATURANA; VARELA, 214).

Em outras palavras, o fenômeno social é explicado através da história das mudanças estruturais destes organismos biológicos (sua ontogenia), enquanto unidades autopoiéticas que mantém sua organização própria a despeito de suas interações recorrentes e estáveis (seus acoplamentos estruturais).

Para a referida teoria, tal modificação estrutural ocorre na unidade a cada momento, seja como uma alteração desencadeada por interações provenientes do meio onde se encontra, seja como o resultado de sua dinâmica interna. Portanto, ocorre um acoplamento estrutural à medida que essas interações adquirem um caráter recorrente e estável desencadeando apenas as modificações estruturais das unidades autopoiéticas sem, contudo, determinar nem informar tais modificações. (MATURANA; VARELA, 2005, p. 86-87).

De qualquer forma, já nessa visão biológica dos sistemas sociais humanos, é destacada a existência de uma clausura operacional e acoplamentos estruturais entre seus componentes de forma diversa do nível sistêmico dos organismos, considerados metassistemas formados pela agregação de unidades celulares, com autonomia mínima em face da pouca ou nenhuma existência independente de seus componentes.

Diferentemente desses últimos, as sociedades, enquanto metassistemas formados pela agregação de unidades metacelulares, seriam não só dotadas de componentes com maior autonomia como também de um domínio lingüístico essencial para a estabilidade operacional de tal sistema e para o acoplamento estrutural dos elementos que o compõem. Segundo 
Humberto R. Maturana e Francisco J. Varela (2005, p. 220-221):

\begin{abstract}
Nos sistemas sociais humanos o quadro é diferente. Como comunidades humanas eles também têm clausura operacional, que ocorre no acoplamento estrutural de seus componentes. No entanto, os sistemas sociais humanos também existem como unidades para seus componentes no domínio da linguagem. A identidade dos sistemas sociais humanos depende, portanto, da conservação e adaptação dos seres humanos não apenas como organismos — num sentido geral —, mas também como componentes dos domínios lingüísticos que eles constituem. Pois bem: por estar associada a seus comportamentos lingüísticos, a história evolutiva do homem é uma história na qual se selecionou a plasticidade comportamental ontogênica que torna possível os domínios lingüísticos - e na qual a conservação da adaptação do ser humano como organismo requer que ele funcione nesses domínios e conserve essa plasticidade.
\end{abstract}

Depreende-se desse primeiro modelo que, como qualquer unidade autopoiética, os sistemas sociais humanos dependem da estabilidade operacional de seus componentes. Esta se aperfeiçoa com a "plasticidade operacional (comportamental) desse sistema", ou seja, por meio da coexistência de diferentes interações em níveis de complexidade diversos e sobrepostos. Assim se apresentam, de um lado, seus elementos, os seres humanos, como organismos que exigem um acoplamento estrutural não-lingüístico entre seus próprios componentes (nível celular), e, de outro, os sistemas sociais resultantes de suas interações e dependentes de acoplamentos estruturados em domínios lingüísticos, "nos quais os indivíduos possam operar com a linguagem e ser observadores". (MATURANA; VARELA, 2005, p. 220-221).

Portanto, mesmo sob o enfoque biológico, para a operação de um sistema social humano o ponto central é o domínio lingüístico gerado por seus componentes e a ampliação de suas propriedades. Tal característica é o que justamente permite aos seres humanos, enquanto componentes desse sistema, operarem como observadores do funcionamento do próprio sistema social e dos demais sistemas autopoiéticos, sendo, ademais, a condição necessária para a realização da linguagem que constitui seu domínio de existência.

Ainda segundo Humberto R. Maturana e Francisco J. Varela (2005), daí decorreria a explicação para o fato do sistema social humano ampliar em benefício próprio a criatividade individual de seus componentes posto que "a coerência e harmonia nas relações e interações dos integrantes de um sistema social devem-se à coerência e harmonia de seu crescimento em meio a ele". Contudo, por incorporar mecanismos coercivos de estabilização a todas as dimensões do comportamento de seus membros, pode se propiciar a constituição 
de "sistemas sociais desvirtuados, que perderam suas características específicas e despersonalizaram seus componentes". ${ }^{15}$

A efetiva transposição dessa teoria dos sistemas autopoiéticos do campo biológico para o social é atribuída por diversos autores ao sociólogo Niklas Luhmann. ${ }^{16}$

Luhmann (1992) postulou que a idéia de auto-referência poderia ser ampliada para além de suas raízes biológicas e elevada a um mecanismo gerador abstrato, servindo de hipótese teórica explicativa para o estudo do sistema social. ${ }^{17}$

Dessa forma, o referido sociólogo alemão agrega à sua teoria algumas inovações da teoria autopoiética biológica como a ênfase no caráter não somente auto-organizador, mas principalmente auto-reprodutivo e auto-referente, isto é, na capacidade do sistema de produzir seus elementos, bem como as suas próprias condições originárias de produção, tornando-se desse modo independente do respectivo meio envolvente.

Destacam-se, em quase todo o seu trabalho, referências à lógica operativa de George Spencer-Brown (1979), ao construtivismo radical e à cibernética de segunda ordem de Heinz von Foerster (1984) e, embora de forma contrastante, menções à teoria estrutural-

\footnotetext{
${ }^{15}$ Os referidos autores chilenos concluem, por fim, que tais sistemas, com esse desvirtuamento de suas funções autopoiéticas, "Assumiram, assim, a forma de organismos, como foi o caso de Esparta. Organismos e sistemas sociais humanos não podem, pois, equiparar-se sem distorcer ou negar as características próprias de seus respectivos componentes" (MATURANA; VARELA, 2005, p. 221).

${ }^{16}$ Nesse sentido, apontam Fritjof Capra (1996, p. 172), José Engrácia Antunes (1989, p. x), Gunther Teubner (1989b, p. 737), Germano Schwartz (2004. p. 27), Celso Fernandes Campilongo (2000a, p. 73, 2002, p. 18 e p. 66), Dário Rodríguez Mansilla e Javier Torres Nafarrate (2003, p. 106 e 122), Orlando Villas Bôas Filho (2006a, p. 12 e p. 101), Jean Clam (2006, p. 19), dentre outros autores.

17 Niklas Luhmann, inclusive, reconhece que a transposição de tal teoria ao campo social não é compreendida por seus principais formuladores nas áreas naturais e biológicas, contudo, defende ainda assim tal possibilidade desde que sejam consideradas características próprias do sistema social, inapreensíveis para o campo de conhecimento de seus iniciais formuladores. Nesse sentido contra-argumenta: "The first surprise will be that the famous protagonists of operational closure at the level of general systems theory strongly reject its application to social systems. Heinz Von Foerster finds this idea shocking; nor would Humberto Maturana and Francisco Varela join in calling social systems autopoietic systems. Why not? The answer is easy. Not being sociologists, these authors think of social systems as consisting of concrete people, individuals with bodies and minds. Of course, it is impossible to admit the closure of social systems which include the reproduction of molecules in cells, or of cells in bodies, or of thoughts in minds, as social operations within the social system. But this mistake simply points to unexplored possibilities of clarification. We have to be very precise in defining the type of operation which reproduces, within a closed network of its own productions, the unity of a social system. This operation can never be defined as the biochemical production of life, nor can it be defined as the reproduction of thoughts by thoughts within the internal darkness of a conscious system. The operation we are looking for can only be communication". (LUHMANN, 1992, p. 1.422).
} 
funcionalista de Talcott Parsons (1966, 1974), além dos estudos de Ludwig von Bertalanffy (1968) e de Humberto R. Maturana e Francisco J. Varela (1980) sobre os sistemas vivos. (BECHMANN; STEHR, 2001, p. 187; RODRÍGUEZ; TORRES, 2003, p. 134; TEUBNER, 1989b, p. $736-737){ }^{18}$

Conforme citado no início desse capítulo, Luhmann (1998) procurou reposicionar a sociologia como uma teoria da sociedade com pretensões de universalidade. Seu objetivo consistia na propositura de um modelo teórico alternativo passível de ser aplicado inclusive de modo reflexivo à própria sociologia que considerasse a complexidade da sociedade moderna, vencendo, assim, os impasses do método tradicional científico de modo a reduzir seu distanciamento de discussões transdisciplinares e do diálogo com os avanços obtidos em outras áreas do conhecimento. ${ }^{19}$

\subsection{Aspectos gerais da Teoria dos Sistemas Sociais de Niklas Luhmann}

A Teoria dos Sistemas Sociais de Niklas Luhmann (1998) tem como ponto central a compreensão da sociedade moderna em toda sua complexidade, a partir de uma abordagem cognitiva e reflexiva que identifica seus processos sociais como processos de comunicação que a diferenciam de maneira auto-referencial.

\footnotetext{
${ }^{18}$ A respeito da pretensão introduzida pelo pensamento luhmanniano observa Celso Fernandes Campilongo (2000a, p. 74): "Luhmann encara o enfoque autopoiético como verdadeira evolução paradigmática da teoria dos sistemas e, particularmente, na teoria da sociologia e na epistemologia das ciências sociais".

${ }^{19}$ Sobre a reflexividade imposta pela teoria dos sistemas para o campo dos estudos científicos, bem como acerca do criticado fechamento da sociologia ao diálogo com outras áreas do conhecimento é pertinente a seguinte citação: "[...] A partir de este concepto inicial se anulan las posibilidades descriptivas de la lógica clásica bivalente y la teoría del conocimiento que la sustenta. Al igual que en la cosmología de Einstein (movimiento y aceleración) la observación del mundo con ayuda de la distinción entre sistema y entorno depende de la ubicación del observador. Esta ubicación sólo puede darse en un lugar del mundo. El observador tiene que operar con secuencias y ser capaz de unir la observación a la observación, es decir, la operación a la operación, lo cual le obliga a llegar a una conclusión 'autológica': si observa en el mundo sistemas que se reproducen a sí mismos, está obligado a considerarse a sí mismo como uno de ellos, pues de otro modo no podría observar su propia observación. El observador se convierte, así, en uno de sus propios objetos de observación. Es esta la única manera de que la teoría de sistemas se universalice, es decir, se convierta en una teoría del mundo que no incluya todo, aun a sí misma, obligada a concebir todo lo que observa como sistema o como entorno. Hasta ahora estas reflexiones fundamentales han sido poco usuales en la sociología. es necesario consultar a físicos como Heinz von Foerster, o a biólogos como Humberto Maturana o a psicólogos como Jean Piaget para constatar que una epistemología operativa con esta estructura no es nada extraordinaria, sino que dispone de argumentos convincentes y referencias empíricas. Sólo la sociología, por carecer de competencia teórica, no ha participado, hasta ahora, en estas discusiones transdiciplinarias. La teoría de sistemas sociales que se presenta aquí trata de anular esa distancia".
} 
Nesse sentido, para o referido autor os sistemas sociais usam a comunicação como seu modo particular de reprodução autopoiética. Seus elementos são comunicações que são produzidas e reproduzidas por uma rede de comunicações que fora dela não podem existir. (LUHMANN, 1992, p. 1423-1424).

Cumpre destacar que a escolha da comunicação como elemento fundamental desses sistemas perfaz mais um ponto de ligação da teoria luhmanniana com o próprio conteúdo da teoria dos sistemas vivos de Maturana e Varela (2005, p. 217), se for considerado que para os referidos neurocientistas chilenos, enquanto observadores, entende-se por comunicativos os comportamentos que ocorrem num acoplamento social, e por comunicação a coordenação comportamental resultante desse acoplamento, sendo a própria noção de comportamento entendida a partir de uma observação exterior e relacional (sistema-ambiente), conforme os citados autores:

O que chamamos de comportamento, ao observar as mudanças de um estado de um organismo em seu meio, corresponde à descrição que fazemos dos movimentos do organismo num ambiente que assinalamos. A conduta não é alguma coisa que o ser vivo faz em si, pois nele só correm mudanças estruturais internas, e não algo assinalado por nós. (MATURANA; VARELA, 2005, p. 153).

Daí porque, para Luhmann (1998), embora com uma clara ampliação desses conceitos, a comunicação é entendida como síntese do processo comunicacional constituído de três etapas indissociáveis: informação, participação e compreensão, que são o produto das seleções realizadas não pelos indivíduos isoladamente (ou por seus "sistemas psíquicos”), mas no interior do próprio sistema social. Tal conceito não está portanto restrito à "metáfora tradicional da "transmissão", centrada no ato de comunicação, segundo a qual se entende que "a comunicação transmite notícias ou informação do emissor ao receptor". (LUHMANN, 1998, p. 141).

Diferentemente de uma simples troca entre emissor e receptor, em que a informação transmitida de um ao outro seria a mesma e dependente da habilidade do emissor, o ato de comunicar, segundo Luhmann (1998, p. 142), "não é mais do que uma proposta de seleção, uma sugestão". A esse respeito cumpre acrescentar:

(LUHMANN, 1998, p. 14). 
[...] A comunicação é o processamento da seleção [...]. O que se comunica não só é selecionado, como também já é seleção e, por isso mesmo, é comunicado. [Assim], a comunicação não deve ser entendida como processo seletivo de duas, mas de três seleções. [...] a primeira designa a própria seletividade da informação; a segunda, a seleção de seu conteúdo; a terceira, a expectativa de êxito, ou seja, a expectativa de uma seleção de aceitação. (LUHMANN, 1998, p. 142-143). ${ }^{20}$

Dessas considerações, como destaca Javier Torres Nafarrate (1998), tem-se claramente que a sociedade deixa de ser considerada como um simples objeto de análise o que implica, por conseguinte, em uma perspectiva totalmente diversa de compreensão dos fenômenos sociais. A esse respeito, esclarece que:

A conseqüência imediata resultante de que o social é uma operação de comunicação é que a sociedade não existe como objeto. A sociedade é pura comunicação e portanto só é possível dela se aproximar mediante distinções. A sociedade não opera como uma gigantesca estrutura objetiva que ninguém vê. Mas antes de tudo, as relações que se apresentam entre os seres humanos concretos se fazem dependentes de uma orientação que se refere às formas de comunicação. Por conseguinte, os sistemas sociais (e com muito mais razão a sociedade) não são propriamente objetos situados num lugar no espaço e tempo. Trata-se decisivamente de uma distinção, mas uma distinção que é real e que produz efeitos reais. (TORRES, 1998, p. 20). ${ }^{21}$

Luhmann (1998) questiona a análise da sociedade do ponto de vista objetivo externo a ela, própria de posições epistemológicas fundadas na dicotomia do paradigma sujeito-objeto, considerando inexistente a possibilidade de haver um objeto "sociedade" acessível à observação independente. ${ }^{22}$

${ }^{20}$ Cf. o original: "[...] La comunicación es el procesamiento de la selección [...] Lo que comunica no sólo es
seleccionado, sino que ya es selección y, por eso mismo, es comunicado. Por ello, la comunicación no se
debe entender como proceso selectivo de dos, sino de tres selecciones. [...] El primer término designa la
propia selectividad de la información; el segundo, la selección de su contenido; el tercero, la expectativa de
éxito, es decir, la expectativa de una selección de aceptación" (LUHMANN, 1998, p. 142-143)
${ }^{21}$ Cf. o original: "La consecuencia inmediata que se deriva de que lo social es una operación de
comunicación, es que la sociedad no existe como objeto. La sociedad es pura comunicación y por tanto es
sólo posible acercarse a ella mediante distinciones. La sociedad no opera como una gigante estructura
objetiva que nadie ha visto. Más bien las relaciones que se aprecian entre los seres humanos concretos se
hacen dependientes de una orientación que se refiere a formas de comunicación. Por consiguiente, los
sistemas sociales (y con mucho más razón la sociedad) no son propiamente objetos que estén situados en un
lugar en el espacio y en el tiempo. Se trata decisivamente de una distinción, pero una distinción que es real y
que produce efectos reales". (TORRES, 1998, p. 20).
${ }^{22}$ A esse respeito, cumpre a transcrição de um pequeno excerto em que Luhmann faz menção específica às 
Por sua vez, não quer com isso propor uma teoria capaz de revelar verdades absolutas que esgotem todas as possibilidades de compreensão dos fenômenos sociais. Com sua teoria dos sistemas sociais, o autor citado pretende transpor os impasses e obscuridades a que chegou a sociologia a partir do amálgama de teorias parciais resultantes de diversas e equivocas combinações de seus autores clássicos.

Dessa forma, situa seu trabalho em face de uma suposta estagnação teórica que teria reduzido a sociologia a um jogo retórico das mais altas pretensões de análise de seus textos clássicos. Em suas próprias palavras:

[...] A unidade da sociologia não aparece, pois, como teoria nem muito menos como conceituação de seu objeto, mas sim como complexidade pura. A disciplina não só se torna intransparente, como encontra sua unidade nessa intransparência. A complexidade é enfrentada só nessa perspectiva: cada tentativa de isolá-la a faz variar tanto que esta não pode ser controlada. Mesmo que se pudesse considerar que, cedo ou tarde, alguém chegue a esgotar o conjunto do pensamento dos clássicos, teria que vê-las com a própria obscuridade produzida. Trata-se, então, de uma relação entre complexidade e transparência; se pode dizer também: de uma relação entre complexidade transparente e intransparente. A renúncia à edificação de uma teoria específica em seu campo não afasta o problema, evita apenas introduzi-lo. Justamente aqui começa o trabalho de tal teoria. Situa a relação com seu objeto de investigação como uma relação entre complexidade intransparente e complexidade transparente. Nunca reclama para si mesma o reflexo total da realidade do objeto nem o esgotamento de todas as possibilidades de conhecimento do objeto. E por isso mesmo, tampouco a exclusividade na pretensão da verdade em relação a outros empreendimentos teóricos que entrem em concorrência. Exige sim, ao invés disso, a universalidade na apreensão do objeto, no sentido de que, como teoria sociológica, trata do todo social e não só de seguimentos (como por exemplo, estratos e mobilidade, particularidades da sociedade moderna, padrões de interação, etc.). (LUHMANN, 1998, p. 08). ${ }^{23}$

potencialidades da distinção entre sistema/ambiente para a própria compreensão das teorias científicas: “Aqui tenemos, también, una superación de la diferencia antigua por una teoría más completa que permite hablar en los sistemas de introducción de autodescripciones, autobservaciones, autosimplificaciones. Ahora se puede distinguir la diferencia sistema/entorno desde la perspectiva de un observador (por ejemplo, la de un científico), y distinguirla también de la diferencia sistema/entorno que se realiza en el sistema mismo: el observador, a su vez, puede ser pensado como un sistema autorrefencial. Relaciones de reflexión de este tipo no sólo revolucionan la epistemología clásica de sujeto-objeto; no sólo desdogmatizan y 'naturalizan' la teoría científica, sino que producen también una comprensión más compleja del objeto por medio de un diseño de teoría, a su vez, más complejo". (LUHMANN, 1998, p. 34).

${ }^{23}$ Cf. o original: "La unidad de la sociología no aparece, pues, como teoría ni mucho menos como conceptualización de su objeto, sino como complejidad pura. La disciplina no sólo se vuelve intransparente: encuentra su unidad en la intransparencia. La complejidad se afronta sólo desde la perspectiva: cada intento de asirla la hace variar tanto que no puede ser controlada. Aun cuando se pudiera contar que, tarde o temprano, uno llegara a agotar el conjunto del pensamiento de los clásicos, tendría que vérselas con la propia oscuridad producida. Se trata, entonces, de una relación entre complejidad y transparencia; se 
Em sua nova teoria da sociedade, a sociologia passa a ser entendida como um "sujeito que lida consigo mesmo" e o significado operacional da sociedade, como a "condição de possibilidade para a própria cognição social" ao passo em que transfere claramente "a estrutura do modo de operação auto-referencial [cognitivo] do sujeito à teoria dos sistemas sociais". (BECHMANN; STEHR, 2001, p. 188). ${ }^{24}$

Busca-se, em linhas gerais, uma superação do realismo epistemológico e individualismo metodológico legados por Max Weber (1999). Nesse sentido, Gunther Teubner (1989b) destaca como elemento comum às teorias de Niklas Luhmann, Michel Foucault e Jürgen Habermas a tentativa de reposicionar a sociologia no campo do conhecimento por meio da substituição dessa forma de realismo por um construtivismo epistemológico e o referido individualismo metodológico, por construções teóricas como auto-organização, discurso e auto-reflexão social. ${ }^{25}$

podría decir también: de una relación entre complejidad transparente e intransparente. La renuncia a la edificación de una teoría específica en su campo no elude el problema, evita sólo el plantearlo. Justamente aqui empieza el trabajo de dicha teoría. Sitúa la relación con su objeto de investigación como una relación entre complejidad intransparente y complejidad transparente. Nunca reclama para si misma el reflejo total de la realidad del objeto ni el agotamiento de todas las posibilidades de conocimiento del objeto. Y por eso mismo, tampoco la exclusividad en la pretensión de verdad en relación con otras empresas teóricas que entren en competencia. Sí reclama, en cambio, la universalidad en la aprehensión del objeto, en el sentido de que como teoría sociológica trata el todo social y no sólo segmentos (como, por ejemplo, estratos y movilidad, particularidades de la sociedad moderna, patrones de interacción, etcétera). (LUHMANN, 1998, p. 08).

${ }^{24}$ Em sua dissertação sobre o tema, afirma Rômulo Figueira Neves (2005, p. 08): “A teoria dos sistemas sociais tem a ambição de ser uma teoria abrangente e de dar conta da análise das diversas formas de organização da sociedade complexa. Seus instrumentos de análise não são, no entanto, conceitos significativos fechados, mas modelos abstratos que descrevem as fronteiras dos sistemas e a forma pela qual os processos comunicativos internos aos sistemas sociais operam. Assim, não existe um processo comunicativo, a priori que funcione em todos os sistemas sociais, mas uma forma de organização e de delimitação dos sistemas que se dá a conhecer apenas com a observação de cada um deles".

${ }^{25}$ Sobre a construção de novas percepções da realidade social, afirma Gunther Teubner (1989b, p. 729): “[...] This, at least, is what the following new theories on law - post-structuralism, critical theory, and autopoiesis - have in common. It is true that Michael Foucault, Jürgen Habermas, and Niklas Luhmann 'gyre and gymble in the wabe', but they do so because the imagine social realities whose reconstruction clearly goes beyond the limits of ordinary language. What makes them seemingly incomprehensible is their radical departure from epistemological premises that are deeply embedded in contemporary thinking on law and society, particularly, from Pizzorno (1989) polemically calls the reification of a 'metafisica quotidiana'- epistemological realism and methodological individualism. Although poststructuralism, critical theory, and the theory of autopoiesis develop quite different visions of modern law, they converge in their antirealism and their anti-individualism". Nesse sentido, ainda segundo Gunther Teubner (1989b), o ponto de convergência entre o pós-estruturalismo de Michel Foucault, a teoria crítica de Jürgen Habermas e a teoria autopoiética de Niklas Luhmann seria a substituição da autonomia individual por processos comunicativos e não por entidades supra individuais. Seria, contudo, na identificação da nova unidade 
Nesse contexto, diferenciação social e formação de sistemas passam a ser vistas como características básicas da sociedade moderna, sendo a Teoria dos Sistemas e a Teoria da Sociedade mutuamente dependentes.

Segundo a observação de Gotthard Bechmann e Nico Stehr (2001, p. 187): “a sociedade [para Luhmann] não é a soma de todas as interações presentes, mas um sistema de uma ordem maior, de tipo diferente, determinada pela diferenciação entre sistema e ambiente".

Luhmann (1998) distingue, portanto, três níveis de formação de sistemas, a partir da teoria geral em que pretende inserir os sistemas sociais (Quadro 1).

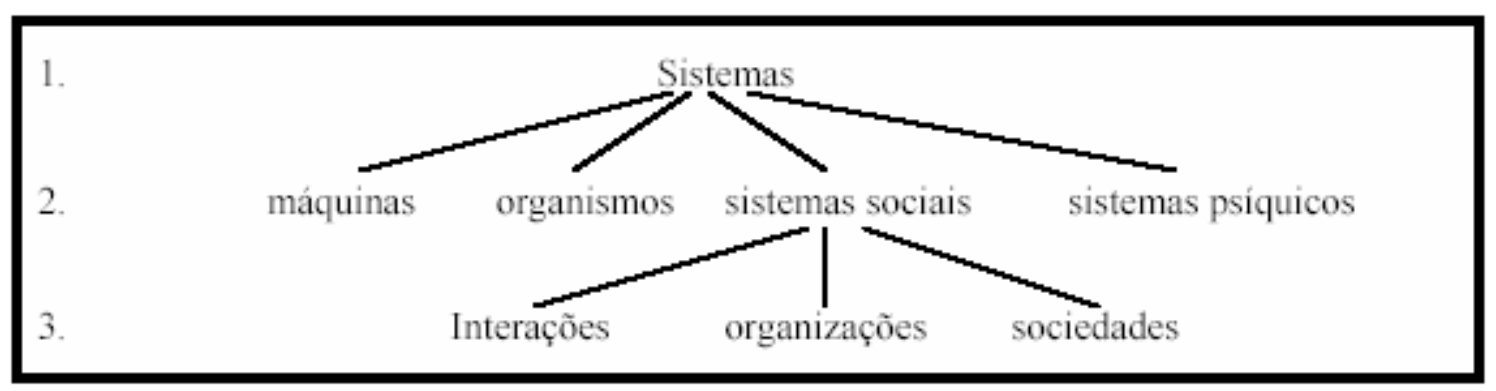

Quadro 1 - Níveis de formação dos sistemas. (LUHMANN, 1998, p. 27).

A sociedade é assim entendida como uma ordem emergente e diversa das especificidades da vida orgânica e do interior das consciências, sendo "a irrupção de uma nova ordem da realidade que não pode ser explicada (nem reduzida) em sua totalidade, a partir das características da infra-estrutura sobre a qual se encontra sustentada". (RODRÍGUEZ; TORRES, 2005).

cognitiva desses processos comunicacionais que esses autores diferem entre si, posto que: "[...] In Habermas's version of critical theory correspondence theories of truth are overturned by consensus theories and 'intersubjectivity' takes the place of the epistemic subject. Foucault and Luhmann are even more radical in their disenchantment of the human individual. For Foucault, the human individual is nothing but an ephemeral construction of an historically contingent power/discourse constellation, which dictates the epistème of a historical epoch. Luhmann completely separates psychic processes from social ones and perceives the human individual in society as a communicative artifact, as a product of self-observation of social autopoiesis. The new epistemic subjects are autopoietic social systems". (TEUBNER, 1989b, p. 732). Porém, cumpre ressaltar que, apesar dessa pertinente observação, Teubner a direciona de acordo com uma leitura construtivista que, em essência, é adotada claramente apenas por Luhmann. Ainda a esse respeito afirma Orlando Villas Bôas Filho (2006a, p. 45): "Sob vários aspectos a interpretação de Teubner acerca das inovações trazidas por Foucault, Habermas e Luhmann à epistemologia tradicional da teoria social apresentase como correta e, por esse motivo, não merece qualquer reparo. Contudo, há que se ter em mente que Teubner interpreta Foucault e Habermas a partir de um construtivismo que é próprio da teoria de Luhmann, o que não deixa de acarretar certos problemas, na medida em que tende a obnubliar contornos próprios desses 


\subsubsection{A distinção entre sistema e ambiente}

O mundo fenomênico abrange um número indeterminado de ações, atividades, seleções de sentido e de relações possíveis que tendem a aumentar no decorrer da história, tornando-se o próprio mundo, enquanto unidade, cada vez mais complexo, inapreensível e contingencial. ${ }^{26}$

Assim, tem-se um aumento considerável de complexidade relacionado a um contínuo processo de formação e diferenciação de sistemas de sentido, cuja função é tentar organizar parte dessa complexidade no curso desse processo histórico e reduzir essa contingência presente nessa ampla possibilidade de relações e sentidos. ${ }^{27}$

dois pensamentos, impondo-lhes demandas que nem sempre são suas”.

${ }^{26} \mathrm{O}$ conceito luhmanniano de contingência será detalhado no tópico referente à "dupla contingência" dos sistemas sociais autopoiéticos. Contudo, é necessário já advertir a sua importância para a compreensão de como a complexidade do mundo é tratada e, paradoxalmente, aumentada pelos processos seletivos de sentido dos sistemas psíquicos e sociais em função de sua contingencialidade. De qualquer forma, a fim de introduzir uma noção menos abstrata que a desenvolvida nessa fase inicial do trabalho, segue a transcrição do seguinte excerto que, embora referente a uma obra anterior à fase autopoiética de Niklas Luhmann, contém em si as idéias embrionárias desse conceito a partir de uma visão ainda voltada ao indivíduo e seu agir: "O homem vive em um mundo constituído sensorialmente, cuja relevância não é inequivocamente definida através do seu organismo. Desta forma o mundo apresenta ao homem uma multiplicidade de possíveis experiências e ações, em contraposição ao seu limitado potencial em termos de percepção, assimilação de informação, e ação atual e consciente. Cada experiência concreta apresenta um conteúdo evidente que remete a outras possibilidades que são ao mesmo tempo complexas e contingentes. Com complexidade queremos dizer que sempre existem mais possibilidades do que se pode realizar [ou atribuir sentido]. Por contingência entendemos o fato de que as possibilidades apontadas para as demais experiências poderiam ser diferentes das esperadas; ou seja, que essa indicação pode ser enganosa por referir-se a algo inexistente, inatingível, ou a algo que após tomadas as medidas necessárias para a experiência concreta (por exemplo, indo-se ao ponto determinado) não mais lá está. Em termos práticos, complexidade significa seleção forçada, e contingência significa perigo de desapontamento e necessidade de assumir riscos". (LUHMANN, 1983, p. 45-46).

${ }^{27}$ Niklas Luhmann ressalta que embora o termo "história" possa se constituir como a dimensão específica da idéia de tempo, ao ser relacionado ao processo de formação dos sentidos, tal designação assume uma conotação diversa da idéia pura e simples de causalidade e desencadeamento de acontecimentos relacionados, mas sim estritamente ligada ao emprego específico de um sentido de maneira diversa de seu uso anterior ou futuro. Assim, expressamente adverte: “[...] Bajo la designación historia no debe entenderse simplemente la secuencia de los acontecimientos en virtud de la cual se puede concebir lo presente como efecto de causas pasadas o como causa de efectos futuros. Lo específico de la historia del sentido radica, más bien, en que posibilita el asimiento discrecional del sentido en los acontecimientos pasados o futuros, es decir, posibilita el saltar la secuencia. La historia tiene lugar cuando las secuencias quedan desligadas. Un sistema de sentido tiene historia en la medida en que limita, ya sea mediante asimientos discrecionales, sean estos determinados acontecimientos pasados (la destrucción del templo, la coronación del Emperador por el Papa, la derrota de Sedán; o hechos más pequeños: una boda, la interrupción de los estudios, la primera condena a pena menor de prisión; el 'destape' de los homosexuales), mediante la finalización del futuro. La historia, por lo tanto, es siempre pasado-presente o futuro-presente, y siempre significa tomar distancia respecto de la secuencia pura, y además, reducción de la ganada libertad de asimiento versátil de todo lo pasado y de todo lo venidero". (LUHMANN, 1998, p. 94). 
Para Luhmann (1998, p. 197), embora não seja unívoco, o conceito de mundo por ele adotado destaca-se como constitutivo das relações sistêmicas. Rompe, portanto, com a tradicional centralização do conceito de mundo tido como um "meio" em relação ao sujeito para situá-lo de modo multicêntrico que, em cada diferenciação, integra todas as diferenças de sistemas/ambiente. Em sua visão, possibilitar-se-ia dessa forma a investigação sociológica que relaciona a semântica do mundo com o desenvolvimento sócio-estrutural do sistema social. ${ }^{28}$

A complexidade social, sua contingência e a referida necessidade de sistemas capazes de representar e dar sentido ao mundo e a suas relações estimulariam a diferenciação entre sistema e ambiente. Nesse contexto, a função dos sistemas consistiria na diminuição da complexidade do ambiente de modo a propiciar a delimitação de seus sentidos e estruturas, sem com isso negar a existência do ambiente, cuja complexidade é sempre maior que a interna do sistema. (LUHMANN, 1998, p. 50). ${ }^{29}$

Há que se ressaltar desde já que o termo estrutura empregado na teoria dos

\footnotetext{
${ }^{28}$ Sob esse ponto, o referido autor trabalha as seguintes considerações: "Naturalmente, o conceito de mundo pode ser concebido de maneiras muito distintas, por exemplo, como totalidade nociva para a salvação fora do próprio grupo, ou como interlocutor do sujeito (necessariamente extramundano). A idéia, muito atraente para os sociólogos, de uma constituição intersubjetiva não ajuda muito: é demasiada evidente e, desde o ponto de vista teórico, não é suficientemente produtiva. Inserimos aqui o conceito de mundo como unidade de sentido da diferença entre sistema e entorno [ambiente] e o utilizamos como conceito último sem diferenças. Sob essa perspectiva, o conceito de mundo não designa nenhuma totalidade objetiva (como queira que se conceba essa totalidade), nenhuma universitas rerum que pode ser pensada sem diferenças. Original e fenomenologicamente, o mundo está dado como unidade inapreensível. No terreno da formação dos sistemas, e em relação com dita formação, é determinável como unidade de uma diferença. Em ambos sentidos, o conceito de mundo indica uma unidade só real para os sistemas de sentido capazes de se distinguir de seu entorno e que, em conseqüência, reflitam a unidade desta diferença como unidade que abarca duas infinitudes, a interior e a exterior. O mundo, desde esta perspectiva, está, portanto, constituído pelo processo de diferenciação entre os sistemas de sentido, pela diferença entre o sistema e o entorno. Este mundo (distinto do que se concebe fenomenologicamente) não é nada original, nada arcaico, é a representação ligada a uma diferença da unidade final. É o mundo depois do pecado original" (LUHMANN, 1998, p. 197-198).

${ }^{29} \mathrm{O}$ sentido do termo complexidade relacionado à referida necessidade sua redução pelos sistemas sociais consiste em "medida de indeterminação ou na carência de informação". A esse respeito, explica o referido sociólogo alemão: "[...] La complejidad es, vista de este modo, aquella información que le hace falta al sistema para poder aprehender y describir con justeza a su entorno (complejidad del entorno) y a sí mismo (complejidad del sistema). Desde el punto de vista de los elementos particulares - por ejemplo, para determinadas acciones o procesamientos de información del sistema -, la complejidad sólo es relevante en este segundo sentido, es decir, sólo como horizonte de selección. Esta segunda versión puede ser usada en los sistemas de sentido para reintroducir la complejidad del sistema dentro del sistema: como concepto, como magnitud desconocida, como factor de miedo, como concepto de inseguridad y riesgo, como planeación, como problema de decisión u como excusa". (LUHMANN, 1998, p. 50).
} 
sistemas de Niklas Luhmann tem um significado peculiar, sobretudo em sua identificação da sociedade como comunicação. A esse respeito o autor citado afirma que: "de forma abstrata, o termo estrutura pode se referir à comunicação ou à ação”. (LUHMANN, 1998, p. 258).

As estruturas que relacionam comunicação com comunicação, próprias dos sistemas sociais, compreendem tudo o que neles pode ser relevante. Uma primeira característica desse conceito está relacionada ao problema da complexidade social com que o sistema tem que lidar.

A formação de suas estruturas procura realizar a transição de uma complexidade não estruturada, "entrópica" e tendente à incoerência, para uma complexidade estruturada. (LUHMANN, 1998, p. 259).

Dessa forma, as estruturas do sistema auto-referenciais definem não apenas o relacionamento entre seus elementos como consideram essa relação de maneira constitutiva para a qualificação de tais elementos que, no caso dos sistemas sociais, remete a própria qualificação pela estrutura dos sentidos das ações selecionados pelo processo comunicacional, como será tratado a seguir.

Contudo, a identidade das estruturas se mantém a despeito da variação a que estão sujeitos os elementos do sistema, sendo que, por essa razão, concluí-se o seguinte:

[...] Essas relações só obtêm valor estrutural se as relações que se estabelecem em cada caso formarem uma seleção de um grande número de possibilidades combinatórias, com as vantagens e os riscos de uma redução seletiva, e unicamente se esta seleção puder manter-se constante, ou seja, reproduzida com elementos novos, ao se alterarem os elementos. Assim, uma estrutura é, além das outras possibilidades, a limitação das relações permitidas no sistema. Esta limitação constitui o sentido das ações e, dentro do funcionamento dos sistemas auto-referenciais, o sentido de uma ação que motiva e torna plausível aquilo que salta à vista como possibilidade de enlace. [...] Traduzido para a terminologia da teoria dos sistemas autopoiéticos (não obstante que esta utiliza o termo estrutura de outra maneira), isto quer dizer que unicamente por meio de uma estruturação limitante um sistema adquire a "direção interna" suficiente que torna possível sua auto-reprodução (LUHMANN, 1998, p. 259-260). ${ }^{30}$

${ }^{30}$ Cf. o original: "Estas relaciones sólo obtienen valor estructural si las relaciones que se establecen en
cada caso forman una selección de un gran número de posibilidades combinatorias, con las ventajas y los
riesgos de una reducción selectiva, y únicamente si esta selección puede mantenerse constante, es decir,
reproducida con elementos nuevos, al cambiar los elementos. Así, una estructura es, aparte de todo lo
demás que puede ser, la limitación de las relaciones permitidas en el sistema. Esta limitación constituye el 
Há que se destacar, desde já, que na Teoria dos Sistemas Sociais de Niklas Luhmann (1998), as referências à história e ao desenvolvimento dos sistemas autopoiéticos partem de um conceito próprio de evolução que não se relaciona, de forma alguma, às idéias de progresso, desenvolvimento linear, avanço em sentido valorativo nem mesmo à existência de etapas hierarquizadas de evolução, mas sim ao aumento da complexidade dos sistemas e ao modo de organização que suas estruturas assumem, ou seja, a forma de diferenciação com que a sociedade lida com seu entorno, sendo a evolução da sociedade como sistema geral composta de "eventos improváveis e imprevisíveis, que geram ao final do processo um ganho evolutivo indeterminável a priori". ${ }^{31}$

Assim, é possível entender que, enquanto comunicação, a sociedade teria evoluído diferenciando-se em pelo menos quatro estágios, possíveis adaptados aos diferentes graus de complexidade neles existentes: (i) diferenciação segmentária; (ii) diferenciação centro/periferia; (iii) diferenciação estratificada, e (iv) diferenciação funcional. (LUHMANN, 1998, p. 379).

Em cada um desses momentos, a sua comunicação esteve organizada e, por

sentido de las acciones, y dentro del funcionamiento de los sistemas autorreferenciales, el sentido de una acción que motiva y hace plausible aquello que salta a la vista como posibilidad de enlace. [....]. Traducido a la terminología de la teoría de los sistemas autopoiéticos (no obstante que esta utiliza el término estructura de otra manera), esto quiere decir que únicamente por medio de una estructuración limitante un sistema adquiere la suficiente 'dirección interna' que hace posible la autorreproducción'. (LUHMANN, 1998, p. 259-260).

${ }^{31}$ A esse respeito, em sua dissertação sobre os conceitos da teoria luhmanniana, sintetiza Rômulo Figueira Neves (2005, p. 44): "As condições para que alguns elementos se encontrem e tornem possível determinada evolução são incertas e improváveis. A evolução, no entanto, restringe alguns caminhos, tornando o sistema mais previsível em alguns aspectos, ao mesmo tempo em que torna outros caminhos possíveis, reafirmando a imprevisibilidade do funcionamento do sistema. Esse processo de formação de premissas e abertura de novas possibilidades pode desencadear diferenciações internas mais constantes, dando início, assim, à formação de outros sistemas. [...] A evolução dos sistemas é o resultado do funcionamento de seus elementos, do crescimento da complexidade interna e da eficácia e suas diferenciações. A estabilização e a sobrevivência dos sistemas geram, progressivamente, ainda mais aumento da complexidade interna, entrando em um ciclo que resulta, muitas vezes, em uma nova diferenciação interna e na fragmentação do sistema em subsistemas". Acrescente-se ainda que, conforme compara Celso Fernandes Campilongo (2002, p. 23): “[...] Como todas as grandes teorias da sociedade - confira-se Durkheim, Marx, Weber e Parsons - Luhmann também adota uma perspectiva evolutiva". Contudo, embora a sociedade para Luhmann tenha sido sempre uma rede de comunicações, Campilongo destaca que para o referido teórico sistêmico a evolução da sociedade não pode ser entendida "como sinônimo de progresso ou qualquer outra referência valorativa", sendo a chave de seu modelo evolutivo a noção de diferenciação funcional como o modo de organização alcançado pela sociedade moderna para lidar com sua complexidade, ou seja o ponto central de sua teoria evolutiva seria a variação histórica dos modos de organização do processo comunicacional da sociedade. 
conseguinte a própria sociedade restou assim diferenciada, a partir de diversos critérios fundamentais, em linhas gerais: "critérios naturais (gênero e idade, por exemplo, nas sociedades primitivas); critérios geográficos (campo e cidade, por exemplo, para as cidades-estados da Grécia clássica), critérios hierárquicos (nobre/plebeu, cidadão/escravo, por exemplo no 'antigo regime') e, finalmente, na modernidade, critérios funcionais (com a estabilização de sistemas especializados, como o direito, a política e a economia)". (CAMPILONGO, 2002, p. 23-24).

De maneira sucinta, uma vez que essa questão é incidente e não constitui o objeto desse trabalho, essa evolução pode ser descrita a partir do seguinte resumo de alguns artigos de Niklas Luhmann presentes em sua coletânea: Essays on self-reference (1990b).

A diferenciação segmentária da sociedade pode ser entendida como uma característica das sociedades arcaicas, com baixa seletividade de seus processos comunicacionais frente a um grau ainda não muito elevado de complexidade do ambiente, com poucas possibilidades de variação, sendo em sua grande parte as expectativas ligadas às relações pessoais, à conservação da vida em face do perigo de extinção demográfica, sendo "estabilizadas" por meio da força.

Seus subsistemas sociais, familiares, tribais, organizados em torno de clãs e aldeias, não estariam ainda diferenciados em termos funcionais mas em torno de valores tradicionais centrados nos referidos critérios naturais - gênero e idade, por exemplo nas sociedades primitivas - que compunham seus meios de comunicação simbolicamente generalizados presentes em seu processo comunicacional de diferenciação interna.

Por sua vez, a diferenciação centro/periferia seria própria das sociedades organizadas a partir de cidade, nas quais o critério geográfico passa a preponderar sobre o natural como forma de seleção e de redução da complexidade emergente dessa diferenciação social. Nesse sentido, o princípio da territorialidade se torna indispensável e a cidade passa a ser considerada o centro de maior difusão da comunicação. Contudo, a centralidade e o isolamento da comunicação aí produzida em relação à periferia desse sistema, bem como o desenvolvimento de novas formas de diferenciação no próprio centro provoca e reflete ao mesmo tempo o aumento de complexidade.

Nesse contexto, a estratificação hierárquica, fundada na desigualdade de classes, faz com que a comunicação ali produzida novamente se diferencie de modo 
estratificado. Os subsistemas dominantes passariam a exercer a representação de todo o sistema de modo a considerar como subsistemas inferiores os demais presentes em seu ambiente que, em boa parte, continuariam ainda estruturando sua comunicação a partir de diferenciações segmentárias e territoriais. Como exemplo dessa forma de diferenciação estratificada e desigual, tem-se a formação da nobreza nos centros dessas sociedades assim diferenciadas.

Desse descompasso entre a comunicação produzida por esses diferentes sistemas sociais, ainda não diferenciados funcionalmente, resultaria um acréscimo de complexidade decorrente da desigual comunicação e da capacidade dos sistemas hierarquicamente organizados de impor sobre os demais suas autodescrições como pretensões globais e prevalentes. (LUHMANN, 1990b, p. 125).

Esse unidirecionamento da comunicação presente na autodescrição global da sociedade a partir de apenas um subsistema, concentrando os mecanismos seletivos, limita o próprio processo de redução e operacionalização da complexidade e, por conseguinte, a relação entre os sistemas sociais dominantes e dominados.

A diferenciação funcional da sociedade surgiria como uma característica adaptativa da sociedade moderna em resposta ao grau insustentável de complexidade com que modelos anteriores, segmentários e estratificados, não poderiam lidar.

A esse respeito, destaca Niklas Luhmann (1992) que a crucial diferença histórica entre a sociedade passada e a moderna consistiria no abandono dessa forma de representação da sociedade na sociedade ocorrido em sua transição para o modo primário de diferenciação funcional que se seguiu à descrita evolução.

A partir dessa comparação, o autor assinala como característica marcante e inevitável da sociedade moderna a perda da representação natural entendida como a impossibilidade da representatio identitatis. A esse respeito, esclarece Luhmann (1992, p. 1434-1435):

[...] Em sociedades tradicionais encontramos modelos para representar a ordem social como relações entre subsistemas, como por exemplo, as relações entre centro e periferia, cidade e campo; ou relações de classe entre classes sociais ou estamentos. A transição para a sociedade moderna dissolveu essa ordem sem substituí-la — Foucault cita a "perda de 
representação" ocorrida no século XVIII. Sob o regime da diferenciação funcional, o sistema social perde sua capacidade integrativa. Reduzido aos seus mecanismos de acoplamento estrutural, continua se autoreproduzindo de forma autopoiética através de comunicação. ${ }^{32}$

Assim, como "a totalidade da sociedade nunca está completamente presente nem pode ser realizada como uma totalidade" a diferenciação funcional teria prevalecido frente às demais formas segmentárias, centro/periferia ou estratificada/hierárquica posto que forneceria ao sistema uma maior possibilidade de redução da complexidade. (LUHMANN, 1990b, p. 125).

Por essa razão, a sociedade moderna teria assumido uma forma sistêmica completamente nova posto que se estrutura em um padrão "significativamente diferente de diferenciação sistêmica utilizando funções específicas como fator para a diferenciação de seus subsistemas". (LUHMANN, 1990b, p. 177).

Feitas essas considerações é possível situar a distinção entre sistema e ambiente na referida teoria sistêmica da sociedade moderna como o resultado desse peculiar modelo de evolução e, com isso, entender porque Luhmann descreve acentricamente a sociedade moderna como policontextual e estruturada de maneira funcionalmente diferenciada em subsistemas comunicacionais, autopoiéticos e autoreferenciais. (LUHMANN, 1998, p. 11).

Com base no conceito de diferença utilizado por George Spencer-Brown (1979) na formulação de sua teoria da forma e da função da diferenciação nos processos de auto-referenciais estudada por Heinz von Foerster (1973), Luhmann (1998, p. 40) destaca a diferença entre sistema e entorno (ambiente), como o "ponto de partida para qualquer análise teórico-sistêmica”. Sobre esse ponto, afirma o referido sociólogo alemão:

[...] Os sistemas estão estruturalmente orientados ao entorno [ambiente], e sem ele, não poderiam existir; portanto, não se trata de um contato

\footnotetext{
${ }^{32}$ Cf. original: “[...] In traditional societies we find devices to represent social order as relations between subsystems, for example, as relations of center and periphery, city and country; or as relations of rank between castes or estates. The transition to modern society dissolved this order without replacing it Foucault cites a 'loss of representation' occurring in the eighteenth century. Under the regime of functional differentiation, the societal system loses its integrative capacity. Reduced to its mechanism of structural coupling, it continues to autopoietically reproduce itself by communication". (LUHMANN, 1992, p. 1434 1435).
} 
ocasional nem tampouco de uma mera adaptação. Os sistemas se constituem e se mantém mediante a criação e a conservação da diferença com o entorno, e utilizam seus limites para regular esta diferença. Sem diferença referente ao entorno não haveria auto-referência já que a diferença é a premissa para a função de todas as operações autoreferenciais. Nesse sentido, a conservação dos limites (boundary maintenance) é a conservação do sistema. (LUHMANN, 1998, p. 40). ${ }^{33}$

Há ainda que levar em conta, a partir dessa diferenciação entre sistema e ambiente, que não se deve afirmar de forma alguma a ocorrência de uma "diferenciação de uma parte do todo", nem mesmo dizer acerca de qualquer "divisão do todo em fragmentos organizados" como equivocadamente já se interpretou essas sutis distinções luhmannianas. (NEVES, 2005, p. 13).

Contra esses possíveis equívocos, adverte Luhmann (1998, p. 42): “A diferença entre sistema e entorno [ambiente] obriga, como paradigma da teoria dos sistemas, a substituição da diferença entre o todo e as partes por uma teoria da diferenciação dos sistemas". Assim, ressalta que tal diferenciação seria simplesmente a "repetição da formação de sistemas dentro de outros sistemas", no interior dos quais se poderia ainda encontrar "diferenciações de diferenças adicionais da distinção sistema/entorno".

Por essa mesma razão, os limites que demarcam a fronteira entre ambiente e sistema não representam em si uma "ruptura de contexto", não sendo possível se afirmar que as interdependências internas sejam, de maneira geral, maiores que as existentes entre sistema e ambiente. Sobre essas nuances, esclarece Niklas Luhmann (1998, p. 41):

[...] Porém, o que designa o conceito de limite é que os processos, ao ultrapassarem os limites previamente fixados (por exemplo, no intercâmbio de energia ou de informação), se colocam sob situações distintas de continuidade (por exemplo, sob outras situações de aplicabilidade ou de consenso). Isso significa, por sua vez, que a contingência do curso do processo, a abertura a outras possibilidades, varia para o sistema segundo se realize dentro do sistema ou no entorno.

\footnotetext{
${ }^{33}$ Cf. o original: "[...] Los sistemas están estructuralmente orientados al entorno, y sin él, no podrian existir: por lo tanto, no se trata de un contacto ocasional ni tampoco de una mera adaptación. Los sistemas se constituyen y se mantienen mediante la creación y la conservación de la diferencia con el entorno, y utilizan sus límites para regular dicha diferencia. Sin diferencia, con respecto al entorno no habría autorreferencia ya que la diferencia es la premisa para la función de todas las operaciones autorreferenciales. En este sentido, la conservación de los límites (boundary maintenance) es la conservación de sistema". (LUHMANN, 1998, p. 40).
} 
Precisamente porque assim se sucede, existem limites, existem sistemas. ${ }^{34}$

Dessa forma, a diferenciação sistêmica e a própria organização dos processos comunicacionais em seu interior dependem de um mecanismo de seleção capaz de distinguir os elementos que o integrarão daqueles presentes em seu ambiente e, assim superar a contingência do mundo, cuja complexidade consubstancia-se na dificuldade de se estabelecer processos comunicacionais sem a estruturação de um sistema social no espaço desorganizado. ${ }^{35}$

Esse mecanismo de seleção seria, portanto, um meio (medium), específico em cada sistema, do qual fazem parte os meios de comunicação, com especial atenção para aqueles simbolicamente generalizados.

Primeiramente, quando relacionado à comunicação, por “meios", Luhmann (1998, p. 156) designa os ganhos evolutivos que permitiram que a noção de comunicação rompesse com sua tradicional conceituação restrita às idéias de seleção de signos e a troca de informações entre seres vivos autônomos e capazes de processar tais informações sem que desse processo idealizado resultassem perdas de sentido, de compreensão e a produção de outros desperdícios.

Apenas com os ganhos evolutivos no sentido do aperfeiçoamento da compreensão dos processos cognoscitivos e comunicacionais é que teria sido possível superar a referida visão idealizada de seus meios, possibilitando que a comunicação sirva funcionalmente para a "transformação do improvável em provável". Essa assertiva pode ser entendida se forem levadas em conta as três "impossibilidades" apontadas pelo autor que tornariam improvável a efetividade da comunicação em sentido tradicional: (i) os

\footnotetext{
${ }^{34}$ Cf. o original: "[...] Pero lo que designa al concepto de límite es que los procesos, al rebasar los límites previamente fijados (por ejemplo, en el intercambio de energía o de información), se colocan bajo situaciones distintas de continuidad (por ejemplo, bajo otras situaciones de aplicabilidad o de consenso). Esto significa, a su vez, que la contingencia del curso del proceso, la apertura a otras posibilidades, varia para el sistema según se lleve a cabo dentro del sistema o en el entorno. Precisamente porque así sucede, existen limites, existen sistemas". (LUHMANN, 1998, p. 41).

35 Segundo Rômulo Figueira Neves (2005), essa contingência dos processos comunicacionais do espaço desorganizado seria, em si, um estímulo para a formação dos sistemas, sendo que "quanto mais um sistema se fecha e evolui, mais ele pode organizar, direcionar e limitar as possibilidades de caminhos de seu próprio funcionamento, em um processo de diminuição, dentro do sistema, da extrema contingência e complexidade do mundo desorganizado" (NEVES, 2005, p. 32).
} 
impasses entre os sentidos atribuídos e percebidos — "que o ego [receptor] entenda o que pretende o alter [emissor]"; (ii) o problema da "acessibilidade dos destinatários" à comunicação, e (iii) questão de seu êxito em termos de aceitação pelo ego do conteúdo selecionado da comunicação como premissa para sua conduta. (LUHMANN, 1998, p. 156157). ${ }^{36}$

A superação desses impasses teria ocorrido com a evolução dos meios citados sendo que a linguagem desses meios destaca-se por intensificar a compreensão da comunicação para além do perceptível. ${ }^{37}$

Por sua vez, com base na linguagem teria sido possível o desenvolvimento dos meios de comunicação, como a escrita, a imprensa e as telecomunicações. ${ }^{38}$

A resolução do problema de aceitação da comunicação teria êxito com o desenvolvimento dos citados meios de comunicação simbolicamente generalizados, que, segundo Luhmann (1998, p. 159), seriam "aqueles meios que utilizam generalizações para simbolizar a relação entre seleção e motivação, quer dizer, para representar a unidade". A

36 Os termos ego e alter são em sua dimensão social utilizados por Luhmann (1998) para designar perspectivas diversas de entendimento que podem ser tanto internas a um sistema social quanto entre sistemas diferentes. Assim esclarece o referido autor: "[...] Por lo tanto, los conceptos ego y alter no designan aqui papeles, personas o sistemas, sino horizontes especiales que agregan y cargan peso las remisiones plenas de sentido. La dimensión social, por consiguiente, está constituida por un horizonte doble y se vuelve relevante en la medida en que en la vivencia y en la acción se perfila el que las perspectivas de entendimiento que el sistema refiere a si mismo no pueden ser separadas de otras, es decir, que la horizontalidad del ego y del alter es imposible como resultado de una exploración ulterior". (LUHMANN, 1998, p. 95).

${ }^{37}$ Conforme explica Luhmann (1998, p. 158): “[...] El lenguaje es un medio que se caracteriza por el uso de signos; utiliza signos acústicos y ópticos referentes al sentido. Esto conduce a problemas complejos que se resuelven por medio de las reglas para el uso de los signos, mediante la reducción de la complejidad, la habituación de una combinatoria limitada. El procedimiento básico, no obstante, continúa siendo la regulación de la diferencia entre el acto de comunicar y la información. Tomada como signo, esta diferencia puede ser la base para la comunicación entre alter y de ego, y ambos pueden, en el uso unívoco de los signos, confirmar su opinión de que pretenden lo mismo. Se trata, entonces, de una técnica muy especial cuya función es ampliar prácticamente al infinito el repertorio de la comunicación comprensible, asegurando así que casi cualquier acontecimiento pueda aparecer y ser trabajado como información".

38 Sobre os meios de comunicação, afirma Luhmann (1998, p. 159): “[...] Estos medios se basan en una descomposición, en una recombinación incongruente de unidades lingüísticas que no pueden disolverse más. Así se logra una expansión inmensa de la amplitud del proceso comunicacional que reactúa, a su vez, sobre lo que se comprueba como contenido de la comunicación. Los medios de comunicación seleccionan mediante su propia técnica, crean sus propias posibilidades de conservación, comparación y mejoramiento, las cuales, no obstante, sólo pueden ser utilizadas con base en estandarizaciones. En comparación con la tradición oral, sujeta a la interacción y a la memoria, los medios de comunicación se expanden y a la vez se limitan, y a así la comunicación sirve como base para las comunicaciones siguientes". 
esse respeito, acrescenta ainda: "são importantes exemplos: verdade, amor, propriedade/dinheiro, poder/direito, e até certo ponto também a fé religiosa, a arte e atualmente, talvez, os 'valores básicos' civilizatoriamente padronizados”.

Os meios de comunicação simbolicamente generalizados diferem-se dos meios de comunicação em acepção ampla, uma vez que se formam a partir de uma evolução histórica do sistema em que se consolidam premissas de diferenciação relacionadas ao ambiente e, assim, possibilitam a condensação mais forte dos sentidos através de uma peculiar codificação binária da linguagem.

Nesse contexto, como exemplo de tal evolução, poderia ser citada, ainda que em linhas gerais nessa parte inicial do trabalho, a formação do sistema jurídico que, como um subsistema social, estaria funcionalmente diferenciado em razão do desenvolvimento de um código binário próprio, direito/não-direito, que asseguraria a originária autoreprodução reflexiva de seus elementos básicos e a sua autonomia frente aos demais subsistemas sociais, ao passo em que operaria como centro gravitacional de uma rede circular e fechada de operações sistêmicas. (ANTUNES, 1989, p. xiv). ${ }^{39}$

A importância desses códigos binários com que os sistemas sociais operacionalizam seus processos comunicacionais consiste na síntese de sentidos neles presentes que facilita o estabelecimento de ligações entre as premissas de decisões e os processos comunicacionais posteriores do sistema.

Contudo, por ser decorrente da formação de meios de comunicação simbolicamente generalizados, o surgimento de códigos binários não exclui de todo a complexidade desse processo de seleção de sentidos e de diferenciação entre o sistema e seu ambiente, sendo, contingencial ao estágio evolutivo desse sistema. Sobre essa

\footnotetext{
${ }^{39}$ Acerca do código binário do sistema jurídico, "direito/não-direito", a sua definição parte da difícil tradução dos termos alemães recht e unrecht, que mesmo em sua língua de origem não seriam unívocos. (VILLAS BÔAS FILHO, 2006b, p. 159). Em traduções inglesas de textos de Luhmann (1989a, 1995), por exemplo, esse código aparece referenciado tanto por lawful/unlawful quanto justice/injustice (LUHMANN, 1989a, p. 139) sem contar o recurso à reducionista terminologia legal/ilegal (LUHMANN, 1995, p. 286). Em francês, os tradutores, em geral, equivalem recht/unrecht aos termos légal/illégal (LUHMANN, 1989b, p. 56). Destaca-se, neste trabalho, a opção pelo emprego da versão "direito/não-direito", mais técnica e não restrita a conteúdos morais nem legalistas, sendo também aquela usualmente empregada nas traduções espanholas das obras de Luhmann (1996, 1998), bem como por diversos de seus comentadores em língua portuguesa. (ANTUNES, 1989; CAMPILONGO, 2002; SCHWARTZ, 2004; VILLAS BÔAS FILHO, 2006b).
} 
peculiaridade, Rômulo Figueira Neves (2005) chama a atenção para o seguinte:

É importante notar que apenas sistemas que desenvolvem uma alta complexidade de seus elementos e uma alta complexidade na utilização da linguagem conseguem desenvolver um meio de comunicação simbolicamente generalizado. Apenas depois de gerar um grande número de possibilidades de produção de sentido e processos comunicativos internos o sistema pode condensar em código binário os sentidos sistêmicos. Os meios de comunicação simbolicamente generalizados estão, portanto, ligados à evolução dos sistemas sociais. (NEVES, 2005, p. 27).

Vista como um sistema comunicativo, a sociedade se utilizaria desses mecanismos em seus processos comunicacionais internos de organização e diferenciação. Nessa linha, sistema e ambiente podem então ser entendidos como dois campos complementares que compõem a complexidade social.

Os sistemas sociais e a própria sociedade enquanto sistema social global seriam então o resultado de processos comunicacionais de suas interações com o ambiente e da diferenciação que perante este estabelecem, não podendo, dessa forma, ser identificados com outros tipos de sistemas como os sistemas vivos e os sistemas psíquicos, nos quais se inserem os seres humanos, sendo esses sistemas "não sociais" entendido como o ambiente da sociedade.

A referida distinção entre ser humano e sociedade se dá no sentido do deslocamento do primeiro para a esfera exterior ao sistema social, para seu ambiente, uma vez que entende a sociedade, enquanto sistema, apenas como comunicação. Tem-se, assim, a tese da separação entre os sistemas sociais e os sistemas psíquicos de modo que o relacionamento entre sociedade e humanidade se daria no acoplamento estrutural entre esses sistemas sociais autopoiéticos, sendo que o primeiro opera na base da comunicação e o segundo na base da consciência. ${ }^{40}$

Diferenciada dos sistemas psíquicos e orgânicos, a sociedade como sistema engloba um intrincado processo de comunicações que visa à redução da complexidade

\footnotetext{
${ }^{40}$ Nesse sentido, Gotthard Bechmann e Nico Stehr (2001, p. 193) consideram a comunicação "uma operação genuinamente social (e a única que é conjunta socialmente) [...] porque pressupõe uma maioria de sistemas de consciência colaboradora ao mesmo tempo que não pode (exatamente por essa mesma razão) ser atribuída como uma unidade a nenhuma consciência individual".
} 
existente fora de si.

Por essa razão, a teoria luhmanniana é acusada de difundir uma idéia de sociedade "radicalmente anti-humanista, não ontológica e construtivista". Conforme Bechmann e Stehr (2001, p. 189):

A suposição mais radical do enfoque teórico maduro de Luhmann é sua
ênfase nas diferenças, mais precisamente nas distinções que não são mais
vistas como diferenças objetivas mas como construções. A substituição
do conceito de sujeito e a transferência da diferenciação sujeito-objeto
para uma distinção entre sistema e ambiente levam Luhmann a uma teoria
pós-ontológica da sociedade, desenvolvida numa base naturalística e
empírica como uma teoria da observação. Esse questionamento
fundamental da filosofia moderna do sujeito e sua distinção entre as
ciências naturais e as humanidades (acrescido da rejeição de um conceito
humanístico-antropocêntrico para definir a sociedade) atraiu um grande
número de críticas, e mais incompreensão ainda, ao enfoque de Luhmann.

De fato, Luhmann (1998, p. 199) postula uma ruptura com a tradição humanista que considera o ser humano como elemento último da sociedade, que se encontra dentro e não fora da ordem social.

Nesse contexto, reconhece como inicialmente impensável a separação entre alma e corpo e a própria decomposição de ambos que se seguiram com os desenvolvimentos sócio-estruturais posteriores quando das revoluções políticas e industriais e com a diversificação das ciências, como a biologia, a psicologia e a sociologia que passaram a se ocupar do ser humano de maneira separada e cada vez mais distanciada das regulações normativas do direito, dos conceitos religiosos e dos valores e fins políticos, centrados na referida normatividade natural da tradição humanista.

A mencionada tradição não só considerava o homem como dependente da ordem social, mas que este estava ligado de uma maneira específica ao viver social de modo que "sua existência só poderia realizar-se em sociedade". Assim, segundo o autor citado, durante a Idade Média o caráter político (urbano) foi substituído pelo caráter social de ordem da sociedade, sendo esse princípio ampliado com a passagem do zoon politikon para o animal sociale, de modo que, em ambos os casos, a natureza do ser humano passou a ser concebida como determinada por requisitos normativos da ordem social. (LUHMANN, 1998, p. 199).

A reconstrução semântica de humanidade, para além daquela relacionada à idéia de ordem em sentido estrito e de sua normatividade natural, teve como seu primeiro 
passo as doutrinas contratuais do "direito racional tardio". Com essa terminologia, Luhmann (1998, p. 200) refere-se ao contratualismo iluminista que concebe a sociedade como um contrato e, assim, formula uma nova máxima para a consideração do homem em sociedade durante esse período de transição: livre, mas subordinada à autoridade da razão.

Contudo, já no século XIX, com o desenvolvimento científico e sua gradual desvinculação do direito, política e religião, com especial atenção para os progressos da biologia, as analogias da sociedade como organismo social, do qual o homem faria parte, parecem cada vez menos naturais, reforçando-se a crítica dessa visão humanistanaturalista. ${ }^{41}$

Por essas razões, Luhmann (1998, p. 201) rompe com as premissas do humanismo clássico e procura reposicionar o ser humano em sua teoria não como integrante do sistema social, mas sim de seu ambiente, o que, por sua vez, "não quer dizer que o homem deva ser considerado [neste novo paradigma sistêmico] como menos importante em comparação com a tradição".

Pretende demonstrar o equívoco das interpretações contrárias à consideração do humano como parte do ambiente da sociedade, sustentando a importância do ambiente para os sistemas sociais e as potencialidades cognitivas que esse reenquadramento oferece para a compreensão do próprio ser humano e de suas liberdades. A esse respeito afirma Niklas Luhmann (1998, p. 201):

A teoria dos sistemas parte da unidade da diferença entre sistema e ambiente. $\mathrm{O}$ ambiente é um momento constitutivo desta diferença e, portanto, não é menos importante que o sistema em si. Nesse nível de abstração, a disposição da teoria permanece completamente aberta para valorizações distintas. $\mathrm{O}$ ambiente pode conservar aspectos que para o sistema podem ser mais importantes (seja qual for o ponto de vista) que os componentes do próprio sistema, mas a alternativa contrária é também

\footnotetext{
41 A esse respeito escreve Luhmann (1998, p. 200): “[...] Las ciencias mismas se distancian de las regulaciones normativas del derecho, de los conceptos religiosos, de los valores y los fines políticos. En el siglo XIX, el concepto de analogía del organismo da la impresión de encogimiento; sobre todo en relación con los progresos de la 'biología', da la impresión de no ser natural. Desde entonces se ha mantenido esta crítica. El humanismo emprende la retirada de la naturaleza hacia el espíritu. La sociología se pregunta por las bases no contractuales de la vinculación de los contratos. El hombre ya no es siquiera capaz de efectuar un contrato. Esto se lo debe a la sociabilidad, a la sociedad". Por essa razão, em outro trabalho, ao responder de forma irônica e ao mesmo tempo crítica aos seus opositores, o referido autor chega a afirmar: "In fact the theory of autopoietic systems could bear the title Taking Individuals Seriously, certainly more seriously than our humanistic tradition. Taken individual, no human being can be part of any other systems. Critics frequently miss this point". (LUHMANN, 1992, p. 1.422).
} 
teoricamente compreensível. Graças à distinção entre sistema e ambiente ganha-se a possibilidade de conceber o homem como parte do ambiente social de maneira mais complexa e, por sua vez, mais livre do que se the concebesse como parte da sociedade, posto que o entorno, em comparação com o sistema, é o campo de distinções de maior complexidade e menor ordem. Assim, se concede ao ser humano mais liberdade em relação ao seu ambiente, particularmente certas liberdades de comportamento irracional e imoral. O ser humano não é já a medida da sociedade; é necessário descartar esta velha idéia do humanismo. Quem poderia sustentar, séria e ponderadamente, que a sociedade pode ainda configurar-se à imagem e semelhança do ser humano? ${ }^{42}$

Nesse mesmo sentido, Celso Fernandes Campilongo (2002, p. 68), ao tratar desse deslocamento dos seres humanos para o ambiente da sociedade, destaca: “Ao contrário do que imaginam os críticos mais apressados dessa tese, isso não comporta, de modo algum, desvalorização do homem perante a sociedade”. Para justificar tal advertência, o referido autor reitera, em primeiro lugar, que a diferenciação entre sistemaambiente, própria da teoria luhmanniana, por si, tem por conseqüência a atribuição de uma importância tão grande ao ambiente quanto aquela do sistema.

Ainda a esse respeito, Campilongo (2002) afasta a possibilidade de que por essa distinção se considere que "o sistema possa manobrar ou conduzir os homens ao seu bel prazer", sendo que, dado a diversidade de possibilidades das relações entre eles estabelecidas, "o sistema não pode determinar o ambiente (do mesmo modo que a sociedade também é mais complexa do que os sistemas psíquicos e nunca é inteiramente determinada ou compreendida pelos indivíduos)”. (CAMPILONGO, 2002, p. 68-69).

\footnotetext{
${ }^{42}$ Cf. o original: "La teoría de sistemas parte de la unidad de la diferencia entre sistema y entorno. El entorno es un momento constitutivo de esta diferencia y, por lo tanto, no es menos importante que el sistema mismo. En este nivel de abstracción, la disposición de la teoría queda completamente abierta para valoraciones distintas. El entorno puede conservar aspectos que para el sistema pueden ser más importantes (sea cual sea el punto de vista) que los componentes mismos del sistema, pero también la alternativa contraria es teóricamente comprensible. Gracias a la distinción entre sistemas y entorno se gana la posibilidad de concebir al hombre como parte del entorno social de manera más compleja y, a la vez, más libre que si se le concibiera como parte de la sociedad, puesto que el entorno, en comparación con el sistema, es el campo de distinción de mayor complejidad y menor orden. Así, se conceden al ser humano más libertades en relación con su entorno, particularmente ciertas libertades de comportamiento irracional e inmoral. El ser humano no es ya la medida de la sociedad; es necesario descartar esta vieja idea del humanismo. ¿Quién podría sostener, seria y ponderadamente, que la sociedad puede aún configurarse a imagen y semejanza del ser humano?” (LUHMANN, 1998, p. 201).
} 


\subsubsection{Sentido e fechamento operacional do sistema}

Para Luhmann (1998, p. 58-59), diferentemente dos sistemas biológicos, para os quais a construção das relações entre sistema e ambiente só é possível através das seleções de comportamento por um outro sistema observador, os sistemas sociais e os próprios sistemas psíquicos têm uma autopoiese própria e particular, o sentido, que permite tanto a auto-referencialidade das operações internas desses sistemas quanto à ocorrência de suas interações.

A partir da evolução ontogênica dos domínios lingüísticos, que para Humberto R. Maturana e Francisco J. Varela (2005, p. 220-221) teria possibilitado o acoplamento estrutural de terceira ordem entre os seres humanos e a formação dos sistemas sociais, Luhmann (1998) destaca o papel fundamental do sentido como um ganho evolutivo que possibilitou o desenvolvimento conjunto dos sistemas sociais e psíquicos para além dessa visão biológica.

Embora se constituam como sistemas auto-referenciais diversos, ambos os sistemas autopoiéticos (sociais e psíquicos) são tidos pela teoria luhmanniana como imprescindíveis uns aos outros, servindo cada qual de ambiente necessário para a evolução do outro. As razões dessa interdependência relacionam-se à evolução de um instrumental comum: “[...] As pessoas não podem permanecer nem existir sem os sistemas sociais e vice e versa. A coevolução é conduzida através desse ganho comum [o sentido] que é utilizado tanto pelos sistemas psíquicos como sociais”. (LUHMANN, 1998, p. 77).

Nessa teoria, a idéia de sentido não se restringe de modo unilateral à consciência, em sua simples existência psíquica, restrita ao consenso e à harmonia do comportamento como seu próprio fundamento consciente. De maneira mais abrangente, “o fenômeno do sentido aparece sob a forma de um excedente de referências a outras possibilidades de vivência e de ação" presente em seu processo de seleção. (LUHMANN, 1998, p. 78).

Enquanto forma de seleção, os mecanismos de dotação de sentido dos processos comunicacionais permitem a estabilização do sistema ao passo em que restringem a complexidade a ser considerada possibilitando a utilização desses sentidos selecionados pelos próprios sistemas em suas operações futuras.

Acerca da redução da complexidade, seria contraditório à própria finalidade de 
sua nova teoria sociológica supor que Luhmann (1998) estivesse propondo a sua exclusão a despeito de considerá-la a característica essencial da sociedade moderna. Nesse sentido, ao tratar do caráter reflexivo da compreensão autopoiética não só da sociedade como da própria ciência, tece as seguintes observações:

[...] A apresentação da teoria, portanto, aplica a si mesma o que aconselha: redução da complexidade. Contudo, complexidade reduzida não significa complexidade excluída, mas sim complexidade elevada. Deixa aberto o acesso a outras possibilidades sempre que suas definições sejam levadas em consideração ou sejam substituídas no justo lugar que a teoria exige. Se abandonasse o nível das definições, desapareceria na neblina o acesso a outras possibilidades de traços lineares e se cairia novamente na complexidade indefinida e impossível de processar. (LUHMANN, 1998, p. 10). ${ }^{43}$

Poder-se-ia, então, destacar a presença em cada sentido de uma complexidade "inconcebivelmente alta (complexidade do mundo) que, se mantém disponível para a operação dos sistemas psíquicos e sociais”. Assim, para o referido autor, segundo a forma e não o conteúdo, o sentido é, portanto, "reprodução de complexidade, uma forma de reprodução que permite o uso pontual onde é empregado, e que por sua vez identifica qualquer uso como seleção e o faz, se é possível assim dizer, responsável”. (LUHMANN, 1998, p. 79).

Acrescente-se que a produção de sentido presente em todos os sistemas psíquicos e sociais permite não só seus processos auto-referenciais como implica em conseqüências para as relações que se estabelecem entre sistema e ambiente. A esse respeito afirma Luhmann (1998, p. 79):

Nem todos os sistemas processam a complexidade e a auto-referência em forma de sentido. Contudo para aqueles que o fazem, só existe essa possibilidade de processamento. Para esses, o sentido se constitui na forma de mundo com que se transcende a diferença entre sistema e ambiente. $\mathrm{O}$ ambiente se dá em forma de sentido e os limites do ambiente são limites de sentido; [...] O sentido, em geral, e os limites de sentido, em particular, garantem o nexo insuperável entre sistema e ambiente

${ }^{43}$ Cf. o original: "[...] La presentación de la teoría, por lo tanto, aplica a sí misma lo que aconseja: reducción de complejidad. Pero complejidad reducida no significa complejidad excluida, sino complejidad elevada. Deja abierto el acceso a otras posibilidades siempre que sus definiciones sean tomadas en cuenta o sean sustituidas en el lugar preciso que requiere la teoría. Si se abandonara el nivel de las definiciones, desaparecería en la neblina el acceso a otras posibilidades de trazos lineales y se caería de nuevo en la complejidad indefinida e imposible de procesar". (LUHMANN, 1998, p. 10). 
mediante uma forma especial de sentido: remissões redundantes. ${ }^{44}$

Tais "remissões redundantes" que compõe o processo de dotação de sentido devem ser entendidas com base no fechamento operacional dos sistemas auto-referenciais e em seu processo interno de diferenciação. Essa clausura operativa dos sistemas sociais é que lhes permitiria produzir de maneira recursiva a seleção desses sentidos e, ao mesmo tempo, tornar possível a geração de novos elementos a partir das informações que se depreendem de seu ambiente.

Luhmann (1998, p. 90) decompõe o sentido em três dimensões: a objetiva, a temporal e a social.

A primeira relaciona-se, nos sistema psíquicos, a todos os objetos com intenção de sentido e, no caso dos sistemas sociais, aos temas de comunicação plena de sentido. Torna, então, possível que sua estrutura remissiva decomponha aquilo a que se refere em “este" e o "outro", como pontos de referência operacionalizados de referências do mundo, sendo horizontes que intervém na constituição objetiva do sentido. (LUHAMNN, 1998, p. 91-92).

Por sua vez, a segunda dimensão do sentido, temporal, refere-se à "diferença entre o antes e o depois", e permite aos sistemas de sentido lidarem com horizontes especiais que se prolongam em direção ao passado e ao futuro, diferenciando-se entre o presente e o ausente. $^{45}$

\footnotetext{
${ }^{44}$ Cf. o original: "[...] No todos los sistemas procesan la complejidad y la autorreferencia en forma de sentido. Pero para aquellos que lo hacen, solo existe esa posibilidad de procesamiento. Para ellos, el sentido se constituye en la forma del mundo con lo cual se trasciende la diferencia entre sistema y entorno. El entorno se da en forma de sentido y los límites del entorno son límites de sentido; por consiguiente, se remiten, al mismo tiempo, hacia afuera y hacia dentro. El sentido, en general, y los límites del sentido, en particular, garantizan el nexo insuperable entre sistema y entorno mediante la forma especial del sentido: remisiones redundantes". (LUHMANN, 1998, p. 79).

${ }^{45}$ Cumpre, então, destacar que, segundo Luhmann (1998, p. 93): "El tiempo es para los sistemas de sentido, la interpretación de la realidad en relación con la diferenta entre pasado y futuro. Aquí, el horizonte del pasado (y también el del futuro) no representa el principio (o el final) del tiempo. El concepto de horizonte excluye precisamente la idea de principio o de final. Más bien, todo el pasado y todo el futuro fungen como horizontes del tiempo - independientemente de que sean representados cronológicamente y en forma lineal o no, De cualquier manera, es imposible experimentar o actuar en alguna parte del pasado o del futuro, pues los horizontes del tiempo cambian de sitio con el avance del tiempo. Futuros y pasados -en ese sentido, completamente idénticos - pueden intentarse o todavía mejor tematizarse, pero no experimentarse o manejarse".
} 
Nesse contexto, a "designação história não deve ser entendida como simples seqüência real de acontecimentos em razão da qual se pode conceber o presente como efeito de causas passadas ou como causa de efeitos futuros". Para a referida teoria sistêmica, a história constitui uma dimensão específica do sentido de tempo relacionada ao estabelecimento discricionário de sentido aos acontecimentos passados ou futuros que permitem saltar a sua seqüência temporal, tendo lugar "quando as seqüências são desligadas". (LUHMANN, 1998, p. 94).

A dimensão social, enquanto terceira dimensão de sentido citada, diz respeito ao "que se supõe respectivamente igual, como alter ego e articula a relevância desta suposição para cada experiência do mundo e fixação de sentido”. (LUHMANN, 1998, p. 94).

O social seria então parte do sentido não porque se vincula a determinados objetos, mas por ser portador de uma reduplicação particular de possibilidades de entendimento. Isto porque os conceitos ego e alter, empregados por Luhmann (1998, p. 95), "não designam aqui papéis, pessoas ou sistemas senão horizontes especiais que agregam e atribuem peso às remissões plenas de sentido".

Uma vez redimensionada na teoria luhmanniana para a compreensão dos processos comunicacionais e conscientes auto-referenciais de dotação de sentido, a dimensão social apresenta-se como um horizonte duplo que se torna relevante na medida em que as perspectivas de entendimento referidas pelo sistema decorrem da vivência e da ação mesmo que estas não possam ser separadas uma das outras. ${ }^{46}$

\footnotetext{
${ }^{46}$ Para o referido sociólogo alemão, o social não se deixa reduzir aos resultados de consciência de um sujeito monádico, o que indicaria o fracasso de todas as tentativas teóricas de constituição subjetiva ou da intersubjetividade. Sobre essa diferenciação conceitual, adverte Luhmann (1998, p. 94-95): "Es importante evitar cualquier tipo de amalgama entre dimensión social y dimensión objetiva. Este ha sido y es el error cardinal del humanismo. El hombre ha sido conceptuado en distintas versiones por su diferencia con el animal, y dotado de sociabilidad (animal social) y de temporalidad (memoria, phantasia, prudentia) y así finalmente declarado sujeto. Aun la teoría del sujeto ubica la relación interna/externa donde deberían distinguirse con base en el doble horizonte, la dimensión objetiva u la dimensión social. A pesar de ello, sin embargo, el hombre sigue siendo un objeto preferido junto al cual existen otros - lo que es evidente en la tendencia hacia la reantropologización de la filosofia trascendental y en su concepto de sujeto. El humanismo también reproduce un concepto de naturaleza y, por lo tanto, debe enfrentarse al dilema de su propia limitación. Es necesario no interpretar la distinción entre dimensión objetiva e dimensión social como distinción entre naturaleza y hombre. El progreso teórico estriba precisamente en evitar este angostamiento humanista".
} 
Contudo, é a partir de sua clausura operativa que os sistemas sociais podem produzir de maneira recursiva a seleção desses sentidos gerando novos elementos com base nas informações que se depreendem de seu ambiente.

Assim, essa recursividade dos sentidos que compõe o seu repertório autoreferencial possibilita não só sua reprodução e a auto-observação de seus elementos internos como, também, a observação externa e o acoplamento com outros sistemas que compõem o seu ambiente, posto que permite ao sistema social referenciá-los como informação para seus processos comunicacionais. ${ }^{47}$

Segundo Rômulo Figueira Neves (2005), os sentidos no contexto da teoria social de Luhmann contribuem dessa forma para o processo de diferenciação do sistema, estando presentes em todas as suas operações:

[...] Para completar o processo comunicativo, o sistema necessita dotar as informações e os acontecimentos de sentido referenciando a um repertório existente e a um meio de comunicação simbolicamente generalizado. Para existir sentido é necessário um sistema que organize formas de relacionar e selecionar as informações e os processos comunicativos. A principal característica da dotação de sentido, para o sistema, é a concepção da virtualidade, ou seja, a capacidade de intelecção de que dada informação ou evento tinha outras possibilidades, outros caminhos possíveis e que, em virtude de uma seleção, outras possibilidades foram abandonadas. Esta característica envolve por um lado o reconhecimento de outras possibilidades no passado e por outro, e por isso mesmo, a manutenção de alternativas para o futuro. Assim, o mecanismo de dotação de sentido dos processos comunicativos restringe

\footnotetext{
${ }^{47}$ Essas três dimensões de sentido exercem na teoria de luhmanniana uma função importante em relação à destautologização da auto-referência do sentido. A esse respeito, discorre Luhmann (1998, p. 91): “[ ...] El sentido tiene sentido: esto permanece como un hecho (correspondientemente no se ponen en duda afirmaciones como: todo sentido tiene sentido, sólo el sentido tiene sentido). Al mismo tiempo, la autorreferencialidad del sentido se reespecifica dimensionalmente con ayuda de las diferencias de cada una de las dimensiones especificas. El futuro es futuro sólo respecto de un presente con pasado; pero no es el pasado y tampoco retorna a él (como lo sugería el modelo circular). Mi consenso sólo lo es en relación con tu consenso, y no hay ninguna clase de argumento objetivo o racional que finalmente pudiera asegurar esa coincidencia (de nuevo, desde la dimensión objetiva). Las autorreferencias deben articularse dentro de cada dimensión del sentido, no puede ser producida por los horizontes de otra dimensión. Por ejemplo, el consenso no puede sustituir al futuro ni ser sustituido por el horizonte objetivo interno del sistema (en esto, por ejemplo, el psicoanálisis, reclama su competencia). Sin embargo, en la medida en que se establecen las diferencias en las dimensiones del sentido (las diferencias de las diferencias de las dimensiones especificas), las interdependencias entre las dimensiones pueden servir para la condicionalización y destautologización de las autorreferencias. Los círculos se romperán. El mundo objetivo obliga a pensar al tiempo asimétricamente, y este obliga a pensar asimétricamente, como gradiente de complejidad, a la relación entre mundo externo y mundo interno. Sólo de esta manera se puede extraer del mundo complejidad estructurada plena de sentido, en la que las operaciones de los sistemas de sentido pueden encontrar su lugar”.
} 
a finalização do processo a uma compreensão, ao mesmo tempo em que também abre a possibilidade para outras operações, que se utilizam daquela como pressuposto. O processo de dotação de sentido também torna permanente a capacidade dos sistemas de se auto-reproduzirem, na medida em que mantém como possíveis todas essas operações que fazem parte do repertório do sistema e que dão lugar a novas operações. (NEVES, 2005, p. 40).

O fechamento operacional dos sistemas sociais se perfaz graças à criação e reprodução de seus elementos de funcionamento em seu interior sem a interferência ou influência de elementos externos, os quais podem contribuir apenas indireta e eventualmente para esse processo em face da recursividade daqueles mecanismos de seleção que compõem processos comunicacionais desses sistemas autopoiéticos.

Dessas considerações, segundo Gotthard Bechmann e Nico Stehr (2001, p. 189), resulta a descrição dos fenômenos sociais como interações e a idéia de que "o mundo (como horizonte de descrições possíveis) é expresso por meio de uma rede de distinções e rótulos contingentes que sempre devem ser entendidos dentro do contexto". Nesse sentido, acrescentam os autores citados:

Sistema, para Luhmann, quer dizer uma série de eventos relacionados um ao outro, ou de operações. No caso dos seres vivos, por exemplo, esses são processos fisiológicos; no caso de sistemas psíquicos, os processos são idéias; e em termos de relações sociais, são comunicações. Os sistemas se formam ao se distinguirem do ambiente, no qual esses eventos e operações ocorrem, e que não pode ser integrado a suas estruturas internas. (BECHMANN; STEHR, 2001, p. 190).

Essa ênfase no aspecto relacional dos sistemas e a idéia correlata de sua separação do ambiente distinguem a teoria sistêmica de Luhmann (1998) daquela proposta por Talcott Parsons (1974) que, em linhas gerais, em seu funcionalismo de persuasão, destaca a adesão coletiva a normas e padrões compartilhados como definição de sistemas.

Por sua vez, para a teoria luhmanniana, essa fronteira operacional (não espacial) dos sistemas sociais é vista, sobretudo, em relação aos sistemas psíquicos (individuais) e demais sistemas que fazem parte de seu ambiente ou entorno. (LUHMANN, 1998).

Essa diferenciação operacional e as estruturas dos sistemas sociais emergentes não seriam porém um dado pré-estabelecido ou pré-ordenado, muito menos auto-evidente, mas um processo contínuo de novas construções do ponto de vista existencial de sua 
forma, portanto, contingenciais e relacionados ao aumento da complexidade social. No mais, diferentemente do funcionalismo de persuasão parsoniano, Luhmann, com essa teorização, não estaria comprometido com a preservação dos sistemas sociais. (BECHMANN; STEHR, 2001, p. 191).

A sociedade vista como um sistema autopoiético de comunicação, caracterizado pela organização auto-reprodutiva e circular de processos comunicacionais, permitiu a Niklas Luhmann (1998) explicar a evolução das sociedades modernas desenvolvidas através de um fenômeno de diferenciação funcional.

\subsubsection{Dupla contingência, programa e diferenciação funcional}

O fechamento operacional dos sistemas sociais engloba todo um processo de criação e reprodução de elementos de funcionamento em seu interior. Por esse motivo, torna-se impossível a sua total compreensão através de uma observação externa, tanto a partir do ambiente quanto do interior de outros sistemas de sentidos, sejam eles também sociais, como, por exemplo, o sistema científico; ou psíquicos, como, da mesma forma exemplificada, a consciência do pesquisador.

De tal constatação decorreria uma segunda noção de contingência desses processos comunicacionais relacionada a essa impossibilidade de se prever suas condições de existência e as operações internas por ele realizadas. Tanto essas condições como as operações citadas são passíveis de mudança em qualquer momento em razão da ampla possibilidade de decisões e de escolhas de sentido que caracteriza a própria complexidade social que o sistema visa reduzir.

Destaca-se, dessa forma, a existência de uma dupla contingência como importante característica da Teoria dos Sistemas Sociais autopoiéticos em estudo. (LUHMANN, 1998, p. 113).

A dupla contingência não se restringe à dificuldade do sistema em lidar com a complexidade desorganizada presente no ambiente, que o leva a se diferenciar recorrendo à auto-referência e ao fechamento operacional de seus processos comunicacionais. Seu caráter dúplice decorre dessa própria diferenciação funcional que tornaria o sistema não totalmente decifrável ("não-transparente") a seus próprios elementos e ao ambiente, impossibilitando-os de prever as respostas sistêmicas aos estímulos selecionados de seu 
exterior ou mesmo àqueles resultantes de suas inter-relações com outros sistemas de sentido (acoplamentos estruturais e interpenetrações). ${ }^{48}$

Ademais, uma vez que essas contingências são reconhecidas pelos sistemas, estes criam mecanismos de seleção em suas operações que passam a fazer parte de seu repertório sistêmico visando à sua proteção de mais essa improbabilidade de comunicação.

Não obstante a hipótese dessa contingência dos processos comunicacionais vir a ser reduzida pelo desenvolvimento do repertório comunicativo próprio do sistema, a mesma volta paradoxalmente a se potencializar com a formação de expectativas operacionais seja, do ponto de vista interno ao sistema, entre seus elementos, seja entre os sistemas de sentido (sociais e psíquicos).

Tais expectativas decorrem do desenvolvimento dos meios de comunicação simbolicamente generalizados e de sua aparente previsibilidade. A relação desses meios com a criação de expectativas comunicacionais resulta do fato de permitirem ao sistema facilitar suas operações seguintes, conectando-as às operações internas pré-existentes e, assim, eventualmente reiterar suas mensagens, repetições e decodificações anteriores em seus processos de dotação de sentido e de seleção das informações. Contudo, trata-se de uma aparente previsibilidade, daí porque como assinala Rômulo Figueira Neves (2005, p. $33)$ :

Os sistemas não têm a expectativa de que suas operações sejam adotadas igualmente por outro sistema e sabem que o mesmo ocorre com a expectativa do outro sistema. As referências [e essas próprias expectativas] do sistema são voltadas para si, já que não podem prever ou definir a operação dos outros sistemas. Forma-se, nessa relação, uma equação com muitas variáveis que têm de ser levadas em conta pelos sistemas, como a expectativa de Alter sobre as operações de Ego e as expectativas de Ego em relação às operações de Alter.

O importante nesse ponto é entender que essas expectativas e as operações

\footnotetext{
${ }^{48}$ Acerca do conceito de contingência na teoria dos sistemas luhmannianos disserta Rômulo Figueira Neves (2005, p. 17): "Essa impossibilidade de previsão pelo ambiente externo das respostas do sistema social a irritações externas, para as quais há uma gama de possibilidades, gera o conceito de contingência, ou seja, não há como uma informação externa pré-determinar uma resposta visto que também internamente há contingências [dupla contingência] que possibilitam processos evolutivos do sistema. Assim, qualquer estímulo externo, como irritação ou ruído, que interesse ao sistema social operacionalmente fechado, é internalizado a partir de processos internos de dotação de sentido".
} 
reflexas dela decorrentes são geradas pela observação mútua entre os sistemas, sendo tais expectativas, em muitas das vezes, conflituosas e contraditórias entre si. Justamente nesse contexto é que as relações de interação, interpenetração e acoplamento estrutural podem ocorrer. Porém, essa observação entre os sistemas e as inter-relações dela decorrentes não pressupõe necessariamente qualquer cooperação, coordenação ou simbiose entre os mesmos. (NEVES, 2005, p. 35).

Além dessa observação pelo sistema do meio ambiente e dos demais sistemas que compõe seu entorno, os sistemas sociais em seu processo auto-referencial e autopoiético requerem uma constante auto-observação de seu funcionamento, que se relaciona inclusive à sua capacidade de controle e ao grau de programação de algumas de suas funções. Nesse sentido:

Deve-se mencionar, com particular ênfase, uma conseqüência estrutural importante que resulta, forçosamente, da construção dos sistemas autoreferenciais: a renúncia à possibilidade de controle unilateral. Pode haver diferenças na capacidade de influência, hierarquias, assimetrizações, mas nenhuma parte do sistema pode controlar a outra sem sucumbir ao mesmo tempo ante o controle. Sob tais circunstâncias é possível, e ainda muito provável, nos sistemas que têm orientação de sentido, realizar um controle mediante a antecipação de um contracontrole. Apesar disso, a garantia de uma estrutura todavia assimétrica (por exemplo, nas condições internas do poder de um sistema) sempre necessita de disposições particulares. Essa problemática do controle se nivela, em parte, ao acentuar a auto-observação. Nesse contexto, isto é, no nível da teoria geral dos sistemas, observação não significa outra coisa que manejo de distinções. Só no caso dos sistemas psíquicos, o conceito pressupõe consciência (se poderia dizer também que, motivado pela observação, surge o meio próprio do sistema, a consciência). Outros sistemas têm que agregar suas próprias possibilidades de observação. A auto-observação é a introdução da diferença entre sistema e entorno no sistema que se constitui através desta diferença. Dita diferença é, por sua vez, um momento operativo da autopoiese, já que na reprodução dos elementos deve assegurar sua reprodução como elementos do sistema e não como qualquer coisa distinta. (LUHMANN, 1998, p. 58). ${ }^{49}$

${ }^{49}$ Cf. original: "Se debe mencionar, con particular énfasis, una consecuencia estructural importante que resulta, forzosamente, de la construcción de los sistemas autorreferenciales: la renuncia a la posibilidad de control unilateral. Puede haber diferencias en la capacidad de influencia, jerarquías, asimetrizaciones, pero ninguna parte del sistema puede controlar a otro sin sucumbir él mismo ante el control. Bajo tales circunstancias es posible, y aún muy probable, en los sistemas que tienen una orientación de sentido, llevar a cabo cualquier control mediante la anticipación de un contracontrol. A pesar de esto, la garantía de una estructura todavía asimétrica (por ejemplo, en las condiciones internas del poder de un sistema) siempre necesita de disposiciones particulares. Esta problemática del control se nivela, en parte, al acentuar la autobservación. En este contexto, es decir, en el nivel de la teoría general de sistemas, observación no significa otra cosa que manejo de distinciones. Sólo en el caso de los sistemas psíquicos, el concepto 
Os programas surgem então nessa teoria como forma de controle interno das operações sistêmicas. Através deles é que os sistemas sociais estabelecem as condições sob as quais certos processos comunicacionais podem ocorrer e os processos que devem suceder a ocorrência de determinadas operações internas.

Reduzem, assim, uma parte da contingência sistêmica uma vez que, por seu meio, os sistemas podem verificar o direcionamento das referidas operações a despeito de sua evolução indeterminada e contingente. ${ }^{50}$

A programação do sistema é complementar à função desempenhada pelo código binário na evolução do sistema. Contudo, ao contrário destes e dos meios de comunicação simbolicamente generalizados, os programas dependem do direcionamento que o sistema social assume ao longo de seu processo de evolução, sendo assim flexíveis. (NEVES, 2005, p. 30).

Ademais, cumpre destacar que os programas mais encontrados nos sistemas sociais são de caráter finalístico ou condicional. (LUHMANN, 1998, p. 290).

Os programas finalísticos têm por função coordenar as operações sistêmicas para determinados resultados estipulados internamente e que, por esse motivo, constituem o objetivo da programação.

Nesse sentido, estabelecem quais seleções devem ser consideradas como válidas para se atingir determinados fins. Tais programas coordenam ainda a participação das pessoas, no curso das interpenetrações entre os sistemas sociais e psíquicos, em seus

presupone la conciencia (se podría decir también que, motivado por la observación, surge el medio propio del sistema, la conciencia). Otros sistemas tienen que allegarse sus propias posibilidades de observación. La autobservación es la introducción de la diferencia entre sistema y entorno en el sistema que se constituye a través de esta diferencia. Dicha diferencia es, a la vez, un momento operativo de la autopoiesis, ya que en la reproducción de los elementos debe asegurarse su reproducción como elementos del sistema y no como cualquier cosa distinta”. (LUHMANN, 1998, p. 58).

${ }^{50}$ Segundo a síntese explicativa proposta por Rômulo Figueira Neves (2005, p. 30): “As expectativas de operações de Alter e Ego são bastante delineáveis no âmbito dos programas. Além disso, as expectativas podem ser conectadas em uma cadeia de operações que dependem entre si, tanto na dimensão da ocorrência propriamente dita, quanto na ordem e na determinação temporal dos diversos processos comunicativos. Dessa forma, os programas servem para diminuir sensivelmente a contingência dos processos comunicativos do sistema no qual operam o programa. Isso não significa que a contingência foi eliminada, nem que os resultados dos processos sobrecomunicativos possam ser previstos, mas apenas que objetivos prévios ou requisitos mínimos foram definidos". 
diversos processos comunicacionais. (NEVES, 2005, p. 31).

Por sua vez, os programas condicionais definem situações e requisitos em que processos comunicacionais deverão ser realizados. Tais definições disponibilizam aos elementos do sistema critérios sob os quais devem ser organizadas as operações do sistema social em que esse programa é desenvolvido. Permitem ao sistema, em sua autoobservação, avaliar a conformação dos procedimentos às condições fixadas pelo programa.

Paralelamente, no que diz respeito à outra característica dessa teoria luhmanniana dos sistemas sociais autopoiéticos, tem-se que a diferenciação dos sistemas não se restringe ao ambiente, mas pode também ocorrer, ainda que de forma um pouco diversa, no interior próprio sistema social.

Sob o ponto de vista das diferenciações funcionais internas, em sua Teoria da Sociedade, Niklas Luhmann (1998, p. 182) sustenta que, a partir desse processo comunicacional geral, novos e específicos circuitos comunicativos vão sendo gerados e desenvolvidos até que estes, enquanto processos comunicacionais emergentes, atinjam um determinado grau de complexidade e perficiência na sua própria organização autoreprodutiva que os levam a se autonomizarem do sistema social geral, originando subsistemas sociais autopoiéticos.

O referido processo em que surgem subsistemas sociais autopoiéticos é de suma importância para a compreensão de toda a teoria sistêmica social ora estudada posto que se objetiva neste trabalho delinear as potencialidades e limitações de tal teoria para a compreensão da força normativa constitucional do direito sanitário que perpassa as supostas relações entre os sistemas jurídico e sanitário. ${ }^{51}$

\footnotetext{
${ }^{51}$ Ressalte-se porém que Luhmann, seguindo uma continuidade em sua obra, ao que tudo indica direcionou seus estudos para a busca da compreensão do funcionamento interno dos sistemas sociais, presente já em seus trabalhos anteriores como em Legitimação pelo procedimento (1980), do que teria resultado uma supervalorização dessa dinâmica interna em detrimento da exploração das potencialidades das inter-relações comunicativas externas, entre os sistemas. (CAMPILONGO, 2000a, p. 81-82). Ademais, em sua dissertação de mestrado intitulada Acoplamento estrutural, fechamento operacional e processos sobrecomunicativos na Teoria dos Sistemas Sociais de Niklas Luhmann, Rômulo Figueira Neves (2005, p. 72) esclarece que "pesquisas nesse sentido foram iniciadas por Luhmann, com os estudos de estrutura social e semântica (Gesellschaftstruktur und Semanitk), mas ele não conseguiu completá-las [até o fim de sua vida]". Nessa linha, os "processos sobrecomunicativos" são apontados na citada dissertação de mestrado como formas de inter-relações sistêmicas não expostas claramente na teoria luhmanniana. Tais processos poderiam, grosso modo, ser entendidos como situações de peculiar suspensão da clausura operativa do sistema que possibilitariam rápidas e reversíveis sujeições de parte de seu processo comunicativo a influências externas
} 
A autonomização do sistema social geral em subsistemas pressupõe a constituição de novos processos comunicacionais através da elevação da complexidade e completude da comunicação produzida em alguns de seus circuitos emergentes. Nesses circuitos especializados surgem novos códigos binários e eventualmente programas sistêmicos próprios que passam a guiar as suas operações auto-reprodutivas de subsistemas sociais a partir da consolidação de novos meios de comunicação simbolicamente generalizados.

Ressalta-se neste ponto que o processo de diferenciação funcional do sistema social global implica no pressuposto teórico de que nenhum dos vários subsistemas emergentes — v.g. os sistemas jurídico, político ou econômico — pode reivindicar a supremacia sobre os demais sistemas sociais nem sequer pretender substituí-los em suas respectivas funções. (LUHMANN, 1992, p. 1434-1435).

Dessa forma, a teoria sistêmica, nos termos até aqui desenvolvidos, propiciou a quebra da tradicional oposição entre sistemas fechados e sistemas abertos na medida em que, no paradoxo autopoiético da clausura auto-reprodutiva, os sistemas biológicos, psíquicos ou sociais estão "abertos" ao meio envolvente graças à sua clausura operativa do próprio sistema. $^{52}$

Em outras palavras, chega-se à conclusão de que a abertura e adaptação de um sistema autopoiético ao seu meio envolvente dependem, paradoxalmente, da capacidade que esse sistema tem de manter intacta a sua própria auto-referencialidade.

Em conseqüência, graças à visão autopoiética, é afastada da relação dos

em situações muito específicas. (NEVES, 2005, p. 67).

52 A esse respeito, Luhmann (1992) diferencia expressamente a teoria dos sistemas sociais da teoria dos sistemas abertos. Destaca, ainda, a inexistência de uma causalidade direta entre as relações do sistema social com seu ambiente o que só é factível a partir de um processo de seleção própria de um terceiro sistema observador que correlaciona a estrutura do sistema com determinadas interações. Situa-se, ao menos nesse ponto, na mesma linha de Humberto R. Maturana e Francisco J. Varela (2005, p. 150-151), posto que entendem que o meio não específica nem sequer instrui as mudanças estruturais do sistema, sendo a relação de causalidade dela decorrente criada pela seleção e dotação de sentido de uma observação externa: "The emergence of closed systems requires a specific form of relations between systems and environments; it presupposes such forms and is a condition of their possibility as well. The theory of 'open systems' describes the forms with the categories of input and output. This model postulates a causal chain in which the system itself serves as the connecting part linking inputs and outputs. The theory of autopoietic systems replaces the input/output model with the concept of structural coupling. It renounces the idea of an overarching causality (admitting it, of course, as a construct of an observer interested in causal attributions), but retains the idea of highly selective connections between systems and environments". (LUHMANN, 1992, p. 1431-1432). 
sistemas sociais com o meio em que estão inseridos a visão até então dominante desses sistemas como realidades totalmente abertas — da qual resultou a crença na capacidade de se regular exogenamente tais sistemas através de estímulos e respostas diretas (inputsoutputs), o que garantiria uma adaptação constante desses sistemas ao meio continuamente em mutação. (LUHMANN, 1998, p. 33).

À luz das idéias de auto-referencialidade de suas operações, de unidade e identidade dos sistemas, passa-se a considerar como fator de sua sobrevivência e estabilidade, frente às mudanças de seu meio envolvente a sua própria capacidade de autoobservação e auto-organização. (ANTUNES, 1989, p. xvi).

Portanto, esse processo de diferenciação funcional interna e a própria natureza auto-referencial dos sistemas autopoiéticos denotam a impossibilidade de se compreender os problemas e as peculiaridades de um dado sistema a partir de uma observação que lhe seja exterior. A teoria autopoiética repercute, assim, no campo da gnosiologia e epistemologia de modo a negar a separação entre a construção científica e seus objetos. (LUHMANN, 1998, p. 424).

\subsubsection{Acoplamento estrutural e interpenetração}

Os acoplamentos estruturais e as interpenetrações apresentam-se como complexas formas de relacionamento entre os sistemas sociais e destes com os elementos de seu ambiente. ${ }^{53}$

\footnotetext{
${ }^{53}$ Acerca da terminologia empregada, os termos acoplamento estrutural e interpenetração decorrem de um aprimoramento teórico de Luhmann, não tendo sido criados simultaneamente.Sobre isso esclarece Rômulo Figueira Neves (2005, p. 49): "O conceito [de acoplamento estrutural] não existia no esboço inicial da teoria, apresentado em Soziale Systeme [em 1984]. Até então, Luhmann utilizava o termo interpenetração, originário da teoria parsoniana, para designar todas as relações inter-sistêmicas. A partir de Die Wissenschaft der Gesellschaft [obra de 1992], o conceito de acoplamento estrutural passa a ser utilizado para designar as relações inter-sistêmicas em geral e o termo interpenetração passa a designar um caso específico". Essa segunda hipótese, a ser restritamente denominada de interpenetração consiste na relação entre sistemas sociais e sistemas psíquicos, que já era tratada na primeira obra mencionada inicialmente publicada em 1984, cuja versão espanhola - Sistemas Sociales: lineamientos para una teoría general, de 1998 - utilizamos nesse trabalho.
} 
As relações entre os sistemas sociais e os elementos de seu ambiente, como outros sistemas sociais ou sistemas psíquicos, são denominadas acoplamentos estruturais em sentido amplo. Designam dessa forma um aparato simultaneamente sutil e complexo com que um sistema se vale das estruturas de funcionamento de um outro sistema a fim de viabilizar seus próprios processos comunicacionais. Segundo Niklas Luhmann (1992, p. 1.432):

O acoplamento estrutural entre sistema e ambiente não contribui com
operações (ou quaisquer outros componentes) para a reprodução do
sistema. É apenas a forma específica com que o sistema pressupõe
estados específicos ou mudanças em seu ambiente e neles confia. A
caminhada pressupõe forças gravitacionais da Terra com limites muito
estreitos, mas a gravitação não contribui com quaisquer passos para o
movimento dos corpos. A comunicação pressupõe estados atentos de
sistemas de consciência, mas estados conscientes não podem se tornar
sociais nem entram na seqüência de operações comunicativas como parte
destas; eles se mantém como estados ambientais para o sistema social.
Acoplamentos estruturais são formas simultâneas (e, portanto, não
causais) de relações. ${ }^{54}$

Conforme essa teoria, o sistema social em suas operações normais não estaria sujeito à observação das estruturas de seus acoplamentos. Porém, em função das seleções por estas realizadas o sistema tem que lidar com perturbações, irritações, surpresas e desapontamentos de modo a assimilar e acomodar tais ambigüidades.

Tais perturbações, contudo, devem ser entendidas como simples construções internas porque aparecem como divergências de expectativas relacionadas à própria estrutura do sistema.

Para Luhmann (1992, p. 1.432), o ambiente não contém em si perturbações nem quaisquer outras formas a isso assemelhadas. Portanto, não se pode falar em transmissão de perturbações do exterior para o interior do sistema.

\footnotetext{
${ }^{54} \mathrm{Cf}$. original: "The structural coupling of system and environment does not contribute operations (or any other components) for the reproduction of the system. It is simply the specific form in which the system presupposes specific states or changes in its environment and relies on them. Waling presupposes the gravitational forces of the earth within very narrow limits, but gravitation does not contribute any steps to the movement of bodies. Communication presupposes awareness states of conscious systems, but conscious states cannot become social and do not enter the sequence of communicative operations as a part of them; they remain environmental states for the social system. Structural couplings are forms of simultaneous (and therefore, not casual) relations". (LUHMANN, 1992, p. 1.432).
} 
Tanto o conceito de clausura operacional quanto o de acoplamento estrutural não são compatíveis com a idéia de trânsito ou troca de informações entre sistema e ambiente. O mesmo se aplica às expectativas cognitivas. Assim como as seleções de informação são sempre construídas internamente, as expectativas cognitivas não passam de formas específicas do sistema se preparar para irritações (surpresas, imprevisibilidades) que ele antecipa da observação de outros sistemas e de seu ambiente.

De modo ilustrativo, pode ser citado o sintético exemplo proposto por Rômulo Figueira Neves (2005) em sua dissertação sobre o tema:

Outro modo de exemplificar o funcionamento do acoplamento estrutural é partindo da análise do acoplamento entre o sistema política e o sistema direito [sic] na elaboração das leis, no processo legislativo. Por um lado, a elaboração das leis é um processo político, que envolve as decisões de poder, a votação de determinações que vinculam toda a população que pertence àquela jurisdição política. Esse processo, no entanto, utiliza e obedece a certos parâmetros legais (que um dia já passaram pelo processo político) e pode ser questionado com base em códigos jurídicos que estão fora do escopo de atuação da política. Os legisladores não precisam ser bacharéis em direito para representar a população nas votações das leis, ou seja, o sistema político não precisa compreender a complexidade do sistema jurídico para realizar suas operações, no máximo precisa conhecer algumas limitações que podem gerar sanções e eliminar a comunicação do sistema político. (NEVES, 2005, p. 52).

Contudo, os acoplamentos estruturais enquanto condição de cognição são fundamentais para o processo comunicacional sistêmico, pois sem eles não haveria a percepção de perturbação e, sem isso, o sistema perderia "oportunidades de aprendizado e de transformação de suas estruturas". (LUHMANN, 1992, p. 1.433).

Nesse sentido, juntamente com a formação de alto grau de complexidade interna, tais acoplamentos apresentam-se como precondição necessária para a construção de regularidades, ordem e redundância necessárias para reduzir e ordenar a complexidade desorganizada em termos da ampla variedade de escolhas de sentido e de direcionamento de ações. (LUHMANN, 1998, p. 169-170).

A construção de regularidades internas do sistema depende, portanto, de acoplamentos estruturais. Nessa linha, esclarece Rômulo Figueira Neves (2005, p. 49):

Quando há um acoplamento estrutural, o processo comunicativo de um sistema aparece no outro não apenas como uma perturbação, mas também como uma ferramenta auxiliar de funcionamento das operações, seu significado, no entanto, vai ser construído apenas dentro do próprio sistema em que foi realizado o processo comunicativo, de forma 
independente do significado que tinha naquele sistema original. Apenas a complexidade operacional de um sistema do ambiente é reproduzida dentro do sistema que realiza o processo comunicativo, não seus processos de cognição.

As interpenetrações, por sua vez, referem-se especificamente aos acoplamentos estruturais entre sistemas sociais e sistemas psíquicos. Contudo, antes de se adentrar nas especificidades dessa inter-relação sistêmica, é preciso retomar como são entendidos os sistemas psíquicos e outros conceitos utilizados na teoria luhmanniana em contraste com as noções de ser humano e pessoa consolidadas pela tradição humanista à que a mesma se opõe.

A teoria dos sistemas sociais luhmanniana distingue a expressão ser humano do termo pessoa. Em linhas gerais, ser humano refere-se tanto aos sistemas psíquicos quanto aos sistemas orgânicos do homem. Já a palavra pessoa, nessa específica teoria, é utilizada para designar uma unidade referenciada na comunicação, existindo tão somente na comunicação e para a comunicação, ou seja, como "a identificação social de um complexo de expectativas dirigidas a um homem individual”. (LUHMANN, 1998, p. 199).

A diferença central entre essa conceituação sistêmica e aquela empregada pela tradição humanista, como foi possível tratar nos itens anteriores, diz respeito à posição do ser humano e ao seu papel em relação à ordem social sendo que para o referido humanismo clássico o ser humano ocupa o centro da ordem social, estando dentro e não fora dela, como elemento da própria sociedade.

De maneira radicalmente oposta, no que diz respeito à teoria luhmanniana, os sistemas psíquicos e consequentemente os seres humanos corporizados não constam dos sistemas sociais, ou seja, do interior sociedade moderna tida como um sistema global de comunicações, mas sim de seu exterior como importantes sistemas autopoiéticos presentes no ambiente (ou entorno) da sociedade, cada qual com formação autônoma fundada em suas próprias operações elementares. (LUHMANN, 1998, p. 236).

Aos sistemas psíquicos aplicam-se, portanto, os conceitos básicos de reprodução fechada e auto-referencial. Diferentemente dos sistemas sociais, sua recursividade se perfaz em torno da produção de consciência a partir de seus elementos internos de consciência. Dada a sua clausura operacional, tais sistemas não dependem, em tese, do ambiente e, por conseguinte, não recebem consciência do exterior nem podem lhe 
transferir tal elemento. Cumpre, destacar que, para a mencionada teoria, por consciência deve-se entender tão somente o modo de operação peculiar dos sistemas psíquicos e não algo que exista substancialmente.

Com base nos estudos de Edmund Husserl sobre a consciência e seu papel nos sistemas psíquicos, afirma Luhmann (1998, p. 242):

Não há dúvida de que os sistemas psíquicos são sistemas autopoiéticos em virtude de sua situação frente ao ambiente (sobretudo porque são sistemas autopoiéticos constituídos sobre a base da consciência e não sobre a base da vida). Utilizam a consciência só no contexto de suas próprias operações e todos os contatos com o entorno (inclusive os que se estabelecem com o próprio corpo) estão mediados pelo sistema nervoso, ou seja, têm que utilizar outros níveis de realidade. O sistema nervoso mesmo é um sistema fechado e por esta razão o sistema psíquico que opera com a consciência tem que se edificar exclusivamente sobre elementos que se constituem a si mesmos. ${ }^{55}$

Nesse sentido, tais sistemas de consciência produzem em seu interior representações do mundo através de circuitos operativamente fechados com base em representações anteriores para, assim, ascender a novas representações.

Esse processo reiterado de reprodução de representações a partir de representações permitiria entender que a própria consciência consiste no reconhecimento da temporalidade da consciência, não restrita à sua dependência do tempo. Assim, "a tese de que a consciência com todas as suas retenções e antecipações sempre opera no presente e que, portanto, nela não pode haver temporalidade, continuamente tem que sustentar-se e subsistir a si mesma (o que Derrida chamará de 'diferença' — différance)". (LUHMANN, 1998, p. 242). ${ }^{56}$

Ademais, tem-se por essa teoria luhmanniana que separa sistemas sociais de

\footnotetext{
${ }^{55}$ Cf. o original: "No cabe duda de que los sistemas psíquicos son sistemas autopoiéticos en virtud de su situación ante el entorno (sobre todo porque son sistemas autopoiéticos constituidos sobre la base de la conciencia y no sobre la base de la vida). Utilizan la conciencia sólo en el contexto de sus propias operaciones y todos los contactos con el entorno (incluidos los que se establecen con el propio cuerpo) están mediados por el sistema nervioso, es decir, tienen que utilizar otros niveles de realidad. El sistema nervioso mismo es un sistema cerrado y por esta razón el sistema psíquico que opera con la conciencia tiene que edificarse exclusivamente sobre elementos que se constituyen a si mismos”." (LUHMANN, 1998, p. 242).

${ }^{56} \mathrm{Cf}$. o original: "[...] la tesis de que la conciencia con todas sus retenciones y anticipaciones siempre opera en el presente y que, por lo tanto, en ella no puede haber temporalidad, continuamente tiene que sustentarse y sustituirse a sí misma (lo que Derrida llamará la 'diferencia'_différance)'”. (LUHMANN, 1998, p. 242).
} 
sistemas psíquicos que a observação destes últimos não permite a observação em si de sua consciência, ao contrário do que se acredita.

Por sua vez, a formação de expectativas é destacada como mecanismo autopoiético de redução da complexidade externa decorrente tanto das relações entre sistema psíquico e sistema social, quanto daquele com o seu ambiente.

Para Luhmann (1998), do ponto de vista dos sistemas psíquicos, a expectativa deve ser considerada como a forma com que esses sistemas podem se expor à contingência do mundo. Sobre essa questão discorre de maneira comparativa:

[...] Então, se trata da mesma forma [de redução da complexidade] utilizada para a formação de estruturas sociais. Num dos casos está proposta como consciência; no outro, como comunicação. De acordo com isso, o conceito de expectativa tem que ser concebido muito amplamente para poder abarcar a sua aplicação no psíquico e no social, assim como nas interdependências correspondentes. [...] Relacionada aos sistemas psíquicos, entendemos por expectativa uma forma de orientação por meio da qual o sistema observa a contingência de seu entorno em relação consigo mesmo e a acolhe como incerteza própria no processo de reprodução autopoiética. (LUHMANN, 1998, p. 246). ${ }^{57}$

Da mesma forma, enquanto complexidade desorganizada, o ambiente não tem nenhum tipo de participação direta no operar fechado da autopoiese psíquica. Para a referida teoria, sua complexidade é articulada e reprocessada pelo sistema psíquico apenas através das expectativas possibilitando-lhe o seu entendimento e utilização de modo operativo. Assim, “o sistema se projeta e logo registra se o esperado ocorre ou não". (LUHMANN, 1998, p. 247).

A formação de expectativas seria dessa forma uma "técnica primitiva de antonomásia" que pode ser trabalhada quase sem condições prévias posto que não pressupõe uma descrição nem um conhecer a fundo do ambiente. Daí porque segundo Luhmann (1998, p. 247): “se pode gerar uma expectativa sem conhecer o mundo". A única

\footnotetext{
${ }^{57}$ Cf. o original: “[...] Entonces, se trata de la misma forma que se utiliza para la formación de estructuras sociales. En uno de los casos está propuesta como conciencia; en el otro, como comunicación. De acuerdo con esto, el concepto de expectativa tiene que concebirse muy ampliamente para poder abarcar la aplicación a lo psíquico y a lo social, así como a las interdependencias correspondientes. [...] En cuanto a los sistemas psíquicos, entendemos por expectativa una forma de orientación por medio de la cual el sistema sondea la contingencia de su entorno en relación consigo mismo y la acoge como incertidumbre propia en el proceso de la reproducción autopoiética". (LUHMANN, 1998, p. 246).
} 
condição necessária é que tal expectativa seja autopoieticamente utilizável,ou seja, que pré-estruture o acesso às representações de enlace.

Esse processo teria como resultado a realização de algumas expectativas ou a formação de frustrações mediante o recursivo repertório de novas possibilidades de comportamento que surgem novamente pré-estruturadas, de tal forma que:

[...] Depois de um determinado tempo de vida, e enriquecidas pelas experiências sociais, as expectativas perdem o caráter de arbitrárias. No avanço normal de uma representação em direção à outra não se cairá no inusitado. Um indivíduo se orienta inevitavelmente pela própria história de sua consciência, por mais singular que tenha sido seu desenvolvimento; a determinação da experiência atual assegura que não possam formar-se qualquer tipo de expectativas. Para isso estão à disposição tipos socialmente padronizados, com os quais um indivíduo pode orientar-se. (LUHMANN, 1998, p. 247). ${ }^{58}$

Refuta-se, então, a possibilidade de comunicação no interior ou entre os sistemas psíquicos porque os processos psíquicos não seriam processos lingüísticos. Tampouco o pensamento comportaria qualquer forma de "conversa interior" (hablar interior) como equivocadamente teria sido sempre sustentado, pois lhe falta o "destinatário interior". No sistema de consciência não haveria um "segundo eu", enquanto instância adicional que examinasse o pensamento linguisticamente formado, no sentido de aceitá-lo ou rechaçá-lo como decisão que trataria de antecipar. (LUHMANN, 1998, p. 249-250).

De maneira similar à auto-reprodução dos sistemas sociais, em que da comunicação desprende-se por si só mais comunicação, assim também haveria no ser humano reproduções auto-referenciais fechadas. Essas poderiam ser então divididas em reprodução orgânica, cujo meio seria a forma de manifestação da vida, e reprodução psíquica, fundada na consciência. Ambos os sistemas autopoiéticos, vida e consciência, seriam do ponto de vista da Teoria da Sociedade luhmanniana a condição prévia da formação dos sistemas sociais de tal forma que "os sistemas sociais só podem se auto-reproduzir se a

\footnotetext{
${ }^{58}$ Cf. o original: “[...] Después de un determinado tiempo de vida, y enriquecidas por las experiencias sociales, las expectativas pierden el carácter de arbitrarias. En el avance normal de una representación hacia la otra no se caerá en lo inusitado. Uno se orienta inevitablemente por la propia historia de la conciencia, por más singular que haya sido su desarrollo; la determinación de la experiencia actual asegura que no puedan formarse cualquier tipo de expectativas. Para ello están a disposición tipos socialmente estandarizados con los cuales uno se puede orientar". (LUHMANN, 1998, p. 247).
} 
continuação da vida e da consciência estiver garantida”. (LUHMANN, 1998, p. 206).

Por essas razões, a interpenetração não pode ser entendida como a relação de duas coisas separadas, muito menos conforme a representação esquemática de círculos que se entrecruzam parcialmente. Os limites de cada sistema podem ser adaptados no campo de operação do outro. Quer-se com isso dizer que todo sistema que participa na interpenetração realiza em si mesmo o outro como diferença entre sistema e ambiente sem com isso desintegrar-se.

Cada sistema pode realizar então sua própria complexidade em relação ao outro, suas próprias descrições e reduções, e, com base nisso, pôr à disposição do outro sua própria complexidade. Assim, a comunicação dos sistemas sociais está obrigada a se orientar continuamente por aquilo que os sistemas psíquicos adotam ou não em sua consciência, porque os limites dos sistemas psíquicos não são, por sua vez, limites das possibilidades de comunicação. (LUHMANN, 1998, p. 205).

Portanto, as interpenetrações, enquanto formas especiais de acoplamentos estruturais são necessárias para a própria existência dos sistemas, pois "a existência dos sistemas psíquicos são condição necessária para a existência dos sistemas sociais, assim como o sistema biológico é condição necessária para a existência dos sistemas psíquicos e vice-versa". (NEVES, 2005, p. 50).

\subsubsection{Interações, Organizações e Sociedade}

As interações e organizações apresentam-se como sistemas sociais parciais, formados por relações inter-sistêmicas, sociais e psíquicas, que constituem processos comunicacionais próprios, dos quais podem emergir novos sistemas sociais mais complexos.

No que diz respeito às interações, estas podem ser entendidas como formas específicas de relação entre sistemas psíquicos. Envolvem relações diretas e presenciais entre os seres humanos marcadas pela formação de processos comunicacionais a partir da percepção mútua, como modo rudimentar de informação.

Segundo Luhmann (1998, p. 353), deve-se distinguir entre sociedade e interação na medida em que esta se refere a uma espécie de sistema social que surge entre os presentes, enquanto que a sociedade, por sua vez, deve ser compreendida como o 
conjunto de todas as comunicações sociais possíveis. Nesse sentido, afirma:

A sociedade e a interação são dois sistemas sociais distintos. A sociedade garante $\mathrm{o}$ fechamento pleno de sentido e a auto-referência de acontecimentos comunicacionais, isto é, garante a cada interação a capacidade de início e finalização, assim como o enlace de sua comunicação. Nos sistemas de interação se apresenta uma espécie de hidráulica da interpenetração. A atração e a pressão da presença atuam sobre os presentes e os motivam a renunciar à sua própria liberdade em favor de determinadas restrições. Por conseguinte, a sociedade não é possível sem interpenetração e vice-versa. Mas ambos os sistemas não se fundem; são indispensáveis um ao outro em sua diferença. (LUHMANN, 1998, p. 373). ${ }^{59}$

Enquanto espécies de sistema social, às interações se aplicam as distinções entre exterior e interior e o fechamento sistêmico como modo operativo.

Uma importante característica dos sistemas de interação refere-se aos processos de percepção decorrentes das relações entre sistemas psíquicos fisicamente presentes. Isto porque é justamente através da presença física — em que se realizam essas específicas relações entre sistemas psíquicos - que se configuram processos de percepção necessários a constituição dos sistemas de interação.

A percepção aqui tratada, ao contrário da comunicação, é um processo menos exigente de seleção de informação. Nesse contexto, pode ser entendida, em linhas gerais, como um ganho de informação psíquica que se transforma em fenômeno social através de uma articulação de dupla contingência marcada pela percepção recíproca e expectativas dela decorrente, isto é, a percepção que um indivíduo tem de ser percebido na presença de outro e vice-versa. (LUHMANN, 1998, p. 269).

A presença dos sistemas psíquicos num dado tempo e espaço gera esse fenômeno de percepção reflexiva que, por sua vez, pode dar início aos processos comunicacionais de maneira quase inevitável, isto porque, segundo Luhmann (1998, p. 370):

\footnotetext{
${ }^{59}$ Cf. o original: "La sociedad y la interacción son dos sistemas distintos. La sociedad garantiza la cerradura plena de sentido y autorrefencial de acontecimientos comunicacionales; es decir a cada interacción le garantiza la capacidad de inicio y finalización, así como el enlace de su comunicación. En los sistemas de interacción se presenta una especie de hidráulica de la interpenetración. La atracción y la presión de la presencia actúan sobre los presentes y los motivan a renunciar a su propia libertad a favor de determinadas restricciones. Por consiguiente, la sociedad no es posible sin interpenetración y viceversa. Pero no se funden ambos sistema; son indispensables uno para el otro en su diferencia". (LUHMANN, 1998, p. 373).
} 
[...] Se alter percebe que é percebido e que sua percepção de ser percebido é percebida, tem que partir de que seu comportamento é interpretado como um comportamento corretamente adaptado. $\mathrm{O}$ fato de que lhe convenha ou não, é também percebido como comunicação que lhe obriga, quase que inevitavelmente, a controlar seu comportamento como comunicação. Inclusive a comunicação de não querer se comunicar segue sendo uma comunicação. [...] Podemos afirmar que, praticamente, nos sistemas de interação é impossível não comunicar, caso opte por evitar a comunicação, deve-se escolher a ausência. ${ }^{60}$

Destaca-se, portanto, que a dimensão social do sentido percebido desempenha funções de seleção, o que produz o próprio limite desses sistemas sociais de interação. Por essa razão, a presença é o princípio constitutivo e formador dos limites dos sistemas interacionais. Essa reunião de pessoas - no sentido estrito de conjunto de expectativas socialmente identificadas — conduz a seleção de percepções e elege as perspectivas em função de sua relevância. (LUHMANN, 1998, p. 371).

Através da interação resulta a seleção dos temas de maneira concreta e, por essa mesma razão, contingente de tal forma que essa contingência represente sua própria sociabilidade, seja em relação ao ambiente da interação, seja, a outras possibilidades de relacionamento que se apresentam aos participantes. Assim, nesse processo de interação, selecionam-se entre possibilidades determinadas, ou pelo menos cada vez mais determináveis, aquelas situações que mantém abertas só uma quantidade limitada de variantes de desenvolvimento com que sua autopoiese pode lidar. (LUHMANN, 1998, p. 375).

No que diz respeito às ações decorrentes das interações, segundo Luhmann (1998, p. 377): "seria um erro pensar numa diferença sistema/ambiente ou ainda supor que a sociedade compreende [apenas] operações abstratas e a interação, de forma oposta, de operações concretas (comunicações, ações)" apenas porque a comunicação social se realiza em sua grande parte, embora não exclusivamente, como interação. Não obstante essas considerações, "a sociedade não exclui, mas inclui a interação. Portanto, não se dá uma

\footnotetext{
${ }^{60}$ Cf. o original: "[...] Si alter percibe que es percibido y que su percepción de ser percibido es percibida, tiene que partir de que su comportamiento es interpretado como un comportamiento correctamente adaptado. El hecho de que le convenga o no, es también percibido como comunicación, lo que le obliga, casi inevitablemente, a controlar su comportamiento como comunicación. Incluso la comunicación de no querer comunicarse sigue siendo una comunicación. [...] Podemos afirmar que, prácticamente, en los sistemas de interacción es imposible no comunicar, si se quiere evitar la comunicación, ha que escoger la ausencia". (LUHMANN, 1998, p. 370).
} 
separação entre distintos tipos de ação: sociais e interacionais”. (LUHMANN, 1998, p. 377).

A despeito do intricando processo de comunicação que pode ser desenvolvido a partir dessa especial forma de inter-relação sistêmica que é a interação, nos limites do presente trabalho cumpre apenas relacionar essa sua contribuição para a redução da complexidade e para a operacionalização dos processos comunicacionais. Isso se dá com a seleção de sentidos que constituem a diferenciação de cada um dos sistemas psíquicos envolvidos, bem como do próprio sistema social em que essas interações ocorrem, o que, por sua vez, pode levar à formação de outros sistemas sociais mais complexos.

Por fim, para que se possa compreender o direito como um sistema social autopoiético, deve-se, antes, destacar algumas considerações sobre os sistemas organizacionais e seu tratamento na teoria dos sistemas sociais de Luhmann (1993, 1998).

As organizações são tidas como espécies peculiares e parciais de sistemas sociais resultantes de acoplamentos estruturais entre sistemas sociais complexos.

Desenvolvem um código de comunicação próprio e diferenciado pela consideração de um critério especial: à idéia de pertencimento. Por essa razão, não seria possível a exata descrição de seus limites, posto que sua abrangência é expressa através de categorias como “membro e não-membro". (LUHMANN, 1993, p. 188).

Cumpre destacar como característica de sua própria autopoiese, que os processos comunicacionais desses sistemas organizacionais não se restrinjam apenas à seleção de sentidos através de códigos de pertencimento, sendo também possível sua diferenciação através de certas "vias de comunicação", formadas por meio de estruturas hierárquicas dentro da organização, as quais determinam as posições e a diferenciação interna do sistema organizacional. (NEVES, 2005, p. 60).

Ainda que não seja possível o seu aprofundamento na presente dissertação, deve-se ressaltar outras importantes características dos sistemas organizacionais que, de certa forma, alinham-se aos elementos e processos comunicacionais gerais dos sistemas sociais de que fazem parte.

Nesse sentido, destaca-se nos sistemas organizacionais a existência de programas referentes aos seus objetivos, metas e condições em que tais objetivos devem ser alcançados. Determinam-se, assim, não apenas os limites de atuação dos membros das organizações no sentido das decisões que lhes são atribuídas como também o próprio modo 
de ascensão dentro da hierarquia da organização, dentre outros aspectos de seu funcionamento. Segundo Rômulo Figueira Neves (2005, p. 60): "Estas definições criam as vias por onde os processos comunicacionais podem ser canalizados — com a linguagem, essas vias constituem um meio para a ocorrência do processo comunicacional”.

Dessa maneira, enquanto sistemas organizacionais, partidos políticos, escolas, universidades, dentre outras organizações sociais, desenvolvem processos comunicacionais que têm significado em mais de um sistema funcional consolidado, embora essas organizações em si estejam, em sua grande parte, reconhecidamente vinculadas a um determinado sistema funcional.

Não obstante essa vinculação, as organizações enquanto sistemas parciais de comunicação têm relevância para outros sistemas consolidados. Isto ocorre em função da dupla referência semântica de seus processos comunicacionais. $\mathrm{Na}$ medida em que resultam do acoplamento estrutural entre sistemas sociais consolidados, os sistemas organizacionais moldam suas estruturas com as operações próprias daqueles outros sistemas, não sendo, portanto, compostos de processos comunicacionais de um único sistema social.

Por essa mesma razão, embora desempenhem um importante papel para a redução da complexidade e mesmo para a administração e seleção de conflitos em relação aos sistemas sociais consolidados, os sistemas organizacionais "não podem preencher todo potencial funcional de nenhum dos sistemas sociais - economia, ciência, política etc. acoplados". (NEVES, 2005, p. 59). ${ }^{61}$

No que diz respeito ao processamento comunicativo dos conflitos, destaca-se a

\footnotetext{
${ }^{61}$ Por outro lado, conforme disserta Rômulo Figueira Neves (2005, p. 61): "Paradoxalmente, as organizações podem ser as guardiãs de alguns processos comunicativos essenciais para o sistema ascendente, mesmo tendo esses processos comunicativos sentidos e relevância em outros sistemas por conta do acoplamento estrutural. É assim, por exemplo, com as organizações igrejas, para o sistema religião, universidade, para o sistema ciência, e partidos, para o sistema política: processos comunicativos essenciais dos sistemas ascendentes, o culto e a pregação, na igreja, a experiência e o exame de validade, na universidade, as convenções e as disputas, nos partidos, têm relevância não apenas no sistema ascendente, mas também em sistemas acoplados. O pastor bem articulado pode estar angariando poder político a ser transformado em um mandato no parlamento nas próximas eleições; o aluno aplicado pode estar angariando prestígio junto a um empregador potencial com os resultados de um experimento científico; e o candidato pode estar vislumbrando uma melhor remuneração do que a recebida em seu emprego ordinário. A relevância das realizações da organização, reconhecidas como parte dos sistemas sociais ascendentes, confere mais autonomia e legitimidade à autopoiese destes sistemas no conjunto da sociedade".
} 
importância dos sistemas interacionais e organizacionais.

$\mathrm{Na}$ teoria luhmanniana dos sistemas, os conflitos sociais devem ser entendidos como a comunicação de uma contradição no sentido de expectativas não aceitas. A expectativa, segundo Luhmann (1998, p. 350), “não tem que referir-se necessariamente ao comportamento rechaçado, pode se referir também a terceiros ou constituir-se na descrição de uma realidade que não é crível para aquele a quem se comunica”.

Tais conflitos referem-se a um procedimento de comunicação preciso e empiricamente concebido que comunica uma negação, um "não", por assim dizer, a uma comunicação anterior. Contudo, não se resumem à frustração ou negação de uma expectativa projetada por outro sistema desde que seja possível deduzir que a comunicação foi compreendida. No caso específico do conflito, para a sua configuração devem ocorrer duas comunicações contraditórias. (LUHMANN, 1998, p. 350).

Essa contradição, enquanto forma de sentido, é a síntese de duas comunicações que, por conseguinte, representam cada qual o produto de três etapas de seleção indissociáveis — informação, participação e compreensão. ${ }^{62}$

Por essa razão, segundo Luhmann (1998, p. 350), seria um equívoco atribuir à

\footnotetext{
${ }^{62}$ Acerca do conceito de contradição utilizado por Niklas Luhmann (1998, p. 324 e ss.) na formulação de sua Teoria da Sociedade, é preciso destacar a profunda diferença de sentido e função por ele atribuídos a esse termo. $\mathrm{O}$ autor citado se opõe tanto a noção geral e valorativa que restringe as contradições a erros lógicos, ou infrações contra as regras da lógica que se deve evitar, quanto ao uso restrito de sua função "dialética". A despeito dessa tradicional construção teórica do campo da lógica e da própria sociologia, para a sua teoria dos sistemas a contradição deve ser entendida como "[...] uma indefinição do sistema e não uma indefinição de uma operação particular" (LUHMANN, 1998, p. 327). Distingue-se, portanto, a atribuição de contradições aos sistemas sociais daquela usualmente referida aos processos operativos dos sistemas psíquicos, posto que se desenvolvem com base em meios diversos: comunicação e consciência. Assim, "[...] Só nos sistemas psíquicos a unidade da contradição consiste em ter consciência de que o contraditório implica na impossibilidade de sua existência, e isso se reflete como 'mera' consciência. A consciência pode seguir adiante graças à contradição, ao atribuí-la a si mesma e ao controlar sua continuação e sua relação com a realidade, mas isso não é mais do que uma opção operativa". (LUHMANN, 1998, p. 329). Por sua vez, quanto aos sistemas sociais, em razão dos mesmos só existirem enquanto sistemas de comunicação, as contradições são produzidas mediante a comunicação de uma negação, tendo, nesse contexto, uma "existência exclusivamente comunicacional (que por sua vez, sem embargo, provoca mais ou menos consciência)". As contradições estariam "incluídas na auto-referência comunicacional dos sistemas sociais, se concebem como um momento dessa auto-referência e não como ataques ao exterior. A comunicação realiza a unidade (e com ela também a possibilidade de contradição), através de uma tríplice seleção. Informação, ato de comunicar e ato de entender são praticados como unidade, mesmo quando sejam distintos os respectivos conteúdos de consciência dos participantes e seus horizontes de seleção. [...] [Conclui-se, então, que:] Por meio dessa unidade de comunicação, o sistema social constitui as contradições válidas para ele". (LUHMANN, 1998, p. 330).
} 
ocorrência de um conflito "uma falta de comunicação (como se a comunicação fosse algo 'bom' suscetível de fracassar)". De maneira oposta, para o referido autor:

[...] o conflito assume momentaneamente a autopoiese, a continuação da comunicação. [...] A comunicação é o processo autopoiético dos sistemas sociais que continua mais além de todos os episódios cooperativos ou antagônicos, sempre que continue. Os conflitos, portanto, servem, precisamente, para a continuação da comunicação por meio do emprego de uma das possibilidades que mantém abertas: a utilização do não. (LUHMANN, 1998, p. 350). ${ }^{63}$

Tem-se, portanto, que na teoria luhmanniana os conflitos surgem corriqueiramente em quase todos os sistemas, como formações cotidianas, e em sua grande parte "constituem banalidades que se resolvem rapidamente". Por essa razão, critica-se "uma teoria dos conflitos" restrita a motivos estruturais ou que só considere os conflitos de "classe" ou de "dominação" como conflitos propriamente ditos. Dessa forma, perder-se-ia de vista "o caráter maciço deste fenômeno e a irrelevância das circunstâncias em que surgem (e em seu lugar introduz dados de fatos que todavia não chegam a um verdadeiro enfrentamento)". (LUHMANN, 1998, p. 352).

Os conflitos guardam, nesse contexto, uma estreita relação com os sistemas interacionais e organizacionais. Isto ocorre, pois é justamente nos conflitos interacionais, que são também conflitos sociais, que se pode identificar sinais de sua relevância social. Nessas hipóteses, existe uma maior probabilidade de que um conflito "se estenda, se aprofunde e se perpetue". (LUHMANN1998, p. 353).

Pode ocorrer, ainda em razão do conflito, a emergência de novos processos comunicacionais gerados para além do sistema de interação, revelando interpenetrações entre os sistemas psíquicos nele presentes e outros sistemas sociais. Como exemplo dessa possibilidade, tem-se, a partir dos temas em conflito, a remissão a referências políticas, morais, científicas e de direito como formas de buscar apoio externo ao sistema de interação. Segundo Luhmann (1998, p. 353):

63 Cf. o original: "[...] el conflicto asume momentáneamente la autopiesis, la continuación de la comunicación. [...] La comunicación es el proceso autopoiético de los sistemas sociales que continúa más allá de todos los episodios cooperativos o antagónicos, siempre que continúe. Los conflictos, por lo tanto, sirven, precisamente, para la continuación de la comunicación por medio del empleo de una de las posibilidades que mantiene abiertas: la utilización del no”. (LUHMANN, 1998, p. 350). 
[...] Também a moral e o direito tendem a fomentar o conflito ao fazer crer a um dos rivais que sua posição é a correta e que é possível expor o adversário ao repúdio público ou ainda à sanção dos tribunais. Da mesma maneira, a argumentação científica pode garantir apoio aos conflitos. Assim, os médicos se arriscam nos conflitos (de fato, seus órgãos representativos são os mais combatíveis na política) porque sabem como curar as enfermidades e podem advertir ao rival que se trata de seu próprio enterro. Posto que, ninguém está em condição de obrigar que se faça a partilha da riqueza, o capital também é fonte do aumento de conflitos sociais. Parte das grandes conquistas da sociedade capitalista é, precisamente, haver dotado os donos do capital de uma grande capacidade de oposição e, em conseqüência, de atitude de conflito frente à política, a qual, não obstante, é tecnicamente soberana e aparentemente autônoma para escolher seus próprios meios. ${ }^{64}$

Contudo, de tais considerações não se pode concluir uma divisão de competências funcionais entre os sistemas de interação e a sociedade, na linha equivocada de que caberia aos primeiros enfrentar apenas os conflitos pequenos e, à sociedade, os grandes conflitos sociais.

Para a referida Teoria da Sociedade, na medida em que os sistemas de interação se reproduzem unicamente na sociedade, as seleções estruturais de conflitos passam a ser o resultado da própria “diferença entre o sistema de interação e o sistema social”. Tal diferença revelaria a importância do conflito social não apenas para o sistema de interação, "como também fora dos limites de interação presente, em que tem capacidade de enlace para as relações sociais". (LUHMANN, 1998, p. 353).

Assim, os limites do sistema de interação são capazes de reconhecer "os sintomas" referentes à capacidade e possibilidade de enlace de seus conflitos internos com o exterior. A esse respeito, acrescenta ainda Luhmann (1998, p. 353): “A moral e o direito, sobretudo, servem para operacionalizar essa sintomatologia".

\footnotetext{
${ }^{64}$ Cf. o original: "[...] También la moral y el derecho tienden a fomentar el conflicto al hacer creer a uno de los rivales que su posición es la correcta y que es posible exponer al adversario al rechazo público o aun a la sanción de los tribunales. De la misma manera, la argumentación científica puede garantizar o apoyo a los conflictos. Así, los médicos se arriesgan en los conflictos (en efecto, sus órganos representativos son los más combativos en la política) porque saben cómo curar las enfermedades y pueden advertirle al rival que se trata de su propio entierro. Puesto que, nadie está en condición de obligar a que se lleve a cabo la repartición de la riqueza, el capital también es fuente de incremento de conflictos sociales. Parte de las grandes conquistas de la sociedad capitalista es, precisamente, el haber dotado a los dueños del capital de una gran capacidad de rechazo y, en consecuencia, de la aptitud de conflicto frente a la política, la cual, no obstante, es técnicamente soberana y aparentemente autónoma para escoger sus propios medios. (LUHMANN, 1998, p. 353).
} 
Por sua vez, em relação à operacionalização comunicacional dos conflitos sociais, as organizações exercem, ao seu modo, a tarefa de selecionar e, assim generalizar, os conflitos particulares socialmente importantes, sobretudo, nas hipóteses em que delas se constituem expectativas não atendidas adequadamente pelo direito e pela moral. De forma exemplificativa, expõe Luhmann (1998, p. 353-354):

[...] Os sindicatos cumprem, com freqüência, esta função. A semântica da "discriminação" tem assumido precisamente esta atividade de revalorização: quando o homossexual é despedido, o crítico da Constituição não é contratado no serviço público, a mulher foge do lar matrimonial, o negro não encontra alojamento, surgem rapidamente organizações e terminologias dispostas a dar ao conflito uma significância geral. ${ }^{65}$

Percebe-se, através da teoria sistêmica luhmanniana, que a redução da complexidade social a condições estruturalmente possíveis, bem como a operacionalização da comunicação através de sistemas sociais funcionalmente diferenciados que formam a sociedade global, necessárias à sua própria adaptação evolutiva, perfazem uma série de relações internas e externas desse sistema comunicacional. Revelam, assim, uma intrincada rede de seleção de sentidos, coordenação de ações, conflitos, organizações, acoplamentos estruturais e interações entre sistemas sociais e psíquicos, de modo circular, auto-reprodutivo e operacionalmente fechado.

Uma vez identificados os seus pressupostos e sua diferenciada base conceitual, é possível empreender o estudo das potencialidades e dos limites de tal teoria para a compreensão do direito, como sistema social autopoiético, sobretudo, no que diz respeito aos programas, conflitos e expectativas (normativas) que envolvem a saúde e os seus acoplamentos estruturais,

${ }^{65}$ Cf. o original: “[...]. Los sindicatos cumplen, con frecuencia, esta función. La semántica de la 'discriminación' ha asumido precisamente esta actividad de revalorización: cuando el homosexual es despedido, el crítico de la Constitución no es contratado en el servicio público, la mujer huye del hogar matrimonial, el negro no encuentra alojamiento, surgen rápidamente organizaciones y terminologías dispuestas a dar al conflicto una significancia general". (LUHMANN, 1998, p. 353-354). 
norteando essa pesquisa pela sua capacidade de agregar e instrumentalizar os avanços conquistados em termos de direitos sociais fundamentais, pelo sistema jurídico constitucional sanitário. 


\section{O DIREITO COMO SISTEMA SOCIAL AUTOPOIÉTICO}

A visão autopoiética do direito é apontada como alternativa para o impasse científico que tem dominado as teorias jurídicas, divididas entre a consideração do direito como sistema normativo fechado ou praticamente autônomo e a sua crítica sociológica como uma esfera decisória condicionada. Ambas seriam insuficientes para explicar o direito na sociedade moderna e direcionar a sua interpretação frente aos novos limites e funções que lhe são colocados pelo alto grau de complexidade das relações sociais que deve regular. (LUHMANN, 1983; TEUBNER, 1989a; BÜLLESBACH, 2002; CAMPILONGO, 2002).

No campo do Direito à Saúde, a teoria dos sistemas sociais de Niklas Luhmann é defendida por Germano Schwartz (2004) como arcabouço teórico indispensável para o reposicionamento do direito em face da crescente complexidade social, como a relacionada ao aumento do risco sanitário dela decorrente e da necessidade de se enfrentar os novos desafios impostos às decisões relativas a esse sistema jurídico de modo a se reforçar o caráter principiológico-constitucional da proteção sanitária.

\subsection{A posição da teoria sistêmica em face das principais teorias analíticas e correntes marxistas do direito}

Pretende-se, inicialmente, situar a visão autopoiética do direito no suposto estágio de transição científica para além do paradigma jurídico positivista.

Deve-se frisar, mais uma vez, que não é o objetivo deste trabalho defender a supremacia de um modelo em relação ao outro, mas dissertar sobre as propostas do pensamento sistêmico e seus limites em relação à efetivação do Direito à Saúde propugnado pela Constituição Federal de 1988 em sua dimensão social e interdisciplinar.

As críticas dos defensores da visão autopoiética do direito ao referido impasse jurídico-científico destinam-se, de um lado, às teorias analítico-formalistas, como a Teoria 
Pura de Hans Kelsen (1998), centradas numa visão científica positivista do direito alheia à sua relação com a sociedade, e, de outro, embora não se tratar do formalismo positivista citado, rejeita-se o enfoque das teorias sociológicas do direito e de suas interações sociais como sistema aberto, compreendendo-o sob a ótica de um "sistema decisional socialmente condicionado" (ANTUNES, 1989, p. xix). ${ }^{66}$

No que diz respeito à Teoria Analítica do Direito, esta se insere no movimento positivista do século XIX e começo do século XX, sendo sua principal influência no campo jurídico exercida pela vertente lógico-analítica que, embora leve em conta fatos positivos - o direito como um algo existente na realidade social, dado positivamente, e por isso acessível a uma análise científica - , procura explicá-lo de modo formal como um sistema "conceitual", lingüístico. ${ }^{67}$

O positivismo jurídico oriundo dessa orientação restringe a ciência do direito à “análise crítica de afirmações normativas e lingüístico-conceptuais, deixando as investigações empíricas fundamentalmente para disciplinas da especialidade, como, por exemplo a sociologia do direito". (MAZUREK, 2002a, p. 370).

Essa vertente lógico-analítica centra seu interesse nas proposições lingüísticoconceituais e pressupõe, a partir da compreensão da estrutura das normas e de seus

\footnotetext{
${ }^{66}$ Há que se distinguir claramente a crítica ao positivismo - enquanto modelo científico de análise do direito e das ciências sociais, sob o axioma da neutralidade valorativa e da busca de "leis naturais da vida social e de uma ciência da sociedade formada segundo o modelo das ciências da natureza" (LOWY, 2003, p. 18-19) — da consideração do Direito Moderno como Direito Positivo, no sentido da contingência de suas estruturas, relacionada à sua contínua adaptação às transformações da sociedade e de sua complexidade no contexto histórico, em oposição ao perene Direito Natural. (LUHMANN, 1983, p. 225; CANARIS, 1996, p. 27 e 30). Para uma visão abrangente e crítica da inadequação e das distorções ideológicas da aplicação do positivismo enquanto modelo científico no campo das ciências sociais recomenda-se a leitura da obra de Michael Löwy (2003) intitulada As aventuras de Karl Marx contra o Barão de Münchhausen: marxismo e positivismo na sociologia do conhecimento.

${ }^{67}$ Esse desenvolvimento histórico é tratado por Tercio Sampaio Ferraz Jr. (1994), como a consolidação da "Ciência Dogmática do Direito". A respeito da influência do positivismo e de seu caráter formalista, afirma o referido autor: "A primeira metade do século XX acentua as preocupações metodológicas já presentes no século anterior. $\mathrm{O}$ início do século é dominado por correntes que o levam às preocupações do pandectismo ao seu máximo aperfeiçoamento - por exemplo, na obra de Kelsen - ou insistem numa concepção renovada do saber jurídico ligando-o à realidade empírica. [...] O jurista aparece aí como o teórico do direito que procura uma ordenação dos fenômenos a partir de conceitos gerais obtidos, para uns, mediante processos de abstração lógica e, para outros, pelo reconhecimento de institutos historicamente moldados e tradicionalmente mantidos. [...] Neste quadro, a ciência dogmática do direito, na tradição que nos vem do século XIX, prevalecentemente liberal, na sua ideologia, e encarando, por conseqüência, o direito como regras dadas (pelo Estado, protetor e repressor) tende a assumir o papel de conservador daquelas regras, que, então, são por ela sistematizadas e interpretadas". (FERRAZ JR, 1994, p. 82-83).
} 
conceitos — da análise de determinadas palavras, por exemplo: direito, coação, moral etc. —, a possibilidade de se "elucidar não só o seu significado, mas, para além disso, os próprios fenômenos sociais nas suas relações uns com os outros”. (MAZUREK, 2002a, p. 370).

Dessa forma, restringindo-se à análise de conceitos jurídicos básicos, espera desenvolver uma teoria sobre a estrutura geral do direito. (FERRAZ JR., 1994, p. 82).

Insere-se, segundo Claus-Wilhelm Canaris (1996, p. 27), numa visão sistêmica do direito restritiva pertencente aos "sistemas de puros conceitos fundamentais".

Embora o referido autor não ignore a importância do instrumental teórico da teoria kelseniana, de seus "sempre pré-elaborados conceitos fundamentais apriorísticos", entende que sistemas como este apresentam grandes limitações para a própria elaboração científica jurídica não sendo capazes de concretizar a unidade valorativa exigida pelo direito. Esta unidade "é sempre de tipo material e só pode realizar-se numa ordem jurídica historicamente determinada" o que estaria aquém das possibilidades daqueles sistemas analíticos, como o kelseniano, que tratam de "categorias puramente formais, que subjazem a qualquer ordem jurídica imaginável" (CANARIS, 1996, p. 27). ${ }^{68}$

Para essa criticada visão formalista-positivista, as normas jurídicas postas pelo Estado assumem a centralidade da análise científica do direito seja sob o prisma de Hans Kelsen (1998) e de sua Teoria Pura — em que tais normas são "o objeto da ciência jurídica, e a conduta humana só o é na medida em que é determinada nas normas jurídicas

\footnotetext{
${ }^{68}$ A mesma crítica é dirigida por Canaris (1996, p. 28) aos sistemas lógico-formais, como o da jurisprudência dos conceitos e do sistema axiomático-dedutivo, que, como os sistemas de puros conceitos formais, seriam inadequados para "exprimir a unidade interior e a adequação de determinada ordem jurídica positiva". Tais limitações decorreriam do conceito positivista de ciência fundado nos ideais metodológicos das ciências naturais, imprimindo à ciência jurídica um caráter estritamente lógico. Sua incongruência em relação à visão sistêmica da ciência jurídica, proposta pelo referido autor, que melhor se adequariam aos objetivos e à essência do direito é assim exposta: "Esta concepção [positivista] da essência e dos objetivos da Ciência do Direito pode-se hoje, sem reserva, considerar como ultrapassada. De fato, a tentativa de conceber o sistema de determinada ordem jurídica como lógico-formal ou axiomático-dedutivo está, de antemão, votada (sic) ao insucesso. Pois a unidade interna de sentido do direito, que opera para erguer o sistema, não corresponde a uma derivação da idéia de Justiça de tipo lógico, mas antes de tipo valorativo ou axiológico. Quem poderia seriamente pretender que a regra de tratar o igual por igual e o diferente de modo diferente, de acordo com a medida da diferença, pode ser acatada com os meios da lógica? Os valores estão, sem dúvida, fora do âmbito da lógica formal e, por conseqüência, a adequação de vários valores entre si e a sua conexão interna não se deixam exprimir logicamente, mas antes, apenas, axiológica ou teleologicamente". (CANARIS, 1996, p. 30$31)$.
} 
como pressuposto ou conseqüência, [...] em que constitui conteúdo de normas jurídicas" (KELSEN, 1998, p. 79) —, seja com uma maior abertura pela teoria estruturalista de Herbert Lionel Adolphus Hart (2001) e seu enfoque na diversificação das normas jurídicas em regras primárias e secundárias.

Enquanto que para a teoria kelseniana a condição de existência do sistema jurídico, restrito ao conjunto escalonado de normas jurídicas válidas, depende de um pressuposto lógico, com o estabelecimento lógico-fictício ("pressuposição lógicotranscendental") de uma norma fundamental (Grundnorm), para Hart (2001), o direito compreenderia um sistema de regras empírico sociais. ${ }^{69}$

Nesse sentido, nas regras primárias, a característica sociológica consistiria em sua manifestação exterior como regra de comportamento, consensual e que se repetiria regularmente, na maioria de um grupo social. O aspecto psicológico de sua existência se manifestaria quando certo comportamento é reconhecido pela maioria do grupo social como padrão geral.

As condições de existência das regras secundárias, de atribuição de competência, dependeriam da utilização de uma regra de reconhecimento por um tribunal ou por outras pessoas para a identificação das regras do sistema, sendo seu aspecto exterior um aplicar, enquanto prática complexa do sistema jurídico.

Segundo a síntese proposta por Per Mazurek (2002a,), essas regras secundárias de reconhecimento, diferentemente das demais, não encontrariam no interior desse sistema

\footnotetext{
${ }^{69}$ Acerca dos limites dessa pressuposição, embora empregue o termo lógico-transcendental para se referir a esse processo cognitivo, Kelsen (1998) busca restringir o seu grau de abstração estipulando sua vinculação com uma dada ordem jurídica, ou seja, sua vinculação a uma Constituição sempre determinada e efetivamente estabelecida, portanto não condicionada a qualquer valor transcendente ao Direito Positivo, daí porque afirma: "[...] A norma fundamental não é, portanto, o produto de uma descoberta livre. A sua pressuposição não se opera arbitrariamente, no sentido de que temos a possibilidade de escolha entre diferentes normas fundamentais quando interpretamos o sentido subjetivo de um ato constituinte e dos atos postos de acordo com a Constituição por ele criada como o seu sentido objetivo, quer dizer: como normas jurídicas objetivamente válidas". (KELSEN, 1998, p. 224-225). Não obstante a extensa argumentação por ele desenvolvida, o fato de propor uma fundamentação metafísica do direito em uma premissa maior que não pode ser posta em questão não deixa de ser abertamente reconhecida: "[...] Por outras palavras: se a norma fundamental não pode ser uma norma querida, mas a sua afirmação na premissa maior de um silogismo é logicamente indispensável para a fundamentação da validade objetiva das normas, ela apenas pode ser uma norma pensada. [...] Uma ciência jurídica positivista apenas pode constatar que esta norma é pressuposta como norma fundamental". Nesse sentido, conclui: "[...] e uma norma que é pensada como pressuposto quando uma ordem coercitiva globalmente eficaz é pensada como um sistema de normas jurídicas válidas". (KELSEN, 1998,
} 
jurídico sua validade, não podendo, sequer, lhes ser atribuído um controle de validade no sentido habitual do termo. A solução para esse "equívoco lingüístico" seria considerar que a regra de reconhecimento, por falta de um ponto de referência interno ao sistema, "não pode ter nem deixar de ter validade, sendo simplesmente aceita". (MAZUREK, 2002a, p. $375)$.

Percebe-se, então, o paradoxo normativo do direito em ambas as correntes analíticas quanto à sua fonte de validade, seja ela pressuposta numa norma fundamental ou num consenso geral e hipotético que se impõe como regra de reconhecimento. Daí porque, segundo Tercio Sampaio Ferraz Jr. (1994, p. 176): "para a dogmática analítica, ordenamento é um conceito operacional que permite a integração das normas num conjunto, dentro do qual é possível identificá-las como normas jurídicas válidas".

De qualquer forma, mais do que o seu encoberto caráter auto-referencial e paradoxal, que na teoria sistêmica é reconhecido como característica própria da diversificação dos sistemas sociais e de sua autopoiese, o ponto central da crítica a tais teorias analíticas relaciona-se ao isolamento do direito, não só no campo de sua "análise" científica, como em sua práxis, deixando de lado suas inter-relações com a sociedade, por ser considerado, enquanto sistema jurídico, sob uma perspectiva a-valorativa ou apenas descritiva. Nessa linha, Niklas Luhmann (1983) antes mesmo de sua completa adesão ao pensamento autopoiético, apontava a seguinte deficiência dessa visão estritamente normativista:

\footnotetext{
Não se pode negar que tal tipologia das normas é em princípio correta e fornece um certo grau de orientação. Mas ela não vai além de classificações incapazes de desvendar a interdependência funcional e a relação, em termos de desenvolvimento, entre os diferentes tipos, e muito menos sua relação com outras estruturas cognitivas, com a diferenciação funcional, etc. (LUHMANN, 1983, p. 42).
}

Um exemplo dessa tentativa de neutralização do direito pode ser extraído de sua distinção da moral. Para o positivismo jurídico, os valores, embora tenham sua existência objetiva reconhecida, estariam situados fora do direito, em uma ordem divina, ultra-positiva ou moral que apenas indiretamente, através de uma crítica moral do Direito

p. 227). 
Positivo, condicionaria a sua modificação ou legitimaria um direito de resistência a uma norma jurídica tão condenável que não mereça obediência. (MAZUREK, 2002a, p. 377).

O problema central da aplicação do direito na teoria analítica consiste na desconsideração de ideais sociais, éticos ou políticos, bem como de suas tensões com os demais sistemas sociais, que, quando muito, são deslocados para a esfera da argumentação jurídica.

Contudo, conforme a crítica de Fábio Konder Comparato (2006), essa separação do elemento axiológico do direito que a leva a se distinguir da moral, tornando dispensável a própria indagação se a ordem jurídica é justa ou injusta, é inaceitável e revela um sofisma evidente, o que leva referido autor à seguinte observação:

[...] A ordem jurídica não existe como uma finalidade em si mesma, mas sempre como meio institucional de se concretizarem certos fins sociais, tidos como valiosos. Que esses fins sociais sejam considerados justos para uma determinada comunidade e injustos para outra não significa que o direito deva reduzir-se a puras normas abstratas. (COMPARATO, 2006, p. 359).

Nesse mesmo sentido, acerca da separação entre direito e moral decorrente dessa teorização jurídica analítica, acrescenta Comparato (2006, p. 360):

De qualquer modo, foi com base nessa concepção asséptica da ordem jurídica que Kelsen pretendeu separar o direito da moral. Para ele, esse discrime pode ser feito segundo o critério kantiano de que a moral rege apenas a conduta interior, enquanto o direito diz respeito ao foro externo das ações humanas. As intenções e motivos nem sempre ficam alheios à análise jurídica, ou ao exame judicial do caso concreto.

Assim, em determinadas situações limites de difícil decisão, em que não existe no sistema uma regra inequívoca para o caso jurídico em questão, também chamados hard cases, evidenciam-se algumas das críticas à compreensão estritamente positivista do direito como sistema fechado, hierárquico de regras válidas, uma vez que, por sua própria lógica interna, a decisão dos juízes nesses casos tende a aparecer como arbitrária ou política posto que não obedece a uma regra específica. (MAZUREK, 2002a, p. 379).

De maneira contrária a essa arbitrária discricionariedade do juiz, poderia ainda ser citada a crítica de Ronald Dworkin (2002) ao positivismo jurídico e sua defesa do emprego dos princípios como normas de interpretação e de aplicação do direito. 
Apesar dessa breve e superficial abordagem das teorias analíticas, em razão de sua natureza marcadamente positivista, criticada no âmbito das ciências sociais por diversos autores como Michael Löwy (2003) e, no meio jurídico, como Claus-Wilhelm Canaris (1996) dentre outros, resta evidente, conforme ressalta Per Mazurek (2002a, p. 380), que tais teorias formais em sua "[...] mera perspectiva neutral, apenas analíticodescritivo do direito, já tem efeitos prático-normativos na medida em que, nas suas análises de conceitos, revele ou oculte questões práticas de política jurídica”.

Por sua vez, quanto à visão oposta do direito, como sistema aberto, condicionado socialmente às relações de dominação e força, impostas pelas relações materiais presentes na sociedade capitalista, apresentam-se as concepções jurídicas marxianas (atribuídas ao próprio Marx) e marxistas (de seus seguidores).

Destacam-se aqui suas duras críticas ao "Direito Burguês" seja em seu viés “economicista" de sujeição às relações econômicas da infra-estrutura, questionado por Eros Roberto Grau (2002, p. 50) como uma interpretação equivocada de Marx e Engels; seja como as empreendidas por Pasukanis (1989), em sua "teoria da circulação de mercadorias", a partir da qual desponta sua crítica à forma jurídica, cujo objetivo principal seria regular os vínculos entre dois agentes econômicos no mercado de modo a permitir e estimular a circulação de mercadorias, organizar a economia capitalista e, assim, garantir o nível de desenvolvimento de suas relações econômicas e sociais. (NAVES, 2000, p. 57).

Pasukanis (1989) ataca abertamente a teoria geral do direito positivista, sobretudo de escolas analíticas como a kelseniana, refutando o alto grau de abstração de seus conceitos jurídicos resultantes da elaboração lógica das normas de direito positivo. Nessa linha afirma o referido autor:

O direito enquanto fenômeno social objetivo não pode esgotar-se na norma, seja ela escrita ou não. A norma, como tal, isto é, o seu conteúdo lógico, ou é deduzida diretamente de relações preexistentes, ou, então, representa, quando promulgada como lei estatal, um sintoma que nos permite prever, com uma certa verossimilhança, o futuro nascimento de relações correspondentes. Para afirmar a existência objetiva do direito não é suficiente conhecer o seu conteúdo normativo, mas é necessário saber se este conteúdo normativo é realizado na vida pelas relações sociais. A fonte habitual de erros neste caso é o modo de pensar dogmático que confere, ao conceito de norma vigente, uma significação específica que não coincide com aquilo que o sociólogo ou historiador compreendem por existência objetiva do direito. (PASUKANIS, 1989, p. 57). 
Nesse sentido, o direito só adquire significação se corresponde a determinadas relações entre sujeitos. Revela-se, assim, a posição teórica antinormativista de Pasukanis (1989), que, segundo Márcio Billarinho Naves (2000, p. 64), “recusa a prevalência da norma sobre a relação, isto é, que recusa a premissa de que é a norma que gera a relação jurídica".

Essa visão do direito e do próprio Estado como um aparelho garantidor e dependente de um "circuito de trocas mercantis que cria as condições básicas para que se opere a distinção entre o público e o privado" desvelaria "o segredo do Estado e das formas políticas burguesas" no sentido da dominação de classe por eles sustentada de modo indireto e mediato. (NAVES, 2000, p. 80).

A função do direito de encobrir e sustentar o desenvolvimento dos modos de produção capitalista dar-se-ia através das abstrações e ficções jurídicas tanto da impessoalidade do Estado quanto da forma jurídica em que se sustentam a liberdade e igualdade de partes nas relações de troca (PASUKANIS, 1989, p. 111-112). ${ }^{70}$

Ao tratar das relações entre a forma da mercadoria e o Estado, Mário Bilharinho Naves (2000) expõe a síntese dessa crítica marxista:

[...] Ora, o caráter público do Estado só pode se constituir em uma sociedade organizada sob o princípio da troca por equivalente, que pressupõe como condição necessária da circulação a presença de sujeitos proprietários que se relacionam de modo voluntário e livre, sem a presença de uma autoridade coatora externa. $\mathrm{O}$ operário não é coagido a vender a sua força de trabalho para o capitalista, ele o faz por livre deliberação de sua vontade, por meio de um contrato. É o que acentua Pasukanis, ao dizer que "O poder político de classe pode assumir a forma de um poder público na medida em que a relação de exploração se realiza

70 Dessa forma, segundo Pasukanis (1989, p. 113): “Qualquer teoria jurídica do Estado que queira alcançar todas as funções do Estado é, no presente, necessariamente inadequada. Não pode ser o reflexo fiel de todos os fatos da vida do Estado e apenas parece uma reprodução ideológica deformada da realidade. A dominação de classe, em sua forma organizada como em sua forma desorganizada, é muito mais ampla do que o domínio do poder estatal. A dominação da burguesia se exprime tanto na dependência do governo aos bancos e grupos capitalistas quanto na dependência de cada trabalhador particular em relação ao seu empregador, e no fato de que os funcionários do aparelho de Estado são intimamente vinculados à classe dominante. Todos estes fatos, cujo número poderíamos multiplicar até o infinito, não possuem qualquer expressão jurídica oficial mas concordam em sua significação, tal como a subordinação dos mesmos operários às leis do Estado burguês, às ordens e decretos de seus organismos, ao julgamento de seus tribunais, etc. Ao lado da dominação de classe direita e imediata constitui-se uma dominação mediata, refletida sob a forma do poder oficial do Estado enquanto poder particular destacado da sociedade. Assim surgiu o problema do Estado que oferece tanta dificuldade à análise quanto o problema da mercadoria". 
formalmente como relação entre dois possuidores de mercadoria independentes e iguais, um dos quais, o proletário, vende a sua força de trabalho e o outro, o capitalista, a compra". (NAVES, 2000, p. 80).

A despeito dessa bem articulada crítica às relações desiguais que a prática trabalhista e a luta hodierna do Direito do Trabalho tenderiam a confirmar, ao menos no campo das relações laborais, Eros Roberto Grau (2002, p. 50) posiciona-se de forma contrária à suposição “inteiramente equivocada [...] de que Marx e Engels teriam concebido o direito como mero reflexo da economia". ${ }^{71}$

A partir de uma releitura funcionalista, que, embora não seja autopoiética, com ela guarda algumas semelhanças, o mencionado autor adere à tese de que o direito não possui apenas uma linguagem, "mas é uma linguagem, na medida em que instrumenta uma modalidade de comunicação entre os homens, seja para ordenar situações de conflito, seja para instrumentalizar políticas". (GRAU, 2002, p. 56).

Por essa razão, o direito não poderia ser visto como uma simples "representação da realidade social, existente fora dela", devendo, contudo, ser entendido como um "nível do todo social", em sentido funcional e não institucional, sendo a hierarquia entre infra-estrutura e supra-estrutura uma metáfora que só poderia ser interpretada como uma "hierarquia de funções, ou seja, [...] hierarquia entre as relações sociais segundo as funções que assumem no processo de produção e reprodução da vida social". (GRAU, 2002, p. 57).

Relativiza-se, dessa maneira, parte das críticas marxistas ao direito a partir da consideração das demais funções que exerce, não sendo apenas condicionado pela econômica, como também a condicionando, posto que ambos seriam interdependentes. Daí porque, com base numa releitura marxista, afirma Eros Roberto Grau (2002, p. 57): “A compreensão dessa realidade nos permite verificar que o direito é, sempre e também no modo de produção capitalista, um instrumento de mudança social, para ser dinamizado,

\footnotetext{
${ }^{71}$ A partir de uma intrincada discussão interpretativa de diferentes trechos das principais obras de Karl Marx e Friedrich Engels, o referido jurista sustenta que: "Afirmar que o modo de produção da vida material (social) - que é diverso do modo de produção dos bens materiais - determina o direito é algo inteiramente distinto da afirmação de que a estrutura econômica (uma das estruturas regionais integras na estrutura global do modo de produção da vida social) determina o direito". (GRAU, 2002, p. 53).
} 
nessa função, ao sabor de interesses bem definidos". ${ }^{72}$

Luhmann (1983), por sua vez, ao tratar das abordagens clássicas da sociologia do direito refere-se à teoria da sociedade de Karl Marx como a reação a uma característica fundamental do desenvolvimento social moderno, qual seja, "a transição do primado sobre a determinação de sentido à sociedade, deslocando-o da política para a economia" ${ }^{73}$

Assim, desenvolveu-se uma teoria sociológica marxista do direito marcada por sua "uniteralidade" na medida em que lhe atribui o papel central de fixar as contradições sociais resultantes do modo de produção capitalista, através da atribuição individual de chances especiais e desiguais, sendo a "totalidade do direito moldada aos interesses dos proprietários", posto que concede e protege a propriedade. (LUHMANN, 1983, p. 23).

Nesse contexto, a visão marxista do direito poderia ser interpretada como "uma dissolução em entrelaçamentos, subjetivos e locais, entre a satisfação de necessidades e o processo decisório (se bem que esse raciocínio não transparece nas exposições oficiosas do marxismo nem na literatura secundária nelas inspiradas)". (LUHMANN, 1983, p. 24).

\footnotetext{
${ }^{72}$ Conforme defende o referido autor: "A superação de leituras equivocadas deita por terra as concepções de que o direito é exclusivamente um produto, puro, das relações econômicas, relações, essas, às quais ele (o direito) seria alheio; de que o direito é somente ideologia, sob a qual as relações de produção dissimulam sua verdade que o direito é uma expressão da vontade de uma classe dominante ou simples meio de dominação, que instrumenta a repressão exercida por essa classe. O direito é mais do que isso. Há de ser visualizado, assim, como instância de um todo complexo, se manifesta no bojo de uma relação de causalidade estrutural (v. trechos das cartas de Engels, acima transcritos), resultante da interação dela — instância jurídica - com as demais instâncias desse todo complexo. [...] Se, por um lado, o direito interfere na constituição, no funcionamento e na reprodução das relações de produção, reproduzindo-as de maneira deformada, ideologicamente, é certo também, de outra parte, que a sociedade capitalista é essencialmente jurídica e nela o direito atua como mediação específica e necessária das relações de produção que lhe são próprias. Tais relações de produção não poderiam estabelecer-se, nem poderiam reproduzir-se, sem a forma do direito (Poulantzas 1967/160 e carta de Engels a Conrad Schmidt, de 27.10.1889, trecho acima transcrito). Em outros termos: a estrutura econômica do capitalismo não existiria se não existisse um direito que supusesse regras gerais e sujeitos abstratos, livres e iguais (Jeammaud, 1986/51). O que importa neste passo é a verificação de que o direito é, sempre, um instrumento de mudança social. O direito é produzido pela estrutura econômica mas, também interagindo em relação a ela, nela produz alterações. A economia condiciona o direito, mas o direito condiciona a economia. [...] Isso nos permite verifica que o direito não é mera representação da realidade social, existente fora dela, porém um nível do todo social. (GRAU, 2002, p. 57-59).

${ }^{73}$ Sobre a forma pela qual a teoria de Marx trabalha essa transição de sentido, explica Luhmann (1983, p. 23): "Ela interpreta o primado da economia, na medida em que este relaciona o econômico com a materialidade das necessidades humanas, como uma verdade antropológica e trans-histórica, formulando nesse contexto uma teoria natural-dialética do desenvolvimento social. A propulsão do desenvolvimento se dá a partir de alterações nas forças produtivas e nas condições de produção que intermedeiam a satisfação de necessidades materiais ou, em termos mais precisos: de contradições sociais que resultam no decorrer do desenvolvimento da produção e da satisfação de necessidades".
} 
Luhmann (1983) reconhece parcialmente a compatibilidade dessa visão estrutural jurídica com o aumento de complexidade da Sociedade Capitalista, no sentido de sua maior adequação à solução de problemas decisórios a partir um "grau máximo de variabilidade estrutural consentido" sustentado pelo direito. Contudo, segundo o referido sociólogo alemão:

A questão, porém, é se esse é o único sentido no qual o direito condiciona
a complexidade sistêmica da sociedade. Certamente não. Aqui se
localizam as limitações da ótica da sociologia marxista do direito,
apresentando ao mesmo tempo um problema que só pode ser
convenientemente articulado por meio de uma abordagem mais abstrata
da teoria sociológica da sociedade. (LUHMANN, 1983, p. 24).

Embora não se possa chamar de estritamente marxista, cabe, ainda que superficialmente, introduzir neste tópico como a Teoria Crítica, sobretudo, através de Jürgen Habermas posiciona-se frente a esse impasse teórico. ${ }^{74}$

Habermas (2001), em sua Teoria da Ação Comunicativa, em certa medida, afasta-se tanto da análise positivista da sociedade e do direito quanto de sua leitura estritamente marxista, como fora mencionado de modo incidental, ao tratar dos Aspectos gerais da Teoria dos Sistemas. Insere-se, ainda que à sua maneira intersubjetivista, na tentativa comum às teorias de Foucault (1979) e Luhmann (1998), apontada por Teubner (1989b, p. 729), de superação do realismo epistemológico e individualismo metodológico legados por Max Weber.

$\mathrm{Na}$ construção das bases para o agir comunicativo, sua teoria além de romper com o citado realismo epistemológico weberiano, distancia-se da concepção de razão

\footnotetext{
${ }^{74}$ Embora se reconheça a influência do pensamento marxista na obra de Jürgen Habermas, esse autor não adota de forma ordenada e direta alguns conceitos e interpretações formulados por Karl Marx, criticando, por exemplo, a redução do processo de constituição do gênero humano ao trabalho técnico-instrumental. (MAZUREK, 2002b, p. 451). No mesmo sentido, apresenta-se a sua conceitualização de sociedade civil e sua maior autonomia em relação à economia, na qual deixa claro a superação de alguns pressupostos marxistas: "[...] O atual significado da expressão 'sociedade civil' não coincide com o da 'sociedade burguesa' da tradição liberal, que Hegel chegara a tematizar como 'sistema das necessidades', isto é, como sistema do trabalho social e do comércio de mercadorias numa economia de mercado. Hoje em dia, o termo 'sociedade civil' não inclui mais a economia constituída através do direito privado e dirigida através do trabalho, do capital e dos mercados de bens, como ainda acontecia na época de Marx e do marxismo. O seu núcleo institucional é formado por associações e organizações livres, não estatais e não econômicas, as quais ancoram as estruturas de comunicação da esfera pública nos componentes sociais do mundo vida". (HABERMAS, 1997, v. 2, p. 99).
} 
prática aristotélica de modo a substituí-la pelo conceito de razão comunicativa, o que, segundo adverte o próprio Habermas (1997, v. 1, p. 19), "vai muito além de uma simples troca de etiqueta". Desta, depreende-se uma nova forma de compreensão da relação entre os indivíduos e destes com o Estado, própria da modernidade, em que os primeiros passam a estar essencialmente ligados à categoria de sujeitos privados, não sendo mais considerados apenas no conjunto que forma certa cultura ou ordem política.

Abandona-se, portanto, a visão de uma sociedade composta de indivíduos e centrada no Estado próprias da teoria normativista do Estado, direito racional, e da tradição filosófica empreendida pela razão prática. Contudo, o referido autor reconhece seus "vestígios filosófico-históricos no conceito de sociedade que se administra democraticamente a si mesma, na qual o poder burocrático do Estado deve fundir-se com a economia capitalista”. (HABERMAS, 1997, v. 1, p. 18).

Para que essa fusão não resulte em uma opressora submissão das estruturas da sociedade civil e da esfera pública decorrentes de sua "contaminação pelos imperativos sistêmicos que emergem da administração e da economia", a teoria habermasiana precisa pressupor 'um 'mundo da vida' e uma 'esfera pública' não colonizados pela racionalidade teleológica que é própria dos sistemas". (VILLAS BÔAS FILHO, 2006a, p. 215).

A saída para essa “contaminação", segundo Habermas (1997 v. 2, p. 310) consiste numa aposta no processo democrático fundado numa nova racionalidade e nova teoria do direito capazes de "assegurar simultaneamente a autonomia privada e pública dos sujeitos de direito". 75

Daí resultaria o nexo conceitual interno entre Estado de direito e democracia, central à sua teoria intersubjetivista, fundada na racionalidade comunicativa, no discurso e numa visão procedimentalista do direito. Nessa linha, afirma:

Por conseguinte, a compreensão procedimentalista do direito tenta

\footnotetext{
${ }^{75}$ Acerca do novo sentido atribuído à razão na sociedade moderna, explica Habermas (1997, v. 1, p. 20): “A razão comunicativa distingue-se da razão prática por não estar adstrita a nenhum ator singular a um macrosujeito sociopolítico. O que torna a razão comunicativa possível é o medium lingüístico, através do qual as interações se interligam e as formas de vida se estruturam. Tal racionalidade está inscrita no telos lingüístico do entendimento, formando um ensemble de condições possibilitadoras e, ao mesmo tempo, limitadoras. Qualquer um que se utilize de uma linguagem natural, a fim de entender-se com um destinatário sobre algo no mundo, vê-se forçado a adotar um enfoque performativo e aceitar determinados pressupostos".
} 
mostrar que os pressupostos comunicativos e as condições do processo de formação democrática da opinião e da vontade são a única fonte de legitimação. Tal compreensão é incompatível não somente com a idéia platônica, segundo a qual o direito positivo pode extrair sua legitimidade de um direito superior, mas também com a posição empirista que nega qualquer tipo de legitimidade que ultrapasse a contingência das decisões legisladoras. (HABERMAS, 1997, v. 2, p. 310).

A razão é, então, reposicionada como meio (medium) lingüístico fundamental em toda a estrutura de seu pensamento, superando-se a tradicional redução da racionalidade ao seu aspecto cognitivo-instrumental, de que resultaria o seu déficit qualitativo, reabilitando-a através de uma mudança de paradigma capaz de superar o logocentrismo da filosofia da consciência criticado por Jacques Derrida, sem contudo, se recorrer a uma crítica radical da razão. (HABERMAS, 1998, p. 287-293). ${ }^{76}$

Nesse sentido, ao Direito Positivo moderno é atribuída a mediação social, como instrumento capaz de amenizar a tensão entre facticidade e validade, diminuindo de maneira segura o risco de dissenso, para, assim, possibilitar a integração social sem o apelo a fundamentações religiosas, metafísicas ou transcendentais, posto que, inserido no mundo da vida, contribuiria para a formação de "maciço pano de fundo consensual" para o agir comunicativo. (HABERMAS, 1997, v.1, p. 40).

\footnotetext{
${ }^{76}$ A crítica da razão efetuada por Habermas é empreendida não no sentido de sua radical negação, mas de sua extensão. Dessa forma, ao invés de identificar o problema da racionalidade moderna como um excesso da razão que serviria para instrumentalizar a dominação social, para a teoria habermasiana, de forma contrária, sua crise resulta de uma deturpação de seus fins, que a transforma numa "ferramenta por excelência de supressão da liberdade". Isso decorreria de um déficit qualitativo de racionalidade que requer uma mudança de paradigma além de seu conceito unidimensional, cognitivo-instrumental, próprio da filosofia da ciência. Nesse sentido, disserta Orlando Villas Bôas Filho (2006a, p. 58): “[...] Não se trata de alargar essa dimensão teleológica da racionalidade, de modo a estender ainda mais a racionalidade cognitivoinstrumental. $O$ déficit de razão apontado por Habermas não se relaciona com essa faceta da racionalidade. Trata-se antes de mostrar que a razão não se reduz ao seu aspecto cognitivo-instrumental, aspecto esse privilegiado por um paradigma que é o da 'consciência de si, da auto-referência de um sujeito que conhece e age isoladamente (...)"”. Ainda sobre esse assunto, acrescenta em sua dissertação de mestrado que: "[...] O projeto de Habermas pode ser entendido como uma mudança de paradigma justamente por negar essa coincidência da parte com o todo, no que concerne à racionalidade, de modo a negar esse paradigma centrado no sujeito, opondo-lhe outro que é o 'da relação intersubjetiva de indivíduos, que socializados através da comunicação se reconhecem mutuamente'. [...] Assim, a mudança de paradigma se dá com a negação do logocentrismo do pensamento ocidental e com a afirmação da compreensão intersubjetiva, o que implica uma negação da redução da razão ao seu aspecto cognitivo-instrumental". (VILLAS BÔAS FILHO, 2006a, p. 59). No que diz respeito ao termo logocentrismo, este remete à filosofia pós-estruturalista de Jacques Derrida, filósofo francês, nascido na Argélia e de origem judaica, que em sua obra criticou a "centralidade do logos [razão] no pensamento ocidental [tendo-a como] questionável em decorrência de seu caráter metafísico, fruto de uma consciência interiorizada que se expressa essencialmente através de uma
} 
Percebe-se, então, que nessa nova proposta interpretativa habermasiana, "as formas de comunicação da formação política da vontade no Estado de direito, da legislação e da jurisprudência, aparecem como partes de um processo mais amplo de racionalização dos mundos da vida de sociedades modernas pressionadas pelos imperativos sistêmicos". (HABERMAS, 1997, v. 1, p. 22). ${ }^{77}$

Diferentemente do que fora exposto sobre o conceito luhmanniano de comunicação e de sua função na redução da complexidade na sociedade, para Habermas (1997), o papel central da comunicação, através da "ação comunicativa", consiste em viabilizar o entendimento por meio da coordenação de ações.

Contudo, para isso, esse agir comunicativo deve partir de quatro "pretensões de validez" - verdade, correção, sinceridade e inteligibilidade —, que, segundo disserta Sidinei Cruz Sobrinho (2005), estariam garantidas por uma espécie de "argumentação transcendental”. Esta, segundo o referido pesquisador, se justificaria ao passo em que “dada a 'impossibilidade de se recusar' determinados pressupostos, é que se concebe a razão comunicativa como aquela capaz de produzir, ou melhor, de reproduzir um mundo de sujeitos autônomos e emancipados”. (CRUZ SOBRINHO, 2005, p. 20).

A Teoria do Agir Comunicativo de Habermas, da mesma forma que a Teoria da Sociedade de Luhmann, apresenta um intrincado conjunto de pressupostos e conceitos próprios que fogem ao objeto deste trabalho acadêmico. Por essa razão, feita essa apertada síntese, deve-se centrar a atenção para o seu conceito de Direito Moderno e para a função a ele atribuída.

Nessa linha, Habermas (1997, v.1, p. 55-60) constrói sua teorização do direito e de sua fundamentação por meio da teoria do discurso, visando reestruturá-lo como sistema jurídico capaz de promover a citada integração social. Instrumentalizada pelo

\footnotetext{
linguagem falada e empreende uma investigação ontológica da realidade”. (HOUAISS, 2005).

${ }^{77} \mathrm{O}$ "mundo da vida" habermasiano seria formado por três componentes que precedem qualquer processo de entendimento, quais sejam: cultura, sociedade e personalidade. Segundo a síntese proposta por Sidinei Cruz Sobrinho (2005, p. 23), em sua dissertação de mestrado sobre Direito Humanos e Democracia em Jürgen Habermas, "a cultura apresenta-se [...] como aquele conjunto de crenças aceitas como verdadeiras em determinada sociedade e utilizadas para entender algo no mundo. Sociedade é, por sua vez, aquele conjunto de normas tidas como legítimas e que permitem uma identidade social e a solidariedade dos sujeitos. Por fim, a personalidade é dada pela própria interação e socialização dos sujeitos".
} 
direito, como medium ou categoria de mediação social, sua teoria do discurso apresenta-se como a via capaz de promover a interação no espaço democrático das dimensões sociais, econômicas, políticas e de direito.

O direito, como medium de regulação da sociedade, trabalharia com as expectativas generalizadas de comportamento remetendo-se a uma forma de ação comunicativa carregada de sentido, a interação. Contudo, para que essa "determinação generalizante de expectativas" aconteça, faz-se necessário que o sentido dessa ação seja compreendido. Para tanto, as relações de ação devem ser analisadas também como relações de sentido.

Dessas expectativas de comportamento decorria uma natureza normativa, uma vez que, segundo Per Mazurek (2002b, p.452) , “de uma série de ações e expectativas de ação, ela seleciona uma ação à custa da outra, a estabiliza como expectativa de comportamento geral, impondo-a mesmo com a ameaça de sanções, caso necessário".

Contudo, a legitimidade desse direito e a validade de suas normas, mesmo considerado como um sistema positivado, estão sujeitas à sua comprovação em face das objeções apresentadas contrafactualmente, prevalecendo na medida em que estiverem de acordo com as pretensões de validade do discurso e de seu núcleo de caráter moral. Portanto, sua positividade apresenta-se como uma simulação de parte da realidade social que apenas se sustenta "até segunda ordem, porque ela pode ser modificada ou colocada fora de ação em qualquer um de seus componentes singulares". (HABERMAS, 1997, v.1, p. $60) .^{78}$

Por sua vez, por considerar que as sociedades modernas não se restringem a questões valorativas, as normas e os processos de entendimento necessários à integração

\footnotetext{
78 Dessa forma, embora reconheça o Direito Moderno como Direito Positivo, Habermas (1992) diverge claramente de sua interpretação em termos analíticos, lógico-formais, remetendo a questão de sua legitimidade não a observância estrita de uma legalidade sacralizada, mas a nova racionalidade democrática que engloba uma abordagem valorativa e moral dessas questões normativas: "Se, em sociedades do nosso tipo, a legitimidade deva ser possível através da legalidade, então, a crença na legalidade, que perdeu as certezas coletivas da religião e da metafísica, tem necessariamente, de se apoiar na 'racionalidade' direito, de uma forma qualquer. Porém, não se confirmou a suposição de Weber de que uma racionalidade independente, livre da moral, inerente como tal, ao direito, é a razão para a força legitimadora da legalidade. Legitimidade deve, sempre, a um poder político, exercido nas formas do direito positivo, cativo de fundamentação, um conteúdo moral implícito nas qualidades formais do direito". (HABERMAS, 1992, p. 54).
} 
habermasiana dependem também do mercado e do poder administrativo, por esse motivo, situa sua teoria do direito no contexto mais amplo de sua teoria da sociedade. Nesse sentido, entende que:

[...] Desta maneira, o direito está ligado às três fontes de integração social. Através de uma prática de autodeterminação, que exige dos cidadãos o exercício comum de suas liberdades comunicativas, o direito extrai sua força integradora, em última instância, de fontes da solidariedade social. As instituições do direito privado e público possibilitam, de outro lado, o estabelecimento de mercados e a organização e um poder do Estado, pois as operações do sistema administrativo e econômico, que se configura a partir do mundo da vida, que é parte da sociedade, completam-se em formas de direito. (HABERMAS, 1997, v.1, p. 61-62).

Tem-se, dessa maneira, que o entendimento comunicativo garantido pelo direito pressupõe estruturas da intersubjetividade, até certo ponto, idealizadas, a partir das quais se formariam os mundos da vida e, de sua racionalização comunicativa, as esferas públicas. Daí resultariam a legitimidade e a própria função do direito conforme explica Orlando Villas Bôas Filho (2006a, p. 214):

[...] Trata-se da metáfora do direito enquanto correia de transmissão que levaria demandas normativas provenientes do "mundo da vida" para o âmbito dos sistemas que, em função de sua orientação codificada e da racionalidade que lhe é correlata, seriam indiferentes a tais demandas. Concebido nesses termos, o direito estará, portanto, fundado em última análise no princípio do discurso que, em termos bastante gerais, consiste na avaliação imparcial de questões normativas de qualquer espécie pelos possíveis envolvidos pelas decisões tomadas.

Essa mediação do direito e a passagem das expectativas sociais do "mundo da vida" para as esferas públicas partiriam da possibilidade de uma descrição compreensiva e representativa da sociedade como um todo, que segundo Luhmann e Fuchs (1988), não é mais alcançável em razão do estágio de diferenciação funcional alcançado pelos sistemas sociais. Assim, não seria mais possível conceber-se uma instância capaz de fornecer tal descrição em termos gerais de sociedade.

Habermas (1997, v. 1, p. 142), por sua vez, atribui a superação desse obstáculo à força normativa do entendimento comunicativo entre sujeitos que se pautam pela compreensão recíproca, a partir de uma racionalidade dialógica centrada não no agir estratégico weberiano, mas no agir comunicativo e na formação de uma vontade política racional. 
Para que haja a institucionalização política, necessária para as formas de comunicações que viabilizam a formação discursiva da vontade política racional, requer-se a transformação do princípio do discurso em princípio da democracia. Da mesma forma, é preciso que o direito apresente-se como a expressão do processo racional de formação da opinião e da vontade. (HABERMAS, 1997, v.2, p. 99-119). ${ }^{79}$

Esse processo depende de que as estruturas da sociedade civil e a esfera pública política não se encontrem contaminadas pelos imperativos que emergem de outros sistemas, como da administração e da economia. Requer-se, assim, primeiramente, não apenas a formação de uma sociedade dinâmica de pessoas privadas no sentido de uma cultura política livre, "mas também de uma esfera privada intacta, o que equivale dizer que ela necessita de um mundo da vida já racionalizado”. (HABERMAS, 1997, v.2, p. 104).

Em outras palavras, conforme a síntese dessa questão exposta por Orlando Villas Bôas Filho (2006a, p. 215), “é preciso que se pressuponha um 'mundo da vida' e uma 'esfera pública' não colonizados pela racionalidade teleológica que é própria dos sistemas".

Porém, o próprio Habermas (1997, v. 2, p. 106-107) reconhece a formação de "barreiras e estruturas de poder" o interior da esfera pública, sobretudo em sociedades complexas em que tal esfera forma uma estrutura intermediária de mediação entre, de um lado, os setores privados do mundo da vida e sistemas de ação especializados em termos de funções, e de outro lado o sistema político.

O poder da mídia, enquanto sistema de comunicação de massas, é destacado como um obstáculo à superação dessas barreiras ao passo em que as esferas públicas

\footnotetext{
${ }^{79}$ A necessidade dessa institucionalização através de uma democracia racionalizada pelo direito se justifica, segundo Habermas (1997, v.2, p. 105), pois, "é preciso lembrar que, na esfera pública, ao menos na esfera pública liberal, os atores não podem exercer poder político, apenas influência. E a influência de uma opinião pública, mais ou menos discursiva, produzida através de controvérsias públicas, constitui certamente uma grandeza empírica, capaz de mover algo. Porém, essa influência pública e política tem que passar antes pelo filtro dos processos institucionalizados da formação democrática da opinião e da vontade, transformar-se em poder comunicativo e infiltrar-se numa legislação legítima, antes que a opinião pública, concretamente generalizada, possa se transformar numa convicção testada sob o ponto de vista da generalização de interesses e capaz de legitimar decisões políticas. Ora, a soberania do povo, diluída comunicativamente, não pode impor-se apenas através do poder dos discursos públicos informais - mesmo que eles tenham se originado de esferas públicas autônomas. Para gerar um poder político, sua influência tem que abranger também as deliberações de instituições democráticas da formação da opinião e da vontade, assumindo uma forma autorizada".
} 
tradicionais das democracias ocidentais estariam por ele dominadas.

Dentre suas várias estratégias de elaboração da informação e influência na opinião pública, nucleares à teoria da indústria cultural, o referido sociólogo alemão destaca a "personalização das questões objetivas, a mistura entre informação e entretenimento, a elaboração episódica e a fragmentação de contextos formam uma síndrome que promove a despolitização da comunicação pública”. (HABERMAS, 1997, v. 2, p. 110). ${ }^{80}$

Apesar dessa constatação, a superação dessas barreiras seria possível a partir da iniciativa e mobilização dos atores da sociedade civil de modo a reivindicar modificações na esfera política e uma readequação de forças entre ela, os sistemas especializados e o sistema político. ${ }^{81}$

Não obstante essa possibilidade, tem-se claramente que tal depende da existência de mundo da vida racionalizado que favoreça "a formação de uma esfera pública liberal com forte apoio na sociedade civil", ou seja, de uma sociedade civil livre e racionalizada ,capaz de identificar as controvérsias públicas. Ademais, é ainda preciso pressupor a disposição e capacidade de seus interlocutores em dialogar na busca do consenso comum e coordenar suas ações para tais mobilizações. ${ }^{82}$

\footnotetext{
${ }^{80}$ Para uma visão mais aprofundada das críticas às relações de poder exercidas pelos meios de comunicação e seu papel na redução do espaço democrático a serviço de outras "racionalidades sistêmicas" no sentido da manipulação da opinião pública e controle dos poderes políticos, a despeito da vasta literatura nacional e internacional, destacam-se, como fonte para maiores referências sobre o assunto, os estudos de José Arbex Jr. sobre O poder da TV (1997), o Showrnalismo e a notícia como espetáculo (2001), O Jornalismo canalha (2003), bem como a vasta bibliografia de Noam Chomsky, em especial a seleção de suas de suas declarações, entrevistas e palestras realizada por Peter R. Mitchell e John Schoeffel (2005) em Para entender o Poder: o melhor de Noam Chomsky, sem contar as publicações do Project Censored News, coordenado por Carl Jensen (1997).

${ }^{81}$ Nesse sentido, afirma Habermas (1997, v. 2, p. 113): "Quando tomamos consciência da imagem difusa e da esfera pública veiculada pela sociologia da comunicação de massa, que aparece submetida ao poder e à dominação dos meios de comunicação de massa, cresce nosso ceticismo com relação às chances de a sociedade civil vir a exercer influência sobre o sistema político. Todavia, tal avaliação vale somente para uma esfera pública em repouso. Pois, a partir do momento em que acontece uma mobilização, as estruturas sobre as quais se apóia a autoridade de um público que toma posição começam a vibrar. E as relações de forças entre a sociedade civil e o sistema político podem sofrer modificações".

${ }^{82}$ Essas condições podem ser depreendidas do seguinte excerto: “[...] O certo é, no entanto, que nas esferas públicas políticas, mesmo nas que foram mais ou menos absorvidas pelo poder, as relações de forças modificam-se tão logo a percepção dos problemas sociais relevantes suscita uma consciência de crise na periferia. E se nesse momento atores da sociedade civil se reunirem, formulando um tema correspondente e o propagarem na esfera púbica, sua iniciativa pode ter sucesso porque a mobilização endógena da esfera
} 
Contudo, segundo Luhmann (1998, p. 147), essa pressuposta predisposição ao consenso, central à perspectiva habermasiana, não se sustentaria não sendo comprovado que as pessoas que participam desse tipo de comunicação estejam dispostas a ceder ao melhor argumento. Para o referido autor sistêmico, mesmo que se admita essa possibilidade, esses acordos racionalmente motivados graças ao agir comunicativo não seria ainda capaz de superar o déficit de racionalidade próprio da sociedade moderna, que em seu entender, estaria relacionado ao processo de diferenciação que leva a sociedade moderna a fragmentar-se em diversos sistemas funcionais.

Como foi exposta no tópico referente aos aspectos gerais da Teoria dos Sistemas Sociais, para Luhmann (1998, p. 395), tal racionalidade pode ser satisfeita apenas por meio da reflexividade, enquanto auto-referência processual sistêmica que viabiliza sua auto-observação e orientação a partir da unidade de sua distinção em relação ao ambiente.

Frente a esses impasses e à necessidade de uma abordagem mais abstrata da teoria sociológica do direito e da própria sociedade que nem por isso deixe de lado seus conflitos, sua contingencialidade e complexidade históricas, a teoria dos sistemas autopoiéticos, no campo da ciência jurídica, seria de grande importância na medida em que representaria a "superação de uma concepção relativamente limitada das relações jurídicas" dadas às contínuas transformações estruturais da sociedade. (BÜLLESBACH, 2002, p. 409).

Há que se ressaltar, porém, que a "teoria sociológica como análise sistêmica", não se restringe à fragmentação, do sistema jurídico, mas pretende relacioná-lo à sua compreensão e da sociedade como um todo. Ademais, a sociedade, vista como um sistema social, compõe-se, segundo Alfred Büllesbach (2002, p. 411), “de ações dirigidas por expectativas, sendo os sistemas vistos como molduras de orientação da ação incorporando

pública coloca em movimento uma lei, normalmente latente, inscrita na estrutura interna de qualquer esfera pública e sempre presente na autocompreensão normativa dos meios de comunicação de massa, segundo a qual os que estão jogando na arena devem sua influência ao assentimento da galeria. Pode-se dizer que, à medida que um mundo da vida racionalizado favorece a formação de uma esfera pública liberal com forte apoio na sociedade civil, a autoridade do público que toma posição se fortalece no decorrer das controvérsias públicas. Pois, em casos de mobilização devido a uma crise, a comunicação pública informal se movimenta, nessas condições, em trilhos que, de um lado, impedem a concentração de massas doutrinadas, seduzíveis populisticamente e, de outro lado, reconduzem os potenciais críticos dispersos de um público que não está mais unido a não ser pelos laços abstratos da mídia — e o auxiliam a exercer uma influência políticopublicitária sobre a formação institucionalizada da opinião e da vontade”. (HABERMAS, 1997, v. 2, p. 116). 
muitas variáveis", dentre as quais estaria o próprio direito.

Tem-se, portanto, que a teoria sistêmica, enquanto teoria sociológica, não se confunde com as teorias fragmentárias que prescindem de um conceito de sociedade global, como as teorias da ação, dos grupos de referência, nem mesmo com a tradicional teoria funcionalista que, em razão da sintética apresentação de perspectivas individuais, perde a natureza de conjunto. (BÜLLESBACH, 2002, p. 412).

\subsection{A autopoiese do direito}

A compreensão do direito e de suas conseqüências na "realidade social", segundo Luhmann (1989a), tem suscitado novas expectativas sobre as possíveis contribuições da sociologia para a administração da justiça.

Dessa perspectiva, nas últimas décadas, teria resultado uma disputa entre algumas áreas do conhecimento que se dedicam ao estudo desse tema, como a jurisprudência e a sociologia clássica, além das abordagens intermediárias como a "Engenharia-social”, o Pragmatismo e a Sociologia Jurídica, sem contudo chegar a uma “adequada sociologia da doutrina legal” ou “teoria legal”. (LUHMANN, 1989a, p. 136).

Para a surpresa dos acadêmicos dessas áreas, o tratamento de tais questões teria sido alterado radicalmente a partir de novos pontos de vista que têm atraído a atenção de juristas e sociólogos. Nesse contexto, inserem-se as pesquisas sobre a teoria geral dos sistemas, a cibernética, a lógica multivalente, as teorias da automação e da informação, e, mais especialmente, a teoria dos sistemas autopoiéticos. (LUHMANN, 1989a, p. 137).

Luhmann (1989a) reconhece que a adoção da autopoiese para a compreensão dos sistemas sociais tem produzido mais confusões do que a esperada solução dos impasses que se propõe a superar. Destaca, no entanto, que esses mal-entendidos relacionam-se ao fato de teoria autopoiética ter suas origens na matemática, na biologia e, mesmo na neurofisiologia, áreas científicas que, em princípio, não levam em conta aspectos sociais.

A despeito de tais obstáculos, como foi possível expor até aqui, o que chamaria a atenção para o modelo autopoiético seria sua peculiar forma de auto-organização e operação, sua estrutura recursiva, que no caso dos sistemas sociais é constituída de processos comunicacionais de seleção e dotação de sentido, assim como o decorrente 
reposicionamento teórico do sujeito nesse processo social. ${ }^{83}$

O tratamento das possibilidades e dos limites dessa teoria para a compreensão do sistema jurídico sanitário requer a retomada da observação feita inicialmente de que Luhmann (1998, p. 14), na construção de sua Teoria da Sociedade, no sentido de se evitar a simples e direta transposição da autopoiese biológica à social, distinguindo sua teoria dos sistemas sociais, caracterizados como sistemas de comunicação, dos demais sistemas orgânicos, naturais e mecânicos que fazem parte do ambiente da sociedade. ${ }^{84}$

Por essa razão, ao discorrer sobre a visão autopoiética do direito, mais uma vez, é retomada essa importante distinção para que sua teoria não seja interpretada como promotora de uma equivocada submissão da compreensão dos sistemas sociais a sua abordagem estritamente biológica. Nesse sentido, chega a ser enfático ao afirmar que a adesão à autopoiese "não significa que os sistemas físicos e sociais devam ser agora interpretados em termos de modelos de sistemas biológicos". (LUHMANN, 1989a, p. 137).

Da mesma forma, rejeita a mera analogia entre biologia e sociologia bem como

83 Nesse sentido, destaca Luhmann (1989a, p. 137): "The new discovery is that biological systems, if not physical systems in general, are characterized by a circular, recursive, self-referential mode of operation. The mode of analysis that has emerged from this discovery has dethroned the 'subject' in its claim to be unique in its self-referentially".

${ }^{84}$ Em resposta às críticas dessa natureza que o acusam de uma "biologização" reducionista do fenômeno social e em defesa de uma teoria transdisciplinar da sociologia que a desloque da teoria da ação para constituir-se uma teoria da comunicação, cuja autopoiese social distingue-se claramente daquela biológica, posiciona-se o referido sociólogo alemão: "Esta orientación hacia la transdisciplinariedad no significa que el orden social sea reducido a hechos psicológicos, biológicos y fisiológicos mediante un procedimiento reduccionista. Y mucho menos que se argumente con analogías físicas, biológicas y psicológicas o echando mano de un recurso retórico con las metáforas correspondientes. Esta objeción es a menudo esgrimida por los sociólogos como un relejo condicionado contra conceptos utilizados por otras disciplinas especialmente el concepto de autopoiesis. Sin embargo, la objeción muestra que no se ha entendido la teoría, ya que esta defiende, precisamente un relativismo radical sistémico y excluye cualquier $\underline{\text { continuum }}$ ontológico de la realidad que hubiera que presuponer en la propia conclusión analógica. Por eso no manejamos el argumento de que, puesto que existen reproducción autopoiética, 'cerradura operativa', evolución, etcétera, en el nivel de las células vivas, dichas estructuras deben existir en los sistemas sociales. [...] Si se quiere aplicar al campo de estudio de la sociología el concepto general de autipoiesis y formularlo como una teoría de los sistemas sociales, se requiere de una indicación precisa respecto de la operación por medio de la cual el sistema se reproduce y luego se diferencia del entorno. Aqui es donde ha fracasado la actual teoría sociológica de la acción, pues el concepto de acción remite al hombre como ser viviente y como conciencia, es decir, no se refiere a un estado de cosas socialmente constituido. La teoría de los sistemas sociales, por ello, debe transformarse de teoría de la acción en teoría de la comunicación, si quiere aplicar el concepto de sistema que hemos delineado en los párrafos anteriores y hablar de sistemas sociales operativamente cerrados, autopoiéticos". (LUHMANN, 1988, p. 14-15). 
o simples uso metafórico que transfere termos biológicos para a sociologia o que, em certa medida, teria ocorrido pela ausência de uma teoria sistêmica geral capaz de evitar o recurso direto aos conceitos emprestados da matemática ou da biologia, sem uma adequada consideração da conveniência de sua transposição desses campos para o social.

Na medida em que considera tais obstáculos à aplicação da teoria autopoiética dos sistemas em áreas sociais como o direito, o referido autor acrescenta a esse problema terminológico a questão da coordenação dos múltiplos níveis envolvidos, que requer a consideração do direito e de toda a sociedade a partir da uma teoria geral dos sistemas sociais capaz de lidar não apenas com sua compreensão como um todo, mas, também, de suas interações e organizações em face dos demais subsistemas sociais. (LUHMANN, 1989a, p. 137-138).

Por essas razões foi preciso desenvolver inicialmente, nos limites desse trabalho, a reconstituição dos aspectos gerais da teoria luhmanniana dos sistemas sociais, com seus principais conceitos e mudanças paradigmáticas, imprescindíveis para a compreensão de sua visão autopoiética do direito, cuja dimensão e pertinência jurídicas serão, finalmente, a discutidas.

Depreendem-se da referida teoria social duas inovações conceituais próprias do paradigma sistêmico em vias de consolidação. A primeira diz respeito à diferenciação do sistema, inspirada pela teoria geral sistêmica, que a concebe como o estabelecimento de diferenças e relações entre o sistema e o ambiente. A segunda inovação seria o reconhecimento de que tal diferenciação só é possível em decorrência do fechamento operacional, auto-referencial, dos sistemas sociais, sem o que não lhes seria possível distinguirem as próprias operações daquelas do ambiente.

A importância desses dois conceitos consiste em seu auxílio para a compreensão da função social do direito, de suas habilidades reflexivas que constituem, de maneira geral, a própria auto-referencialidade do sistema jurídico.

Embora diferenciado funcionalmente, o direito não está apartado, ou fora, da sociedade, mas em seu interior, uma vez considerada como sistema global de comunicação.

De sua inter-relação com os demais subsistemas sociais que compõem a sociedade resulta um novo sentido para a autonomia do sistema jurídico, posto que tais 
subsistemas, auto-referentes e diferenciados, mantém processos comunicacionais internos independentes ao mesmo tempo em que conservam um elevado grau de dependência entre si e de seus respectivos ambientes, seja dos demais subsistemas sociais sob a ótica interna da sociedade, seja em relação ao ambiente que lhe é externo à sua dependência dos elementos e/ou sistemas de natureza física, biológica ou consciente, como os sistemas psíquicos. (LUHMANN, 1989a, p. 139).

Essa consideração simultânea e aparentemente paradoxal tanto da independência quanto da dependência do direito não pode ser resumida à tradicional expressão "autonomia relativa do direito", posto que esta se apresenta como insuficiente para explicar as relações sistêmicas de independência e dependência citadas. O conceito de autonomia quando aplicado a essa teoria sistêmica, na melhor das hipóteses, refere-se apenas ao fechamento ou clausura operacional do sistema como condição de sua própria abertura cognitiva.

Por sua vez, o sistema jurídico distingue-se em vários aspectos de seu ambiente, tanto interno quanto externo à sociedade, daí porque se afirmar que "o direito não é a política, nem economia, nem religião, muito menos educação, [...], embora não possa existir se todos esses demais não participarem também [do sistema social global]”. (LUHMANN, 1989a, p. 139).

Nesse mesmo sentido, ao discorrer sobre a inovação introduzida por essa concepção autopoiética do sistema jurídico, Campilongo (2000b) defende que, graças à abertura cognitiva e ao fechamento operacional, o Direito Moderno consegue estabelecer um elevado grau de interdependência com os demais sistemas sociais (v.g. política, economia, ciência, dentre outros), mantendo-se sensível às demandas dos mesmos (seu ambiente), sem contudo perder sua unidade e capacidade de diferenciação em seu interior para além da tradicional estrutura normativa hierárquica piramidal. A esse respeito sustenta:

[...] Dessa perspectiva, o sistema jurídico é um só, pouco importando se as cadeias normativas são múltiplas, não-hierarquizadas, informais ou produzidas em diferentes contextos. Essa unicidade decorre da função do direito e não da arquitetura do sistema normativo. A globalização demanda novas diferenciações no interior do sistema jurídico, mas não é capaz de corromper sua função. (CAMPILONGO, 2000b, p. 143).

A despeito dessa diferenciação e autonomia operacional, não deixaria de existir 
uma estreita relação entre direito e os demais sistemas sociais. Nesse sentido, posiciona-se o próprio Luhmann (1989a, p. 139):

[...] Portanto, como qualquer sistema autopoiético, o jurídico mantém um alto grau de dependência de seu ambiente sendo que a artificialidade da diferenciação funcional do sistema social como um todo apenas aumenta essa dependência. Ademais, como um sistema fechado, o direito é completamente autônomo no que diz respeito a suas próprias operações. Apenas o direito pode dizer o que é direito [lawful] e o que é não-direito [unlawful], e ao decidir essa questão deve sempre referir-se ao resultado de suas próprias operações e às possíveis conseqüências de suas operações sistêmicas futuras. ${ }^{85}$

Dessa forma, através de suas operações, o sistema jurídico não se exclui da sociedade mas coopera para própria reprodução autopoiética do sistema social como um todo.Visto como um subsistema de comunicação interno ao sistema de comunicação maior que seria a própria sociedade, o direito contribui através de sua autopoiese para a construção da própria realidade social. ${ }^{86}$

\subsubsection{Operacionalização e função do sistema jurídico}

A operação interna do sistema jurídico, para Luhmann (1989a, p. 140), consiste num peculiar "processamento de expectativas normativas que são capazes de se manter em situações de conflito".

Partindo-se do pressuposto de que, enquanto sistema social, a sociedade deva ser entendida como comunicação, caberia ao direito a função de estabilizar suas expectativas comunicacionais, contribuindo para a formação dos meios de comunicação

\footnotetext{
${ }^{85}$ Cf. o original: "[...] Thus, like every autopoietic system, it is and remains to a high degree dependent on its environment and the artificiality of the functional differentiation of the social system as a whole only increases this dependency. And yet, as a closed system, the law is completely autonomous at the level of its own operations. Only the law can say what is lawful and what is unlawful, and in deciding this question it must always refer to the results of its own operations and to consequences of the system 's future operations". (LUHMANN, 1989a, p. 139).

${ }^{86}$ A respeito desse papel do Direito na construção da realidade social, esclarece Luhmann (1989a, p. 138139): “[...] This means not only that the legal system fulfills a function for society - that it "serves" society - but also that the legal system participates in society's construction of reality, so that in the law, as everywhere in society ordinary meaning of words (of names, members, designations for objects and actions, etc.) can, and must, be presupposed".
} 
simbolicamente generalizados. Portanto, ainda que não seja capaz de garantir que tais expectativas em si não sejam eventualmente frustradas, o sistema jurídico deve assegurar a sua manutenção no sistema social como expectativas "mesmo no caso de sua frustração e de que alguém dela venha a saber e comunicá-la adiante”. (LUHMANN, 1989a, p. 140).

Essas expectativas, tratadas ao se discorrer sobre os aspectos gerais da Teoria dos Sistemas Sociais luhmanniana, são estruturas internas comuns aos sistemas de sentido, como os sistemas sociais e psíquicos. Referem-se tanto a seus próprios processos internos de dotação de sentido quanto àqueles externos de outros sistemas, pressupostos a partir da auto-observação e das observações recíprocas decorrentes dos acoplamentos estruturais entre esses sistemas, que lhes permitem absorver e controlar o duplo problema da complexidade e contingência.

Antes mesmo de sua abordagem em termos declaradamente autopoiéticos, Luhmann (1983), ao discorrer sobre a sociologia do direito e sua função na sociedade, já antecipava, em linhas gerais, sua visão funcionalista do direito e as linhas interpretativas que formariam sua Teoria da Sociedade, destacando-se o papel das expectativas no processo de dotação de sentido e observação entre os sistemas tanto sociais quanto psíquicos. $^{87}$

Nesse contexto inicial, o conceito de expectativa já era tratado sob a perspectiva das relações entre os indivíduos, ou, em termos autopoiéticos, às interações entre sistemas psíquicos, embora de forma ainda não acabada e tendente a um enfoque intersubjetivista, haja visto a seguinte assertiva de Luhmann (1983, p. 46):

Sobre essa situação existencial desenvolvem-se estruturas correspondentes de assimilação da experiência, que absorvem e controlam o duplo problema da complexidade e contingência. Certas premissas da experimentação e do comportamento, que possibilitam um bom resultado seletivo, são enfeixadas constituindo sistemas, estabilizando-se relativamente frente a desapontamentos. Elas garantem

\footnotetext{
${ }^{87}$ Sobre a evolução do pensamento luhmanniano e a coerência de sua leitura do direito desde suas primeiras obras anteriores a fase declaradamente autopoiética, esclarece, em sua tese de doutoramento, Orlando Villas Bôas Filho (2006b, p. 145): “Conforme já observado anteriormente, a produção de Luhmann sobre o direito é bastante vasta e abrange um período longo, de modo que muitas de suas obras são anteriores à incorporação do conceito de autopoiesis em sua teoria. Não obstante, não há uma ruptura na obra de Luhmann que invalide seus escritos anteriores. Ao contrário, os desenvolvimentos posteriores de Luhmann acerca do direito não apenas estão em consonância com as análises mais antigas, como, inclusive, retomam uma série de problemáticas nelas constantes".
} 
uma certa independência da experimentação com respeito a impressões momentâneas, impulsos instintivos, excitações e satisfações facilitando assim uma seleção continuada também ao longo do tempo, tendo em vista um horizonte de possibilidades ampliado e mais rico de alternativas. As comprovações e satisfações imediatas são em parte substituídas por técnicas de abstração de regras confirmadamente úteis, e de seleção de formas adequadas de experimentação e de auto-certificação. A esse nível do comportamento seletivo podem ser formadas e estabilizadas expectativas com relação ao mundo circundante. Seu efeito seletivo é ao mesmo tempo inevitável e vantajoso, motivando assim a retenção de tais estruturas, mesmo frente a desapontamentos [...] $\mathrm{Na}$ experimentação a complexidade e a contingência de outras possibilidades aparecem estruturalmente imobilizadas como "o mundo", e as formas comprovadas de seleção relativamente imune a desapontamentos aparecem como sentido, cuja identidade pode ser apreendida - por exemplo como coisas, homens, eventos, símbolos, palavras, conceitos, normas. Nelas se ancoram as expectativas. (LUHMANN, 1983, p. 46).

A formação de estruturas gerais de expectativas apresenta-se, nessa fase inicial, como resposta à necessidade de segurança e previsibilidade, ainda que meramente consciente e sujeita a frustrações ("desapontamentos"), das quais o sistema psíquico depende não apenas para poder se "imunizar" parcialmente contra tais frustrações, mas, principalmente, para se integrar socialmente, avaliar o significado de suas ações a partir das expectativas que os outros tem dele mesmo e, dessa forma, amenizar o risco de que suas expectativas em relação aos demais venham a se revelar equivocadas. ${ }^{88}$

Nesse sentido, as interações, como forma de acoplamento estrutural entre sistemas psíquicos, favorecem essa estruturação de expectativas a partir dos processos de atribuição de sentido no interior de cada consciência na medida em que o "comportamento

\footnotetext{
${ }^{88}$ Essa estruturação de expectativas demanda já no âmbito dos sistemas psíquicos seria justificável, segundo o referido sociólogo alemão, pois: "Neste mundo complexo, contingente, mas mesmo assim estruturalmente conjecturável existem, além dos demais sentidos possíveis, outros homens que se inserem no campo de minha visão como um 'alter ego', como fontes eu-idênticas da experimentação e da ação originais. A partir daí introduz-se no mundo um elemento de perturbação, e é tão-somente assim que se constitui plenamente a complexidade e a contingência. [...] O preço disso [ou seja de absorver as perspectivas dos outros] está na potencialização do risco: na elevação da contingência simples do campo de percepção, ao nível da dupla contingência do mundo social. Reconhecer e absorver as perspectivas de um outro como minhas próprias só é possível se reconheço o outro como um outro eu. [...] Com isso, porém, tenho que conceder (sic) que o outro possui igualmente a liberdade de variar seu comportamento, da mesma forma que eu. Também para ele o mundo é complexo e contingente. Ele pode errar, enganar-se, enganar-me. Sua intenção pode significar minha decepção. O preço da absorção de perspectivas estranhas é, formulado em termos extremados, sua inconfiabilidade. [...] Frente à dupla contingência necessita-se (sic) outras estruturas de expectativas, de construção muito mais complicada e condicionada as expectativas”. (LUHMANN, 1983, p. 46-47).
} 
do outro não pode ser tomando como fato determinado, ele tem que ser expectável em sua seletividade, como seleção entre outras possibilidades do outro". (LUHMANN, 1983, p. 47).

Em razão de tal seletividade basear-se na interpretação das estruturas de expectativas do outro, uma integração "confiável” requer a possibilidade de se formular expectativas não só sobre seus comportamentos e operações, como, principalmente, sobre as próprias expectativas desse outro sistema. ${ }^{89}$

Portanto, para que essas interações sociais se realizem não basta o aspecto presencial e que cada sistema "experimente" as possibilidades de sentido atribuídas pelos outros sistemas psíquicos, ou sociais como na hipótese de interpenetrações entre esses dois tipos de sistemas de sentido, sendo preciso possibilitar-lhes "ter uma expectativa sobre a expectativa que o outro tem dele". Nesse contexto, estruturas e sistemas sociais normativos, como o direito, desempenhariam a função de integrar o nível "das expectativas imediatas de comportamento, na satisfação ou no desapontamento daquilo que se espera do outro", ao nível "de avaliação do significado do comportamento próprio em relação às expectativas do outro". (LUHMANN, 1983, p. 48).

Não se pode com isso afirmar que o direito conduza apenas à cooperação e estabilização de expectativas ou que seja capaz de impedir que as mesmas sejam frustradas, pois trabalha a partir de sua estruturação.

$\mathrm{Na}$ medida em que resultam de um processo comunicacional de seleção e

\footnotetext{
${ }^{89}$ Sobre a função confiança na redução da complexidade do mundo, enquanto realidade incomensurável de informações e possibilidades de decisões, e sua atuação no sentido de assegurar expectativas e direcionar decisões internas aos sistemas, recomenda-se a leitura de uma das primeiras obras de Niklas Luhmann (2005) intitulada Confianza (Verlagsgesellschaft), que embora publicada pela primeira vez em 1968, contém já o esboço inicial de suas questões referentes ao aumento da complexidade do mundo e o levantamento de como a confiança pode ser entendida como um mecanismo de redução de tal complexidade que oferece uma segurança ilusória, nem por isso irrelevante, que possibilita a tomada de decisões de ação no presente e a de planejamento e orientação para o futuro mesmo em face da contingencialidade do mundo. Nesse sentido, distingue confiança de esperança relacionando a primeira a uma racionalização de expectativas voltadas a decisões: "La confianza solamente está implicada cuando la expectativa confiable hace una diferencia para una decisión; de otro modo, lo que tenemos es una simple esperanza. [...] Por lo tanto, la confianza siempre recae en una alternativa crítica, en la que el daño resultante de una ruptura de la confianza puede ser más grande que el beneficio que se gana de la prueba de confianza asegurada. De aqui que el que confia toma conocimiento de la posibilidad del daño excesivo provocado por la selectividad de las acciones de otros y adapta una posición hacia esa posibilidad. El que tiene esperanza simplemente tiene confianza a pesar de la incertidumbre. La confianza refleja la contingencia. La esperanza elimina la contingencia”. (LUHMANN,
} 
dotação de sentido em um mundo complexo, a partir das operações de seleção dos processos comunicacionais de cada sistema autopoiético, as estruturas de expectativas, com as quais o direito trabalha, "não são capazes de garantir a plena determinação das seleções por ela realizadas, mas apenas torná-las mais prováveis, o que implica admitir que o problema da frustração das expectativas é imanente a qualquer estrutura desse tipo". (VILLAS BÔAS FILLHO, 2006b, p. 148-149).

Embora tenha essa função generalizante de expectativas, algumas vezes o direito pode contribuir de modo contrário para a própria ampliação e generalização dos conflitos, como foi possível verificar na exposição inicial sobre o conceito luhmanniano de interação e da função desempenhada por certas organizações, como os sindicatos, na generalização e institucionalização de conflitos particulares, interacionais, não satisfeitos ou mesmo agravados pela frustração das expectativas a partir de seu inesperado tratamento inicial pelo próprio sistema jurídico. (LUHMANN, 1983, p. 48, 1998, p. 353).

Por sua vez, sistemas sociais como o jurídico utilizam um outro estilo de redução da complexidade e estabilização de expectativas, servindo de orientação aos sistemas psíquicos. Tem-se, dessa forma, a estabilização de expectativas objetivas, buscando uma "simplificação através de uma redução generalizante". Nesse processo, tais expectativas "podem ser verbalizadas na forma do dever ser, mas também podem estar acopladas a determinações qualitativas, delimitações da ação, regras de cuidado, etc." (LUHMANN, 1983, p. 52).

Sobre esse aspecto simbólico da estabilização de expectativas empreendida pelos sistemas sociais, sua função de "síntese regulativa de sentido" não seria plenamente captada, segundo Luhmann (1983, p. 52), se sua compreensão se restringir à visão da expectativa comportamental e à questão coercitiva da garantia do comportamento conforme as expectativas. A esse respeito adverte:

[...] Essa função tem seu centro de gravidade no plano reflexivo da expectativa sobre expectativas, criando aqui segurança em termos de expectativas, à qual se segue, apenas secundariamente, a segurança sobre o comportamento próprio e a previsibilidade do comportamento alheio. É muito importante, para a compreensão do direito, ter uma visão clara

2005, p. 40-41). 
dessa diferença. Isso porque a segurança na expectativa sobre expectativas, seja ela alcançada por meio de estratégias puramente psíquicas ou por normas sociais, é uma base imprescindível de todas as interações, e muito mais importante que a segurança na satisfação de expectativas. (LUHAMNN, 1983, p. 52-53).

O direito trabalha a generalização dessas expectativas de expectativas a partir das três dimensões de sentido - a dimensão temporal, a dimensão social e a dimensão objetiva - devendo produzir "congruência seletiva" entre elas de modo a garantir a manutenção contrafática de expectativas normativas. (LUHMANN, 1983. p. 114-115, 1998, p. 90).

Antes, porém da abordagem desse processo, é preciso, ainda que de modo sucinto, delimitar as distinções entre as expectativas normativas das demais expectativas cognitivas.

A distinção entre essas formas de expectativas, segundo Luhmann (1983, p. 56), “não é definida em termos semânticos ou pragmáticos, nem referenciada aos sistemas afirmativos que as fundamentam ou à contradição entre afirmações informativas e diretivas - mas sim em termos funcionais, tendo em vista a solução de um determinado problema". 90

Refere-se, portanto, ao tipo de antecipação que será produzida pelos sistemas de sentido para a absorção das frustrações. Nesse contexto, duas são as possibilidades: (i) a adaptação da expectativa à situação que lhe é contrária ou (ii) a sua manutenção a despeito de sua frustração, em situações de conflito, daí porque a expressão "manutenção contrafática de expectativas normativas”.

Enquanto que as expectativas cognitivas, uma vez não atendidas, caracterizam uma "nem sempre consciente disposição de assimilação em termos de aprendizado", as

\footnotetext{
${ }^{90} \mathrm{O}$ termo normativo ao ser relacionado à expectativa não diz respeito à dicotomia entre "dever ser" e "ser", própria do direito. Uma vez que qualifica expectativa, opõe-se não ao "ser", mas ao cognitivo em termos funcionais e não semânticos. Daí porque, segundo Luhmann (1983, p. 57): “Toda expectativa é fática, seja na sua satisfação ou no seu desapontamento o fático abrange o normativo. A contraposição convencional do fático ao normativo deve, portanto, ser abandonada. Ela é uma construção conceitual errônea, como no caso de se querer contrapor ser humano e mulheres; uma manobra conceitual que nesse caso é prejudicial às mulheres, e naquele ao dever ser. O oposto adequado ao normativo não é fático, mas sim o cognitivo. Só é possível optar-se coerentemente entre essas duas orientações com respeito ao tratamento de desapontamentos, e não entre o fático e o normativo".
} 
expectativas normativas, de forma oposta, "caracterizam-se pela determinação em não assimilar os desapontamentos", ou seja, estas últimas mantêm-se como expectativas apesar da situação que as contraria. (LUHMANN, 1998, p. 56).

A normatização de expectativas através do direito opera inicialmente na dimensão temporal de sentido. A norma nesse contexto teórico, segundo a síntese de Orlando Villas Bôas Filho (2006b, p. 150), “seria, assim, uma forma de estruturação temporal das expectativas, que consistiria em fixar uma dada expectativa como normativa e, mediante mecanismos de absorção das frustrações, neutralizá-la contra as condutas que dela se desviam".

Dessa forma, a normatividade do direito poderia ser entendida, em linhas gerais, como uma espécie de estabilidade contrafática. ${ }^{91}$

Contudo, a generalização de expectativas pelo direito não se restringe a sua normatização na dimensão temporal, mas compreende, como foi possível introduzir acima, uma "congruência seletiva" entre esta e as demais dimensões de sentido, social e objetiva, a fim de garantir a sua referida manutenção contrafática.

Se na dimensão temporal essa generalização se dá através da fixação de normas, na dimensão social o direito ela envolve o mecanismo de institucionalização de expectativas comportamentais. (LUHMANN, 1983, p. 77).

A institucionalização surge da necessidade de direcionamento das expectativas normativas com o propósito de reduzir a sua exposição às frustrações ou mesmo ao conflito com outras expectativas normativas não limitadas a dois, mas a três ou mais sistemas de sentidos, que levem também às frustrações.

Tal necessidade relaciona-se à menor tolerância dos sistemas à frustração de

\footnotetext{
91 Nesse sentido, afirma Luhmann (1989a, p. 140): "In a way that no other system does, the law processes normative expectations that are capable of maintaining themselves in situations of conflict. The law cannot guarantee, of course, that these expectations will not be disappointed. But it can guarantee that they can be maintained, as expectations, even in case of disappointment, and that one can know this and communicate it in advance. From the sociological point of view, that normativity is nothing but counterfactual stability. To formulate this differently: in that it protects expectations, the law frees us from the demand that we learn from disappointments and adjust to them. It thereby holds out the prospect of resolving conflicts (and at the same time makes it possible to seek out and withstand conflicts), for it contains a preliminary decision (however unclear it may be in the individual case) about who has to learn from disappointment and who does not".
} 
expectativas normativas em comparação às cognitivas, devendo ser direcionadas de forma a poderem ser bem sucedidas. Cabe ao mecanismo de institucionalização de expectativas normativas, segundo Luhmann (1983, p. 77), “delinear o grau em que as expectativas podem estar apoiadas sobre expectativas de expectativas supostas em terceiros".

Nesse sentido, a institucionalização envolveria a "função de terceiros no sentido neutralizante, objetivador, amenizador de disputas", os quais estariam presumivelmente dispostos a sustentar as expectativas institucionalizada contra as condutas que as frustram. (LUHMANN, 1983, p. 78).

Surge aqui a delicada questão do "consenso pressuposto das expectativas institucionalizadas", sendo que tal institucionalização "não traria um fomento ao consenso. Ao contrário, ela antecipa ficcionalmente o consenso, de modo a fazer com que ele passe a ser pressuposto e não precise mais ser concretamente expresso". (VILLAS BÔAS FILHO, 2006b, p. 151).

Essa integração de expectativas no sentido realizado pela institucionalização remete normalmente ao consenso.Segundo Luhmann (1983, p. 79), desde "a derrocada do direito natural afirma-se que a vigência do direito está fundamentada em convicções comuns".

Porém, ainda segundo o referido autor, o problema do consenso "tem que ser melhor refletido, e desenvolvido no sentido dos mecanismos que sustentam a interação", não sendo possível a sua apreensão apenas como uma variável empírica, dado o potencial muito limitado de concretização da experimentação e a diversidade de possíveis temas com que tem que lidar. Por considerar "o consenso fático como uma experimentação sincrônica no tempo e em seu sentido", além de muito raro, seria rico em determinações em um sentido concreto, não sendo possível "uma experimentação totalmente adequada, e muito menos um pleno consenso". (LUHMANN, 1983, p. 79).

Tal institucionalização de expectativas sobre expectativas só é possível como mecanismo de "aproveitamento de um mínimo em experiências simultâneas e sinônimas", que devem ser distribuídas de maneira igual entre os significados e os momentos socialmente relevantes, tornando o próprio consenso não apenas “expectável” e "ativável”, mas, sobretudo, expansível em suas predisposições. A esse respeito, concluí:

Dessa forma, a função das instituições reside menos na criação e mais na economia do consenso, que é atingida, principalmente, na medida em que 
o consenso é antecipado na expectativa sobre expectativas, ou seja, como pressuposto, não mais precisando, em geral, ser concretamente expresso. È essa institucionalização que permite uma comunicação rápida, precisa e seletiva entre pessoas. Pode-se trocar fluentemente de situações e parceiros, sem perder a base de entendimento e ter que reconstituí-la repetidamente. Quando a institucionalização envolve desconhecidos, até mesmo neles pode ser presumido um consenso, e suposto que mesmo sem um entendimento prévio explícito exista uma concordância genérica quanto a um conjunto mínimo de expectativas sobre expectativas. (LUHMANN, 1983, p. 80).

Dentre as diversas formas de institucionalização de expectativas podem ser citadas, no sistema jurídico, o contrato e o procedimento, embora não seja possível neste trabalho adentrar-se em suas especificidades. ${ }^{92}$

Portanto, ao se institucionalizar expectativas normativas na dimensão social de sentido, mais do que a ampliação do consenso, busca-se uma distribuição de riscos, de modo que as expectativas e condutas contrárias à instituição tenham contra si o peso de uma auto-evidência presumida. (LUHMANN, 1983, p. 81). ${ }^{93}$

Segundo, Celso Fernandes Campilongo (2002, p. 124-125), essa função do direito denota a crítica luhmanniana ao consenso global e ao fundamento moral da democracia, o que por sua vez não quer dizer que a mesma seja antiliberal ou autoritária, pois, duvidar da "possibilidade do consenso - consenso no mínimo improvável nas sociedades altamente diferenciadas e complexas - significa reconhecer legitimidade ao

\footnotetext{
${ }^{92}$ Para uma visão detalhada do papel desempenhado pelo procedimento e contrato na institucionalização de expectativas normativas deve-se recorrer aos seguintes estudos de Luhmann sobre Legitimação pelo procedimento (1980) e sua Sociologia do direito (1983, p. 88-93), devidamente citados na referência bibliografia deste trabalho.

${ }^{93}$ Com isso, o referido teórico alemão não pretende reduzir a institucionalização a um mecanismo restrito à compulsão social, de simples e impositiva determinação, antidemocrática, de comportamentos. Segundo Luhmann (1983, p. 81), embora surja obrigatoriamente, a institucionalização não atua como uma compulsão que exclui outras possibilidades, mas sim "mantém boa parte da variedade das projeções normativas, certas possibilidades de divergência e principalmente possibilidades de modificação na adaptação a condições alteradas". Mais do que uma pressuposição em sentido racional universal, trata-se de uma antecipação de consenso que pode ser questionado e resistido. Tal possibilidade é, inclusive, tratada pelo autor ao se referir aos desafios lançados àquele cujas expectativas sejam contrárias à instituição, este "precisa arriscar uma iniciativa, sem estar protegido por expectativas pré-estabelecidas.[...] [Nesse contexto] a crítica a expectativas institucionalizadas está acoplada a pretensões de liderança, as quais, independentemente de conteúdos, provocam resistências. [...] Para derrubá-la necessita-se a palavra. O atacante tem que encontrar as palavras certas, os argumentos que desestabilizam a instituição". (LUHMANN, 1983, p. 82).
} 
dissenso. Até aqui, em termos bem sintéticos, não há nada de antidemocrático". ${ }^{94}$

Para o referido jurista, a função do sistema jurídico, mais do que garantir o consenso e fundamentar moralmente o ordenamento jurídico, seria "assegurar ao direito a capacidade de manter elevada a complexidade social e conferir às decisões judiciais uma adequada consistência em relação às expectativas normativas”. (CAMPILONGO, 2002, p. 125-126).

A dimensão social da generalização de expectativas pelo direito através da institucionalização constitui-se um mecanismo seletivo para além do sistema imediato de interação, para além dos presentes que se fundamenta

[...] não na concordância fática de determináveis manifestações de opiniões, mas sim no sucesso ao superestimá-las. Sua continuidade está garantida enquanto quase todos suponham que quase todos concordem; e possivelmente até mesmo enquanto quase todos suponham que quase todos suponham que quase todos concordem. Daí surge, comparativamente ao consenso fático, uma maior estabilidade uma mais apurada sensibilidade. Constituídas sobre a área movediça da experiência concreta através de mecanismos de seleção, as instituições podem tornar-se amplamente independentes da distribuição fática das experiências reais com respeito a temas e momentos, e também das entradas e saídas de seus participantes, passando então a moldar elas mesmas a estrutura de expectativas desses processos. (LUHMANN, 1983, p. 84-85).

Embora relacionada às operações internas do sistema jurídico, dada a sua peculiar função no sistema social global, essa generalização de expectativas na dimensão social, e objetiva como se verá a seguir, contribui para o desenvolvimento dos meios de comunicação simbolicamente generalizados de modo a permitir aos demais sistemas, em seus acoplamentos estruturais com os demais, facilitar suas operações de sentido e observação, conectando as expectativas comunicacionais generalizadas pelo sistema jurídico às suas operações internas pré-existentes e, assim, eventualmente reiterar suas mensagens, repetições e decodificações anteriores em seus processos autopoiéticos de

\footnotetext{
${ }^{94}$ Campilongo (2002, p. 122-133) contra-argumenta da seguinte forma em defesa da teoria sistêmica e de sua importância para compreensão da própria teoria democrática por ele desenvolvida: "Para a visão que a teoria dos sistemas tem da democracia não existe um futuro, mas sim vários futuros possíveis, contingentes e imprevisíveis para a sociedade e para a própria democracia. O que se descarta - e isso nada tem de antiliberal ou autoritário - é, definitivamente, o oposto: que se possa predeterminar o futuro. Perdem seu tempo aqueles que se ocupam em denunciar as supostas ligações do pensamento de Luhmann com o autoritarismo e com a apologia do "status"'. (CAMPILONGO, 2002, p. 127).
} 
dotação de sentido e de seleção das informações.

Deve ainda,ser considerada a generalização das expectativas na dimensão objetiva de sentido.

Enquanto que as dimensões temporal e social "atuam seletivamente sobre o que é possível [expectável] no sentido prático" (LUHMANN, 1983, p. 94), a generalização objetiva das expectativas consiste em fixar um ou alguns pontos de referência abstratos, entendidos inicialmente como "complexões de expectativas" a partir das quais as expectativas podem ser estabelecidas de forma concreta.

Tais complexões constituem-se pontos de referência abstratos pois através delas "as expectativas comportamentais podem transformar-se de cópia em modelo, podem ser 'seguidas' ou 'não seguidas', podem tornar-se objeto de entendimentos sociais ou opiniões de orientação a sanções ou ao escamoteamento de desvios". Quer com isso dizer que a generalização das expectativas normativas em sua dimensão social condensa expectativas comuns e reiteradas em manifestações simbolizáveis de sentidos. (LUHMANN, 1983, p. 95).

Dessa forma, a identificação de complexões de expectativas permite "a conservação e a reativação de expectativas, sedimentando-as como acervo cultural". Por conseguinte, operacionaliza os processos comunicacionais sistêmicos na medida em que reduz a necessidade de se recriar constantemente suas expectativas a cada caso, sendo possível "deduzi-las sempre que necessário, a partir de um dado contexto organizado em termos de seu sentido". (LUHMANN, 1983, p. 98).

Nesse sentido, as complexões de expectativas contribuem para o que Luhmann (1998), em sua fase autopoiética, identificou como a formação dos meios de comunicação simbolicamente generalizados.

No que diz respeito aos processos comunicacionais do sistema jurídico, tais complexões de expectativas, ou meios de comunicação simbolicamente generalizados, representam as bases sob as quais “as normas assumem o caráter de algo que 'vige', que os direitos assumem o caráter de algo que se possa 'ter', que os institutos do direito tornam-se disponíveis como tipos que podem ser escolhidos através de decisões”. (LUHMANN, 1983, p. 98).

A contribuição dessa dimensão para a compreensão da função social do direito, 
não restrita a um funcionalismo vazio, asséptico e distanciado da realidade consiste na promoção da própria seleção do conteúdo das expectativas normativas. Por essa razão, além de manter certa continuidade nas expectativas, essa dimensão mais abstrata de sentido serve de referência para expectativas aferíveis em casos concretos. Nesse sentido, utiliza quatro princípios de identificação de expectativas para a consecução dessas funções: (i) pessoas; (ii) papéis; (iii) programas; (iv) valores. (LUHMANN, 1983, p. 99). ${ }^{95}$

Para os fins desse trabalho, a atenção deve ser centrada na função atribuída aos programas e valores na referida teoria sistêmica.

A diferenciação da sociedade moderna requer do sistema jurídico um alto grau de abstração, fortemente variável, que só pode ser atendido através de uma complexão de expectativas não mais restrita à unidade de um ator dentro de um papel (mesmo que intercambiável e não identificado pessoalmente), "mas sim apenas em uma regra decisória verbalmente fixada, cuja aplicação seja garantida através da institucionalização". (LUHMANN, 1983, p. 102).

Para Luhmann (1983, p. 102), essas "regras" seriam os programas. Estes teriam condições de aplicabilidade específicas, relacionadas às expectativas de ações ou de determinadas conseqüências de ações que se é legitimo esperar. Dessa forma, "os programas exercem a dupla função de servir de apoio a decisões e expectativas". (LUHMANN, 1983, p. 102).

Como foi possível compreender no tópico referente à dupla contingência, programa e diferenciação funcional dos sistemas sociais, os programas surgem como

\footnotetext{
${ }^{95}$ A delimitação de cada um desses princípios extrapolaria os limites deste trabalho. Assim, cumpre apenas a transcrição de um excerto sintético em que os mesmos são relacionados entre si, permitindo uma introdutória explanação de seus sentidos e do enfoque dado aos programas pela abordagem sociológica luhmanniana do direito: "Dessa forma, as pessoas, os papéis, os programas e os valores representam diferentes momentos da generalização, através dos quais expectativas comportamentais podem ser enfeixadas por meio de um principio objetivo de identificação, e assim, ancoradas no mundo exterior. Podemos partir da constatação de que as sociedades mais complexas necessitam crescentemente de premissas mais abstratas das expectativas, para poderem permitir e legitimar estruturalmente mais amplas possibilidades em termos de expectativa e comportamentos. Seria, porém, demasiadamente simples, e evidentemente incorreto, supor um desenvolvimento a partir da orientação individual, passando pela normalização através de papéis e programa, e finalmente desembocando em normas sedimentadas valorativamente (por exemplo como normas ideológicas). Aparentemente o que ocorre é que com a crescente complexidade da sociedade todos os planos da generalização são mais fortemente exigidos tendo então que ser mais nitidamente diferenciados". (LUHMANN, 1983, p. 104).
} 
mecanismo de controle interno das operações comunicacionais do sistema. Permitem-lhe estabelecer as condições sob as quais certos processos comunicacionais podem ocorrer e os processos que devem suceder a ocorrência de determinadas operações internas.

Dessa maneira, reduzem uma parte da contingência sistêmica, direcionando suas operações apesar de sua evolução indeterminada e contingente.

A programação é, portanto, complementar à função desempenhada pelo código binário na evolução do sistema, sendo variável de acordo com o direcionamento que o sistema social assume ao longo de seu processo evolutivo.

Essa função programática não seria satisfeita ao se identificar a complexão de expectativas apenas ao nível mais abstrato da generalização, ou seja aos valores.

Em julgamentos sobre a preferibilidade de ações, os valores não especificariam quais ações têm preferência sobre outras, sendo, assim, entendidas como "referências muito indeterminadas para a formação e a integração de expectativas”. Segundo Luhmann (1983, p. 103-104):

\begin{abstract}
Ao contrário do campo dos programas, a esfera dos valores apresenta uma complexidade muito indeterminada com referência à ação permitida, oferecendo grandes possibilidades de consenso, sendo assim dificilmente modificável, além de conter uma série de contradições práticas - e tudo isso são indicadores de que os valores preenchem uma outra função que os programas. Por exemplo, podemos estar seguros de defender um valor considerável e não nos ridicularizamos ao propugnarmos pela saúde pública. Em termos grosseiros isso também delimita o campo de eventos e ações que podem ser observados da mesma forma; permanece porém em aberto quais são as ações que devem fomentar a saúde pública, e que por isso deveriam ser esperadas normativamente, quanto dinheiro (de outras pessoas) a saúde pública poderia custar, e também se ela seria preferencial no caso de conflito com outros valores, por exemplo econômicos, culturais, de liberdade e da dignidade individuais. Diferentemente dos programas, os valores são formulados tão abstratamente que a relação recíproca entre os diferentes valores não pode ser estabelecida em termos constantes. Podemos institucionalizar e generalizar abstratamente somente as próprias posições valorativas, mas não as relações entre elas.
\end{abstract}

Para o referido autor, o centro de gravidade da formação de estrutura sociais e sua conseqüente diferenciação sistêmica, dado o estágio de desenvolvimento atual da sociedade moderna, teriam se deslocado para os planos intermediários dos papéis e programas, nos quais a complexidade da sociedade pode ser reproduzida adequadamente. Neste processo comunicacional "as pessoas seriam identificações demasiadamente 
concretas, e os valores seriam demasiadamente abstratos". (LUHMANN, 1983, p. 107). ${ }^{96}$

Ademais, cumpre destacar que os programas mais encontrados nos sistemas sociais são de caráter finalístico ou condicional. (LUHMANN, 1998, p. 290).

Os programas finalísticos têm por função coordenar as operações sistêmicas para determinados resultados estipulados internamente e que, por esse motivo, constituem o objetivo da programação.

Embora o caráter condicional seja fortemente destacado no sistema jurídico, a sua evolução demonstra que o mesmo não se restringe a esse tipo de programação. Como se verá ao tratar do Constitucionalismo Social e da Interpretação da Constituição Federal brasileira de 1988, destaca-se o papel conferido aos programas finalísticos na própria atribuição de sentido de aos seus códigos internos, ou seja na interpretação do direito, o que a sua compreensão científica não pode mais ignorar.

Em conclusão parcial a esse levantamento teórico da visão autopoiética do direito, destaca-se que a generalização das expectativas normativas empreendida pelo sistema jurídico requer, na dimensão temporal de sentido, a sua normatização, a fim de garantir a manutenção de tais expectativas no futuro, mesmo em face de supervenientes fatos e condutas que lhes sejam contrários.

Por sua vez, a generalização empreendida pelo sistema jurídico depende da institucionalização das expectativas normativas na dimensão social de sentido, ainda que para tanto se valha de uma pressuposta antecipação do consenso de terceiros.

Por fim, em sua dimensão objetiva, essa seletividade do direito congruente de expectativas seria completada através da formação de meios de comunicação simbolicamente generalizados, nos quais as complexões de expectativas se autonomizam dos casos concretos permitindo a recursividade das operações seletivas de sentido, no interior dos sistemas sociais. Nessa dimensão, destacam-se os programas que garantiriam

\footnotetext{
${ }^{96}$ Nesse contexto, segundo Luhmann (1983, p. 108-109): “O direito adquire seu centro de gravidade em papéis específicos e programas específicos para o processo decisório jurídico. A diferenciação de papéis jurídicos, que trabalham segundo programas decisórios próprios, deve ser uma das condições históricas para uma mais forte separação dos diferentes planos das expectativas. Isso não significa que as pessoas e os valores perdem seu significado para o direito, mas sim que a identificação e a mutabilidade das complexões de expectativas no direito não mais estão vinculadas à unidade de uma pessoa ou à justificativa através de um
} 
um mínimo de coerência interna à auto-referencialidade do direito, exercendo o controle interno de suas operações comunicacionais, seu direcionamento e as condições sob as quais tais processos comunicacionais podem e devem ocorrer.

Destaca-se, por conseguinte, que essa atividade desempenhada pelo sistema jurídico, muito além das críticas correntes sobre seu suposto funcionalismo reducionista, tem certa finalidade relacionada ao campo dos valores e aos programas.

Nesse sentido, o próprio código binário — direito/não-direito — utilizado pelo sistema jurídico para processar as referidas expectativas sociais contém em si valores positivos (justiça) e valores negativos (injustiça) que excluiriam, ademais, as contradições do sistema e outros valores que não lhes são próprios, contribuindo, em última instância, para a sua própria diferenciação sistêmica. ${ }^{97}$

\subsubsection{Desdobramentos da autopoiese do sistema jurídico}

A partir da inicial concepção autopoiética biológica de Maturana e Varela (2005) e dos avanços teóricos da autopoiese do social luhmanniana, outros pesquisadores além do próprio Niklas Luhmann, como Gunther Teubner (1989a), Celso Fernandes Campilongo (2002), Germano Schwartz (2004), Orlando Villas Bôas Filho (2006b), procuraram demonstrar a existência de uma autopoiese específica do sistema jurídico.

Teubner (1989a, p. 53) é enfático ao afirmar a autopoiese do direito que deve ser compreendido como um sistema social "de segundo grau, autonomizando-se em face da Sociedade, enquanto sistema autopoiético de primeiro grau, graças à constituição autoreferencial dos seus próprios componentes sistêmicos e à articulação destes num hiperciclo".

valor. Separação não quer dizer isolamento, mas apenas invariância relativa e variabilidade independente".

${ }^{97}$ A esse respeito, Luhmann (1989a) desenvolve o seguinte raciocínio: "Processing the expectations requires a binary code that contains a positive value (justice) and a negative value (injustice), and that artificially excludes both contradictions (justice is injustice, injustice is justice) and other values (utility, political expediency, and so forth). This coding is of decisive significance for the differentiation of the legal system, as it provides the system with its own internally constituted form of contingency. Everything that enters the law's sphere of relevance can be either lawful or unlawful, and anything that does not fit into this code is of legal significance only if it is important as a preliminary question in decisions about justice and injustice". (LUHMANN, 1989a, p. 140). 
Visto como um subsistema funcionalmente diferenciado, de segundo grau, o direito pode se desenvolver à medida que for capaz de produzir seus próprios elementos de maneira exclusiva. Assim, através da repetição de um de seus elementos básicos, a decisão, o direito pode produzir e reiniciar sua própria autopoiese, num processo contínuo de autoreferencialidade, pois que ele próprio define suas premissas de validade por intermédio de uma norma jurídica e das decisões judiciais. (TEUBNER, 1988, p. 221).

Contudo, para o referido jurista, não se quer com isso afirmar um total isolamento do direito, nem que esta auto-referência se confunde com self-constitution. (TEUBNER, 1988, p. 222). ${ }^{98}$

Segundo Germano Schwartz (2004), a própria positividade do direito exige que o mesmo seja variável, no sentido de poder continuamente reprocessar através das decisões jurídicas as frustrações pelo próprio direito produzidas, e, dessa maneira, servir de base para a sua mudança. A esse respeito complementa: “Assim, forma-se o sistema do direito de forma autopoiética. Fechado em seu interior, mas aberto ao entorno, Sua evolução reside na interação de sua parte endógena, absorvida pelo exógeno social”. (SCHWARTZ, 2004. p. 68).

Tem-se, portanto, a recursividade hermética do sistema jurídico como pressuposto de sua autopoiese.

Para Gunther Teubner (1989a), a auto-reprodução do direito ocorre sempre que as normas jurídicas se relacionam aos atos judiciais, às decisões jurisprudenciais, e viceversa, ou nas hipóteses em que se verifica a convergência entre as normas procedimentais e a doutrina. A esse respeito, afirma o referido autor:

O direito torna-se autopoiético quando as suas auto-descrições permitem desenvolver e aplicar uma teoria de fontes jurídicas no contexto da qual as normas possam ser geradas através de precedentes jurisprudenciais ou outros processos de criação jurídica endógena. A normas jurídicas são então definidas por referência a operações jurídicas, isto é, componentes sistêmicos 'produzem' componentes sistêmicos. Este é, de resto, o caso do moderno direito 'positivo': as normas jurídicas podem apenas ser

98 Segundo enfatiza Gunther Teubner (1988. p. 222): “it is one thing when a system constitutes its components, i.e., when it defines self-referentially its elements, structures and processes as units and uses them operatively. Its is another thing if the system reproduces itself in the sense that elements produce structures and vice versa". 
produzidas através de atos jurídicos especificamente definidos, consistam em leis, em decisões judiciais, ou em estatutos organizacionais, ou associativos, nos nossos dias, o próprio direito consuetudinário deve ser visto como um direito de criação jurisprudencial, já que a sua validade jurídico-positiva depende de um ato jurídico 'constitutivo' (e não meramente 'declaratório'). (TEUBNER, 1989a, p. 85).

Após abordar a característica auto-referencial e auto-reprodutiva do direito, enquanto sistema comunicativo normativamente fechado, José Engrácia Antunes (1989) faz a seguinte analogia entre o pensamento autopoiético e a teoria kelseniana, destacando a diferença de suas respectivas estruturações teóricas, aquela circular, esta piramidal:

Se Kelsen pensou poder encontrar numa fictícia Grundnorm a panacéia para o eterno problema do fundamento último da racionalidade jurídica, Teubner e os adeptos da teoria autopoiética eliminam o próprio problema ao salientar a circularidade e auto-referência do direito. (ANTUNES, 1989, p. xiii).

Do até aqui exposto, pode-se entender como o sistema jurídico, em tais visões sistêmicas, se apresenta, ao mesmo tempo, operativamente fechado e cognitivamente aberto ao ambiente, ou meio no qual se insere. Segundo André-Jean Arnaud e M. J. Farinas Dulce:

Devemos considerar que a relação que o sistema jurídico mantém com o extrajurídico não é uma relação normativa, mas nesse caso, uma relação "cognitiva" ("abertura cognitiva do sistema"), porque se trata de um processo auto-regulado (regulado do interior). Isso significa que, na comunicação, a informação ou os 'estímulos' externos são transformados pelo sistema, ao longo do processo auto-referencial. (ARNAUD; DULCE, 2000, p.168).

Ademais, embora aberto cognitivamente à observação de seu ambiente, o sistema jurídico mantém sua autonomia a partir da atribuição de sentido aos estímulos percebidos através de seu próprio código comunicativo: direito/não-direito.

Estabelecendo-se como subsistema funcionalmente diferenciado do sistema social, o sistema jurídico somente terá sua autonomia afetada quando o seu código estiver em perigo, ou seja, quando começar a tomar decisões com base em códigos de outros subsistemas.

Por sua vez, como destaca Germano Schwartz (2004, p. 70), o sistema jurídico possui também outros subcódigos que derivam daquele primeiro e que o auxiliam a 
continuar a produzir a unidade mediante a diferença, tais como: "legislação/jurisprudência", “normas jurídicas/normas positivas”, jurídico/antijurídico" etc.

\subsection{Críticas ao pensamento sistêmico do direito}

Rolf Kühn (2001), em sua descrição dessa teoria, sugere certa superficialidade na redução de complexidade social empreendida tanto internamente quanto externamente pelos sistemas luhmannianos. Nesse sentido, afirma o referido autor:

[...] A diferença adicional entre estrutura e processo leva a perceber que todos os processos do sistema reduzem a complexidade tanto externa quanto interna. Esse abaixamento da complexidade produz, porém, sempre uma versão simplificada, que é a condição prévia para a adjunção de outros processos. A compreensão entre a complexidade menor e uma complexidade maior (por exemplo, o mundo) realiza-se de um modo interno por meio do equilíbrio restabelecido graças à seleção consertada das estruturas e dos processos. (KÜHN, 2001, p. 622).

Em que pese ser a função dos processos de seleção comunicacional de cada sistema de reduzir a complexidade desorganizada do ambiente, organizando-a a partir de suas estruturas internas de sentido, essa simples descrição da teoria dos sistemas menospreza o seu potencial explicativo das relações inter-sistêmicas.

Contudo, se tal redução de complexidade for considerada sob o aspecto reativo, interno, no sentido de reprocessar e responder às demandas e expectativas projetadas pelo próprio sistema em relação aos demais, de modo a reafirmar a confiança em seu sistema como no caso do direito, através de sua adequação aos seus fins (justiça, segurança, potencialização da dignidade da pessoa humana, previsibilidade etc.) - , sem contar o fato de que tal complexidade ao menos não é mais ignorada nos acoplamentos estruturais entre os sistemas e em seus processos comunicacionais e de enlace, é possível constatar que o processo de decisão do sistema jurídico não deixa de considerar tal complexidade embora objetive a sua redução.

Assim, tal processo de seleção de sentido e organização de níveis de complexidade operacionalizáveis pelo sistema jurídico implica, em certa medida, na própria decisão sob os riscos dessa redução de complexidade ou de sua simples negação, o que não tem sido observado no formalismo jurídico positivista, "asséptico" segundo Comparato (2006, p. 360), que tem provocado perda de legitimidade e eficácia jurídicas 
frente aos demais subsistemas sociais. Nesses termos, esse reducionismo parcial não seria apenas aceitável, senão também necessário para que o sistema jurídico cumpra sua função social.

Devem ser também consideradas outras críticas à teoria dos sistemas sociais autopoiéticos, como as de Ulrich Beck (1999, p. 188-189) que aponta para uma profunda mudança social decorrente da formação de uma "sociedade mundial transnacional" em que a própria diferenciação funcional estaria perdendo sentido, sendo que a globalização, nesse contexto, serviria apenas para facilitar o bloqueio dos demais sistemas pelo econômico. Em sua oposição, contra-argumenta Celso Fernandes Campilongo (2000b, p. 117):

Apenas uma visão incompleta da teoria dos sistemas pode levantar essas
suspeitas. Não é razoável pensar que, num sistema social de
complexidade espantosamente crescente, como é o caso da "sociedade
global", seja possível a retomada de esquemas simplistas da organização
da comunicação. Apesar da extraordinária força que as relações de
mercado e a economia internacional ganharam com a globalização, nada
indica que o Estado, as leis, a ciência ou, em linguagem técnica, os
subsistemas funcionalmente diferenciados da política, do direito, da
ciência, etc., estejam se tornando indiferenciados ou completamente
submetidos a um único vértice, supostamente econômico. Melhor do que
"indiferenciação funcional", como quer BECK, a globalização torna cada
vez mais evidentes as intensas interdependências entre os subsistemas.
Nessas situações, a sociedade diferenciada funcionalmente sempre reagiu
propiciando estruturas que estabilizassem mecanismos de controle dessas
interdependências. Foi assim com o contrato nas relações entre o sistema
jurídico e o sistema econômico (a famosa passagem do "status" ao
"contrato"). Foi assim, também, com as Constituições nas
interdependências entre o sistema político e o sistema jurídico (com a
passagem do "governo dos homens" para o "governo das leis"). Quanto
maiores as interdependências do sistema com o ambiente, maiores as
aquisições evolutivas que permitem a manutenção da integridade dos
subsistemas.

Quanto às críticas à compreensão dos sistemas como uma "rede", segundo Campilongo (2000b, p. 145), o problema do sistema jurídico "reside menos na sua arquitetura formal ('pirâmide' ou 'teia de aranha') e muito mais na sua especificidade funcional (operar com base num código particular que permite produzir comunicação sobre o direito e o não-direito)".

Nessa linha, o referido autor não ignora as tensões e conflitos internos ao próprio sistema que, em princípio, a idéia de relações em rede, não hierarquizadas, aparentemente encobriria: 
Ingênuo imaginar que, nas condições de alta complexidade impostas pela globalização, o direito emane como o fruto cristalino de consensos, acordos e concessões mútuas, pautadas pelo princípio da solidariedade e por comportamentos socialmente aceitos. O direito tende a ser, crescentemente, fruto de decisões, isto é, direito posto. Por isso, o direito da globalização com muita evidência, também é construção, artifício e contingência. Diante de escolhas assim difíceis, as regras da democracia, além de viabilizar as decisões são imprescindíveis. (CAMPILONGO, 2000b, p. 145-146).

Observa-se, nesse sentido, que se por um lado alguns ideólogos da teoria dos sistemas autopoiéticos luhmannianos, das relações em rede, não deixam de considerar as relações de força ou conflitos que impedem o completo consenso nessas relações comunicacionais, de outro lado, autores como Campilongo (2000b), embora respondam a esse impasse frisando o caráter decisório próprio da autopoiese jurídica, acabam, por sua vez, relegando a solução de tais "escolhas difíceis" à procedimentalização formal das "regras da democracia", o que, partindo-se da boa-fé de seus defensores, não deixa de refletir uma similar e aparente ingenuidade acima refutada.

O apelo a tais "regras da democracia" devem aqui ser entendidas como a recusa ou o temor da formação de uma arbitrária tecnocracia jurídica decorrente da hipótese de se permitir que as premissas de decisão do sistema jurídico fiquem relegadas a seus próprios “operadores". Tal interpretação parece ignorar as recentes modificações do Direito Constitucional, ou para usar o termo técnico - em sua mais recente diferenciação que se depreende do Constitucionalismo Social e das novas teorias — práticas de interpretação constitucional (evolutiva, principiológica e finalística), que estabelecem todo uma nova e segura, ao menos não arbitrária, técnica decisória aos agentes do sistema jurídico (doutrinadores, juízes, advogados, dentre outros), incorporando a sua clausura operacional uma auto-organização orientada para a efetivação da própria democracia e demais valores constitucionalmente erigidos.

Depreendem-se tais observações da superficial crítica empreendida por essa corrente sistêmica às "velhas teorias do direito", sem contudo explicitar nesse julgamento a consideração das mudanças recentes na Teoria da Constituição e da própria modificação do sistema político como, por exemplo, a relativização da clássica e equivocada separação (total) dos poderes, ou seja, de seu silêncio sobre a nova complexidade social brasileira que exigiu a reorganização de seus subsistemas sociais e não apenas dos sistemas jurídico e político, a partir da Constituição Federal de 1988. A despeito dessas transformações, 
equivocadamente se resumem a afirma:

\begin{abstract}
A teoria do direito não se encontra em condições de resolver essas questões de maneira definitiva. Não há evidências empíricas nem construções teóricas capazes de responder categoricamente a esses desafios. As velhas teorias do direito - que não são sequer capazes de levantar essas questões - são de pouca valia no presente. Entretanto, é possível formular algumas hipóteses sobre o direito da sociedade globalizada. Assim como o sistema político - ou qualquer outro sistema parcial - é incapaz de controlar seu ambiente externo (não apenas em termos territoriais, mas, principalmente, em termos funcionais), também o sistema jurídico não está habilitado a substituir as operações do sistema político e econômico. Em outros termos: as funções operativas, estruturas, mecanismos seletivos, códigos e programas do sistema não são intercambiáveis. (CAMPILONGO, 2000b, p. 147).
\end{abstract}

Em que pese tais considerações, não parece ser esse o entendimento das funções do sistema jurídico depreendidas constitucionalmente a partir dos processos sobrecomunicacionais da sociedade brasileira em 1988, quando do grande acoplamento estrutural entre os subsistemas sociais que resultou na Constituição Federal de $1988 .{ }^{99}$

Como será detalhado ao se tratar do Constitucionalismo Social, mesmo em termos de teoria autopoiética social que identifica a sociedade como uma rede de processos comunicacionais, a Assembléia Constituinte de 1987, mais do que uma simples manifestação do sistema político, representou o acoplamento estrutural singular dos diversos subsistemas sociais que compõem a sociedade brasileira num processo democrático histórico que reordenou, a partir de seus próprios embates inter-sistêmicos os códigos e muitos processos comunicacionais comuns que servem de base recursiva para a operacionalidade interna desses vários sistemas.

A Constituição Federal resultante expressa os novos meios de comunicação simbolicamente generalizados dos quais passam a se valer os sistemas sociais, não apenas jurídico e político, mas também econômico, dentre outros, em seu processo comunicacional interno, delimitando suas novas fronteiras e sua autopoiese.

99 Os "processos sobrecomunicativos" dos sistemas autopoiéticos, segundo Neves (2005) podem ser entendidos como formas peculiares e raras de inter-relações sistêmicas não expostas claramente na teoria luhmanniana. Em linhas gerais, poderiam ser entendidos como situações de peculiar suspensão da clausura operativa do sistema que possibilitariam rápidas e reversíveis sujeições de parte de seu processo 
No que diz respeito ao tema desse trabalho, cumpre, desde já destacar que as competências, atribuições e finalidades (programas) do sistema jurídico apresentam uma maior complexidade interna, sobretudo em razão dos direitos sociais, que passam a integrar o nosso peculiar Estado Democrático (Social) de Direito, e do controle constitucional da efetivação de suas políticas públicas no sentido de se construir realmente uma sociedade livre, justa e solidária, que as atuais teorias sistêmicas parecem desconsiderar. Esse tema será retomado neste trabalho no capítulo 5, após o levantamento da conformação do sistema sanitário brasileiro e de suas inter-relações sistêmicas.

\subsection{O acoplamento estrutural entre o sistema jurídico e o sistema sanitário}

Do que foi postulado até aqui, pode-se afirmar que a Teoria dos Sistemas, aplicada às ciências sociais, procura explicar, em sentido amplo, a ordenação da vida em sociedade para além da dicotomia clássica entre Estado e Sociedade, presente na Teoria Geral do Estado.

A constituição de sistemas autônomos é favorecida nas sociedades contemporâneas em face da complexidade assumida por suas relações econômicas e sociais, que, do ponto da Teoria Analítica do direito, dificulta o monismo jurídico, explicando dessa maneira, por um lado, a multiplicidade de fontes de direito e sua especialização. $^{100}$

Da mesma forma, esse processo de diferenciação funcional estudado pela teoria autopoiética também é favorecido pela fragmentação da sociedade e conseqüente multiplicidade de subsistemas presentes na sociedade, que, em última análise, dificulta a sua unidade de sentido.

Um terceiro fator associado a esse processo, que será abordado apenas superficialmente nesta parte do trabalho, diz respeito à globalização (ou mundialização) da

comunicativo a influências externas em situações muito específicas. (NEVES, 2005, p. 67).

${ }^{100}$ Neste sentido, poderíamos citar os estudos de Alexandre Santos de Aragão (2002), em sua obra sobre "Agências Reguladoras e a Evolução do Direito Administrativo Econômico", bem com a análise de Floriano Peixoto de Azevedo Marques Neto (2002, p.73-98), sobre a "A Nova Regulação Estatal e as Agências Independentes". 
economia, que assume assim uma plataforma mundial e não mais simplesmente nacional ou regional.

A globalização aumenta a autonomia e a força do sistema econômico, v.g., a mobilidade de deslocamento dos investimentos econômicos internacionais, que diminui a sua "submissão" aos sistemas políticos legais. Esse é um bom exemplo da nova dinâmica sistêmica que será exposta e que diz respeito ao acoplamento entre os subsistemas, ou seja, às suas formas de interações.

Observe-se que no caso citado, o sistema político não desaparece, continua a existir e a ser necessário. O que ocorre é que o mesmo não tem mais a supremacia sobre o sistema econômico que tinha na perspectiva tradicional. (FARIA, 2002).

O Pensamento autopoiético procura explicar essa ordenação social a partir da existência de vários sistemas organizados sob uma lógica própria (v.g. sistema jurídico; sistema econômico; sistema político; sistema sanitário, etc.).

Esses sistemas, segundo a teoria exposta, apesar de autônomos, não se encontram isolados, sendo articulados entre si, de modo que essa interação não implica, de forma alguma, na subordinação de um sistema ao outro, mas sim na troca de informações, estímulos e respostas às demandas entre esses sistemas.

Em linhas gerais, são interdependentes, sendo fundamental que um sistema não prevaleça sobre o outro, sob pena de se quebrar o equilíbrio dinâmico desses mesmos sistemas.

Segundo Corsi, Baraldi e Espósito (1996, p. 16) o acoplamento estrutural de dois sistemas consiste na relação entre os sistemas ou destes com seu ambiente, ou seja, entre as estruturas de um e outro sistema, influindo não em sua auto-reprodução, mas delimitando as condições cognitivas que devem se fazer presentes para que se possa, cada qual, continuar a reprodução de seus processos comunicacionais internos dentro de sua própria autopoiese.

Ressalte-se, portanto, que o acoplamento estrutural entre os sistemas jurídico e sanitário não deve afastar a autopoiese própria de cada sistema.

Assim, editadas leis de conteúdo sanitário, por exemplo, o sistema jurídico deveria responder aos problemas a partir de uma dinâmica interna ao sistema jurídico que leve em conta o seu próprio código “direito/não-direito”. (SCHWARTZ, 2004, p. 74). 
Por sua vez, ocorrerá a quebra dessa dinâmica sistêmica, quando, continuando o exemplo citado, o Poder Judiciário não conceder uma prestação sanitária sob o argumento de falta de verba orçamentária, fato este que revela uma extrapolação sistêmica contrária a sua função primária que é a redução e não o aumento da complexidade de tal questão positivada.

Dessa forma, a tomada de decisões como esta não estaria conforme o código jurídico e por isso careceriam de legitimação (LUHMANN, 1980).

Assim afirma Leonel Severo Rocha (1988, p. 11):

No momento em que o Estado enquanto programador do direito deixa de ser o centro da organização política, a programação sofre uma perda de racionalidade, recuperando a indeterminação que visa reduzir. Neste sentido, em muitas questões jurídicas o poder judiciário em vez de simplesmente aplicar a programação condicional necessita recorrer a fundamentações extra-estatais. Ou seja, a quebra da racionalidade do controle do Estado sobre a política faz com que a política invada setores do direito forçando o judiciário a tomar decisões de um outro tipo: a programação finalística.

No caso do acoplamento entre os sistemas sanitário e os sistemas político, econômico e jurídico, seria interessante ainda citar o seguinte exemplo desenvolvido por Germano Schwartz (2004, p. 73-74):

Pode-se pensar que o código sanitário e seus subcódigos façam com que o sistema sanitário fique por demais dependente da sociedade e de seus demais subsistemas funcionais, o que é incorreto. [...] Ademais, a interdependência com os demais sistemas autônomos da sociedade pode, no caso da relação com o sistema jurídico, ser vista na edição de leis sobre esse processo. Assim é a lei 9313/96, que obriga ao Estado o fornecimento de medicamento gratuito aos pacientes portadores do vírus HIV. Atualmente, esses pacientes são incuráveis. Mas o prolongamento da vida pode-lhes garantir uma cura a ser descoberta no futuro. Nesse lapso temporal intermédio, tais pacientes votam e, sob o ponto de vista do código político, são vistos através do código Governo/Oposição. Também é verdade que, para o sistema econômico, os pacientes podem ou não adquirir os remédios. Ou o governo adquirir para eles. A partir dessa ótica, o vírus HIV é perscrutado sob a funcionalidade Pagamento/NãoPagamento. Nessa esteira, a legislação possui um significado político e econômico e, se legalmente válida, traz, simultaneamente, uma mudança estrutural no sistema jurídico.No entanto, os sistemas jurídico e sanitário continuam a operar com seus códigos próprios que lhes são exclusivos. A construção da doença, seu diagnóstico, tratamento, informação e aconselhamento, seguem sendo objetos únicos do sistema sanitário.

A função desse acoplamento consiste, portanto, na contínua "irritação" dos 
sistemas, na constante ressonância provocadora de respostas dos sistemas autopoiéticos a esses estímulos recíprocos (SCHWARTZ, 2004, p. 74).

Neste sentido, conclui Luhmann (1996, p. 103):

Os acoplamentos estruturais não determinam os estados do sistema, sendo sua função estabelecer uma permanente irritação (perturbação: Maturana) do sistema; ou do ponto de vista do sistema, trata-se da permanente capacidade de ressonância, a qual se ativa constantemente por meio dos acoplamentos estruturais..$^{101}$

Têm-se, com isso, as principais idéias relacionadas à visão autopoiética do sistema jurídico e suas implicações no campo mais específico do direito à saúde, sob o prisma do acoplamento estrutural entre os sistemas jurídico e sanitário, as quais serão retomadas no capítulo 5, ao se tratar da interpretação do Direito à Saúde e do processamento das expectativas normativas a ele relacionadas com especial atenção para a influência dos programas constitucionais na delimitação do conteúdo dos códigos jurídicos responsáveis pela seleção de sentido e abertura cognitiva desse sistema.

Vistas as peculiaridades da autopoiese do sistema jurídico, com base no arcabouço conceitual estudado, delinearam-se as linhas gerais acerca da complexa interrelação desenvolvida por este sistema com os demais sistemas sociais, bem como os seus mecanismos internos de adaptação às demandas exteriores filtradas e selecionadas, graças à sua dinâmica decisória circular e auto-referente interna, ou seja, ao conjunto das relações que compõe os processos comunicacionais desse sistema.

Contudo, o estudo crítico dessas inter-relações deve ser situado em seu contexto histórico, social, político e econômico, necessário para a posterior compreensão da força normativa constitucional do sistema jurídico sanitário bem como de seu potencial transformador da realidade a partir de sua autopoiese e tratamento conferido às permanentes tensões com os demais sistemas sociais decorrentes dos obstáculos da “constituição real" brasileira frente aos quais deve manter e generalizar contrafactualmente

${ }^{101}$ Cf. o original: "Los acoplamientos estructurales no determinan los estados del sistema, sino que su función en abastecer de una permanente irritación (perturbación: Maturana) al sistema; o visto desde el sistema, se trata de la permanente capacidad de resonancia: la resonancia del sistema se activa constantemente mediante los acoplamientos estructurales". (LUHMANN, 1996, p. 103). 
as expectativas normativas.

Dessa forma, requer a prévia abordagem da conformação do atual sistema sanitário brasileiro e da racionalidade interdisciplinar de sua autopoiese.

\title{
2.4.1 A autopoiese do sistema sanitário
}

A autopoiese do sistema sanitário está associada à elevação da complexidade desse sistema, bem como ao alargamento do conceito de saúde que deixa de ser visto sob os aspectos curativo e preventivo, aliando-se aos mesmos uma qualidade promocional, ligada à qualidade de vida. Assim, pode ser citado, de modo exemplificativo e em linhas gerais, o amplo conceito de saúde elaborado pela Organização Mundial de Saúde que a entende como o "completo bem-estar físico, mental e social e não apenas a ausência de doenças", recepcionado pelo artigo 196, da Constituição Federal Brasileira de 1988, sendo esta questão considerada no capítulo 4.

O importante é aqui introduzir que o aumento da complexidade do sistema sanitário na sociedade contemporânea é associado aos avanços que a medicina implantou no tratamento, na prevenção e na promoção de doenças. Nesse sentido, afirma Germano Schwartz (2004, p. 56):

\begin{abstract}
A complexidade social influencia o sistema sanitário, fazendo com que inexistam hegemonias ideológicas, científicas ou técnicas neste campo do saber, o que leva a falhas estruturais na organização da atenção médica inclusive por causa da supervalorização das conquistas médicas. Desse jogo, nascem a necessidade do incremento nos custos da atenção médica, a mercantilização da saúde e os questionamentos éticos sobre saúde pública que se reportam e causam novamente a missão imprecisa da saúde pública. Da conjuntura desses fatores nasce, portanto, a complexidade sanitária contemporânea.
\end{abstract}

Tamanha complexidade reproduz um determinado processo de diferenciação funcional, que nos permite abordar a saúde como um subsistema social autopoiético.

Retomando a idéia de diferenciação funcional dos sistemas autopoiéticos, temse que, através de um esquema binário, tais sistemas - funcionalmente diferenciados podem excluir valores terceiros, através de processo seletivo de sentido de alta tecnicidade que permite um processamento de informações entre ambos os pólos de modo a reafirmar sua unidade. 
Por sua vez, o sistema sanitário possuiria uma especificidade em relação a essas codificações. (SCHWARTZ, 2004, p. 58).

$\mathrm{Na}$ grande parte dos subsistemas, em sua estrutura binária, o código tem um valor positivo e outro negativo, que exclui uma terceira possibilidade.

O ponto positivo normalmente exerce uma função de enlace da operação interna do sistema, ao passo em que o negativo tem como função a condição de reflexão do sistema.

Ocorre que, segundo o próprio Niklas Luhmann (2000), no caso do sistema de saúde, sucede o contrário, sendo o seu valor negativo, a "enfermidade", é que possui a capacidade de enlace, ao passo em que a "saúde" serve apenas de valor de reflexão. (LUHMANN, 2000, p. 25).

Nesse contexto, a enfermidade pode ser considerada, num primeiro momento, como o elemento decisivo, razão porque "no âmbito do sistema sanitário, o alvo dos médicos e dos pacientes não reside no lado positivo, no ponto de reflexão. A prática tende do positivo para o negativo. O objetivo é a libertação de doenças. A meta é dada pelo valor negativo - a doença". (SCHWARTZ, 2004, p. 59).

Por outro lado, há que se ter em mente que, graças à ampliação do conceito de saúde, o sistema sanitário não intervém apenas quando alguém se encontra doente. (SCHWARTZ, 2004, p. 60).

A inserção do combate aos riscos sanitários, o exercício das funções de precaução e prevenção impôs uma complexidade ainda maior a esse sistema, que, por conseguinte, requer o abandono da visão meramente patogênica de saúde em favor de uma nova visão, denominada "salutogênica” por Guillod e Sprumont (1996, p. 352).

Partindo do pressuposto de que as mudanças estruturais no sistema sanitário se dão a partir de seu próprio código, Germano Schwartz sintetiza a seguinte compreensão desse sistema autopoiético:

Dessa forma, a própria estruturação do código sanitário pode reafirmar a idéia de que a saúde deve ser pensada a partir da saúde. Esse é um fato, caso se deseje uma saúde construída em direção ao futuro, uma vez que os processamentos curativos e mágicos dirigem-se essencialmente ao passado. Nesse sentido, a saúde é o ponto de reflexão do sistema sanitário, sua imagem-horizonte, seu objetivo almejado e desejado. Por outro lado, a doença é o aspecto fático, a mola propulsora dos elementos factíveis tendentes a uma reestabilização do sistema. Mas ambos os pólos 
se integram na busca pela saúde. Jamais na busca pela doença. Jamais pensando a doença como sinônimo de saúde. Mas sim, como seu equivalente funcional - assim como é o esquema vida/morte (na maioria dos casos, a vida é programada a partir da percepção - ou não - da morte). Disso decorre a possibilidade de se afirmar que somente por intermédio do código Saúde/Enfermidade é que o sistema sanitário poderá orientar-se para sua função: a saúde. Ao sistema sanitário pertencem, portanto, todos os dados que se relacionam com o conjunto de diferenças dos dois aspectos do código. (SCHWARTZ, 2004, p. 60).

Feitas essas considerações gerais acerca da autopoiese dos sistemas jurídico e sanitário, cumpre, nos próximos capítulos, desenvolver a análise do modo como se opera a interação entre esses subsistemas autopoiéticos, sob a ótica do pensamento sistêmico desenvolvido na primeira parte deste trabalho. 


\title{
O PAPEL DA MEDICINA SOCIAL NO ESTADO MODERNO E AS TENSÕES ENTRE OS SISTEMAS SOCIAIS NO DESENVOLVIMENTO DAS POLÍTICAS PÚBLICAS DE SAÚDE
}

\begin{abstract}
O estudo do sistema jurídico sanitário e a delimitação de sua força normativa constitucional dependem da consideração das principais relações entre este e os sistemas sociais político, econômico e científico que têm informado a organização da saúde pública nas sociedades ocidentais e a atuação do Estado Moderno nas questões a ela relacionadas.

Objetiva-se, assim, complementar a abordagem teórica até aqui desenvolvida com o levantamento de questionamentos históricos capazes de fornecer uma aproximação do sentido em que se desenvolveram os processos comunicacionais da sociedade e a diferenciação funcional de seus sistemas sociais em torno da organização estatal das ações e serviços de saúde.
\end{abstract}

Esse recurso foi utilizado pelo próprio Luhmann (1992, p. 1434) que, ao contextualizar, por exemplo, sua explicação teórica acerca da diferenciação funcional presente na passagem das sociedades tradicionais para a sociedade moderna, cita Michel Foucault (1966) e seu estudo sobre a dissolução da ordem através da perda de representatividade social no século XVIII, durante a referida transição para a modernidade.

Sendo assim, é de suma importância para a fundamentação dos resultados desse trabalho a abordagem histórica das inter-relações entre os diversos sistemas sociais em torno dos sentidos da saúde, inicialmente no contexto europeu e, no capítulo seguinte, através confrontação das conclusões obtidas ao final deste terceiro capítulo com as peculiaridades e a dinâmica própria dos sistemas sociais brasileiros.

Uma das primeiras questões a serem discutidas, portanto, diz respeito à origem e evolução da atuação do Estado em matéria de saúde da população e a 
conseqüente diferenciação funcional de seus processos comunicacionais em torno do sistema sanitário.

De um lado, pode-se situar Sueli Gandolfi Dallari (1987), Paulo Antônio de Carvalho Fortes (DALLARI; FORTES, 1997, p. 187-202) e Marcus Faro de Castro (2003, p. 379-390), dentre outros estudiosos da saúde pública, os quais identificam a Revolução Industrial como o “divisor de águas” da responsabilização do Estado em matéria de saúde.

A referida autora identifica a passagem para o Capitalismo Industrial como o marco referencial da mudança da proteção da saúde da população, a ponto de afirmar que "até o século XIX, o Estado, o governo da sociedade, não foi chamado a participar como provedor da saúde de seu povo". Nesse sentido, destaca a industrialização e o aumento considerável da demanda por mão-de-obra sadia, necessária para a manutenção da produção nos grandes centros urbanos. (DALLARI, 1987, p. 08).

O Estado teria, então, assumido a responsabilidade pela manutenção da saúde dos trabalhadores para garantir os lucros da classe empresarial, ameaçada tanto pela diminuição de produtividade em função dos problemas de mão-de-obra, quanto pela cobertura dos custos de proteção da saúde dos empregados com seu próprio capital.

Por razões ligadas à transferência dos custos com a "manutenção de seus estoques de mão-de-obra", Sueli G. Dallari (1987, p. 08) entende que "o primeiro grupo social que reivindicou do Estado a responsabilização pela saúde do povo foi o empresariado industrial”. Só posteriormente, a partir da $2^{a}$ metade do século XIX, é que os movimentos operários organizados teriam passado a reivindicar o Direito à Saúde e melhores condições de trabalho.

De outro lado, alguns pesquisadores desse mesmo tema, como Paul Singer, Oswaldo Campos e Elizabeth Machado de Oliveira (1981), George Rosen (1979, 1994) e Michel Foucault $(1974,1979)$ demonstram em seus estudos que a atuação do Estado na saúde da população precede à Revolução Industrial do século XIX, não se restringindo em sua origem a certos grupos de trabalhadores ou a interesses industriais propriamente ditos. Poderia, assim, ser situada essa atuação estatal em diferentes momentos da história contemporânea numa inter-relação política, econômica, científica e social de poder.

O controle do Estado sobre a saúde e o corpo do trabalhador, enquanto força 
de trabalho, enfatizado pelos primeiros autores, para essa segunda corrente, seria apenas uma das etapas finais de formação dessa nova saúde pública, possível graças à socialização do corpo pela Medicina Moderna num contexto anterior ao desenvolvimento industrial inglês, já em meados do século XVIII.

Dessa forma, teria sido apenas em "último lugar, na 2a metade do século XIX, que se colocou o problema do corpo, da saúde e do nível da força produtiva dos indivíduos”. (FOUCAULT, 1979, p. 80).

Os estudos destes cinco últimos autores citados tratam da atuação estatal nas questões relacionadas à saúde de diferentes populações a partir de uma longa contextualização histórica e social, desde as antigas práticas de saúde pública, anteriores às revoluções científicas do final do século XVIII, até o desenvolvimento de uma nova saúde pública, marcada pelo nascimento da Medicina Social, fundamental para a estruturação e evolução do Estado Moderno e a diferenciação do atual sistema sanitário.

Entendida como uma estratégia bio-política de controle social dos corpos, a Medicina Social e a nova conformação da saúde pública por ela influenciada são identificadas como o instrumento central do desenvolvimento dos Estados nacionais europeus e do próprio sistema capitalista desde sua fase comercial. (SINGER; CAMPOS; OLIVEIRA, 1981; ROSEN,1979, 1994; FOUCAULT,1974, 1979).

Ademais, cumpre ressaltar outro questionamento crucial referente à evolução do sistema sanitário que servirá de suporto ao presente estudo e que diz respeito a um ponto específico da tese de Foucault (1979), o qual demanda uma breve, porém necessária, reconstituição dos antecedentes históricos da saúde pública.

Este segundo questionamento aparentemente incidental a este capítulo é crucial para as conclusões foucaultianas e para a fundamentação da tese por ele defendida ao abstrair seus resultados em três modelos de Medicina Social, também abordadas nos tópicos seguintes.

De acordo com o referido autor francês, além do fato dessa atuação do Estado em matéria de saúde da população e de maneira organizada ter precedido à Revolução Industrial, tal atuação teria se desenvolvido através da articulação entre ciência, política e econômica contribuindo para o fortalecimento e expansão do aparelho estatal e para o grande salto tecnológico da própria medicina. 
Neste último ponto, diferentemente de sua suposta evolução gradual, inicialmente individualista, desde as civilizações antigas, até os dias atuais, para Foucault (1979) a Medicina Moderna, tal como é conhecida nos dias de hoje seria tributária não das práticas antigas, mas sim dessa inter-relação sistêmica contemporânea, constituindose, desde o seu primeiro momento como uma prática de intervenção coletiva sobre o corpo social.

Frente a essa inicial controvérsia e à questão incidental descrita, faz-se necessária uma breve reconstituição dos antecedentes históricos da saúde pública e da referida Medicina Social para, nos capítulos seguintes, discutir-se a autopoiese do sistema sanitário brasileiro e a função do direito em seu processo de efetivação e resolução de seus conflitos sistêmicos.

\subsection{Antecedentes históricos da saúde pública}

O levantamento dos aspectos gerais da história antiga e medieval da saúde pública destina-se à delimitação do panorama pré-moderno da medicina, distinguido por Foucault (1979) como sendo caracterizado por intervenções estatais esporádicas e não uniformes na prática da medicina e nos demais condicionantes da saúde da população.

A contraposição dessas práticas antigas ao desenvolvimento da Medicina Moderna e aos seus desdobramentos em Medicina Social objetiva, primeiramente, aferir a tese de Foucault (1979) relativa ao nascimento da Medicina Moderna.

Por sua vez, para os fins deste trabalho, a comprovação ou não dessa tese repercute sobre o questionamento das origens das inter-relações sistêmicas em torno da saúde e da própria forma como o sistema sanitário brasileiro se diferenciou, na medida em que os citados autores do direito sanitário e da história da saúde pública divergem não apenas sobre os seus mencionados marcos históricos como também a respeito de uma gradual coletivização dos cuidados com a saúde, a partir de supostas práticas médicas privadas e individualizadas, em oposição a um início já coletivo e estatizado da Medicina Moderna, inserida em diversas políticas sanitárias desde o século XVIII e sem precedentes na história antiga.

A importância dessa abordagem comparativa consiste no questionamento feito pelo autor citado que propõe a negação da idéia "mítica" que equivocadamente 
identificaria a evolução da saúde pública e da medicina ocidental como um processo de desmantelamento e substituição de uma originária prática coletiva de "instituições mágico-religiosas" pela organização de uma assistência médica clientelista e privada.

Pretende-se, portanto, o estudo dessa tese contrária que afasta a suposição de um início privado, individual e "clínico", meramente econômico, das modernas práticas sanitárias, as quais só teriam sido corrigidas e socializadas por um posterior processo estatal de coletivização. Em sentido oposto, seria possível infirmar tal suposição, demonstrando-se que ambas as práticas de saúde, medicina privada e medicina socializada, apresentavam-se já no século XVIII como "duas faces de um mesmo processo". (FOUCAULT, 1979, p. 193).

A racionalidade sistêmica inicial da saúde é assim recontextualizada possibilitando um novo "nível de análise explicativa e sistematizada". Neste, o processo gradual de diferenciação funcional e de organização das políticas da saúde identifica as doenças como um problema político e econômico. Com essa nova "noso-política", a organização e o controle das políticas de saúde passam a ser monopolizados nos aparelhos de Estado, propiciando o fortalecimento estatal e o desenvolvimento das práticas e do conhecimento científico sanitários. (FOUCAULT, 1979, p. 194). ${ }^{102}$

No período em questão referente história antiga e medieval da saúde pública, as múltiplas políticas de saúde e os encargos com os problemas sanitários ficaram restritos às ações de grupos religiosos, associações de socorro e beneficência e, posteriormente, de sociedades científicas, ainda de forma incipiente e não organizada.

\subsubsection{Povos antigos}

As origens mais rudimentares da saúde pública podem ser relacionadas às civilizações antigas, não diferenciadas funcionalmente, situadas há quatro mil anos no norte da Índia no Punjab, região situada na fronteira entre Índia e o Paquistão, cujos sítios

\footnotetext{
${ }^{102} \mathrm{O}$ antepositivo nos(o)-, do grego nósos, refere-se aqui à idéia de doença. (HOUAISS, 2005). Empregado junto ao termo política designa, na obra de Michel Foucault (1979), uma nova forma de gestão da vida e de controle sobre os corpos pelo poder estatal, não restrita à domesticação e vigilância dos indivíduos, mas sim relacionada ao gerenciamento das populações através da instituição de "verdadeiros programas de
} 
arqueológicos de Mohenjo-Daro, nos Vales da Índia e de Harappa, evidenciam atividades ligadas à saúde comunitária voltadas a questões de saneamento e habitação dessas antigas cidades. (ROSEN, 1994, p. 31).

Outros exemplos poderiam ser citados, como os achados egípcios da cidade de Kahum no Médio Império (2100-1700 a.C.) e das ruínas de Tel El-Amarna, do século XIV a.C., passando pelos grandes aquedutos da cultura creto-micênica, dois mil anos antes da Era Cristã, nos quais a configuração dessas cidades históricas denota certo conhecimento sobre a influência de elementos ambientais na saúde e as formas de enfrentamento de seus problemas relacionados à vida comunitária. (ROSEN, 1994, p. $32)$.

Essa consciência sanitária estava diretamente ligada à religiosidade dos povos antigos, segundo George Rosen (1994, p.32):

[...] No decorrer de longos períodos da História, crenças e práticas religiosas avizinharam limpeza e religiosidade. As pessoas se mantinham limpas para se apresentarem puras aos olhos dos deuses, e não por razões higiênicas. Egípcios, mesopotâmios e hebreus, e outros povos, davam valor a esses hábitos.

Tal religiosidade, característica das antigas civilizações do Oriente e do Mediterrâneo, insere-se na conformação do chamado Estado Antigo, Oriental ou Teocrático, no qual, conforme explica Dalmo de Abreu Dallari (1998, p. 62), "a influência predominante foi religiosa, afirmando-se a autoridade dos governantes e as normas de comportamento individual e coletiva como expressões da vontade de um poder divino".

Nesse sentido, na maior parte do tempo, as doenças e epidemias tiveram suas causas relacionadas a questões sobrenaturais e às ações dos médicos antigos e medievais restringiram-se aos grupos de sintomas dado o grau de desconhecimento quanto à natureza das moléstias e suas distinções. (ROSEN, 1994, p.33). ${ }^{103}$

administração da saúde, da higiene etc". (REVEL, 2005, p. 32).

103 George Rosen (1994), ao abordar esse tema, faz referência à “teoria teúrgica da doença”, de acordo com a qual, "por milhares de anos, se consideravam as epidemias julgamentos divinos sobre a perversidade do ser humano. [Ademais, o referido autor acrescenta a crença segundo a qual] apaziguando-se os deuses 


\subsubsection{Grécia}

Por sua vez, no que diz respeito ao mundo Greco-Romano, ainda em termos restritos às origens da saúde pública, embora esta não estivesse totalmente destituída de aspectos religiosos, a literatura da Grécia Clássica representa o marco da gradual “libertação do pensamento", durante os séculos V e IV a.C., no sentido da busca de uma teoria científica e racional a respeito das causas das doenças relacionando-as a causas naturais como o clima e o ambiente físico. (DALLARI, 1995, p. 17-18).

Destacam-se os escritos do Corpo Hipocrático, especialmente o livro Ares, Águas e Lugares, no qual Hipócrates, considerado o pai da medicina, discorre de maneira teórica e prática acerca de certos problemas de saúde, delimitando atitudes das comunidades gregas e as principais doenças por ele identificadas e classificadas em endêmicas e epidêmicas, conforme a freqüência de sua incidência. (ROSEN, 1994, p. 37). 104

No período histórico da Grécia antiga, a civilização helênica encontrava-se organizada em cidades-Estados, denominadas polis, auto-suficientes, caracterizadas de modo geral por uma organização política independente. Tais cidades-Estados envolveram-se em longos movimentos de conquista e dominação de outros povos sem, contudo, consolidar uma efetiva expansão territorial nem sequer uma "integração entre vencedores e vencidos numa ordem comum", que permitisse a configuração de um Estado grego único em torno do qual as recentes práticas médicas fossem organizadas. (DALLARI, 1998, p. 64).

Não obstante essa fragmentação política, já no século V a.C., nos escritos hipocráticos contidos em Ares, Águas e Lugares, constata-se certa oferta de assistência à

\footnotetext{
irados, evitar-se-iam as punições. No Egito, por exemplo, Sekhmet, deusa da pestilência, provocava epidemias, se irritada, e as extinguia quando acalmada". (ROSEN, 1994, p. 34). Nesse mesmo sentido, Ediná Alves Costa e Suely Rozenfeld (2000) destacam que alguns povos antigos, como os babilônios e os hindus, "estabeleceram preceitos morais e religiosos - fixados nos códigos de Hamurabi e de Ur-Namu, respectivamente - e regras sobre a conduta dos profissionais que tratam das doenças". (COSTA; ROZENFELD, 2000, p. 19).

${ }^{104}$ Segundo consta na obra Uma História da Saúde Pública de George Rosen (1994, p.48), "O Corpo Hipocrático (Corpus Hippocraticum) é a coleção onde se reúnem os escritos atribuídos a Hipócrates e a seus discípulos. Esses escritos começaram a ser reunidos na Biblioteca de Alexandria, no século II a.C.”
} 
saúde que, ligada às peculiares condições da prática médica nesse período, permite não apenas caracterizar a Medicina então praticada como uma "vocação itinerante", como também identificar indícios de alguns serviços "públicos" atualmente associados à saúde pública. Segundo George Rosen (1994, p. 38):

Como outras artes e ofícios na Grécia antiga, a Medicina era uma vocação itinerante. Havia um certo número pequeno de médicos, e o médico hipocrático, como outros profissionais, por exemplo, o sapateiro ou o artista, praticava seu ofício indo de uma cidade a outra. Nas cidades menores, só esses profissionais itinerantes prestavam serviços. Se encontrava bastante trabalho, abria sua loja (o iatreion) e se estabelecia por um tempo. Comunidades maiores tinham médicos municipais permanentes. Cerca de 600 a.C., certas cidades começaram a nomear médicos. Se uma comunidade desejasse ter um médico, oferecia-lhe um salário anual e se reunia o dinheiro para pagá-lo através de uma taxa especial; ao fim do século $\mathrm{V}$, esse procedimento se generalizou pelas cidades gregas. Garantia-se ao médico algum provento mesmo quando não havia muito trabalho. Em larga medida, o médico de comunidade atendia os necessitados. Durante o período helenístico, essa prática era comum em toda região dominada pela cultura grega.

Se essas primeiras iniciativas relacionadas, de maneira geral, à “administração da saúde pública" variavam de acordo com o tamanho e a riqueza dessas cidades-Estados gregas, foi com a prática romana que esse legado cultural, no que diz respeito tanto à medicina quanto às idéias sanitárias helênicas, se tornou mais complexo e uniforme em termos administrativos. (ROSEN, 1994, p. 40).

\subsubsection{Roma}

Roma, como explica Dalmo de Abreu Dallari (1998, p. 64), "sempre manteve as características básicas de cidade-Estado, desde sua fundação em 754 a.C., até a morte de Justiniano, em 565 da era Cristã”, apesar de suas várias formas de governo do Estado Romano, de suas extraordinárias conquistas e expansão no intento de constituir um império mundial.

Destaca-se, nesse contexto, o seu sofisticado sistema de suprimento de água e saneamento composto de aquedutos construídos a partir de 312 a.C. junto a grandes estradas romanas como a Via Ápia pelo censor Ápio Cláudio Crasso, que abasteciam praças, banheiros e outras fontes públicas, segundo as informações contidas no livro De 
Aquis Urbis Romae (Os aquedutos da cidade de Roma), preparado na gestão de Sexto Júlio Frontino, comissário de água de Roma, em 97 d.C. (ROSEN, 1994, p. 41). ${ }^{105}$

Em relação à rede de esgoto, devem ser citadas a construção pelo rei Tarquínio Prisco (que governou de 616 a 579 a.C.) do grande esgoto de Roma, denominado cloaca maxima, "tão valioso quanto o suprimento de água romano", e a existência de latrinas públicas, além de um sistema regular de canos sob as ruas para eliminar a água de superfície e esgotos. (ROSEN, 1994, p. 43).

Apesar dos referidos avanços no suprimento de águas, considerados sem "paralelo na História", e do complexo sistema de esgotos, supervisionados por censores republicanos, que compõem a notável engenharia sanitária romana, quanto ao "lado sombrio da saúde pública", segundo George Rosen (1994, p. 43), "nem sempre se permitia às massas usufruir das instalações higiênicas existentes". Tal constatação é depreendida do registrado nos quarteirões mais pobres e cortiços apinhados desses bairros romanos.

O tratamento desigual no acesso a esses bens, já na Roma antiga, pode ser compreendido com base nas considerações de Dalmo de Abreu Dallari (1998) sobre a lenta e gradual evolução dos direitos e sua extensão a outras camadas sociais que compunham a plebe romana e aos membros dos povos conquistados, desde o Edito de Caracala de 212 até o Edito de Milão, de 313:

Uma das peculiaridades mais importantes do Estado Romano é a base familiar da organização, havendo mesmo quem sustente que o primitivo Estado, a civitas, resultou da união de grupos familiares (as gens), razão pela qual sempre se concederam privilégios especiais aos membros das famílias patrícias, compostas pelos descendentes dos fundadores do Estado. Assim como no Estado Grego, também no Estado Romano, durante muitos séculos, o povo participava diretamente do governo, mas a noção de povo era muito restrita, compreendendo apenas uma faixa estreita da população. [...] Gradativamente, em longa e lenta evolução outras camadas sociais foram adquirindo e ampliando direitos, sem que,

\footnotetext{
${ }^{105}$ Em relação à organização desse sistema público de água, George Rosen (1994) destaca que, ainda sob o reinado do imperador Marcus Ulpius Trajanus, de 98 a 117 d.C., este não atendia a todas as regiões da cidade, restando a muitos habitantes, como os da margem direita do rio Tibre, recorrer à água de poços. Ademais, só era possível obter um suprimento privado de água com uma permissão imperial. Daí porque, em geral, "só havia suprimento particular para cidadãos prósperos, ao passo que os outros empregavam os serviços de carregadores ou buscavam sua própria água. O usufruto de um suprimento privado de água dependia do pagamento de uma taxa, ou honorários, ao tesouro imperial”. (ROSEN, 1994, p. 42).
} 
até o final, desaparecessem a base familiar e a ascendência de uma nobreza tradicional. (DALLARI, 1998, p. 64-65).

Esse panorama é importante para a compreensão da organização da assistência médica e, de um modo geral, da própria administração da saúde pública nesse período da história romana.

No que diz respeito às doenças, não obstante os citados avanços em termos de engenharia sanitária, de 707 a.C. até o Império de Justiniano, entre 527 a 565 d.C., várias foram as epidemias e endemias que assolaram Roma nos diversos momentos de sua história, dentre elas destacam-se a peste bubônica, varíola, difteria, malária, febre tifóide, disenteria até a tuberculose, como foi diagnosticado posteriormente a partir dos relatos de autores clássicos. (ROSEN, 1994, p. 44-45).

Há também registros e poemas romanos desse período dos quais se depreende a existência de diversas doenças relacionadas diretamente ao trabalho. Contudo, apesar da influência negativa de certas atividades sobre a saúde dos trabalhadores ser conhecida pelos romanos, "nada se fazia para proteger esses trabalhadores". (ROSEN, 1994, p. 46). 106

A assistência médica teve um desenvolvimento irrisório neste período, sendo poucos os avanços em termos de teoria e prática médicas, mesmo após o início da migração de médicos gregos para Roma no século III a.C., durante a República e ainda no início do Império. Além disso, de acordo com George Rosen (1994, p. 46): “o conhecimento e a técnica da Medicina beneficiavam apenas os abastados; os pobres se confiavam à medicina folclórica popular e aos deuses".

Em termos históricos e culturais, a contribuição romana nessa matéria restringiu-se à organização dos serviços médicos. Segundo o autor citado, no século II d.C. foi criado uma espécie de serviço público pelo qual médicos denominados archiatri

\footnotetext{
${ }^{106}$ Interessante se faz a transcrição do levantamento empreendido por George Rosen (1994) a respeito da saúde dos trabalhadores em Roma a partir da interpretação de poemas e escritos naturalistas da época: "Os romanos sabiam da relação entre ocupações e enfermidades. Plínio diz que algumas doenças são mais comuns entre os escravos. Vários poetas fazem referências incidentais aos perigos de certas ocupações. Marcial menciona as doenças peculiares aos que trabalham com enxofre; Juvenal fala das veias varicosas, dos augures e das doenças dos ferreiros; e Lucrécio se refere à dura sorte dos mineradores de ouro". (ROSEN, 1994, p. 45).
} 
(chefes dos médicos, ou médicos principais em grego) eram nomeados para várias cidades e instituições. (ROSEN, 1994, p. 46-47).

Regulamentada por volta de 160 d.C. por Antonino Pio, Imperador de Roma de 131 a 161, a nomeação desses oficiais médicos tinha por principal função assistir aos cidadãos pobres. Resta, contudo, imprecisa a gratuidade desse serviço público, pois, embora tivessem seus salários fiscalizados pelos decuriones, ou conselheiros, ainda segundo Rosen (1994, p. 47), "parece que eles recebiam de quem pudesse pagar, mas esperava-se [que] tratassem de graça os que não pudessem".

Posteriormente, no período do império, aumentaram-se as formas de assistência médica, inclusive as relacionadas ao exercício privado da medicina, sendo diversificada a forma de organização desses serviços. ${ }^{107}$

Dentre essas novas formas de assistência, a organização do hospital é apontada como importante contribuição romana. ${ }^{108}$

Nesse sentido, George Rosen (1994, p. 47) destaca a existência de estabelecimentos privados de enfermarias, chamadas valetudinaria, já no século I d.C., usadas tanto por escravos quanto por romanos livres. Esses estabelecimentos nas províncias, de acordo com algumas passagens de obras de Galeno, teriam se transformado posteriormente em hospitais sustentados por fundos públicos. ${ }^{109}$

\footnotetext{
${ }^{107}$ Nessa linha, expõe George Rosen (1994, p. 47): "Na Roma imperial havia várias formas de assistência médica, além da oferecida pelos clínicos municipais. Muitos médicos exerciam uma prática privada. Havia também outros grupos de assalariados, ligados à corte imperial, e outros, às escolas de gladiadores ou aos banhos. Quando foi imperador (222-235 d.C.) Alexandre Severo organizou o serviço médico da casa imperial. Em alguns casos, médicos se ligavam a famílias, que lhes pagavam uma soma, anual, pelo atendimento durante o ano inteiro".

${ }^{108}$ A esse respeito, complementa George Rosen (1994, p. 47): “A criação de hospitais públicos para civis encontra paralelo na instituição de hospitais militares em pontos estratégicos. Nesses acampamentos, ou em cidades provinciais próximas, criaram-se também, para os oficiais do império e suas famílias, instituições similares. Eventualmente, sob a influência do cristianismo, razões humanitárias influenciaram no surgimento de hospitais públicos em muitas localidades. Uma mulher cristã de nome Fabíola estabeleceu a primeira instituição de caridade em Roma, no século IV. A fundação, durante a Idade Média, de hospitais para pobres e indigentes nasceu das valedutinaria romanas".

109 Claudius Galeno, nascido em 130 d.C., em Pérgamo, teria sido um médico dos imperadores Marco Aurélio, Commodus e Septimus Severus de grande sucesso. Atribui-se a ele a autoria de cerca de 400 livros abrangendo vários campos do conhecimento, como filosofia, matemática, gramática, leis e medicina; Algumas dessas obras foram recuperadas através de traduções do árabe e outras, em latim, podem ser encontradas no Museu Britânico que possui 84 diferentes edições de suas obras. (REZENDE, 2002a).
} 
Em termos mais amplos, a administração da saúde pública em Roma só teria atingido um certo grau de sistematização administrativa eficiente no período imperial, sob o comando de Augustus Octavianus, primeiro imperador romano de 27 a.C. a 14 d.C.:

\begin{abstract}
Apenas sob Augusto a administração dos vários serviços públicos de saúde se organizou em um sistema. Durante a República, por exemplo, nenhum departamento permanente se responsabilizava pela manutenção dos aquedutos que foram dilapidados. Augusto criou uma Câmara de Água para cuidar do suprimento de água. A inscrição em uma moeda de prata, M'Acilius triumvir valetudinis, indica a existência de uma comissão de saúde com uma função específica. Havia, ainda, oficiais próprios para os banhos. Agripa, ministro de Augusto, foi edil em 33 a.C. Tinha como deveres a supervisão dos banhos públicos, incluído o teste dos aparelhos de aquecimento, e a limpeza e o policiamento. No tempo de Nero, os aediles supervisionavam a limpeza das ruas, pelas quais se responsabilizavam os proprietários das casas. Cabia-lhes, ainda, cuidar das ruas e mantê-las planas. Controlar o suprimento de alimentos também era função dos edis; eles inspecionavam os mercados e tinham o direito de proibir a venda de gêneros estragados. A máquina criada por Augusto e seus sucessores para manter e administrar os serviços no interior do Império absorveu essas funções. (ROSEN, 1994, p. 48).
\end{abstract}

Apesar desses avanços, com a posterior desintegração do mundo grecoromano e o ingresso da Europa no período medieval, sobreveio o "declínio da cultura urbana e uma decadência da organização e da prática da saúde pública”. (ROSEN, 1994, p. 51).

Entendida de maneira geral como um período de aproximadamente mil anos, entre 500 e 1500 d.C., a Idade Média apresenta-se como um dos mais completos e heterogêneos períodos da história, de grande instabilidade política, fortemente marcada pelo cristianismo, pelas invasões bárbaras e pelo feudalismo. (DALLARI, 1998, p. 66).

Nesse novo contexto, a tradição e a cultura romana ficaram relegadas em certa medida ao Império Bizantino, Roma Oriental, menos afetado pelas invasões e pelo declínio econômico vivenciados pela Europa Ocidental.

Assim, Bizâncio, que se transformou em Constantinopla, atual Istambul, passou a ser o centro cultural, sede da cultura médica da Europa, preservando-se através 
dos árabes o referido legado greco-romano. (ROSEN, 1994, p. 52). ${ }^{110}$

\subsubsection{Idade Média}

A partir do século III, a Europa Ocidental passou por um período de diversas invasões empreendidas, especialmente ao norte, pelos povos germanos, eslavos, godos, dentre outros considerados bárbaros pelos romanos, o que constituiu um "fator de grave perturbação e profundas transformações na ordem estabelecida". (DALLARI, 1998, p. $68)$.

Desse modo, aliado à expansão do cristianismo, o grande desafio desse período pode ser entendido como o de conciliar a cultura dos invasores bárbaros com os ensinamentos da religião cristã e a herança clássica do extinto império romano. (ROSEN, 1994, p. 52).

Tais invasões e as diversas guerras internas decorrentes da desagregação do Império Romano levaram ao estabelecimento do Feudalismo, entendido como sistema político, econômico e social que vigorou na Europa ocidental durante esse período.

A sociedade feudal caracterizava-se politicamente pela descentralização do poder, localizado em cada feudo nas mãos do senhor feudal. Uma vez impossibilitado o desenvolvimento do comércio, sua base econômica voltou-se fundamentalmente para a agricultura de subsistência.

Do ponto de vista social, estava organizada em dois estamentos, ou grupos sociais com status fixos: o dos senhores feudais, proprietários de grandes extensões de terra, e o grupo dos servos, em sua maior parte de camponeses, descendentes dos antigos colonos romanos, presos à terra, os quais, em troca do seu uso e de proteção militar,

\footnotetext{
${ }^{110}$ Istambul é atulamente a maior cidade da Turquia, situada no estreito do Bósforo que separa o continente europeu do asiático. Fundada em 667 a.C. pelos gregos de Megara com o nome de Bizâncio, passou, posteriormente, para o domínio romano sendo reconstruída em 330 d.C. com o nome de Constantinopla pelo imperador Constantino I para servir de capital do império. Com a cisão do império, Constantinopla tornou-se a capital do Império Romano do Oriente, mais tarde conhecido como Império Bizantino. Com a queda de Roma, Constantinopla passou a ser o centro da cristandade no oriente. Foi tomada em 1453 pelos turcos otomanos, marcando o fim da Idade Média. O sultão otomano fez dela a capital do Estado turco. Só em 1923, após a queda da monarquia, a capital da Turquia passou para a cidade de Ancara. (WIKIPÉDIA, 2005).
} 
foram obrigados a prestar serviços e pagar diversos tributos ao seu respectivo senhor feudal. (JAGUARIBE, 2001, p. 385). ${ }^{111}$

Durante o primeiro período medieval ou Alta Idade Média, também conhecido como "Idade das Trevas", de 500 a 1000 d.C., velhos costumes e ritos pagãos foram empregados para lidar com os problemas de saúde.

Dessa forma, muitos dos problemas de saúde desse período, ao menos na Europa Ocidental, passaram a ser enfrentados, em sua grande parte, com orações, penitências e a invocação de santos na medida em que, através do cristianismo, propugnava-se a intrínseca relação entre doença e pecado, sendo a doença considerada uma espécie de punição divina dos pecados cometidos. (ROSEN, 1994, p. 53).

Observa-se, portanto, que os problemas de saúde voltaram, de certa forma, a serem tratados em termos mágicos e religiosos.

A formação dessa forte cultura religiosa pode ser entendida em função do destacado papel da Igreja cristã na Idade Média, cuja importância cresceu fortemente desde 391, quando o Imperador Teodósio, por meio do Edito de Tessalônica, declarou o cristianismo a religião oficial do Império Romano. Com a decadência do Império Romano, a Igreja Cristã tornou-se a maior instituição feudal da Europa Ocidental.

Firmou-se, assim, o teocentrismo como mentalidade medieval, posto que a Igreja passou a determinar as normas, a orientar comportamentos estabelecendo, dentre os ideais do homem medieval, a prioridade dos valores teológicos em todos os níveis da vida social. (JAGUARIBE, 2001, p. 386-387).

Por essas razões, as atividades comunitárias de saúde e o próprio conhecimento de saúde e higiene herdados da cultura greco-romana ficaram restritos ao império das ordens monásticas da Igreja.

\footnotetext{
${ }^{111}$ Ao tratar da caracterização do Estado Medieval, Dalmo de Abreu Dallari (1998) destaca a influência do feudalismo e o papel crucial da propriedade rural, senão vejamos: "Para compreender a organização feudal é preciso ter em conta que as invasões e as guerras internas tornaram difícil o desenvolvimento do comércio. Em conseqüência, valoriza-se enormemente a posse da terra, de onde todos, ricos ou pobres, poderosos ou não, deverão tirar os meios de subsistência. Assim, pois, toda a vida social passa depender da propriedade ou da posse da terra, desenvolvendo-se um sistema administrativo e uma organização militar estreitamente ligados à situação patrimonial”. (DALLARI, 1998, p. 69).
} 
Nesse contexto, os mosteiros tornaram-se "o último refúgio do saber", apresentando um "número muito grande de recursos higiênicos" que, já no século IX , lhes permitiu servir de "modelo para as comunidades urbanas que, por volta do século $\mathrm{X}$, começaram a se desenvolver na Europa”. (ROSEN, 1994, p. 53).

Por sua vez, os principais problemas sanitários da Idade Média são associados ao renascimento da vida urbana após as cruzadas - movimento militar e religioso organizado pelo Papa para libertar Jerusalém do poder dos "infiéis" (turcos seldjúcidas), durante os séculos XI ao XIII.

Em função das peculiaridades das cidades medievais - muitas delas, antigas colônias romanas, situadas em importantes rotas comerciais; outras, formadas em torno dos castelos de senhores feudais com fortificações circundantes para a proteção contra invasões - muitos de seus problemas de saúde resultaram de sua incapacidade de acomodar a sua crescente população, sendo a aglomeração de pessoas apontada como uma das características mais marcantes de tais cidades.

Outro importante fator para o agravamento das condições de saúde nesses pequenos centros urbanos da Idade Média consistia na conservação dos hábitos da vida rural entre os costumes de seus habitantes.

Dessa forma, animais grandes e pequenos eram mantidos dentro das cidades e em precárias condições higiênicas, sem contar o fato de que "por muito tempo as ruas não tiveram calçamento e receberam toda sorte de refugos e imundícies". (ROSEN, 1994, p. $54)$.

Por essas razões, os principais problemas sanitários da vida urbana nesse período podem ser identificados com a limpeza das ruas e o destino do lixo, bem como, com a oferta de um suprimento adequado de água aos habitantes dessas cidades medievais. $^{112}$

\footnotetext{
112 A esse respeito, interessante se faz a transcrição das observações e do importante levantamento realizados por George Rosen (1994, p. 56): "A luta das autoridades municipais contra essa situação se reflete no grande número de regulamentos e editos e, também, nos repetidos avisos, ameaças e apelos dirigidos aos cidadãos. Houve, ademais, várias ações de resultados positivos. Algumas cidades criaram matadouros municipais, a que a matança dos animais maiores se restringiu. A mais antiga referência a essa matéria está contida em um documento de Augsburgo, datado de 1276. Introduziu-se a pavimentação das
} 
Duas grandes epidemias, a peste de Justiniano, em 543, e a Morte Negra, em 1348, marcaram o começo e o fím da Idade Média. Nesse ínterim, diversas doenças se fizeram presentes dentre as quais se destacam: lepra, peste bubônica, varíola, difteria, sarampo, influenza, ergotismo, tuberculose, escabiose, erisipela, antraz, tracoma, miliária, dentre outras. Nesse contexto, o "medo da pestilência" se tornou uma constante na vida do homem medieval sendo que as "medidas de proteção resultaram da união de idéias médicas e religiosas". (ROSEN, 1994, p. 57).

Justamente em função da lepra, tida como a grande praga da Europa ao lado da peste bubônica, desenvolveu-se nessa época uma nova forma de ação relacionada à saúde pública, utilizada até os dias atuais, baseada no isolamento de pessoas vítimas de doenças contagiosas.

A pessoa com lepra era identificada como uma ameaça pública e destituída de seus direitos civis, podendo ser considerada socialmente morta. Percebe-se, assim, o quanto tais práticas de isolamento simbolizavam uma "terrível exclusão da sociedade humana". (ROSEN, 1994, p. 61). ${ }^{113}$

ruas, com a finalidade de mantê-las limpas, em Paris, em 1185. Praga viu as primeiras ruas calçadas em 1331, Nurembergue em 1368, Basiléia em 1387, Augsburgo em 1416. A canalização, ou seja, o escoamento dos dejetos para poços cobertos, representou outro passo importante. Em Paris, se exigia a existência, em toda casa grande, de um cabiet d'aisance destinado a drenar os dejetos até os canais. Severas penalidades aguardavam os que não respeitassem a lei. Em ordenações municipais de Milão, do século XIV, merecem muita atenção esgotos e cloacas, a serem construídos em lugares aprovados pelas autoridades, e cavados até uma profundidade em que não emitissem o mínimo odor. Em Londres, lançavam-se os esgotos no rio Tâmisa. Mas sendo limitada a capacidade de depuração do rio, uma série de ordens e regulamentações, a partir de 1309, indica a necessidade contínua de se resolver melhor o problema. No entanto, mesmo quando se contrataram limpadores de rua para retirada da cidade entulhos e imundícies, usando-se carroças, os habitantes continuaram a jogar refugos no rio Tâmisa".

${ }^{113}$ Acerca da origem dessa medida e seu exercício através da Igreja, explica George Rosen (1994, p. 60): "Essa face do trabalho em Saúde Pública começou a aparecer no início da Idade Média, quando a lepra passou a ser um importante problema de saúde. Como os médicos não tivessem nada a oferecer, a Igreja assumiu a liderança do processo, usando como princípio orientador o conceito de contágio do Velho Testamento". Ainda segundo o referido autor, foram assim adotadas as idéias presentes no livro do Levítico, que considerava contagiosa a impureza espiritual e também os processos fisiológicos. Por essa razão, essas pessoas deveriam "ser isolados do resto da comunidade até elas se submeterem a ritos de purificação específicos. [...]. Seguindo os preceitos apresentados no Levítico, a Igreja assumiu o encargo de combater a lepra. O Concílio de Lião, em 582, restringiu a associação livre dos leprosos com pessoas sadias, política seguida, e refinada, por concílios posteriores. Em 644, Rotário, rei lombardo, lançou um edital para regulamentar o isolamento dos leprosos. Gregório de Tours descreve uma casa de leprosos em Paris, no século VI; estabelecimentos similares se ergueram em Metz, Verdun e Maestricht, no século seguinte. Depois do século X, o número de leprosários cresceu enormemente; no início do século XIII existiam, só na França, cerca de duas mil casas de leprosos, ao passo que em toda a Europa chegavam a 
Outra importante prática sanitária cuja origem remonta à Idade Média é a quarentena. George Rosen (1994) faz a seguinte síntese sobre a evolução dessa prática de prevenção sanitária:

A partir de 1348, o povo de Veneza, e de outras comunidades, desenvolveu o sistema da quarentena. Em 1374, Bernabo Visconti, Duque de Milão, promulgou um decreto para prevenir a introdução e a difusão da peste. Pelo edito, ordenava-se a remoção de todos os pacientes da cidade para um campo, onde morreriam, ou se recuperariam. Quem tivesse atendido um paciente de peste, deveria ser isolado, por quatorze dias, antes de reassumir suas relações sociais com outras pessoas. $\mathrm{O}$ mesmo período de observação valia para viajantes ou mercadores infectados, ou simplesmente suspeitos de ter a doença. No mesmo ano 1374, Veneza, novamente ameaçada, negou a entrada a todos viajantes, veículos e navios, suspeitos ou infectados. Três anos depois, em 27 de julho de 1377, o conselho municipal de Regusa, na costa dálmata, ordenou um período de isolamento de trinta dias, para os oriundos de áreas atingidas pela peste. Mais tarde estendeu-se esse período para quarenta dias, ordem do termo quarentena, derivado de quarantenaria. [...] Segundo Hecker, a razão para o estabelecimento de um período de quarenta dias residia na crença, generalizada nos séculos XIII e XIV, de ser o quadragésimo dia o da separação entre as formas agudas e crônicas das doenças. Também se recorria à Bíblia para atribuir ao número quarenta um significado especial. O dilúvio, por exemplo, durou quarenta dias, e também outros episódios bíblicos". (ROSEN, 1994, p. 63-64).

A partir da experiência adquirida junto aos doentes com lepra, o princípio do isolamento foi estendido ao combate da peste bubônica, também conhecida como "Morte Negra”. Dessa forma, uma vez notificada a existência de pacientes, os mesmos eram isolados em suas casas, recaindo sobre todas estas e sobre todas as pessoas que tivessem contato com o paciente uma espécie de impedimento, que os obrigava a permanecer isolados por um período determinado em condições rigorosas até se verificar que não estivessem com a peste, tendo suas necessidades de alimento atendidas por mensageiros especiais e outras autoridades municipais. (ROSEN, 1994, p. 62-63).

Todo esse panorama permite compreender de que forma se encontrava a saúde pública na Idade Média, que embora não compreendesse um sistema organizado,

cerca de dezenove mil. O terceiro Concílio de Latrão, em 1179, ocupou-se, em detalhes, da enfermidade, e as políticas então estabelecidas vieram a prevalecer no resto do período medieval". (ROSEN, 1994, p. 60$61)$. 
denota a conformação de uma "máquina administrativa para prevenção de enfermidades, supervisão sanitária para a proteção da saúde comunitária [...] ligada à natureza da administração da municipalidade medieval”, marcada pela religiosidade, sendo os leigos, e não os médicos, que cuidavam de sua administração. (ROSEN, 1994, p. 65).

A assistência médica, por sua vez, era exercida pelos clérigos no início da Idade Média. Sustentados pela Igreja, estes primeiros médicos medievais exerciam a medicina como caridade. (SINGER; CAMPOS; OLIVEIRA, 1981, p. 17).

De acordo com George Rosen (1994, p. 66), somente a partir do século XI o número de médicos leigos começou a aumentar. Estes passaram, então, a assumir postos assalariados como médico de algum senhor feudal ou de uma cidade, dedicando-se, ainda, à prática privada a fim de garantir seu sustento. Além desses, haveria também alguns "médicos municipais", voltados para o tratamento dos pobres e para a investigação de doenças incomuns ou epidêmicas.

O referido autor, em seu levantamento histórico da saúde pública, descreve uma separação entre médicos e cirurgiões e a conseqüente diferenciação entre os grupos beneficiados por esses profissionais, próprios da sociedade estamental dessa época:

Durante a Idade Média, uma nítida separação entre médicos e cirurgiões se desenvolveu. Trabalhando com as mãos, o cirurgião continuou a ser um artífice, a aprender seu ofício com um mestre. Cada grupo ocupava um degrau diferente na escala social, relegando-se os cirurgiões a um nível inferior. (ROSEN, 1994, p. 67).

Apesar do inicial distanciamento da cultura greco-romana e de seus descritos avanços em matéria de saúde pública, durante a Idade Média desenvolveu-se a percepção da necessidade de uma assistência social não restrita às situações de enfermidade, mas também voltada para outros infortúnios o que representou um dos grandes legados desse período. Essa idéia de assistência teria se desenvolvido tanto na Europa oriental, islâmica, quanto em sua porção ocidental, predominantemente cristã. (ROSEN, 1994, p. 67).

O caráter religioso e social dessa assistência aos enfermos pode ser evidenciado a partir da criação dos hospitais, considerada por grandes historiadores da saúde pública, como George Rosen (1994, p. 71), uma das grandes façanhas sanitárias medievais juntamente com algumas medidas administrativas, como a quarentena, e com a própria idéia de assistência social desenvolvidas nesse período. 
A criação de hospitais nos principais centros urbanos do oriente, como os existentes em Bagdá por volta de 970, por soberanos como os califas Harun Al-Rachid e Al-Maktadir, e por funcionários públicos nos séculos IX e X, indicam a evolução dessa assistência social e o alto nível da Medicina nas terras muçulmanas. (ROSEN. 1994, p. $67)$.

Porém, conforme destaca Sueli Gandolfi Dallari (1987), esses primeiros hospitais, de maneira geral, tinham pouco em comum com as modernas instituições nosocômicas. ${ }^{114}$

Seguindo a mesma linha das citadas medidas de isolamento, como explica a referida autora, tais instituições surgem inicialmente como "um meio de defesa das pessoas sadias" da visão desagradável da doença e, posteriormente, do próprio perigo de contágio. (DALLARI, 1987, p. 07).

No Ocidente, os hospitais medievais encontravam-se, muitas vezes, restritos a pequenas casas de assistência de enfermagem e têm a sua origem relacionada diretamente à Igreja. (SINGER; CAMPOS; OLIVEIRA, 1981, p. 17).

Nesse sentido, destaca-se a contribuição das ordens monásticas medievais, cujos mosteiros, dotados de um infirmitorium, ou local do tratamento, de uma farmácia e

\footnotetext{
${ }^{114}$ A esse respeito, Singer, Campos e Oliveira (1981), em seu estudo sobre a evolução histórica dos serviços de saúde, afirmam que: "Antes do ano de 1867, em que se introduziu o conceito de antissepsia e, mais tarde, o de assepsia, as condições de vida para os pacientes nos hospitais eram abomináveis considerados sob o prisma atual. Os hospitais eram sujos, com pouca ventilação e superlotados. [...] Freqüentemente os pacientes eram postos dois a dois numa cama, sem que se levasse em conta o tipo de enfermidade ou a condição do enfermo. Nessas circunstâncias, muitas vezes ocorria que perecesse um paciente, e o cadáver permanecia na cama junto ao enfermo vivo, durante várias horas. [...] Não surpreende que só os inteiramente desamparados se internassem em hospitais. Os que estavam melhor de vida se faziam, sempre que possível, tratar em casa". (SINGER; CAMPOS; OLIVEIRA, 1981, p. 24-25). Nesse mesmo sentido, ao discorrer sobre o horror da população aos hospitais, de forma estarrecedora, assevera Michel Foucault (1974, p. 09): "Até meados do século XVIII ninguém saía do hospital. Ingressava-se nestas instituições para morrer. A técnica médica do século XVIII não permitia ao indivíduo hospitalizado abandonar a instituição com vida. O hospital era um claustro para morrer, era, como se dizia na época, um 'mouroir': um lugar para morrer". Esse distanciamento entre os hospitais modernos e a maioria dos hospitais medievais, além do rudimentar nível científico da época, ainda desprovida dos avanços da Medicina Moderna, iniciados nos séculos XVIII e XIX, pode ser entendido, de acordo com George Rosen (1994), em razão de uma certa dualidade de sua natureza e função, sendo questionado o grau de sua utilidade para o cuidado dos doentes em sentido estrito. Assim, segundo o referido historiador: "É provável a existência de todos os graus de variação, desde enfermarias destinadas quase exclusivamente ao tratamento dos doentes, até simples alojamentos. Em suma, porém, desde o século VIII e até o século XII, o hospital monástico representou quase a única instituição, na Europa, cuja função principal residia no cuidado do doente". (ROSEN, 1994, p. 68).
} 
de uma horta de plantas medicinais, serviam para o cuidado não apenas de clérigos doentes como também de viajantes e peregrinos. (ROSEN, 1994, p. 68).

Esse monopólio da Igreja em relação à assistência médica medieval começou a ser gradualmente afetado, já no século XIII, e, em maior grau após a Reforma Protestante, mesmo nos países católicos, à medida que as autoridades municipais, não eclesiásticas, passaram a se encarregar dos hospitais medievais e da administração das questões então relacionadas à saúde pública. (SINGER; CAMPOS; OLIVEIRA, 1981, p. 17).

Essa transição, contudo, não excluiu totalmente o clero, por meio de seus monges e freiras, do cuidado dos enfermos. (ROSEN, 1994, p. 69; COSTA; ROZENFELD, 2000, p. 20).

Foi tão somente com a Renascença, em meio ao caldo de cultura do Mercantilismo e do Absolutismo do século XVI, que a história da saúde pública ingressou num novo período, desenvolvendo-se de maneira não uniforme em direção ao seu sentido moderno e científico. (SINGER; CAMPOS; OLIVEIRA, 1981, p. 17).

Essa mudança do paradigma sanitário, como fora dito, não ocorreu de modo uniforme, sendo caracterizada por um processo lento e desigual, no qual o Humanismo Renascentista, vivenciado pela Europa ocidental, sobretudo pela Itália, representou apenas a sua primeira fase, entre os séculos XIV e XV. (ROSEN, 1994, p. 77).

As Cruzadas, embora não tenham atingido os seus objetivos religiosos, possibilitaram a abertura do mar mediterrâneo, antes controlado pelos árabes, o renascimento do comércio entre a Europa e o Oriente, e, conseqüentemente, a formação de muitas cidades na Europa.

O surgimento de uma nova classe social, a classe média burguesa, acabou por introduzir uma nova noção de riqueza, qual seja, a noção de riqueza mercantil. (COSTA; ROZENFELD, 2000, p. 20).

Os métodos de comércio e os ofícios manuais da burguesia passaram a depender de novas formulações intelectuais. Nesse contexto, ganham destaque o ideal da calculabilidade numérica e toda uma interpretação quantitativamente exata da natureza, próprias da emergente economia monetária.

Tal racionalidade, associada ao contexto de formação dos Estados Nacionais 
europeus, favoreceu o crescimento e a consolidação de seus governos centrais. Atento a essa estreita relação entre o desenvolvimento científico da época e às necessidades políticas, afirma George Rosen (1994, p. 77): “O desejo de riqueza como motivo da guerra, e a consciência da utilidade da tecnologia para alcançar o poder, levaram soberanos e estadistas a incentivar homens de engenhosidade inventiva e saber técnico".

A antiga saúde pública foi sendo modificada pouco a pouco com o surgimento de novas ciências, especialmente com a criação de uma espécie aritmética política, entendida como um meio para se aumentar a prosperidade e o poder nacionais, que tinha a população como um dos objetos centrais de seu interesse. (ROSEN, 1994, p. 98). ${ }^{115}$

Nesse contexto, a manutenção de uma população sadia e o enfretamento de seus problemas relacionados à saúde e à doença foram revistos sob a ótica de sua repercussão para o fortalecimento político e econômico do Estado. (SINGER; CAMPOS; OLIVEIRA, 1981, p. 18).

Por sua vez, Michel Foucault (1979), ao tratar de tais modificações, identifica a conformação de uma nova política de saúde a partir do século XVIII, com características próprias, não sendo possível, segundo seus estudos, estabelecer uma relação de anterioridade ou de derivação entre as formas de medicina privada, individualistas, até então desenvolvidas pelos modelos antigos de saúde pública, e as novas políticas de saúde, entendidas como políticas médicas, estatais e coletivas.

Por esses motivos, nega a idéia supostamente "mítica", de um desmantelamento e substituição de uma prática coletiva de "instituições mágicoreligiosas", que estaria na origem da medicina ocidental, pela organização clientelista privada.

Da mesma forma, o citado autor afasta a suposição de um início privado,

\footnotetext{
${ }^{115}$ Observa-se, contudo, que tal desenvolvimento foi inicialmente lento. Assim, o padrão de saúde pública, bem como sua organização e administração praticamente não mudaram significativamente, sendo mantidas, ainda entre os séculos XVI a XVIII, o mesmo padrão criado pela comunidade urbana medieval, pois conforme a observação de George Rosen (1994, p. 78): "Com o desenvolvimento de Estados Nacionais, de quando em quando governos centrais assumiam ações. No geral, porém, cabia à comunidade local cuidar dos problemas de Saúde Pública. E quando novos problemas surgiam, ajustavam-se ao modelo existente".
} 
individual, "clínico", meramente econômico, da Medicina Moderna, que supostamente teria sido lentamente corrigido e socializado através de um processo estatal de coletivização. Em sua interpretação, o século XVIII demonstraria que ambas, medicina privada e medicina socializada, "são duas faces de um mesmo processo". (FOUCAULT, 1979, p. 193).

Para o referido filósofo francês, o desenvolvimento da medicina clínica, centrada no diagnóstico, na terapêutica individual, "não pode ser dissociada da organização, na mesma época de uma política da saúde e de uma consideração das doenças como problema político e econômico que se coloca às coletividades e que elas devem tentar resolver ao nível de suas decisões de conjunto”. Essa espécie de nosopolítica, embora não seja nova, apenas ao final do século XVIII teria se sujeitado a "novas regras" e a um novo "nível de análise explicativa e sistematizada". (FOUCAULT, 1979, p. 194).

A organização e o controle dessas políticas de saúde, até então, não se encontravam monopolizadas nos aparelhos de Estado. Com esse preliminar levantamento da história antiga e medieval da saúde pública é possível observar a existência de múltiplas políticas de saúde e diversos meios de se encarregar dos problemas médicos, como as desenvolvidas por grupos religiosos, associações de socorro e beneficência, sociedades científicas, sendo esporádicas, e não uniformes, as intervenções do Estado na prática da medicina e nos demais condicionantes da saúde da população.

Contudo, desde o final século XVIII, sociedades européias como a francesa e a alemã passaram a apresentar alguns traços marcantes dessa nova noso-política com o deslocamento para a esfera estatal dos problemas de saúde pública, que até o final do século XVII estavam relegados às referidas técnicas assistenciais.

Dessa forma, a saúde e a doença, como fato de grupo e de população, passaram a ser problematizadas no século XVIII "a partir de instâncias múltiplas em relação às quais o Estado desempenha papéis diversos". (FOUCAULT, 1979, p. 194).

Observa que, anteriormente a essa mudança, a medicina enquanto "serviço" era vista tão somente como um dos componentes dos "socorros", de modo que "na figura do pobre necessitado [...] a doença era apenas um dos elementos de um conjunto que compreendia também a enfermidade, a idade, a impossibilidade de encontrar trabalho, a ausência de cuidados", restando essa "medicina-serviço" limitada em sua grande parte às 
fundações de caridade. (FOUCAULT, 1979, p. 195).

Ainda segundo Michel Foucault (1979, p. 196), essa primeira mudança pode ser entendida como uma ruptura com a "sacralização global do pobre" e a conseqüente “decomposição utilitária da pobreza”.

As transformações que se seguiram teriam sido empreendidas em atenção às críticas realizadas nesse período por economistas e administradores que identificavam a prática dessas fundações de assistência como mal investimento, ou seja, como uma forma de capitalização que produz ociosos e tira pessoas dos circuitos de produção.

Assim, a partir de distinções funcionais entre as pessoas pobres, poderia ser estabelecido como objetivo do Estado tornar a pobreza útil ao sistema econômico e desonerar a sociedade de seu peso. ${ }^{116}$

Outro processo mais amplo, desenvolvido no mesmo período e de grande importância, diz respeito ao "surgimento da saúde e do bem-estar da população em geral como um dos objetivos essenciais do poder político”. (FOUCAULT, 1979, p. 196). ${ }^{117}$

$\mathrm{Na}$ linha da já mencionada "aritmética política" descrita por George Rosen (1994, p. 98), baseando-se no século XVIII, Foucault (1979) destaca a inserção da saúde entre as funções desempenhadas tradicionalmente pelo poder, juntamente com a ordem e o enriquecimento.

O exercício destas três funções (ordem, enriquecimento e saúde) teria sido garantido pelo aparelho estatal denominado "polícia", entendido como o conjunto de mecanismos, regulamentos e instituições, através do qual, até o final do Antigo Regime, assegurava-se a "ordem, o crescimento canalizado das riquezas e as condições de manutenção da saúde em geral”. As atividades de polícia estariam, portanto, voltadas a três grandes direções: "respeito da regulação econômica; respeito das medidas de ordem; e respeito às regras de higiene". (FOUCAULT, 1979, p. 197).

\footnotetext{
116 Essa distinção da pobreza, dava-se, em linhas gerais, entre os “ bons e maus pobres, os ociosos voluntários e os desempregados involuntários; aqueles que podem fazer determinado trabalho e aqueles que não podem nada". (FOUCAULT, 1979, p. 196).

${ }^{117}$ Nesse mesmo sentido, convergem os estudos de George Rosen (1979); Paul Singer, Oswaldo Campos e Elizabeth M. de Oliveira (1981), e Ediná Alves Costa e Suely Rozenfeld (2000).
} 
Nesse contexto, o que chama a atenção é a decomposição dos procedimentos mistos de assistência através do deslocamento dos problemas de saúde de seu tratamento restrito nos socorros de caridade para o âmbito mais geral de uma polícia médica.

No entanto, a finalidade desta atuação estatal por meio da polícia médica junto à saúde da população relaciona-se a uma questão muito mais ampla do que simplesmente a preservação, manutenção e conservação da força de trabalho.

Para Foucault (1979), tratar-se de um projeto de tecnologia da população, no qual o corpo dos indivíduos e o corpo da população se apresentam como portadores de novas variáveis “mais ou menos suscetíveis de investimentos rentáveis”, sendo que: “Os traços biológicos de uma população se tornam pertinentes para uma gestão econômica e é necessário organizar em volta deles um dispositivo que assegure não apenas sua sujeição, mas o aumento constante de sua utilidade”. (FOUCAULT, 1979, p. 198).

\subsection{O impacto da Medicina de Social da conformação das políticas de saúde européias}

Michel Foucault (1979), em sua Microfísica do Poder, trata da socialização do corpo através do desenvolvimento da Medicina Moderna e de sua instrumentalização nos campos da saúde pública e estrutura de Estado. Tal socialização corresponderia a uma estratégia bio-política, na mesma linha da citada "aritmética política" desenvolvida pelo mercantilismo e absolutismo em relação às questões de saúde do povo, descrita por George Rosen (1994, p. 98).

Seus estudos a esse respeito são importantes para a compreensão da saúde pública dadas as características e a abrangência atribuídas à Medicina Moderna, entendida como Medicina Social, coletivizada, e o seu papel decisivo na conformação de novas formas de política de saúde e do atual processo de medicalização indefinida, que serão discutidos no decorrer deste capítulo.

Antes, porém, faz-se necessário retomar a tese inicialmente citada do pensamento foucaultiano que, ao tratar do desenvolvimento dessa nova política da saúde, distingue as formas de Medicina Antiga - grega, egípcia e a própria Medicina Medieval, tratadas no item anterior — da Medicina Moderna ou Científica, desenvolvida a partir do final do século XVIII, entre Morgani e Bichat e o aparecimento da anatomia patológica. 
Nesse sentido, considera aquelas primeiras formas de lidar com a saúde como práticas médicas preponderantemente individualistas, privadas, cujas dimensões coletivas teriam sido "extraordinariamente discretas e limitadas" se comparadas à Medicina Moderna e ao seu impacto na redefinição da abrangência das intervenções estatais em nome da saúde pública. (FOUCAULT, 1979, p. 79).

Sua tese consiste na compreensão da Medicina Moderna como Medicina Social, ou seja, uma prática coletiva que se sustenta sobre "uma certa tecnologia do corpo social", a qual somente num de seus aspectos seria individualista e valorizaria a relação médico-doente.

Ademais, Foucault (1979, p.85) questiona também a idéia de uma lenta e gradual evolução da medicina privada para a medicina coletiva. A esse respeito, o contexto alemão do final do século XVIII em que a saúde pública, relacionada à assistência médica e à própria medicina em seu sentido amplo, já se encontrava estatizada ao máximo. Tem-se, desse modo, o exemplo de um desenvolvimento acentuadamente burocratizado e coletivizado da medicina, um século antes da tardia unificação de reinos alemães num único Estado, antecedendo, inclusive, a própria evolução da medicina clínica.

O referido autor sustenta que só com o capitalismo teria ocorrido essa passagem da medicina privada para a medicina coletiva, e não o contrário, ou seja, as práticas de saúde pública, sociais e coletivas, estariam estritamente ligadas, desde sua origem, a uma estratégia bio-política.

Visto o corpo como uma realidade bio-política, a primeira forma capitalista de controlar a sociedade teria sido sobre os corpos, no controle biológico, somático ou corporal, antes mesmo do controle sobre sua consciência e ideologia. (FOUCAULT, 1979, p. 79).

Esse processo de socialização do corpo e de assunção da Medicina Moderna como estratégia bio-política pelos Estados e a conseqüente formação da Medicina Social teria ocorrido em três etapas: a primeira relacionada ao desenvolvimento da "Medicina de Estado"; seguida da conformação da "Medicina Urbana"; chegando, ao final, à constituição de um modelo de "Medicina [dos Pobres e] da Força de Trabalho". (FOUCAULT, 1979, p. 80). 


\subsubsection{Medicina de Estado — modelo alemão, século XVIII}

A formação da Medicina de Estado relaciona-se ao desenvolvimento administrativo dos Estados Modernos, à "Ciência de Estado", sobretudo, alemã do século XVIII (Staatswissenschaft), ligada não apenas aos componentes do Estado, como recursos naturais e à sua população, mas, principalmente, ao seu funcionamento e aparelhamento político, ou seja, ao conjunto de conhecimentos específicos para assegurar o melhor funcionamento do Estado. (FOUCAULT, 1979, p. 80-81).

Essa forma estatizada de medicina teria surgido antes mesmo do desenvolvimento da Medicina Científica de Morgagni e Bichat com o objetivo de atender não às necessidades industriais no sentido da formação de uma força de trabalho, mas sim com o propósito de assegurar, aperfeiçoar e desenvolver a força do Estado, através da administração da saúde do próprio corpo dos indivíduos que compõem globalmente esse Estado em seus conflitos econômicos e políticos com seus vizinhos. (FOUCAULT, 1979, p. 84 ; ROSEN, 1979, p. 147, 1994, p. 98). ${ }^{118}$

Assim, por exemplo, tem-se o "entusiasmo pelo crescimento populacional" dirigido e estimulado pelo Estado, apontado como um dos traços marcantes do

\footnotetext{
${ }^{118}$ A respeito da importância de Giovanni Battista Morgagni (1682-1771) para o desenvolvimento da Medicina Científica, afirma Joffre M. de Rezende (2003): "Giovanni Battista Morgagni foi o fundador da Anatomia Patológica. Foi professor de anatomia na Universidade de Pádua durante 56 anos. Em 1761, aos 70 anos de idade, publicou sua monumental obra em cinco volumes De sedibus et causis morborum (Da sede e causas das doenças), fruto de seus estudos e observações em autópsias por ele realizadas ou orientadas. Procurou correlacionar os sintomas apresentados em vida pelos enfermos com as lesões anatômicas encontradas nos diferentes órgãos. Dentre os seus relatos mais importantes cumpre destacar os de aneurisma sifilítico da aorta, atrofia amarela aguda do fígado, meningite secundária à otite, câncer do estômago, úlcera gástrica, colelitíase, endocardite, estenose mitral, insuficiência aórtica, estenose pulmonar, esclerose das coronárias, tetralogia de Fallot, coarctação da aorta e ileíte regional. Os seus contemporâneos não alcançaram o verdadeiro significado de sua obra, uma das principais fundações da Medicina Moderna". (REZENDE, 2003). Por sua vez, sobre a vida e a obra do médico francês M. François Xavier Bichat (1771-1802), esclarece Rezende (2002b): "Faleceu aos 31 anos. Estudou em Montpelier, Lyon e Paris e foi médico do Hotel Dieu nos dois últimos anos de sua vida. Profundamente interessado nos problemas da vida e da morte, realizou mais de 600 autópsias e chegava a passar a noite junto dos cadáveres; Escreveu um tratado de anatomia descritiva denominado Anatomie génerale appliquée à la physiologie, em 4 volumes, no qual lançou a idéia dos tecidos na formação dos órgãos. Seu livro Recherches physiologiques sur la vie et la mort teve várias edições e contém um grande número de observações fisiológicas e patológicas. No prefácio da $5^{\text {a }}$ edição, publicada em 1829 , assim se expressou Magendie referindo-se à Bichat: 'Son esprit observateur, son génie experimental, sa manière lucide de présenter les faits expliquent la grande influence que ce livre a exercé sur l'esprit des physiologistes et des médecins"'.
} 
pensamento político e econômico no final do século XVII, presente ao longo do século XVIII, sendo esta ênfase "quase fanática na densidade populacional [...] justificada por razões políticas, econômicas e militares”. (ROSEN, 1979, p. 145).

Insere-se na citada racionalidade mercantilista desenvolvida desde o final do século XVI, a partir da qual as principais nações européias introduziram a preocupação com o estado de saúde de sua população e as políticas dela decorrentes no cerne das razões de Estado (raisons d'Etat), características da filosofia política absolutista dominante. Nesse período, segundo Ediná Alves Costa e Suely Rozenfeld (2000, p. 21):

As bases para a intervenção na saúde do povo se estabeleceram segundo o pensamento de que para aumentar o poder e a riqueza nacionais era necessário uma população grande, bem cuidada e controlada. Nesse contexto, surgiram, no final do século XVIII, as estatísticas populacionais e o conceito de polícia médica.

Nesse mesmo sentido, George Rosen (1979) em sua compilação de ensaios sobre a história da assistência médica, intitulada Da polícia médica à medicina social, com base nas lições de Friedrich Meinecke (1924), sintetiza a influência do ideário mercantilista, enquanto política de poder, na conformação da discutida política social de saúde, característica da Medicina Social formada nesse período, da seguinte maneira:

A atitude do pensamento mercantilista em relação à sociedade
organizada se revela caracteristicamente em sua relação com o Estado.
Na medida em que o poder era considerado como o primeiro interesse
do Estado, a maioria dos elementos da política mercantilista era
explicitada e justificada pelo fortalecimento do poder do reino.
Politicamente, raison d'etat era o fundamento da política social. O que
o poder nacional exigia, segundo a visão dos governantes e de seus
conselheiros, era em primeiro lugar uma população densa; em segundo
lugar, uma população materialmente bem provida; em terceiro lugar,
uma população sob o controle do governo para que pudesse ser utilizada
de acordo com as necessidades do poder público. Nos diferentes lugares
e épocas em que a doutrina mercantilista foi colocada em prática, foram
enfatizados diferentes aspectos. Mas de alguma forma sempre se
reconheceu que para a população ser eficazmente utilizada no país era
preciso dar atenção aos problemas de saúde. (ROSEN, 1979, p. 146-
147).

Embora as potências da época como Inglaterra, França e Áustria já calculassem nesse mesmo período a força ativa de suas populações, observa-se que a preocupação sanitária desses Estados restringia-se ao acompanhamento de índices de saúde da população através de tabelas de natalidade e mortalidade e do incentivo ao 
crescimento populacional, sem, contudo, intervir de maneira efetiva e organizada para elevar esses níveis de saúde. ${ }^{119}$

De forma diversa, em função do cameralismo, versão alemã do mercantilismo, nos Estados alemães teria se desenvolvido uma prática médica efetivamente centrada na melhoria do nível de saúde de sua população, através do desenvolvimento da noção de polícia médica (mediziniche Polizei), que passou a ser efetivamente aplicada no final do século XVIII e início do século XIX. (FOUCAULT, 1979$, p. 83$).^{120}$

${ }^{119}$ Em relação aos limites ingleses à implementação real desse ideário de "aritmética política", no contexto inicial de sua formação enquanto política nacional de saúde, George Rosen (1994) em sua célebre obra, Uma história da saúde pública, destaca: "A aritmética política era apenas um meio para um fim, a saber, a prosperidade e o poder nacionais. [...] Olhavam-se os problemas de saúde e doença, principalmente, com o fim de se manter e aumentar uma população sadia, em termos, portanto, de seu significado para o fortalecimento político e econômico do Estado. [...] Aceitar essa premissa implicava aceitar também a responsabilidade de remover impedimentos à plena expansão desses recursos. Criar condições e oportunidades para promover a saúde, prevenir a doença e oferecer cuidados médicos aos necessitados, constituía um aspecto maior dessa responsabilidade. Essa visão implicava um conceito de política nacional de saúde, aceito, e levado adiante, tanto na Inglaterra quanto no continente. [...] A despeito de suas grandes potencialidades, as idéias desses pensadores não produziram resultados imediatamente tangíveis. Suas propostas não levaram a ações concretas porque ocorriam em sentido contrário ao de importantes tendências políticas e administrativas. Sua efetiva execução exigiria a existência de uma administração local desenvolvida, com controle centralizado. Mas precisamente essa rede de administração, depois da Revolução Inglesa do século XVII, tinha desaparecido". (ROSEN, 1994, p. 98-99). No que diz respeito à repercussão prática desse ideário na França, suas primeiras ações estiveram voltadas ao incentivo do crescimento populacional sem, contudo, representar uma mudança substancial das condições de saúde da população, conforme George Rosen (1979, p. 144-145): "Em termos de medidas reais tomadas para estimular o crescimento da população, a França superou todos os outros países. Como parte de seu programa econômico, Jean Baptiste Colbert, ministro de Luís XIV, foi responsável por leis que isentavam de impostos aqueles que se casassem cedo. Em um ato de 1669 referente ao Canadá, ele chegou a impor multas aos pais que não casassem suas filhas antes dos dezesseis anos e seus filhos antes dos vinte. [...] Dentro do mesmo espírito, um oficial francês propôs em 1711 que um subsídio de trinta livres fosse concedido a cada casamento, baseando sua proposta na certeza de que 'sendo esta assistência conferida só a jovens, não é inteiramente inútil ao Estado, pois ele multiplicará os súditos a preço baixo"”.

${ }^{120}$ Nesse sentido, posiciona-se George Rosen (1979), ao tratar do papel do cameralismo para o desenvolvimento do pensamento e da própria ação dos Estados alemães nas relações sociais de saúde: "O termo cameralismo tem duas conotações. Por um lado, designa as idéias que apareceram para explicar, justificar e guiar as tendências e práticas centralizadoras da administração e da política econômica da monarquia absolutista nos estados alemães do final do século XVII e no século XVIII. Por outro lado, refere-se às tentativas feitas no mesmo período de elaborar, através da emergente ciência política e social contemporânea, uma visão sistemática do funcionamento dos vários serviços administrativos como base para o treinamento dos funcionários públicos". (ROSEN, 1979, p. 147). Por sua vez, segundo Michel Foucault (1979), as razões para o desenvolvimento dessa ciência de Estado e, conseqüentemente, da Medicina de Estado, enquanto principal política de saúde desse período, originalmente na Alemanha, estariam relacionadas à ausência de unificação ainda no século XVIII, sendo que, em função da justaposição de quase-estados em constantes conflitos e afrontamentos entre si, estas pequenas unidades estavam obrigadas a se medir umas às outras, se comparar e imitar seus métodos de organização, na tentativa de modificar as relações de força entre elas, diferentemente de grandes Estados como a França e 
O termo polícia médica teria sido empregado pela primeira vez em 1764 por Wolfang Thomas Rau, em seu livro Gedanken von dem Nutzen und der Nothwendigkeit einer medicinischen Policey-Ordnung in einem Staat. (ROSEN, 1979, p. 165). ${ }^{121}$

Ao tratar das origens históricas da saúde pública, Ediná Alves Costa e Suely Rozenfeld (2000) atribuem uma grande importância ao desenvolvimento da polícia médica, como forma de controle sobre o exercício da medicina e conformação de todo um sistema de políticas de saúde, sobretudo, a partir do século XVIII. Segundo as citadas autoras:

O termo polícia, derivado da palavra grega politeia - constituição ou administração de um Estado - já era usado por escritores alemães no século XVII, como ramo da administração da Saúde Pública. Com a publicação da obra de Peter Frank a noção de polícia médica disseminou-se em países europeus, servindo de base para muitas propostas de intervenção sobre os problemas de saúde e saneamento do meio, sendo especialmente útil como guia para os funcionários públicos encarregados de regular a atividade humana. (COSTA; ROZENFELD, 2000, p. 21).

A noção de polícia médica compreende a criação de uma política médica estatal implementada por meio da regulamentação administrativa. Inicialmente, baseavase num sistema de observação da morbidade não restrito aos quadros de nascimento e morte, mas que levava em conta diversos fenômenos epidêmicos e endêmicos em diferentes cidades e regiões, observados e registrados por seus hospitais e médicos. A saúde do povo era então buscada "através da melhoria ou de remoção de muitas condições danosas à comunidade". (ROSEN, 1979, p. 166).

Segundo Singer, Campos e Oliveira (1981, p. 18), a “criação de uma 'polícia médica' era vista como parte do cuidado e controle dos desvalidos, de que o Estado, nas monarquias absolutistas da Europa, estava começando a se incumbir”.

Inglaterra que "funcionariam a um nível relativamente inconsciente". Outra razão para esse excepcional desenvolvimento administrativo na Alemanha antes mesmo da potência política francesa e da mais economicamente forte Inglaterra, seria a estagnação econômica alemã, no século XVIII, logo após a guerra dos trinta anos. Tal conjuntura teria bloqueado o impulso econômico, deixando uma "burguesia economicamente desocupada". Assim, em troca de empregos públicos, essa burguesia teria oferecido "seus homens, sua capacidade e seus recursos, etc., à organização dos Estados”. (FOUCAULT, 1979, p. 81-82).

${ }^{121}$ Segundo a tradução de George Rosen (1979, p. 165): "Reflexões sobre a utilidade e a necessidade de 
Os referidos autores acrescentam que essa atividade, cujo "traço básico" era a "autoridade", foi inicialmente atribuída à medicina, amparada pelo Estado, levando "à criação de serviços de saúde com as características essenciais dos que hoje existem". (SINGER; CAMPOS; OLIVEIRA, 1981, p. 18).

A instauração desse sistema foi possível graças à normalização da prática e saber médico, empreendida por meio do controle pelo Estado de seu ensino e sua certificação profissional, bem como, pela criação na Alemanha de órgãos administrativos centralizados de informações e de ordenação das práticas, subordinadas a um poder superior. (FOUCAULT, 1979, p. 84).

Esse processo poderia ser entendido sob a perspectiva do movimento de normalização ocorrido na Europa, sendo que "enquanto a França normalizou primeiramente seus canhões e professores, a Alemanha normalizou seus médicos". (FOUCAULT, 1979, p. 83).

Surge, então, a figura do médico como administrador da saúde da população com a criação de postos de funcionários médicos nomeados pelo governo com responsabilidade sobre determinados distritos e regiões, como se verifica na Prússia do século XIX. Tais postos eram integrados e subordinados a uma administração central, conformando, assim, a organização médica estatal própria dessa emergente tecnologia de Medicina de Estado. (FOUCAULT, p. 84).

\subsubsection{Medicina Urbana — modelo francês, final do século XVIII}

A Medicina Urbana apresenta-se como outro modelo importante para a compreensão do papel bio-político da Medicina Social, pois propiciou a instauração de novas práticas e conceitos informadores das políticas de saúde, como a sofisticação do antigo modelo da quarentena surgido na Idade Média e a adoção de uma postura autoritária e campanhista de intervenção sobre os corpos, o espaço e as coisas, com base na teoria dos miasmas, introduzindo as noções de salubridade, higiene pública, dentre outras, de grande impacto no campo da saúde pública. (FOUCAULT, 1979).

um regulamento de polícia médica para um Estado”. 
Diferentemente da Medicina de Estado alemã, embora marcado por sua influência, o modelo francês relaciona-se ao desenvolvimento das estruturas urbanas, sendo que, ao menos em sua origem, não contava com uma forte estrutura de Estado, característica do modelo alemão. ${ }^{122}$

Suas origens podem ser compreendidas a partir da conformação das grandes cidades francesas do final do século XVIII, entre 1750 e 1780, marcadas por uma multiplicidade de territórios heterogêneos e poderes rivais.

$\mathrm{Na}$ segunda metade do século XVIII, surge o problema da unificação do poder nas grandes cidades e a necessidade de se organizar o "corpo urbano de modo coerente, homogêneo, dependendo de um poder único e bem regulamentado". (FOUCAULT, 1979, p. 86)

Dentre as principais razões econômicas para essa unificação, destaca-se o papel das cidades nesse período como "lugar de mercado que unifica as relações comerciais". Soma-se a esse panorama a crescente importância desses centros urbanos como lugar de produção, dada a evolução da industrialização recente. (FOUCAULT, 1979, p. 86).

Por conseguinte, a multiplicidade então existente de jurisdições e de poderes rivais apresentava-se como um obstáculo ao desenvolvimento dessas práticas econômicas.

Não obstante essas razões econômicas, a unificação do poder urbano colocava-se também como importante questão política frente ao aumento das tensões sociais no interior das cidades, dado o desenvolvimento desses centros e o aparecimento de uma população operária pobre.

\footnotetext{
${ }^{122}$ Sobre a influência do modelo alemão e do mercantilismo que caracterizou as políticas nacionais de saúde nos séculos XVII e XVIII, mais especificamente acerca de seu impacto sobre a França, destaca George Rosen (1979, p. 187-188): “A abordagem francesa das relações sociais da saúde e da doença está marcada por sua influência. Apesar dos franceses não terem neste período elaborado uma formulação sistemática comparável ao conceito de polícia médica, eles estavam conscientes das implicações do conceito de política em relação aos problemas de saúde. (Na verdade, o termo policia é de origem francesa). [...]. Entretanto, o termo 'polícia médica' não teve uma aceitação geral na literatura francesa. [...] Um exame geral da literatura francesa deixa claro que, quando os higienistas franceses estudavam as relações das condições políticas e sociais, com a saúde, eles o faziam a partir de referências muito diferentes daquelas às quais a origem e o desenvolvimento do conceito de polícia médica estão ligados".
} 
Dessa forma, modificou-se consideravelmente a configuração e a complexidade das relações sociais, as quais deixaram de ser restritas a pequenos grupos sociais e passaram a configurar "uma espécie de afrontamento entre rico e pobre, plebe e burguês", resultando em agitações e levantes urbanos cada vez mais numerosos e freqüentes. Tais fenômenos, apesar de antigos, ganharam uma maior intensidade no século XVIII e contribuíram, dentre outras grandes revoltas contemporâneas, para a Revolução Francesa. (FOUCAULT, 1979, p.86).

$\mathrm{Na}$ Europa, até o século XVII, o "grande perigo social” era relacionado às questões provenientes do campo, sendo as revoltas camponesas decorrentes de más colheitas, aumento de impostos e da pauperização dessas comunidades rurais consideradas os maiores levantes dessa época.

Contudo, no final do século XVIII, enquanto as revoltas no campo diminuíam, as revoltas urbanas passaram a ser mais freqüentes, sobretudo, em razão da formação nesses centros de uma "plebe em vias de se proletarizar". (FOUCAULT, 1979, p. 86).

Nesse contexto, desenvolve-se uma espécie de medo urbano, relacionado à concentração de pessoas nas cidades, à considerável modificação dos costumes e à degradação do ambiente nas oficinas e fábricas e do próprio espaço urbano, que, em termos mais amplos, apontavam para as questões das epidemias urbanas, para a falta de estrutura e de saneamento, bem como, para a irregularidade dos cemitérios. ${ }^{123}$

De tais considerações é possível entender como se desenvolveu a "necessidade de um poder político capaz de esquadrinhar esta população urbana" e desse modo controlar a "inquietude político-sanitária" que acompanhou o crescimento desses centros urbanos. (FOUCAULT, 1979, p. 86).

\footnotetext{
${ }^{123}$ Sobre essas questões, a partir do pensamento de Cabanis, discorre Michel Foucault (1979, p. 87): "Cabanis, filósofo do final do século XVIII, dizia, por exemplo, a respeito da cidade: 'Todas as vezes que homens se reúnem, seus costumes se alteram; todas as vezes que se reúnem em lugares fechados, se alteram seus costumes e sua saúde'. Nasce o que chamarei de medo urbano, medo da cidade, angústia diante da cidade que vai se caracterizar por vários elementos: medo das oficinas e fábricas que estão se constituindo, do amontoamento da população, das casas altas demais, da população numerosa demais; medo, também, das epidemias urbanas, dos cemitérios que se tornam cada vez mais numerosos e invadem pouco a pouco a cidade; medo dos esgotos, das caves sobre as quais são construídas as casas que estão sempre correndo o perigo de desmoronar".
} 
Essa situação de intranqüilidade afetava consideravelmente a burguesia emergente. Uma vez que o poder encontrava ainda centrado nas mãos das autoridades tradicionais, restou àquela classe social outras formas de intervenção, tomando a direção das ações voltadas ao enfrentamento dessas questões político-sanitárias, de modo a reivindicar para si o exercício do poder. (FOUCAULT, 1979, p. 87).

Dentre as estratégias adotadas, destaca-se a retomada e a sofisticação do modelo de intervenção médico e político da quarentena, relacionado historicamente aos regulamentos de urgência que existiam na Europa desde o fim da Idade Média. Tais regulamentos, de maneira geral, implicavam na restrição da liberdade dos indivíduos que deveriam ficar em sua casa, junto à sua família e assim permanecer para serem localizadas e se aferir a sua condição sadia ou enferma.

Para controlar o confinamento das pessoas em suas casas, introduziu-se na França um sistema de divisão da cidade em bairros ou distritos, cada qual sob a responsabilidade de uma autoridade. Esta, por sua vez, deveria supervisionar os inspetores incumbidos de percorrer as ruas, vigiar a permanência das pessoas dentro das casas e aferir suas condições de saúde durante esse período de confinamento. ${ }^{124}$

Esse modelo de quarentena representou o ideal de boa organização sanitária das cidades européias do século XVIII e, como fora discutido, desenvolveu-se a partir das experiências com a lepra e a peste negra durante a Idade Média.

Feitas essas considerações, é possível compreender em que medida essa tecnologia de intervenção social, desde suas origens, está relacionada a um sistema de exclusão baseado no isolamento dos indivíduos com o fim de "purificar o espaço urbano" sendo que, sob essa racionalidade político-sanitária, "medicalizar alguém era mandá-lo para fora e, por conseguinte, purificar os outros". (FOUCAULT, 1979, p. 88).

\footnotetext{
124 Tais inspetores, além de impedir a movimentação das pessoas, estavam incumbidos de diariamente relatar ao prefeito da cidade tudo o que tinham observado, contribuindo de certa forma para a manutenção de um registro centralizado de informações. Dentre suas funções, durante o período de quarentena, constava o dever de contar diariamente os habitantes que se apresentavam à janela de suas casas para informar ao registro geral quais continuavam vivos. Caso alguém não aparecesse, presumia-se que estava doente e, assim, era separado em uma enfermaria especial fora da cidade, sendo, possível através desse sistema de "revista exaustiva dos vivos e dos mortos", a invasão de casas para a sua suposta desinfecção. (FOUCAULT, 1979, p. 88).
} 
Destaca-se, ainda, esse modelo de Medicina Social por ter influenciado não só a política sanitária de outras cidades européias, mas também, a conformação de algumas políticas de saúde no Brasil, como de seu modelo campanhista e autoritário, característico da forma de intervenção da polícia sanitária brasileira, sobretudo, durante a Primeira República. (COSTA; ROZENFELD, 2000, p. 25).

Tal modelo político-sanitário de exclusão foi aperfeiçoado com o desenvolvimento da Medicina Urbana francesa no sentido de não apenas excluir os indivíduos do convívio social em determinados períodos de emergência, mas de estabelecer um constante monitoramento e controle sobre seus corpos e sobre a organização de sua vida social a partir do esquadrinhamento do espaço urbano.

Nesse sentido, o poder político da medicina "evoluiu" daquele modelo descrito de intervenção da Idade Média para um sistema de distribuição dos indivíduos, de seu isolamento, controle e vigilância, sob o argumento de verificar o seu estado de saúde, através da fixação da sociedade num "espaço esquadrinhado, dividido e inspecionado". (FOUCAULT, 1979, p. 89).

Do sistema de simples exclusão passou-se a uma espécie de internamento através da análise minuciosa da cidade, da individualização e do registro permanente. A revista militar substitui a purificação religiosa, como nova forma de organização políticomédica da sociedade.

Dentre os objetivos desse modelo, destacou-se a análise dos lugares de acúmulo tudo que pudesse provocar doenças no espaço urbano. Essa atenção para além dos indivíduos e da doença, propriamente dita, é apontada como um importante avanço para a formulação do saber médico e a organização da sociedade no espaço urbano. ${ }^{125}$

\footnotetext{
${ }^{125}$ Dentre essas modificações, a identificação dos cemitérios como locais de perigo para a saúde apresentase como um ponto essencial. Segundo Michel Foucault (1979), frente à necessidade de "esquadrinhar, analisar e reduzir esse perigo que os mortos constituem", a partir de 1780 teria ocorrido uma considerável emigração dos cemitérios franceses para a periferia das cidades, bem como, a adoção de caixões e sepulturas individualizados. Para o referido autor, tal medida político-sanitária teve grande impacto na própria cultura das "sociedades modernas", posto que da análise dessa evolução depreende-se que o culto aos mortos, tal como modernamente se apresenta, não decorreria do cristianismo, sendo a individualização do cadáver, do caixão e do túmulo uma prática surgida, ao menos na Europa, no final do século XVIII por razões "político-sanitárias de respeito aos vivos" e não por motivos "teológico-religiosos". A título exemplificativo dessa assertiva, o referido autor cita a transferência do Cemitério dos Inocentes do centro de Paris, provocada nessa época pelo apelo de Fourcroy, importante químico do final do século XVIII.
} 
O controle introduzido por essa Medicina Social francesa estendeu-se, de maneira inovadora, também sobre a circulação das coisas e elementos naturais, como a água e o ar, não se restringindo à circulação dos indivíduos.

A partir da teoria dos miasmas, desenvolvida pela ciência do século XVIII, acreditava-se que o ar, a direção dos ventos, e outros elementos atmosféricos, como a umidade, eram grandes fatores patógenos que influenciavam a formação de vapores (miasmas) prejudiciais à saúde, decorrentes da decomposição de matérias orgânicas.

Apresenta-se, então, como objetivo da Medicina Urbana o estabelecimento de uma boa circulação da água e do ar e a organização desses elementos, dos esgotos e demais dejetos humanos, identificados como os principais fatores relacionados às doenças epidêmicas das cidades. Nesse contexto, era defendida a idéia de que, para manter a qualidade do ar e das águas nas cidades, seria preciso viabilizar a sua circulação.

Com a organização do espaço e da vida urbana, medicalizados através dessa Medicina Social francesa, foi promovida a integração da prática médica com outras ciências, como a física e a química que voltavam seus estudos para a análise do ar, da água e suas relações com as condições de vida da população. Integradas pelo processo de urbanização, essas ciências contribuíram para o aperfeiçoamento e disseminação das práticas médicas. ${ }^{126}$

Segundo Foucault (1979, p. 92), tais fatos permitem relacionar o surgimento da medicina científica não a uma simples evolução da "medicina privada, individualizada", mas, fundamentalmente, da socialização e modificação das práticas médicas, como estabelecimento de uma medicina coletiva e social que a inseriu no "funcionamento geral do discurso e do saber científico".

Dessa forma, a Medicina Moderna (e, conseqüentemente, as principais políticas de saúde pública por ela fortemente influenciadas) surge e se desenvolve,

(FOUCAULT, 1979, p. 90).

${ }^{126}$ A esse respeito, destaca-se o papel das comissões formadas por médicos, químicos e outros membros das academias de ciências francesas, no sentido de opinar sobre os melhores métodos de arejamento das cidades, como a construção de grandes avenidas e de corredores de ar e de água. (FOUCALT, 1979, p. 90-91). 
enquanto ciência, a partir da Medicina Urbana enquanto "medicina das coisas: ar, água, decomposições, fermentos; uma medicina das condições de vida e do meio de existência", não restrita ao estudo dos homens isoladamente considerados, servindo para a revalorização da relação entre organismos e o meio natural, que embora inicialmente delineada pelos gregos, com os avanços tecnológicos e científicos do final do século XVIII assume uma nova dimensão. (FOUCAULT, 1979, p. 92). ${ }^{127}$

O restabelecimento da relação entre o meio natural e o organismo aumentou a eficácia da medicina e a compreensão do próprio organismo. Ademais, nesse contexto e em função da medicalização da cidade no século XVIII, cumpre destacar a introdução das importantes noções de salubridade e de higiene pública, centrais para o desenvolvimento da Saúde Pública enquanto prática social efetiva.

A esse respeito, Ediná Alves Costa e Suely Rozenfeld (2000) chamam a atenção para essas duas idéias originárias da Medicina Urbana francesa do século XVIII e sua importância para a Saúde Pública, especialmente para a da Vigilância Sanitária:

[...]. Outro conceito fundamental na constituição da Vigilância Sanitária surgiu no final do século XVIII, na França: a noção de salubridade. Este conceito dizia respeito ao estado das coisas, do meio e de seus elementos constitutivos que, em sendo salubres, favorecem a saúde. Dessa noção, se originou, no século XIX, a de higiene pública, como controle político-científico do meio. (COSTA; ROZENFELD, 2000, p. 21).

Essa noção de salubridade não se confunde com a de saúde, como será tratado mais à frente. A idéia de salubridade relaciona-se à base material para assegurar e melhorar a saúde. Segundo Michel Foucault (1979, p. 93): "Salubridade e insalubridade são o estado das coisas e do meio enquanto afetam a saúde". Ainda segundo o referido autor, dessa noção é que surge posteriormente a noção de higiene pública entendida como "técnica de controle e de modificação dos elementos materiais do meio que são suscetíveis de favorecer ou, ao contrário, prejudicar a saúde”.

\footnotetext{
127 Acerca da importância da Medicina Urbana no desenvolvimento científico da Medicina Moderna, através da atenção ao meio natural e às coisas que circundam os indivíduos, Michel Foucault $(1979$, p. 93) enfatiza: "Não se passou da análise do organismo à análise do meio ambiente. A medicina passou da análise do meio à dos efeitos do meio sobre o organismo e finalmente à análise do próprio organismo. A organização da medicina foi importante para a constituição da medicina científica".
} 
Por fim, há que ser ressaltado que, embora a Medicina Urbana francesa fosse dotada de um caráter autoritário, sua intervenção, ao menos em sua fase inicial, restringiu-se aos espaços comuns e à restrição parcial da liberdade dos indivíduos, não entrando, contudo, em conflito direto com a propriedade privada, considerada um princípio sagrado no contexto liberal francês do século XVIII. ${ }^{128}$

\subsubsection{Medicina dos Pobres e da Força de Trabalho - modelo inglês, século XIX}

A Medicina dos Pobres e da Força de trabalho, conforme o modelo de Michel Foucault (1979), está compreendida na $3^{\text {a }}$ etapa de desenvolvimento Medicina Social, durante o século XIX, como parte do processo de socialização do corpo e assunção da Medicina Moderna como estratégia bio-política pelos Estados.

A partir da experiência inglesa, o citado autor apresenta esse modelo político de saúde pública como o último estágio da Medicina Social. Integra, portanto, seu processo de formação, cujo primeiro objeto de medicalização teria sido o Estado, depois a cidade e, apenas em último lugar, os pobres e trabalhadores.

O modelo inglês difere da Medicina Urbana francesa, caracterizada pelo controle político-científico do meio, na qual os pobres não eram ainda vistos como um perigo para a saúde da população, mas sim o ambiente, o meio natural que circunda e serve de base material para a saúde dos indivíduos. Segundo explica Foucault (1979, p. 94), a característica fundamental do modelo francês de Medicina Social "é a habitação

\footnotetext{
${ }^{128}$ Nesse sentido, destaca Michel Foucault (1979, p. 91-92): “Um ponto, entretanto, não tinha sido tocado até o final do século XVIII, que diz respeito ao conflito entre a medicina e os outros tipos de poder: a propriedade privada. A política autoritária com respeito à propriedade privada, à habitação privada não foi esboçada no século XVIII a não ser sob um aspecto: as caves. As caves, que pertencem ao proprietário da casa, são regulamentadas quanto a seu uso e quanto às galerias que podem ser construídas. Este é o problema da propriedade do subsolo, [...] de saber a quem elas pertenciam. Elaborou-se uma legislação autoritária sobre a apropriação do subsolo que estipulava, em meados do século XVIII, que o subsolo não pertencia ao proprietário do solo, mas ao Estado e ao rei. Foi assim que o subsolo privado parisiense foi controlado pelas autoridades coletivas, enquanto a superfície, ao menos no que concerne à propriedade privada, não o foi. Os espaços comuns, os lugares de circulação, os cemitérios, os ossuários, os matadouros foram controlados, o mesmo não aconteceu com a propriedade privada antes do século XIX. A burguesia que, para sua segurança política e sanitária pretendia o controle da cidade, não podia ainda contradizer a legislação sobre a propriedade que ela reivindicava, procurava estabelecer, e só conseguirá impor no momento da Revolução Francesa. Daí, portanto, o caráter sagrado da propriedade privada e a inércia de todas as políticas médicas urbanas com relação à propriedade privada".
} 
privada não ser tocada e o pobre, a plebe, o povo não ser claramente considerado um elemento perigoso para a saúde da população. O pobre, o operário, não é analisado como os cemitérios, os ossuários, os matadouros, etc".

Dentre as razões pelas quais no século XVIII os pobres não eram identificados como fonte de perigo médico, não figurando como objeto central dos modelos de Medicina Social alemão e francês, encontra-se o aspecto quantitativo dessa parcela da população que, embora crescente, ainda não alcançava números alarmantes nesse período.

Outro importante motivo consiste na função desempenhada pelos pobres na dinâmica daquelas cidades, sobretudo na França, sendo eles os responsáveis pela realização das atividades essenciais ao funcionamento urbano, como serviços de entrega, correspondência, dentre outros, constituindo, dessa forma, parte da própria “instrumentalização da vida urbana”. (FOUCAULT, 1979, p. 94).

Por sua vez, na Inglaterra, a conformação da sua Medicina Social esteve relacionada ao desenvolvimento de sua peculiar política social, fortemente influenciada pelo Puritanismo, enquanto núcleo de valores comuns e aceitos pelas seitas protestantes desde o século XVII, que já na primeira fase mercantilista do capitalismo inglês contribuiu para que a crescente população pobre inglesa recebesse uma atenção diferenciada.

Segundo preleciona George Rosen (1979, p. 191), a partir dos estudos de D. Marshall e K. Schweinitz, após a Idade Média, “um dos resultados do desaparecimento da velha ordem foi o aumento da pobreza" na Inglaterra.

Para Leo Huberman (1983, p. 107), a generalização da miséria, o aumento considerável do número de pobres e de mendigos na Europa durante os séculos XVI e XVII, em pleno período de prosperidade de países como a Inglaterra, Holanda, França e Espanha, tem entre suas principais causas as sucessivas guerras dessa época, como a Guerra dos Trinta anos na Alemanha, em que dois terços da população então existente desapareceu.

Outra importante causa desse fenômeno relaciona-se ao efeito sobre a Europa do influxo de metais preciosos, como o ouro e a prata das colônias espanholas na América e a sua rápida circulação em decorrência da abertura e expansão do capitalismo 
comercial europeu em nível internacional. ${ }^{129}$

Dessa forma, o total de dinheiro em circulação aumentou consideravelmente, desvalorizaram-se as moedas nacionais, reduzindo a capacidade aquisitiva da população em geral, e, conseqüentemente, "uma verdadeira revolução nos preços, tal como ocorrera apenas três ou quatro vezes nos últimos mil anos da história mundial". (HUBERMAN, 1983, p. 109).

Esse aumento dos preços, embora benéfico para os mercadores da época, acabou por prejudicar fortemente vários setores, dentre os quais os governos (que "tinham dificuldades cada vez maiores em equilibrar a receita e a despesa"), os trabalhadores assalariados e a classe dos proprietários que viviam da renda fixa de anuidades, pensões e de outros bens que produziam um juro fixo. (HUBERMAN, 1983, p. 112-113).

Em termos gerais, tais modificações não só levaram ao empobrecimento da população como também à modificação das estruturas sociais e econômicas do final do século XVIII e começo do século XIX, fazendo desaparecer a "velha idéia de que a terra era importante em relação ao total de trabalho sobre ela executado". A esse respeito, sintetiza Leo Huberman (1983, p. 118):

[...] O desenvolvimento do comércio e indústria, e a revolução dos preços, tornaram o dinheiro mais importante do que os homens, e a terra passou a ser considerada como fonte de renda. As pessoas haviam aprendido a tratá-la como tratam a propriedade em geral - tornou-se um brinquedo de especuladores que compravam e vendiam pela oportunidade de fazer dinheiro. O movimento de fechamento das terras provocou muito sofrimento, mas ampliou as possibilidades de melhorar a agricultura. E quando a indústria capitalista teve a necessidade de trabalhadores, encontrou parte da mão-de-obra entre esses infelizes desprovidos de terra, que haviam passado a ter apenas a sua capacidade de trabalho para ganhar a vida.

Nesse contexto, inserem-se, inicialmente, diversos atos referentes aos pobres,

\footnotetext{
129 Conforme explica Leo Huberman (1983), em sua História da Riqueza do homem, o "[enorme suprimento de prata, levado da América para a Espanha] circulava por toda a Europa tão logo era desembarcado. Os reis da Espanha travaram uma série de guerras tolas, uma após a outra — e pagavam em dinheiro pelo abastecimento e pelos soldados. Os espanhóis compravam mais do que vendiam [...] e o dinheiro lhes fugia das mãos para os bolsos dos mercadores que os abasteciam". (HUBERMAN, 1983, p. 108-109).
} 
consolidados na Lei dos Pobres Elizabetana de 1601, "que se tornou a base da administração inglesa da Lei dos Pobres por mais de dois séculos”. (ROSEN, 1979, p. 191).

A referida Lei de 1601, em princípio, não tratava especificamente de assuntos de saúde, voltando-se apenas ao socorro dos "aleijados, fracos, velhos, cegos e outros que sejam pobres e incapazes para o trabalho". (ROSEN, 1979, p. 192).

Contudo, na prática, a Lei dos Pobres foi sendo gradativamente ampliada para incluir a atenção médica e outros serviços de saúde, de modo a representar um marco importante no processo evolutivo dos serviços de saúde e da atuação do Estado inglês em seus cuidados e controle. (SINGER; CAMPO; OLIVEIRA, 1981, p. 17).

Essa tendência assistencial, tal como estabelecida em 1601, não persistiu por muitos anos. A Guerra Civil entre os partidários do rei Carlos I da Inglaterra e o Parlamento, liderado por Oliver Cromwell, de 1642 a 1649, desorganizou a administração da Lei dos Pobres, prenunciando uma considerável alteração na abordagem dessas questões sociais.

A pobreza passou, então, a ser encarada como uma "vergonhosa doença social [...], uma abominação, causada por falta de vigor moral e labuta sistemática". (ROSEN, 1979, p. 192-193).

Em função da expansão do pensamento mercantilista, somou-se a esse quadro que associava a pobreza a um vício individual, eticamente condenado, a sua identificação como "uma fonte potencial de lucro para o Estado, e, além disso, uma conveniência pública". 130

Nesse primeiro momento, destaca-se o desenvolvimento da aritmética política com os trabalhos de William Petty, sua atenção à análise funcional e quantitativa dos problemas econômicos e sociais, que, "na busca de regularidades matemáticas em

\footnotetext{
${ }^{130}$ De acordo com George Rosen (1979, p. 193): “[...] Durante a Commonwealth, foram propostos projetos relativos ao pobre e à utilização de seu trabalho; o número destas propostas aumentou muito nas décadas seguintes à Restauração. Podemos encontrar nestas propostas uma mistura de finalidades, entre as quais se sobressaem as considerações mercantilistas e a perspectiva de lucro. Com uma notável perspicácia, procurou-se computar o custo nacional da ociosidade, assim como determinar, através de cálculos elaborados, em quanto a riqueza nacional aumentaria se os pobres da Inglaterra se tornassem produtivos".
} 
acontecimentos humanos como nascimentos, mortes e incidência de doenças", acabou sendo posteriormente considerado como um dos "pioneiros da estatística com sua obra sobre mortalidade publicada em 1662”. (ELIAS, 2004, p. 42).

Inserido no pensamento mercantilista da época, a partir da teoria política hobbesiana, no sentido da razão de Estado em que o governo pode estabelecer quaisquer políticas e medidas para aumentar o poder e a riqueza nacionais, William Petty destacou as implicações econômicas e sociais dos problemas de saúde, sendo suas opiniões consideradas a maior contribuição inglesa anterior ao século XIX nesta área do pensamento social. $^{131}$

A despeito desse desenvolvimento teórico, a Inglaterra não chegou a implementar uma política social uniforme em função das características administrativas de seu governo entre 1662 e a emenda à Lei dos Pobres de 1834, de modo que a concessão e gestão dos benefícios previstos aos pobres ficaram restritas aos interesses da administração eclesiástica, em nível paroquial. Conforme explica George Rosen (1979, p. 206-207):

Durante o início deste período, idéias, propostas e programas relacionando os aspectos sociais da saúde tomaram como pontos de partida tanto a responsabilidade da paróquia, no que diz respeito ao atendimento aos pobres quanto o desejo de aumentar a riqueza nacional empregando em manufaturas os destituídos. A Lei dos Pobres elizabetana determinava que a paróquia daria o 'necessário auxílio aos aleijados, incapazes, velhos, cegos e outros... incapazes para o trabalho, e eventualmente o alcance desta provisão veio a incluir a atenção médica. Tal provisão em relação ao doente significava que a paróquia tinha que assumir responsabilidades consideráveis. Entretanto, os

\footnotetext{
${ }^{131}$ Nesse sentido George Rosen (1979) destaca a essa contribuição de William Petty, resumindo suas as principais idéias: “[...] Para Petty, a importância política e econômica da população era básica. Conseqüentemente, qualquer medida destinada a prevenir danos à população, por doença e morte, era objeto de profunda consideração. O controle da doença transmissível, especialmente da peste, e a diminuição da mortalidade infantil seriam, de acordo com Petty, de grande valia para se alcançar tal objetivo. Esta convicção permeia várias de suas sugestões para o combate à peste e para a criação de maternidades. [...] Petty recomendava a criação de hospitais de isolamento para onde os pestosos seriam removidos e onde receberiam atenção médica. [...] Ele também pedia a criação de maternidades, pensando particularmente nas mulheres grávidas que não fossem casadas. Petty considerava que, em troca de tal iniciativa governamental, as crianças ficariam sob a custódia do Estado e o serviriam durante 25 anos, aumentando conseqüentemente as reservas de mão-de-obra do país. Ele também acreditava que alguns outros grupos da população eram de relevância imediata para o governo, aqueles estimados como os mais produtivos - fazendeiros, manufatureiros, comerciantes, marinheiros e soldados. Em sua opinião, estas profissões 'são os pilares de qualquer comunidade'. Por este motivo, sugeriu a realização de estudos sobre morbidade e mortalidade nas diferentes profissões”. (ROSEN, 1979, p. 202).
} 
oficiais paroquiais geralmente não tinham nem o treinamento para desempenhar tais funções nem o desejo de fazê-lo. Esta situação deu origem, na administração paroquial, à prática comum de contratar particulares para realizar tarefas públicas. Este sistema de 'contratar' ou de 'arrendar o pobre' tornou-se um traço característico da administração inglesa da Lei dos Pobres [sic] do século XVIII. Seguindo essa característica geral, os oficiais paroquiais freqüentemente contratavam um médico local para tratar dos pobres. [...] A prática de arrendar funções públicas, como a do atendimento ao pobre, tornou-se popular porque era considerada uma oportunidade para redução de impostos. Um sistema desse tipo estava destinado a permitir abusos. Entretanto, deve-se reconhecer que uma certa atenção médica foi dada e que o tipo de administração desenvolvida nesta área teve influência na elaboração posterior de planos voltados para a oferta de atenção médica.

Assim, já no século XVII, antes mesmo das questões econômicas e sociais levantadas pela Revolução Industrial, é possível destacar um distinto tratamento dessa população pobre, alvo de específicas políticas sociais e de atenção médica, conformadas por uma corrente de pensamento que, posteriormente, serviria de base para a “combinação de utilitarismo, comercialismo e filosofia experimental que caracterizou a abordagem aos problemas sociais no período seguinte à Restauração e durante o século XVIII”. (ROSEN, 1979, p. 196).

Em relação à identificação e ao tratamento da população pobre como fonte de perigo, em sentido amplo, não restrito ao caso inglês, na Europa tais modificações teriam surgido apenas após a metade do século XIX, relacionando-se diretamente a importantes questões políticas e econômicas.

Dentre essas razões, destaca-se a considerável força política alcançada pela população pobre, capaz de se revoltar e participar de grandes levantes sociais, como as Revoluções Francesa e Industrial e demais agitações do começo do século XIX..

Tais agitações podem ser associadas às modificações ocorridas na organização e execução dos serviços essenciais para a instrumentalização da vida urbana (v.g. sistema postal de carregadores) que, a partir do século XIX, deixaram de ser executados pelos pobres, contribuindo para "uma série de revoltas populares" pela perda da possibilidade de subsistência que tais serviços lhes garantia. (FOUCAULT, 1979, p. 94).

Por sua vez, até o surgimento da grande cólera de 1832 que se propagou por toda a Europa, atingindo mais a população proletária e plebéia, a coabitação no mesmo 
tecido urbano entre ricos e pobres ainda não era considerada um perigo sanitário e político para a cidade. Só então é que se decidiu dividir o espaço urbano que passou a ser organizado em bairros pobres e ricos, graças à extensão do poder político, nos moldes da Medicina Urbana francesa, também sobre o direito da propriedade de habitação privada. (FOUCAULT, 1979, p. 95).

Embora coexistissem na Inglaterra alguns projetos inspirados tanto no modelo alemão quanto francês, surge uma nova forma de Medicina Social no século XIX relacionada ao avançado estágio industrial inglês, à emergência de necessidades econômicas e operacionais específicas dessa emergente organização capitalista e ao agravamento das questões sociais citadas.

George Rosen (1979) destaca os aspectos econômicos e estratégicos do desenvolvimento do capitalismo industrial inglês que contribuíram para a reformulação da organização do serviço de atendimento aos pobres na Inglaterra do século XIX.

Nesse sentido, a assistência aos pobres legada pelo sistema pré-industrial era vista pelos "líderes do novo industrialismo" como um obstáculo "irracional" na medida em que, além de garantir a assistência aos pobres capazes, sua organização e as respectivas leis de moradia que os prendiam à sua paróquia, geravam uma imobilidade entre o campo e as cidades, assistindo ao trabalhador rural desempregado ou subempregado, de forma a manter uma reserva de mão-de-obra rural contrária às necessidades da “civilização industrial que surgia”. (ROSEN, 1979, p. 228).

Em defesa de uma oferta "perfeitamente elástica" de mão-de-obra para a indústria, "livre" para o jogo do interesse econômico, os ideólogos dessa visão economicista de progresso industrial postulavam a regulação da pobreza e ociosidade com base na razão e necessidade ao invés de uma provisão legal dirigida aos pobres que serviria apenas para o "incitamento à ociosidade".

Dessa forma, os "pobres deviam ser compelidos a se defenderem sozinhos e estimulados a se ajudarem sendo econômicos", fazendo-se necessária a remoção dos impedimentos sociais da época para "assim libertar o imenso potencial de iniciativa 
individual". (ROSEN, 1979, p. 229). ${ }^{132}$

Em 1832, o Parlamento inglês cria uma Comissão Real sob a responsabilidade de Edwin Chadwick, que viria a formular o relatório de 1834 sobre a administração e o funcionamento da Lei dos Pobres. Segundo George Rosen (1979, p. 231):

O Ato de Emenda à Lei dos Pobres, que se tornou lei em 14 de agosto de 1834, incorporava os princípios do Relatório e os implementava. As providências do Ato podem ser divididas em duas partes, uma englobando os princípios que previam o atendimento ao pobre, ou tratando da nova máquina administrativa. Os princípios previam atendimento bastante restrito. Pessoas capazes e suas famílias não deviam receber assistência, a não ser em uma casa de trabalho bem regulada. Além disso, o grupo de pobres capazes devia ser "menos beneficiado" ou, em outras palavras, mais miserável que o trabalhador na pior colocação fora da casa de trabalho. Quanto à parte relativa à administração, o traço marcante era o empenho em assegurar centralização, uniformidade e eficiência.

Tal reformulação em 1834 da Lei dos Pobres de 1601 dá início, então, à socialização da medicina inglesa por meio do controle médico do pobre nela prescrita.

Para se beneficiar dessa nova assistência social, os pobres deviam se submeter a diversas formas de controle médico, ou seja, à "assistência controlada", introduzida como forma de proteção das classes ricas através da garantia da saúde das classes pobres. (FOUCAULT, 1979, p. 95).

Ainda segundo Foucault (1979, p. 96), a Lei dos Pobres foi apenas o primeiro elemento desse sistema, sendo complementada posteriormente, por volta de 1870, "com a organização de um serviço autoritário, não de cuidados médicos, mas de controle médico da população".

Nesse contexto, em 1875, vários sistemas de Health Service e Health Officers (chegam a mil sistemas no final do século XIX) passam a ser implementados, com as seguintes funções: (i) Controle de vacinação obrigatória; (ii) Organização do registro de

\footnotetext{
132 A racionalidade desse entendimento tem suas bases no princípio da empresa privada como a mola principal do progresso social, fundada em bases teóricas como a doutrina da necessidade filosófica centrada na crença na ordem natural da sociedade —, a economia política de Adam Smith, Malthus e Ricardo, bem como a filosofia administrativa de Bentham. (ROSEN, 1979, p. 228).
} 
epidemias e doenças perigosas com a declaração compulsória pelas pessoas, e (iii) Identificação e eventual destruição de lugares e focos de insalubridade.

O Health Service complementou a Lei dos Pobres, pois, diferentemente desta, não se restringiu à implementação de serviços médicos destinados apenas aos pobres e sim a toda a população, geralmente com cuidados médicos que tinham por objeto a coletividade com medidas preventivas similares às da Medicina Social Urbana francesa. Pode-se, portanto, considerar que o Health Service como a continuação dos controles garantidos pela Lei dos Pobres, ampliando o controle das classes mais pobres em sentido coletivo.

Essa nova forma de controle que, embora coletivo, destinava-se prioritariamente às classes pobres caracterizou o Health Service inglês e encontrou forte resistência popular através de pequenas insurreições anti-médicas na Inglaterra durante a segunda metade do século XIX. (FOUCAULT, 1979, p. 96).

Tal resistência popular à medicina organizada como forma de controle, à medicalização autoritária proposta por esse sistema de saúde pública, ocorreu não só na Inglaterra, como em diversos países, contando, inclusive, com o apoio de grupos de dissidência religiosa durante o século XIX. Tem-se, portanto, uma espécie de luta pelo direito a não se submeter à medicina oficial, ou seja, a reivindicação do direito sobre o próprio corpo contra a medicalização autoritária.

Não restrita a países protestantes, em países católicos teria ocorrido similar reação de grupos religiosos e da população pobre contra esse modelo de Medicina Social dos Pobres, sendo a experiência inglesa apenas um exemplo (v.g. o significado da peregrinação de Lourdes que se iniciou no final do século XIX). (FOUCAULT, 1979, p. 96).

A característica diferenciada da Medicina Social inglesa do século XIX em relação à Medicina de Estado alemã e à Medicina Urbana francesa do século XVIII consiste em ser aquela "essencialmente um controle da saúde e do corpo das classes mais pobres para torná-las mais aptas ao trabalho e menos perigosas às classes mais ricas" (FOUCAULT, 1979, p. 97).

Sua importância reside no fato de ter sido o modelo que persistiu, servindo de base para a organização da medicina e das políticas nacionais de saúde durante o final do 
século XIX e a primeira metade do século XX.

Tal foi possível pois, diferentemente dos citados sistemas alemão e francês, a Medicina Social inglesa permitiu a realização de três sistemas médicos sobrepostos e coexistentes: "uma medicina assistencial destinada aos mais pobres; uma medicina administrativa encarregada de problemas gerais como a vacinação, as epidemias, etc; e uma medicina privada que beneficiava quem tinha meios para pagá-la”. Assim, foi possível relacionar "assistência médica ao pobre, controle de saúde da força de trabalho e esquadrinhamento geral da saúde pública, permitindo às classes mais ricas se protegerem dos perigos gerais". (FOUCAULT, 1979, p. 97).

Posteriormente, com o advento do plano Beveridge, esse sistema sanitário inglês de que articula os três setores da medicina, o assistencial, o administrativo e o privado, teria sido exportado com algumas alterações para "os sistemas médicos dos países mais ricos e industrializados da atualidade [segunda metade do século XX]" (FOUCAULT, 1979, p. 98).

\subsubsection{Plano Beveridge e a saúde no Estado de Bem-Estar Social Europeu}

Pretende-se, neste tópico, verificar o valor simbólico do Plano Beveridge no contexto da Segunda Guerra Mundial e a inserção da saúde na nova dimensão dos direitos e encargos assumidos pelo Estado Moderno.

A partir do modelo inglês de Medicina Social e de sua expansão para os demais países desenvolvidos, descritos por Michel Foucault (1974, 1979), será discutida em que medida a introdução da saúde na macroeconomia, a socialização dos riscos e déficits da saúde no século XX e o desenvolvimento de algumas políticas públicas européias de bem-estar podem contribuir para a compreensão de sistemas sanitários modernos, como o brasileiro.

O Plano Beveridge insere-se na reconstrução da Europa no segundo pósguerra do século XX. De acordo com Kathleen Jones (1991), ainda durante a Segunda Guerra, o governo britânico foi levado a rever suas políticas e serviços sociais em 
resposta às expectativas dos sistemas sociais e da população em geral quanto à reorganização do país em termos de uma sociedade mais igualitária, capaz de garantir uma efetiva retribuição pelo esforço de guerra que vinha sendo exigido. ${ }^{133}$

Segundo José Corrêa Villela (2006, p. 72-73), as propostas contidas nesse plano, mais do que uma simples inovação, podem ser entendidas como uma reavaliação das medidas sociais que vinham sendo desenvolvidas na Grã-Bretanha, desde a reforma à Lei dos Pobres em 1834, que permitiu traçarem-se os caminhos para a reestruturação da política social inglesa. Nesse sentido, afirma:

O primeiro trabalho do Comitê foi fazer um balanço sobre tudo o que houvesse em termos de seguros sociais e serviços similares, mostrando o que existia e o que tinha para ser implantado de forma a suprir as carências e necessidades dos ingleses. Chegou-se a conclusão de que havia: deficiência em termos de serviços de saúde, subsídios para funeral e socorros para maternidade; órgãos administrativos complexos, desconexos e de custo elevado, que, por conseqüência, não ofereciam bom rendimento ( $\S 1^{\circ}$ a $3^{\circ}$ do Relatório). (VILLELA, 2006, p. 75). ${ }^{134}$

O governo de coalizão de Winston Churchill apresentou ao parlamento inglês em 1942 o referido Plano Beveridge, formalmente denominado Social Insurance and Allied Services, coordenado por William Beveridge, ex-diretor da London School of

\footnotetext{
${ }^{133}$ Para a referida autora, as demandas da população britânica em torno das políticas de reconstrução não se limitavam aos efeitos da Segunda Grande Guerra, mas remontavam ao período entre guerras, à década de 1930, às conseqüências econômicas e sociais ainda decorrentes da Primeira Guerra Mundial. Nesse sentido explica a preocupação do Estado em elaborar, ainda no curso da Segunda Guerra, um plano de reconstrução do país que seguiria a retomada da paz: "[...] The demand and the response came less out of wartime experience, which was then of under two years' duration, than out of the still recent memories of the 1930s. One generation of men had fought a war, and had been kept. There was a grim determination that this should not happen again. Politicians who wanted to mobilize effort for victory could only call on the people to makes sacrifices if the they demonstrated clearly that new promises would be mad, and that this time they would be fulfilled". (JONES, 1991, p. 122).

${ }^{134}$ Nesse sentido, complementa José Corrêa Villela (2006, p. 77): "O Comitê que Beveridge presidia fez uma fusão da legislação esparsa já existente, ampliando-a e consolidando-a; padronizou os benefícios existentes e incluiu novos: seguro acidente de trabalho, abono familiar (ou salário família), seguro desemprego e outros seis auxílios sociais: auxílio funeral, auxílio maternidade, abono nupcial, benefícios para esposas abandonadas, assistência às donas de casa enfermas e auxílio-treinamento para os que trabalhavam por conta própria. No diagnóstico da miséria, o Comitê apontava como suas causas: salários insuficientes para manter a família, interrupção e perda dos salários e a falta ou a insuficiência de um plano estatal de seguro social que atendesse realmente as pessoas durante a ocorrência de qualquer risco (doença, incapacidade, velhice, viuvez, desemprego). Também apontava que deveria melhorar a assistência à infância, como forma de incentivar o nascimento de filhos, bem como elaborar um projeto de reabilitação, de forma a readaptar o acidentado ou o desocupado e proporcionar, novamente, sua inserção no mercado de trabalho (§§ 11 a 13)”.
} 
Economics, nomeado chefe da comissão responsável pela revisão das políticas de seguro social e pelo estudo de propostas para a reconstrução do país no pós-guerra, em 1941 por Arthur Greenwood, então ministro do conselho de guerra britânico. (VILLELA, 2006, p. 74). ${ }^{135}$

Embora interpretado como uma proposta ambiciosa e não realista por boa parte do Partido Conservador, sendo sua implementação reconsiderada por Winston Churchill, houve um imediato reconhecimento popular de que esse plano era dirigido a uma Inglaterra mais igualitária e propunha um amplo sistema de Segurança Social.Tal visão foi corroborada e de certa forma difundida por sua síntese na famosa frase "from the cradle to the grave" (do berço ao túmulo), utilizada pela imprensa para se referir ao Plano Beveridge, o que aumentou a notoriedade de seu propositor. (JONES, 1991, p. 130). ${ }^{136}$

Rejeitado inicialmente o Plano Beveridge, o governo passou a elaborar, entre 1943 e 1945, outro estudo denominado White Paper Chase que, ao contrário do primeiro, resumia-se a "tímidas incursões nas áreas da saúde, educação, seguro social, questões agrárias e outras poucas questões sociais”. (CORREIA; CORREIA, 2002, p. 10).

Seguiu-se a essa contraproposta um debate público histórico sobre a política social inglesa com a participação de diversos grupos representativos em todo o país, inclusive dentro das Forças Armadas, o que levou à retomada do Plano Beveridge logo após

\footnotetext{
${ }^{135}$ Embora o referido trabalho tenha sido realizado em conjunto com outras pessoas, em seu relatório final restou apenas a menção a Sir William Beveridge. Kathleen Jones (1991), ao tratar dessa particularidade, refere-se à responsabilidade assumida por Beveridge sobre as propostas políticas presentes no referido relatório que, segundo ele, não poderiam ser reduzidas à expressão de opinião dos civis que participaram de sua elaboração, mas sim que deveriam ser encaminhadas como uma importante questão política para a decisão ministerial e, alguns pontos, para a própria decisão do governo como um todo. Nesse sentido, a referida autora transcreve a justificativa do próprio William Beveridge, nomeado "chairman" para esse trabalho: "All the members of the Committee other than the Chairman are civil servants. Many of the matters deal with in the Report raise questions of policy, on which it would be inappropriate for any civil servant to express an opinion except on behalf of the Minister to whom he is responsible; some of these matters are so important as to call for decision by the Government as a whole". (JONES, 1991, p. 125).

${ }^{136}$ Sobre a inicial recusa de seu plano de reconstrução social do país no pós-guerra pelo governo, a despeito do crescente prestígio e reconhecimento pessoal que the foi conferido pelo povo inglês e pela comunidade internacional William Beveridge, em sua autobiografia, teria assim se manifestado, segundo a transcrição de Kathleen Jones (1991, p. 131): “[...] while the British people and the free world outside Britain were applauding the Minister the Beveridge Report, the Government of Britain, other than the Minister of Information, showed to the report an attitude of marked reserve, and to its author an attitude which developed from ignoring him into boycott".
} 
o fim da guerra com a subida ao poder do Partido Trabalhista inglês. (JONES, 1991, p. 132). ${ }^{137}$

Em linhas gerais, as bases dessa proposta podem ser sintetizadas a partir das seguintes diretrizes que moldaram a sua elaboração:

(i) consideração de experiências passadas e a tentativa de não se deixar levar por interesses setoriais como aqueles que dificultaram a aprovação do National Insurance Act de 1911, aproveitando-se a união social promovida pela guerra;

(ii) eleição de cinco questões principais a serem atendidas pelo plano com o objetivo de promover não apenas segurança social, mas viabilizar uma política mais global de progresso para o país, denominadas os "cinco gigantes na estrada da reconstrução" (five giants on the road to reconstruction), quais sejam: Necessidade (Want), Doença (Disease), Ignorância (Ignorance), Carência (Squalor) e Desemprego (Idleness);

(iii) implementação do plano por meio da cooperação entre Estado e indivíduo, sendo a segurança social promovida pelo Estado garantida aos indivíduos e suas famílias através de suas contribuições. (JONES, 1991, p. 126).

Ademais, com o referido plano, buscava-se organizar a administração, o financiamento e a seleção dos benefícios a serem ofertados por esse novo sistema de segurança social com base em seis princípios fundamentais: (i) benefício uniforme; (ii) contribuição em quotas justas; (iii) unificação da responsabilidade administrativa;

\footnotetext{
${ }^{137}$ A esse respeito, ao reconstituírem o histórico e a importância do Plano Beveridge para a consolidação da idéia de Seguridade Social, sobretudo das linhas gerais da Previdência Social, Marcus Orione Gonçalves Correia e Érica Paula Barcha Correia (2002) tecem as seguintes considerações sobre a sua implementação: "É estranho que Beveridge, um liberal como se autodenominava, após realizar um Plano extremamente social, tivera este rejeitado exatamente pelos liberais (Partido Conservador e Churchill). Mais estranho ainda é que pouco após, entre 1944 e 1949, com a ascendência de um governo trabalhista ao poder, tenha esse liberal tido o seu Plano implementado. Exatamente após a repulsa conservadora de um plano por demais utópico, o Partido Trabalhista inglês implementou os "cinco gigantes" - referência às cinco metas principais - do Plano Beveridge. [...] Percebe-se que, a despeito de talhado por um liberal para liberais, o Plano acabou por ser utilizado por socialistas rumo ao socialismo. Na origem, portanto, a Previdência Social se adequava perfeitamente ao Estado Socialista, sendo que o Welfare State se apoderou da idéia, adaptando-o às suas necessidades" (CORREIA; CORREIA, 2002, p. 10).
} 
(iv) benefício adequado; (v) compreensão (comprehensiveness) — entendida como a promoção de todas as necessidades básicas e previsíveis da população - e (vi) classificação dos setores da população a ser atendida em seis classes: empregados, autônomos, donas de casa, outros com idade de trabalho, aqueles muito jovens ou em idade demasiadamente avançada para proverem-se. (VILLELA, 2006, p. 79-80).

Destaca-se entre suas prioridades a preocupação especial não apenas com a pensão por idade como também com a atenção destinada à infância e à doença, depreendida dos cuidados destinados às crianças e das propostas para a construção de um efetivo sistema de saúde e pleno emprego. (CORREIA; CORREIA, 2002, p. 09). ${ }^{138}$

No que diz respeito especificamente à saúde, segundo Villela (2006, p. 83):

Uma das justificativas do Comitê para a implantação de um serviço de saúde e reabilitação era o fato de que a ausência desses serviços sobrecarregaria os custos com benefícios e reabilitações. Portanto, para diminuir tais custos haveria necessidade de se implantar uma medicina preventiva; os patrões deveriam ser mais cautelosos com relação à saúde dos trabalhadores, diminuindo assim a sua contribuição sobre os riscos; etc. ( $\S 426$ a 437).

É importante frisar a ruptura do trabalho organizado por William Beveridge com as políticas assistenciais inglesas anteriores, não obstante tenha partido inicialmente de uma proposta de reavaliação e sistematização das mesmas nos termos de sua primeira diretriz citada. Apresenta-se tal ruptura na medida em que em seu novo plano três coisas foram propostas: (i) o fim da visão vitoriana de caridade; (ii) que as empresas comerciais de seguro não fossem excluídas desse mercado apesar da consistente proposta de atuação

\footnotetext{
${ }^{138}$ Sobre essas questões específicas, vale a transcrição de sua síntese feita por José Corrêa Villela (2006, p. 82-83): "Várias questões ligadas aos subsídios à infância estão contidas nos $\S \S 410$ a 425, com um estudo detalhado sobre as necessidades das crianças em função de vários parâmetros: números de filhos; idade; pais empregados ou não; problemas que poderiam advir do subsídio, como por exemplo, ter filhos somente para ter direito; a baixa taxa de natalidade requeria um incentivo ao nascimento; família com menos posses deveriam ter as mesmas condições de criar seus filhos de maneira similar àquelas que as têm; responsabilidade deveria ser do Estado para o pagamento de tais benefícios e não advir de contribuições dos segurados ao Fundo de Segurança Social; o valor de benefício deveria ser escalonado de acordo com o número de filhos, pois alguns gastos seriam comuns entre eles, por exemplo, etc. Como forma de atacar o outro problema - a velhice - , o Relatório continha uma proposta, de aplicação imediata, para conceder, de direito - em decorrência das contribuições pagas - pensões adequadas a todos os idosos que haviam contribuído, sem necessidade de prova de falta de recursos, por um período de vinte anos. No caso de falta de recursos, as pensões assistenciais teriam valores diferentes daquelas contributivas, e nesse caso, a prova da pobreza seria obrigatória ( $§ 16$, com remissão aos $\S \S 254-257$ )”.
} 
estatal nessa área de seguro social, e (iii) a garantia da liberdade individual de escolha, no sentido dos princípios liberais por ele defendidos. (JONES, 1991, p. 126).

Dessa forma é confirmada a articulação, descrita por Foucault (1979, p. 98), dos aspectos assistencial, administrativo e privado da Medicina Social inglesa no novo sistema de segurança social inaugurado pelo Plano Beveridge.

No que diz respeito ao sistema sanitário inglês, este passou então a se desenvolver, na origem do Welfare State britânico com a eleição dos trabalhistas em 1945, tendo o Plano Beveridge um importante papel na conformação tanto do National Insurance Act quanto do National Health Service Act, ambos de 1946. Este último, tinha por fim estabelecer um serviço de saúde público e gratuito capaz de responder pela saúde física e mental da população assegurando a prevenção, o diagnóstico e o tratamento de doenças do que resultou o National Health Service (NHS) em 1948. ${ }^{139}$

Os planos para o Serviço Nacional de Saúde inglês (National Health Service) passaram por um longo debate, desde o começo de 1943, envolvendo complexas questões, dentre as quais se destacam, como principais problemas, a incorporação dos hospitais voluntários, municipais e privados de grande prestígio a esse novo sistema centralizado no Ministério da Saúde, bem como o enfrentamento de questões corporativistas como a da classe médica que tinham interesse em manter sua autonomia profissional não estando os médicos dispostos a se tornarem empregados assalariados desse serviço público. (JONES, 1991, p. 140).

Somente após o Partido Trabalhista assumir o governo e nomear Aneurin Bevan para ministro da saúde, graças às extensas negociações por ele travadas com os grupos de interesse, foi possível aprovar em 1946 a lei referente a esse novo Serviço Nacional de Saúde, o National Health Service Act, que por questões administrativas só

\footnotetext{
139 Cumpre ressaltar que, segundo Villela (2006, p. 76), seria "um equívoco confundir o Welfare State inglês com o Plano Beveridge", devendo este ser entendido como um dos três pilares, ao lado da educação e saúde, que viriam a resultar no Estado de Bem-Estar Social britânico. Em que pesem a correção dessa observação e os novos debates e estudos que se seguiram a esse plano, sobretudo quanto à organização dos novos serviços nacionais de saúde, em termos simbólicos é inegável a importância do Social Insurance and Allied Services "beveridgiano" para a retomada da saúde/doença entre as cinco grandes questões sociais ("the five giants on the road to reconstruction") por ele projetadas amplamente na opinião pública inglesa a partir de 1942.
} 
viria a iniciar seus trabalhos em 5 de julho de $1948 .{ }^{140}$

Em sua redação final, todos os tipos de hospitais passaram de alguma forma para o controle do Ministério da Saúde, embora com dois status diferentes. Dessa forma, a maioria dos hospitais, tanto aqueles previamente voluntários, municipais ou privados, foram submetidos à administração de Regional Hospital Boards (RHBs), que podem ser entendidos como Conselhos ou Juntas Hospitalares Regionais, num total de 13 RHBs, delimitados territorialmente com base nas 13 áreas de defesa aérea civis fixadas ainda no tempo da guerra.

Esses mesmos hospitais, em um grau de menor complexidade administrativa, tinham parte de suas questões tratadas por comissões, Hospital Management Committees, cada qual responsável por um pequeno grupo de hospitais em uma área específica.

Por sua vez, graças a um "engenhoso compromisso", os grandes hospitais voluntários que gozavam de um maior status e prestígio, relacionados ao seu destacado papel no treinamento médico e desenvolvimento de pesquisas em saúde, recusando-se a essa submissão, foram excetuados dessa estrutura, passando a serem designados de "teaching hospitals" (hospitais de ensino). Nesse sentido, cada RHB ficaria relacionado a um desses centros de ensino, que estavam ligados a uma universidade de medicina.

Assim, os hospitais da Inglaterra e do País de Gales teriam sido incorporados nesses termos ao Serviço Nacional de Saúde com exceção de poucas instituições privadas ou caritativas descredenciadas pelo Ministério da Saúde, geralmente a seu próprio

\footnotetext{
${ }^{140}$ Retomando, ainda que superficialmente, as interações entre os sistemas sociais e os sistemas psíquicos no sentido de como cada sistema interpreta a realidade de seu entorno em seus processos de dotação de sentido a partir de suas próprias referências, é interessante citar o histórico pessoal do então ministro da saúde inglês, Aneurin Bevan, que embora não tenha por si só levado a cabo o novo plano de serviços à saúde, tem reconhecidamente um importante papel na luta por sua implementação, sendo, nas diversas obras referentes a esse tema (JONES, 1991; BBC, 2006; WIKIPÉDIA, 2006), destacado a sua origem pobre e os problemas de saúde de seu pai, mineiro do Sul do País de Gales que o levaram não apenas a lutar pelo fim da Lei dos Pobres como a defender a necessidade premente de um Serviço Nacional de Saúde. A esse respeito, afirma Kathleen Jones (1991, p. 141): "Bevan, formerly a miner from South Wales, had his own very strong views about both the abolition of the Poor Law and the need for a National Health Service. His father, also a miner, had died from pneumoconiosis - and without compensation from the mine owners, because the condition was not then scheduled as an industrial disease". Nesse mesmo sentido, consta de sua biografia no website da BBC (2006): "Aneurin Bevan was one of the most important ministers of the post-war Labour government and the chief architect of the National Health Service. His father was a miner and the poor working class family in which Bevan grew up gave him first-hand experience of the problems of poverty and disease".
} 
pedido. (JONES, 1991, p. 141).

Os médicos responsáveis pelas consultas foram empregados nessas Juntas Hospitalares Regionais (Regional Hospital Boards) ou em secretarias dos governadores (Board of Governors), sendo-lhes, contudo, permitido trabalhar em uma base seccional que lhes deixasse tempo para atender a pacientes particulares. (JONES, 1991, p. 141142).

A Clínica geral passou a ser administrada por Conselhos Executivos (Executive Councils), com comissões separadas para médicos, dentistas, farmacêuticos, e suplementares serviços oftálmicos. Contudo, os clínicos gerais que antes comercializavam com liberdade seus serviços teriam ainda sido compensados pela perda do direito de fazê-lo com a implementação desse sistema público administrativo. (JONES, 191, p. 142-143). ${ }^{141}$

Da mesma forma, embora não chegassem a constituir um sistema oficialmente misto (público/privado), os hospitais poderiam dispensar cuidados diferenciados para pacientes particulares, geralmente com quartos privados. Porém, tais serviços e acomodações deveriam ser postos à disposição de qualquer paciente do Serviço Nacional de Saúde inglês, caso necessário em virtude do estado de urgência. (JONES, 1991, p. 142).

As autoridades locais, com a aprovação do ministro, estavam incumbidas da prevenção de doenças e dos demais cuidados de pessoas doentes ou com deficiência mental não providos pelos serviços hospitalares. Destaca-se, aqui, o considerável grau de delegação do Serviço Nacional de Saúde às autoridades locais na complementação e inovação desses serviços preventivos e de assistência básica. (JONES, 191, p. 142).

Nesse contexto Foucault (1974) ressalta o valor simbólico do Plano Beveridge, elaborado em plena Segunda Guerra, ou seja, num ambiente singular em que

\footnotetext{
${ }^{141}$ A esse respeito, cumpre citar os comentários do Ministro da Saúde, Aneurin Bevan, posteriores ao National Health Service Act, transcritos por Kathleen Jones (1991, p. 143): “The field in which the claims of individual commercialism come into most immediate conflict with reputable notions of social values is that of health. [...]. Preventable pain is a blot on any society. Much sickness, and often permanent disability arise from failure to take early action, and this in its turn is due to high costs and the fear of the effects of heavy bills on the family. [...] You can always 'pass by on the other side'. That may be sound economics. It could be worse morals".
} 
se passou a afirmar não mais simplesmente o "direito de viver, mas um direito diferente, mais rico e complexo, o direito à saúde". É, portanto, em meio à devastadora guerra que "uma sociedade se atribui a tarefa explícita de assegurar a seus membros não somente a vida, mas a vida em boa saúde”. (FOUCAULT, 1974, p. 01-02).

Os conceitos de saúde e direito à saúde serão retomados e, enfim, discutidos detidamente no capítulo 4. Cumpre, em princípio, tratar das modificações e diferenciações sistêmicas nos processos comunicacionais sociais, sobretudo político e econômico, que teriam ocorrido desde a incidência de novas questões e expectativas em torno do sentido de saúde, estimulada pelas propostas e pelos desdobramentos do Plano Beveridge.

Dessas modificações introduzidas no Serviço Nacional de Saúde inglês e de sua articulação com no sistema mais amplo de Segurança Social proposto inicialmente pelo referido plano, tem-se que o Estado passa a assumir o encargo da saúde numa dimensão diferente daquela por ele desenvolvida desde o século XVIII. ${ }^{142}$

Já com o Plano Beveridge, a preocupação se volta para os indivíduos, ocorrendo a seguinte inversão: "não mais o indivíduo em boa saúde para o Estado, mas o Estado para o indivíduo em boa saúde”. (FOUCAULT, 1974, p. 02).

Outra razão de seu valor simbólico seria a decorrente inversão provocada na própria moral do corpo e não apenas nesse direito. Dos modelos de Medicina Social até então desenvolvidos depreendia-se uma moral do corpo restrita à obrigação do indivíduo em assegurar sua saúde através da própria higiene. Nesse sentido, Foucault (1974), ao delinear essa moral do corpo, chama a atenção para o seguinte fato:

[...] No século XIX, produziu-se, em todos os países do mundo, uma enorme literatura sobre a saúde, sobre a obrigação que os indivíduos têm de assegurar sua saúde, a de sua família, etc. A noção de limpeza, da higiene como limpeza, está no centro de todas estas exortações morais sobre a saúde. Houve uma vasta literatura sobre a limpeza: é

\footnotetext{
${ }^{142}$ Como foi possível desenvolver, com base na estudo foucaultiano desse tema, do século XVIII até o início do século XX, a tarefa do Estado de assegurar a saúde física dos indivíduos representava "essencialmente assegurar a força física da nação, assegurar sua capacidade de trabalho, de produção, como também sua capacidade de defesa e ataque militar", respondendo, dessa maneira, a fins estritamente nacionalistas e ao ideário mercantilista e, logo em seguida, industrial dessa época. (FOUCAULT, 1974, p. 02).
} 
preciso ser limpo para estar em boa saúde, isto é, para poder trabalhar, para que os filhos sobrevivam e assegurem também o trabalho social e a produção. A limpeza é a obrigação de assegurar boa saúde a si e aos que o cercam. (FOUCAULT, 1974, p. 02-03).

Só a partir da metade do século XX, segundo o referido autor, teria surgido uma noção diferente da obrigação de limpeza e higiene citadas, qual seja, "o direito de estar doente quando se tem desejo e necessidade". Assim, destaca que o "direito à interrupção do trabalho, substitui, no século $\mathrm{XX}$, a velha obrigação de limpeza que caracterizava a relação moral dos indivíduos com seus corpos". (FOUCAULT, 1974, p. $03) .{ }^{143}$

Além dessas modificações, a terceira razão para a consideração do Plano Beveridge como um marco para a compreensão da diferenciação funcional do sistema sanitário moderno seria a introdução da saúde no campo da macroeconomia. Tal processo insere-se na socialização dos riscos e déficits da saúde e da interrupção do trabalho, os quais não podiam mais ser suportados pelos seguros privados como as caixas de pensões. Deste modo, as despesas referentes à garantia da saúde e ao enfrentamento do conjunto de seus condicionantes passam para o orçamento e a competência do Estado. (FOUCAULT, 1974, p. 03).

Contudo, essa atuação estatal não se restringiria à cobertura dos custos e das necessidades em saúde servindo além disso como um instrumento de "certa redistribuição econômica". O sistema de regulação e de cobertura econômica da saúde e da doença

\footnotetext{
${ }^{143}$ A superação ou não dessa moral higienista do corpo no contexto dos sistemas sociais brasileiros será retomada ao discutirmos nos capítulos seguintes, o conceito de "promoção da saúde" e sua função na efetivação do direito à saúde. Pode-se, aqui adiantar a atualidade das questões levantadas por Michel Foucault (1974) a respeito dessa inicial responsabilização dos indivíduos por sua saúde, sobretudo levandose em consideração a crítica de Eduardo Navarro Stotz e José Wellington Gomes Araújo (2004) à visão dominante da Organização Mundial da Saúde e do Banco Mundial do que deve ser a promoção da saúde nos países em desenvolvimento. Preconiza-se para esses países um ideário de promoção centrado na "criação de uma nova cultura da saúde", através de um "programa de extremo autoritarismo" que pressupõe "que as pessoas não têm uma cultura da saúde, não vêem a saúde como um bem desejável e precisam ser conscientizadas da sua importância". Tem-se com isso uma possível retomada dessa moral higienista na medida em que, a partir dessas diretrizes e do próprio contraste programático entre as Conferências de Ottawa de 1986 e Bogotá de 1992 sobre o tema da promoção em saúde, há que se considerar que "uma das mudanças relevantes na prática da saúde pública no Brasil, desde o advento da promoção, tenha sido a sofisticação das estratégias de culpabilização das próprias vítimas da incúria sanitária, além da creditação oficial das teorias do condicionamento comportamental (behaviorismo), absolutamente avessas a qualquer pedagogia da problematização". (STOTZ; ARAÚJO, 2004, p. 12-13).
} 
funcionaria como mais um mecanismo de correção de parte da desigualdade de renda pois asseguraria "a todos as mesmas possibilidades de se tratar e, eventualmente, de se curar". ${ }^{144}$

Nesse sentido, o corpo, a saúde e a doença que, desde o século XVIII, já estavam socializados através da Medicina Social, de meados do século XX em diante, "se tornam [também] um instrumento de socialização dos indivíduos”. (FOUCAULT, 1974, p. 03).

Com esse novo direito, essa nova moral e a nova economia, a saúde torna-se um importante objeto de disputas políticas, surgindo uma "nova política do corpo". Daí porque afirma Foucault (1974, p. 04): “[com o fim da Segunda Guerra] não há partido político, nem batalha política, em nenhum país mais desenvolvido que não se coloque o problema da saúde e da maneira como o Estado assegurará e financiará as despesas de saúde dos indivíduos”.

Revela-se, dessa forma, a "história do corpo", negligenciada por boa parte dos historiadores, segundo Foucault (1974), distinta da "história das almas" usualmente empreendida pelo discurso, pensamento e pelas representações teóricas dominantes.

Nessa "história do corpo no mundo ocidental" proposta pelo referido autor, os anos 40-50 seriam o marco de novos sentidos de direito, moral, política e economia do corpo, pois, a partir daí, o corpo teria se tornado um dos "objetivos principais da intervenção do estado, um dos grandes objetos de que o Estado deve se encarregar". (FOUCAULT, 1974, p. 04).

Por conseguinte, é graças a essa estatização da medicina que a mesma e a própria saúde pública, de maneira mais geral, teriam assumido suas funções modernas dando um grande salto tecnológico e científico, sendo, por exemplo, a descoberta dos antibióticos contemporânea ao surgimento dos grandes sistemas de seguro social.

Contudo, este novo regime, em que o cuidado com o corpo voltado à saúde torna-se um dos principais objetos de intervenção estatal ("somatocracia"), viveria em crise, posto que apesar de todo esse avanço tecnológico na luta contra as doenças e do

\footnotetext{
${ }^{144}$ Nesse sentido, afirma Michel Foucault (1974, p. 03): "E não somente por seu custo. Através da saúde, da doença e da maneira como vão ser cobertas as necessidades de saúde, procurar-se-á operar uma certa redistribuição econômica. Uma das funções das políticas orçamentárias da maior parte dos países, a partir do começo do século XX, era assegurar, pelo imposto, um certo nivelamento, senão das fortunas ao menos das rendas. Esse redistribuição não será mais atribuída ao orçamento, mas ao sistema de regulação e de cobertura econômica da saúde e da doença. Assegurando a todos as mesmas possibilidades de se tratar e,
} 
novo papel econômico e político, sobretudo, da medicina, esta não chegou a propiciar o "avanço do bem-estar sanitário" esperado, mas pelo contrário, teria levado "a uma curiosa estagnação da medicina e saúde pública”. (FOUCAULT, 1974, p. 05).

Da descrição dessa crise feita por Foucault (1974), é possível compreender não apenas a conformação da Medicina Moderna, como a complexidade assumida pelo próprio sistema sanitário, dada a diferenciação funcional dos sistemas científico, político e econômico no que diz respeito à comunicação voltada à saúde e os acoplamentos estruturais por eles realizados em torno de alguns temas relacionados à saúde.

Portanto, mais do que uma simples questão relacionada à dicotômica assistência individual versus assistência social, a complexidade sanitária da qual faz parte a citada crise da medicina relaciona-se às mudanças técnicas e epistemológicas tanto da Medicina Moderna quanto do conjunto das práticas sociais em que se insere.

Nesse contexto, destaca-se a questão dos efeitos negativos da medicina. Se até um período recente tais efeitos eram em sua grande parte associados à ignorância médica, ao estágio pouco evoluído de sua pesquisa científica, sendo sua "nocividade [...] julgada e medida em proporção a sua não cientificidade”, já no século XX, a Medicina passa a ser considerada perigosa não em sua falta de cientificidade ou ignorância, mas sim na medida em que é uma ciência, "na medida em que sabe". (FOUCAULT, 1974, p. 07).

Esse risco, próprio da complexidade da Medicina Moderna, relaciona-se à sua “iatrogenia positiva”, ou seja, aos efeitos negativos ou incontroláveis decorrentes da própria intervenção médica racionalmente fundada que afeta a própria espécie humana e sua história, introduzidas "em um domínio de probabilidade e risco" de dimensões desconhecidas e incomensuráveis. Podem ser citados, como exemplo dessa iatrogenia, a diminuição da resistência dos organismos pelo uso de medicamentos em tratamentos antiinfecciosos, os perigos da manipulação genética, a criação de "armas biológicas" etc. (FOUCAULT, 1974, p. 08-09). ${ }^{145}$

eventualmente, de se curar, pretende-se corrigir parte da desigualdade de rendas".

${ }^{145}$ Segundo o referido autor, a nova dimensão do risco e a ocorrência dos efeitos negativos decorrentes da Medicina Moderna caracterizam-se pela sua extensão além do indivíduo, sua família ou descendência, que 
Outro aspecto fundamental para a compreensão dos sistemas sanitários modernos refere-se ao fenômeno apontado por Foucault, já em 1974, da "medicalização indefinida”. Esta decorre da extensão da medicina no século XX para fora de seu domínio tradicional, ou seja, para além da "demanda do doente, seu sofrimento, seus sintomas, seu mal-estar" e dos próprios limites da doença, que seriam o seu objeto de domínio habitual. (FOUCAULT, 1974, p. 12).

À medida que o exercício da medicina, na linha de seu citado desenvolvimento como Medicina Social, se constitui como ato de autoridade, sua intervenção sobre o corpo social não mais se restringe à demanda do doente, impondo-se, por vezes, sobre o indivíduo doente ou não. Os exemplos desse intervencionismo perpassam desde a supervisão e seleção médica previa dos recrutas das Forças Armadas, o exame admissional ao trabalho, o rastreamento de doença na população, dentre tantos outros, até a avaliação da sanidade de um acusado por um crime.

Em relação à intervenção médica não restrita à doença, esta se desenvolve de modo cada vez mais amplo, sobretudo, em relação ao controle e à avaliação dos comportamentos, de sua "normalidade", e dos condicionantes físicos e sociais da saúde.

Dessa forma, não apenas Medicina Moderna como as próprias políticas de saúde pública passaram a ser dotadas de um poder autoritário com função normalizadora, não restrita à existência de doença ou à demanda do doente sendo que tudo "o que assegure a saúde do indivíduo, seja salubridade das águas, o sistema de habitação ou o regime urbanístico, é hoje um domínio da intervenção médica”. (FOUCAULT, 1974, p. 13).

Nesse sentido, Foucault (1974, p. 13) destaca a assunção no século XX pelos

\footnotetext{
passariam a atingir toda a espécie humana. Assim, as possibilidades médicas atingem uma nova dimensão, a "bio-história". Quer-se com isso dizer que enquanto a evolução da vida, descrita por Darwin, dava-se por acidentes, que embora de ordem histórica ainda assim estavam ligados às leis gerais da vida, já nessa nova dimensão e risco trazidos pela Medicina atual, acentua-se a mútua implicação entre história e vida, sendo que a história passa a ser dotada do "poder" mesmo de reassumir a vida interferindo drasticamente em seus processos. Daí decorreria o mal-estar socialmente compartilhado quanto aos efeitos da ação médica, sendo uma das características fundamentais de sua atual crise a recusa "radical e bucólica da medicina" que se internaliza de maneira difusa na consciência da população e que decorre da identificação do saber médico como um perigo com conseqüências negativas e imediatas não apenas aos indivíduos como à própria história. (FOUCAULT, 1974, p. 10-12).
} 
médicos do papel de regulação da sociedade através da normalização de condutas, substituindo-se o sistema codificado de leis dirigidas pelos juristas no século XVII e XVIII, pela "perpétua distinção entre o normal e o anormal, e a perpétua tarefa de reproduzir o sistema da normalidade".

Essa expansão do domínio interventivo das práticas sanitárias não mais restritas aos doentes e às doenças decorreria de seu "desbloqueio epistemológico" ocorrido no final do século XVIII, no contexto do desenvolvimento da Medicina Social. Teria sido graças à atenção para outras coisas que não apenas os doentes, como se depreende claramente do modelo urbano francês, que a medicina deixa de ser essencialmente clínica e passa a ser social, o que lhe permitiu libertar-se, desde então, da “estagnação científica e terapêutica em que se encontrava”. (FOUCAULT, 1974, p. 14).

Portanto, se até o século XIX, a população não se encontrava ainda completamente medicalizada, atualmente todo "domínio exterior à medicina" já estaria medicalizado e as críticas a medicina seriam não para negá-la em si, mas "em nome de um saber médico mais completo, mais fino e difuso". (FOUCAULT, 1974, p. 15). ${ }^{146}$

Por fim, para compreensão das tensões e acoplamentos estruturais entre o sistema sanitário e os sistemas político e econômico, é necessário ainda considerar a terceira característica da Medicina Moderna, descrita por Foucault (1974, 17), entendida como "a economia política da medicina".

Desde o século XVIII, como foi possível verificar ao tratarmos do desenvolvimento da Medicina Social, a saúde já era relacionada aos problemas econômicos objetivando-se, através da medicina, responder às necessidades mercantilistas, à citada aritmética política dos Estados nacionais em fase de consolidação

\footnotetext{
${ }^{146}$ A esse respeito afirma Michel Foucault (1974, p. 15): "No século XIX, a medicina tinha ultrapassado os limites dos doentes e das doenças, mas ainda existiam coisas que continuavam não médicas e que não apareciam como medicalizáveis. A medicina tinha um exterior e podia-se conceber uma prática do corpo, uma higiene, uma moral da sexualidade, etc., que não eram controladas nem codificadas pela medicina. A Revolução Francesa, por exemplo, concebeu uma série de projetos de moral do corpo, de higiene do corpo, que não deviam estar, de modo algum, nas mãos dos médicos. Pretendia-se uma espécie de regime político feliz, em que a gestão dos corpos, da higiene, da alimentação, o controle da sexualidade, seriam confiados a uma consciência coletiva e espontânea. [...] O que é diabólico na situação atual é que cada vez que se quer recorrer a um domínio exterior à medicina percebe-se que ele já foi medicalizado. E, quando se quer objetar à medicina suas insuficiências, seus inconvenientes ou seus efeitos nocivos, isso é feito em nome de um saber médico mais completo, mais fino e difuso".
} 
e, posteriormente, às demandas do capitalismo relativas à manutenção e reprodução da força de trabalho.

Por sua vez, essa "economia política da medicina" diz respeito ao novo e principal papel econômico assumido pela Medicina Moderna, não mais restrita às funções citadas mas sim relacionada à produção direta de riqueza com a introdução da saúde em si no mercado, como um objeto de consumo. Segundo Foucault (1974, p. 18):

\begin{abstract}
Atualmente, a medicina encontra a economia por outro caminho. Não, simplesmente, porque é capaz de reproduzir a força de trabalho, mas porque é diretamente capaz de produzir riqueza, na medida em que a saúde é objeto de desejo para uns e de lucro para outros. A saúde, enquanto objeto de consumo, enquanto pode ser produzida por uns laboratórios farmacêuticos, médicos, etc. - e consumida por outros os doentes potenciais ou atuais - tornou-se um objeto econômico importante, entrou no mercado.
\end{abstract}

Destaca-se, portanto, a inserção do corpo no mercado, mediada pela medicina, inicialmente como força de trabalho assalariada e, depois, por meio do consumo de saúde, o que, por conseguinte, teria propiciado diversas "disfunções no sistema de saúde e da medicina contemporânea”. (FOUCAULT, 1974, p. 19).

Contudo, a entrada da saúde no mercado não propiciou um aumento proporcional do nível de saúde. Diferentemente da relação entre o nível de vida e o nível de consumo, em relação à saúde, não se observa uma significante melhoria de seus indicadores à medida que o consumo médico aumenta. Essa assimetria seria demonstrada por diversos estudos que relacionam consumo de serviços e produtos de saúde às alterações no nível de vida. Tais estudos, em linhas gerais, têm demonstrado que "as variáveis do meio, em particular o consumo alimentar, a educação, a renda familiar, são fatores que influem muito mais do que o consumo médico". (FOUCAULT, 1974, p. 19).

Essa ausência de relação direta entre o crescente consumo médico e o nível de vida, segundo Foucault (1974, p. 20), revelaria o seguinte paradoxo econômico: "um crescimento do consumo que não é acompanhado de nenhum fenômeno positivo do lado da saúde, da morbidade e da mortalidade".

O referido autor, acrescenta ainda outro paradoxo relacionado à nova economia política da saúde no sentido de que "as transferências sociais que se esperavam dos sistemas de seguro social não desempenham o papel desejado", persistindo a 
desigualdade do consumo de serviços médicos entre ricos e pobres, a tal ponto, que seria possível ainda falar de um "sobre-consumo dos mais ricos" custeado pelos pobres nos sistemas de seguro social que estenderam seus serviços a todos os consumidores de serviços médicos como na França. (FOUCAULT, 1974, p. 20).

A organização dos serviços de saúde nos sistemas de seguro social teriam, portanto, reiterado as desigualdades não propiciando a igualdade de consumo médico esperado.

Nesse contexto, ao contrário do que pode parecer, os médicos não seriam os mais beneficiados por esse processo social de medicalização indefinida, mas sim a indústria farmacêutica, os "trustes farmacêuticos" é que ficariam com os lucros proporcionados pela doença e pela saúde, sendo sustentada, inclusive pelo financiamento coletivo desse sistema sanitário. (FOUCAULT, 1974, p. 21).

O mencionado o autor reposiciona a prática e o saber médico como simples intermediários entre a indústria farmacêutica e a demanda dos clientes, sendo os médicos meros "distribuidores de medicações e medicamentos".

Dessa forma, estaria ocorrendo a ampliação dos processos de medicalização generalizada e dos mecanismos da bio-história iniciados no século XVIII com a evolução da Medicina Social, o que permitiria entender os sistemas sanitários europeus e as tensões sistêmicas por eles enfrentadas.

Feitas essas digressões históricas, foi possível rever o desenvolvimento do Estado e de sua relação com as questões de saúde da população, discutindo-se a conformação do sistema sanitário moderno com base no modelo inglês que, segundo Foucault (1974), teria sido exportado para outros países a partir do Plano do Beveridge.

Pretende-se, a seguir, verificar em que medida essa Medicina Social — cerne da Medicina Moderna, suas características e a sua atual crise apontadas — relaciona-se ao modelo biomédico implementando no Brasil, contra o qual se insurgiu o Movimento pela Reforma Sanitária, a partir da década de 1970, resultando dessas tensões programáticas o novo sistema sanitário brasileiro garantido pela Constituição Federal de 1988. 


\section{O SISTEMA SANITÁRIO NACIONAL A PARTIR DA FORMAÇÃO DO ESTADO E DA ORGANIZAÇÃO DA SAÚDE NO BRASIL}

Uma vez delimitado o panorama das inter-relações sistêmicas entre política, economia, ciência e saúde, que se pode depreender dos modelos de Medicina Social, do desenvolvimento histórico da Saúde Pública européia e de sua relação com a formação do Estado Moderno, estudados por Foucault (1979, 1974), Rosen (1979, 1994) e Singer, Campos e Oliveira (1981), é possível dar continuidade a este trabalho com o levantamento das origens históricas da atuação do Estado brasileiro em matéria de saúde a fim de verificar a pertinência desses modelos explicativos para a compreensão do sistema sanitário nacional.

Esse tópico destina-se, portanto, ao estudo da influência dos modelos europeus de Medicina Social, como o de Medicina Urbana francesa cujo expoente seria o Sanitarismo Campanhista, na conformação do sistema sanitário brasileiro, sobretudo, em suas políticas de saúde da primeira metade do século XX.

Pretende-se retomar a configuração geral das práticas sanitárias desde a Primeira República, tendo em vista os principais condicionantes políticos, sociais e econômicos próprios da realidade brasileira e as respostas dos sistemas sociais nacionais que se seguiram às expectativas decorrentes da introdução do modelo de Bem-Estar Social e das políticas keynesianas, dos Estados desenvolvidos em seu processo de disseminação para os demais países em desenvolvimento, a partir da metade do século passado.

Nesse sentido, será questionada a possibilidade de se utilizar o término da Segunda Guerra Mundial e todo o contexto social, político e econômico europeu como determinantes de uma suposta reformulação da atenção dos sistemas sociais brasileiros e do próprio Estado para com a saúde de sua população, em mesmo grau de importância e força transformadora capaz de superar o paradigma bio-político até então vigente no Brasil. (DALLARI; FORTES, 1997). 
Enquanto Foucault $(1974,1979)$ relaciona a passagem da medicina privada para a medicina coletiva ao desenvolvimento do próprio capitalismo, sendo as práticas de saúde pública originariamente ligadas a uma estratégia bio-política voltada ao fortalecimento do Estado e à viabilização das práticas econômicas, alguns autores como Sueli Gandolfi Dallari (1987) e Gilberto Hochman (1998) ressaltam, contudo, que no caso brasileiro a conquista da saúde pública como política de Estado decorreria de um longo processo histórico de coletivização e nacionalização dos cuidados com a saúde por meio de uma ampliação gradual da atividade estatal e de suas políticas públicas.

Essa coletivização do bem-estar poderia ser entendida, de maneira geral, como ocorrida em três etapas: primeiramente, restrita a cuidados individuais sendo a saúde uma questão de ordem privada, sujeita às condições econômicas de cada indivíduo. Num segundo momento, tais cuidados passariam a ganhar uma vertente coletiva, embora ainda restrita em razão de seu caráter voluntário, assistencial e local, para, só então em sua terceira fase, tornarem-se cuidados estatais e, por conseguinte, a saúde vir a ser identificada como um bem público. (HOCHMAN, 1998, p. 23).

Haveria um paralelo entre a coletivização do bem-estar e a contínua transformação do Estado brasileiro, na medida em que tal coletivização decorria de processos específicos de mudança e rearranjo nos elos da interdependência humana.

Assim, Hochman (1998, p. 52) afirma que a evolução da complexidade das configurações sociais teria levado ao enfrentamento da doença como um mal público, carecedor de ações públicas de saúde e de saneamento. Tal processo teria sido desencadeado, dentre outros fatores, pelos desordenados fluxos migratórios para as cidades e em razão dos processos de urbanização e industrialização a eles relacionados.

Não obstante esse contraponto e as peculiaridades do processo histórico brasileiro, ao tratar da formação do paradigma moderno nacional, no sentido da "invenção do Brasil moderno", Micael M. Herschmann e Carlos Alberto Messeder Pereira (1994, p. 26) destacam do imaginário moderno brasileiro, presente já na virada entre os séculos XIX e XX, a preocupação do Estado republicano “em impor uma racionalidade que correspondesse às transformações sociais, econômicas e políticas ocorridas na Europa no 
último quartel do século XIX”, a fim de favorecer a aplicação de capitais estrangeiros no país. $^{147}$

Nesse contexto, segundo os autores citados, essas remessas de dinheiro teriam sido acompanhadas de "um conjunto de valores e modelos que a elite dirigente desejava incorporar como referência para a sociedade”. Ademais, sua importância para a formação dos sistemas sanitário e científico brasileiros é descrita da seguinte forma:

[...] [Tais valores eram] inspirados no modelo puritano, ascético e europeu e ganharam corpo nas reformas sanitárias, pedagógicas e arquitetônicas deste século. Esses valores foram aglutinados em formulações filosóficas e científicas que procuravam ter junto à sociedade um efeito moral, normatizador. A palavra de ordem é sintonizar-se com a Europa, ou melhor 'civilizar-se' o mais rápido possível, de modo que o país pudesse, o quanto antes, competir no mercado internacional. (HERSCHMANN; PEREIRA, 1994, p. 26).

Justifica-se, desse modo, a importância de comparar os modelos de Medicina Social e a conformação da Saúde Pública européia com sua "adaptação" às peculiaridades sociais brasileiras, sobretudo, em razão de seu valor simbólico e dos conflitos decorrentes da tentativa de sua imposição autoritária. ${ }^{148}$

Diversos autores ao tratarem da trajetória da saúde no Brasil, da evolução das políticas públicas e dos serviços a ela associados e de sua relação com a construção do Estado nacional, organizam seus trabalhos em pelo menos três períodos, destacando (i) as mudanças sociais e econômicas do final do século XIX e a conseguinte organização inicial

\footnotetext{
${ }^{147}$ Como exemplo da importância dessas mudanças no cenário Internacional decorrentes da Revolução Industrial e da nova dinâmica imposta pelas economias européias e norte-americana para o Brasil, os citados autores destacam o Funding Loan de 1898, "que restaurou a situação financeira do país e viabilizou a remodelação da capital federal (reforma empreendida pelo prefeito Pereira Passos na primeira década deste século)". (HERSCHMANN; PEREIRA, 1994, p. 26).

148 Sobre o papel simbólico dessa "modernização" forçada da sociedade brasileira a partir do Estado e sua intervenção no corpo social e no espaço urbano já no início do século XX, afirmam Micael M. Herschmann e Carlos Alberto Messeder Pereira (1994, p. 27): “A reformulação do espaço urbano foi uma das estratégias adotadas por este Estado, no início do século XX. A cidade, com sua organização físico-espacial, seus rituais de 'progresso' - como no caso das exposições nacionais e internacionais —, passa a ter um caráter pedagógico. Torna-se símbolo por excelência de um tempo de aprendizagem, de internalização de modelos. Assim, quando estes especialistas-cientistas se propunham a reformar, a organizar, mesmo que em nível superficial, a esperança que tinham era de que essa projeção externa, pública, citadina, pudesse atingir e orientar os indivíduos. Talvez um dos exemplos mais significativos dessa intervenção junto à sociedade seja o da medicina da Belle Époque que, aliando-se à estratégia desse Estado 'modernizador', esbarrou nos hábitos e condutas dos que repetiam a tradição familiar herdada dos tempos do Império".
} 
da saúde entre a Proclamação da República e 1930; (ii) a consolidação das bases estruturais do sistema de saúde e sua relação com a previdência entre 1930 e 1964, e (iii) a crise e reformulação do sistema de saúde a partir da organização do Movimento pela Reforma Sanitária de 1967 até a sua institucionalização na Constituição Federal de 1988. ${ }^{149}$

Antes, porém, de se iniciar o estudo desses três períodos marcantes da evolução do sistema sanitário nacional, deve-se, num breve apanhado histórico, retomar a conformação inicial da atuação brasileira em saúde, ainda que de forma superficial, a partir de seus antecedentes históricos que se estendem da colonização, passando pela Independência, até a Proclamação da República em 1889.

\subsection{Antecedentes históricos do Brasil-Colônia à Proclamação da República}

O período colonial caracteriza-se, basicamente, pelo predomínio de doenças contagiosas, como varíola e febre amarela, por serviços de saúde organizados de forma precária e, em sua grande parte, restritos ao Rio de Janeiro, bem como pelo exercício de uma prática médica baseada em conhecimentos tradicionais.

No início da colonização, o estado de saúde da população estava relacionado, de maneira geral, ao encontro e à fusão de três "etnias" — a indígena, a européia e a africana —, submetidas a "uma situação artificial e estranha a seus modos habituais de vida" e, por conseguinte, a novas experiências acerca das doenças. Dessas novas interrelações e das condições de vida estabelecidas na colônia teria resultado uma "nosologia peculiar e diferente daquela de cada um dos grupos populacionais que a condicionaram". (SINGER; CAMPOS; OLIVEIRA, 1981, p. 90-91). ${ }^{150}$

\footnotetext{
${ }^{149}$ Nesse sentido, posicionam-se Singer, Campos e Oliveira (1981, p. 88-137), Costa e Rozenfeld (2000, p. 22-35), Lima, Fonseca e Hochman (2005, p. 27-58) e Aciole (2006, p. 119-196).

${ }^{150}$ Nesse sentido, complementam Singer, Campos e Oliveira (1981, p. 91-92): “A população indígena, aqui encontrada pelo colonizador branco, longe de ser modelo de higidez, como faziam crer alguns relatos iniciais, apresentava suas doenças, algumas das quais, por desconhecidas, não eram relatadas. [...]. A chegada dos colonos, em número crescente, e a intensificação das relações comerciais com a metrópole provocaram rápida disseminação de graves doenças, impondo aos colonizadores e aos nativos pesadas perdas de vida. [...]. O início do tráfego entre Brasil e África e a chegada dos primeiros escravos trouxe consigo outro grupo de enfermidades, [...], cuja presença entre nós é mencionada já nos primeiros anos da
} 
Essa situação teria se agravado em 1808 com a chegada da Família Real Portuguesa ao Brasil e a abertura dos portos ao comércio exterior que se seguiu. Assim, intensificaram-se não apenas o tráfego de escravos e as relações econômicas e sociais, como também, a introdução de novas doenças em terras brasileiras. (SINGER; CAMPOS; OLIVEIRA, 1981, p. 93).

Nesse período, a organização dos serviços de saúde moldava-se, de certa forma, pelo sistema existente em Portugal. (COSTA; ROZENFELD, 2000, p. 23).

Por essa razão, de um lado, os serviços de saúde dos militares eram de responsabilidade dos representantes do Cirurgião-mor dos Exércitos de Portugal, que supervisionavam os serviços médico-hospitalares, o ensino e exercício da cirurgia, e a atividade dos demais atores médicos e leigos, e, de outro, a assistência desses serviços de saúde à população pobre ficava restrita aos cirurgiões barbeiros, sangradores, empíricos, curandeiros, às parteiras e curiosas ou, em termos mais amplos, às iniciativas particulares, que, na mesma linha do desenvolvido em Portugal, fundavam e mantinham, em nome da caridade cristã, obras de misericórdia destinadas aos indigentes, viajantes e doentes. (SINGER; CAMPOS; OLIVEIRA, 1981, p. 96-97). ${ }^{151}$

Em resposta ao novo quadro social e econômico, novas medidas foram tomadas como a instituição das Escolas de Cirurgia e a intensificação do controle sanitário dos portos a fim de criar as "condições de aceitação dos produtos brasileiros no mercado internacional". (COSTA; ROZENFELD, 2000, p. 23).

Nesse contexto, tem-se a criação do cargo de Provedor-mor de Saúde da Corte e Estados do Brasil pelo Príncipe Regente Dom João através do Decreto de 27 de julho de 1809 com a "finalidade de preservar o bem público e particular, sujeito a ser alterado por contágio comunicado por embarcações, passageiros e mercadorias que demandavam o

colonização".

${ }^{151}$ Sobre essas ações beneficentes de cunho assistencial e cristão, a título exemplificativo, pode ser citada a fundação da primeira Santa Casa do Brasil, denominada Irmandade da Misericórdia e o Hospital de Todos os Santos, por Brás Cubas em 1543 na cidade de Santos, sendo, inclusive, realizada em data anterior à chegada do primeiro médico ao país. A essa iniciativa seguiram-se a instituição da Santa Casa de Olinda, em 1540; da Bahia, em 1550; do Rio de Janeiro, em 1582; de Belém do Pára em 1654, e de São Paulo, em 1714, dentre outras. Além dessas entidades sem fins lucrativos, os jesuítas proviam alguns serviços assistenciais em suas enfermarias, junto aos colégios e às suas obras de catequese dos índios. (SINGER; CAMPOS; OLIVEIRA, 1981, p. 97). 
porto do Rio de Janeiro e das demais cidades litorâneas". (SINGER; CAMPOS; OLIVEIRA, 1981, p. 98).

Seu regimento pelo Alvará de 22 de Janeiro de 1810 previa a vigilância sanitária dos portos, a construção de um Lazareto em Boaviagem para a quarentena da tripulação de navios suspeitos ou com casos confirmados de enfermidades contagiosas, o controle de mercadorias e comestíveis, bem como a inspeção em matadouros e açougues públicos, sendo essas atividades sanitárias prescritas marcadas por seu caráter “fiscalizador, julgador e punitivo" e as autoridades responsáveis por sua aplicação dotadas do poder de tributar e de arrecadar as taxas sobre esses serviços. (BRASIL, 2005; COSTA; ROZENFELD, 2000, p. 23).

Surge, então, um novo tipo de prática sanitária inspirado no modelo de polícia médica europeu, próprio da Medicina de Estado alemã, com a entrada em vigor do referido Regimento da Provedoria e a posterior regulamentação da vigilância de boticas, drogas e medicamentos, além da fiscalização e dos exames para o licenciamento do exercício da medicina e da farmácia, sendo previsto, inclusive, exames de medicina e farmácia para leigos. (SINGER; CAMPOS; OLIVEIRA, 1981, p. 99).

Contudo, segundo Costa e Rozenfeld (2000, p. 23), na prática, essas intervenções estatais foram de pouco alcance no território brasileiro, não tendo quase eficácia fora da sede do governo.

A esse respeito, afirma Tânia Salgado Pimenta (2004, p. 68-69):

Todo o aparato burocrático existente nunca foi suficiente para impor a oficialização a todos cujas práticas cabiam dentro da definição de categorias legais, ou para reprimir as atividades consideradas ilegais. [...] Os terapeutas populares, com toda a diversidade que essa categoria abarca, constituíam a maioria e eram aceitos e requisitados pela população. $O$ discurso oficial pretendia que os terapeutas nãooficializados fossem procurados apenas porque não haveria médicos e cirurgiões em número suficiente e porque estes cobrariam mais caro. Dessa forma, os primeiros seriam "tolerados" pela burocracia. Contudo, temos visto que havia uma correspondência entre os tratamentos oferecidos pelos terapeutas populares e as necessidades de quem recorria a eles, o que dificultava qualquer tentativa de reprimi-los. ${ }^{152}$

\footnotetext{
${ }^{152}$ Nesse mesmo sentido, destacam Singer, Campos e Oliveira (1981, p. 103): "Deve ser ainda salientado que a prática médica e terapêutica no Brasil-colônia não fugia aos padrões generalizados, fundamentando-se o tratamento, em grande parte, em sangrias e purgativos, que eram utilizados, indistintamente, em todas as
} 
Nessa linha, poderiam ainda ser citadas a criação, em 1811, da Junta de Instituição Vacínica da Corte - subordinada à Fisicatura, órgão de fiscalização do Reino, sob a competência do Intendente Geral da Polícia da Corte e do Estado do Brasil e do Físico-mor do Reino - , de Institutos Vacínicos em São Paulo, Minas Gerais e Rio Grande do Sul, e no ano seguinte do Laboratório Químico-prático do Rio de Janeiro, sob a inspeção do Ministério da Marinha. ${ }^{153}$

Após a proclamação da Independência, ocorre um reaparelhamento geral do Estado, sendo, no caso dos serviços sanitários, decretada inicialmente a municipalização desses serviços. Por essa razão, as Câmaras Municipais passaram a se reorganizar estabelecendo seus regimentos sanitários. (COSTA, ROZENFELD, 2000, p. 23).

Nesse contexto, é destacada a criação da Sociedade de Medicina do Rio de Janeiro, em 30 de junho de 1929, que passou a exercer uma "profunda influência sobre as decisões governamentais em matéria de saúde pública". (SINGER; CAMPOS; OLIVEIRA, 1981, p. 103). ${ }^{154}$

Sobre o papel decisivo dessa organização na conformação do embrionário sistema sanitário brasileiro e a influência do Modelo de Medicina Social francesa depreendida das medidas por ela remendadas, afirmam Costa e Rozenfeld (2000, p. 24):

[...] A Sociedade de Medicina e Cirurgia, criada em 1829, constituiu-se

doenças".

${ }^{153}$ Conforme descreve Tania Fernandes (1999), em seu estudo sobre a introdução da vacina antivariólica no Brasil já no século XIX, logo após a sua descoberta por Edward Jenner em 1797, apesar do "projeto ambicioso de d. João no sentido da difusão plena da vacina antivariólica, a atuação da junta foi muito inexpressiva diante da magnitude dos problemas decorrentes da doença, tanto na capital como nas demais províncias, o que era constantemente ressaltado nas publicações oficiais". (FERNANDES, 1999). Dessa forma, embora introduzida em 1804, a vacina antivariólica tornou-se obrigatória em todo o Império do Brasil somente em 1846, com o Decreto n. 464, de 17 de agosto. Ainda assim, dada a gravidade da varíola como problema de saúde pública de especial atenção governamental nesse período, além da vacinação, foi instituído no Rio de Janeiro, em 1882, o isolamento dos variolosos na tentativa de reduzir a propagação da doença, sendo que a cultura da linfa variólica animal só passou a ser produzida no Brasil a partir de 1884, na Imperial Escola de Veterinária de Pelotas, de onde era fornecida para todo o país. (SINGER; CAMPOS; OLIVEIRA, 1981, p. 100-101).

154 Atuante desde sua fundação em 1829, a Sociedade de Medicina do Rio de Janeiro alterou sua denominação para Imperial Academia de Medicina em 1835 e, com a Proclamação da República, a partir de 21 de novembro de 1889, passou a se chamar Academia Nacional de Medicina. (SINGER;CAMPOS; OLIVEIRA, 1981, p. 104). 
em importante aliada do Estado. Inspirada na medicina francesa, a entidade centralizava a explicação das doenças no meio ambiente, criando, assim, uma relação entre a ordem moral e a saúde, e colaborava na elaboração de normas sanitárias e na proposição de medidas para o combate de doenças. E cobrava do Estado ação enérgica contra todas as demais práticas de cura, consideradas charlatanismo, mesmo se as práticas de medicina oficial só abarcassem uma pequena faixa da população.

Dentre seus trabalhos, destaca-se o apoio técnico à Câmara Municipal do Rio de Janeiro na elaboração do Código de Posturas de 1832, que, em linhas gerais, estabelecia o regramento dos cemitérios e enterros, das ações sanitárias frente a doenças contagiosas, pântanos e águas infectadas, matadouros, currais, açougues e gêneros alimentícios; uma nova normatização para o exercício da medicina e da farmácia; a fiscalização de medicamentos, hospitais, casas de saúde, introduzindo, ainda, o licenciamento e controle das primeiras fábricas da época. (COSTA; ROZENFELD, 2000, p. 24).

A despeito dessa inicial descentralização, frente a sua ineficácia na redução dos problemas sanitários, sobretudo na capital do Império, parte dos serviços de saúde voltou para a competência do Estado como o Serviço de Inspeção de Saúde dos Portos que, em 1843, passou à jurisdição privativa do Ministério do Império. (SINGER; CAMPOS; OLIVEIRA, 1981, p. 99). ${ }^{155}$

Tais medidas não foram, no entanto, capazes de conter a febre amarela e demais doenças que continuaram a afligir o Império. Sendo assim, em 1876, em nova tentativa de lidar com esses problemas, foi criada uma comissão responsável pelo estudo dos mesmos e pela proposição de soluções capazes de superá-los. Dessa forma, novas providências foram recomendas como a reorganização dos serviços sanitários terrestres e marítimos em todo o Império dentre várias medidas para melhorar as condições higiênicas da cidade do Rio de Janeiro. (SINGER; CAMPOS; OLIVEIRA, 1981, p. 100).

Nessa nova proposta, situa-se a Reforma Mamoré, de 1886, que levou à criação

\footnotetext{
${ }^{155}$ Nesse movimento de reorganização administrativa, podem ainda ser citadas a centralização no Governo Imperial do Serviço Sanitário da Cidade em resposta aos primeiros casos de febre amarela em 1849, que demonstravam a precariedade da organização sanitária municipal; a criação de uma Comissão Central de Saúde Pública, de comissões paroquiais, e, em 1850, a instituição de uma Junta de Higiene Pública encarregada da conservação da salubridade pública, a qual foram incorporadas a Inspeção de Saúde dos Portos do Rio de Janeiro e o Instituto Vacínico. (SINGER; CAMPOS; OLIVEIRA, 1981, p. 99).
} 
do Conselho Superior de Saúde Pública e divisão dos serviços sanitários em duas inspetorias gerais: uma de higiene, incumbida da denominada higiene terrestre - com priorização da capital imperial - e outra de saúde dos portos, responsável pela higiene marítima. (HOCHMAN, 1998, p. 95). ${ }^{156}$

Conclui-se, portanto, que o período colonial e a fase inicial da independência brasileira foram marcados pelo predomínio de doenças contagiosas, serviços precários de saúde, restritos ao Rio de Janeiro, e por formas incipientes de controle e oferta de assistência médica à população em geral. A esse respeito, sintetizam Costa e Rozenfeld (2000, p. 24):

[...] A nação brasileira que veio se formando, desde a Colônia, se caracterizou por imensas desigualdades sociais, pela manutenção de um quadro sanitário negativo para a maioria da população e pela edição de muitas leis e normas, sem observância das mesmas. E por sistemas de saúde que vão se estruturando essencialmente voltados para a doença, com imenso descaso pelas medidas de cunho preventivo e coletivo e de promoção da saúde.

Dessa breve reconstituição histórica depreende-se, ainda, a organização incipiente dos serviços sanitários nacionais, voltados em sua maior parte à viabilização das trocas comerciais com o exterior, sendo tal organização marcada pela incorporação parcial de ações sanitárias nos moldes da Medicina Social européia, não acompanhadas de uma organização administrativa capaz de implementá-las satisfatoriamente nem mesmo na Capital do Império brasileiro.

\footnotetext{
${ }^{156}$ Proposta pelo então Ministro de Estado dos Negócios do Império, o Barão de Mamoré, tal reforma partia da ênfase ao combate à precária situação sanitária do Rio de Janeiro através do saneamento da Capital e da implementação de diversas medidas sanitárias, consolidadas na grande Reforma dos Serviços Sanitários do Império. Nesse sentido, as ações sanitárias foram divididas em "serviço sanitário terrestre e serviço sanitário marítimo, fincando a direção entregue a duas repartições distintas, com sede na capital do Império e denominadas Inspetoria Geral de Higiene e Inspetoria Geral de Saúde dos Portos. Além delas, foi instituído na corte um Conselho Superior de Saúde Pública que tinha a missão de opinar sobre questões de higiene e salubridade geral. Datam dessa Reforma as primeiras medidas governamentais relativas ao trabalho de menores nas fábricas, aos doentes mentais e serviços de higiene escolar". SINGER; CAMPOS; OLIVEIRA, 1981, p. 100).
} 


\subsection{A República Velha e a conformação inicial do sistema sanitário brasileiro}

Singer, Campos e Oliveira (1981, p. 88) assinalam o período compreendido entre o final do século XIX e início do XX como um marco para o estudo das questões de saúde no Brasil, pois compreende um momento de grandes mudanças sob o ponto de vista da situação da saúde da população, da organização sanitária e da evolução do conhecimento médico-sanitário nacionais. ${ }^{157}$

Enquanto na Europa desenvolvia-se a Medicina Social - impulsionada tanto pelas citadas diferenciações de seus sistemas sociais, políticos, econômicos e científicos no contexto da formação de seus Estados nacionais, da urbanização e das Revoluções Industrial e Francesa - o Brasil passou por um considerável enriquecimento material após 1860, desigual do ponto de vista geoeconômico, com o empobrecimento do Nordeste do país enquanto que a área centro-sul desenvolvia-se economicamente devido à expansão da cultura cafeeira, ao crescimento do comércio internacional e às novas relações de produção deles decorrentes.

Nesse mesmo período, apesar de continuar a ser um país predominantemente rural, tem-se o aumento do processo de urbanização e a formação de um esboço de classe média urbana em algumas cidades da região sudeste que ganharam maior relevância como portos exportadores e sedes do rudimentar aparelho burocrático estatal em formação. Além dessas mudanças, podem ser destacadas a expansão da rede de transportes e a ocorrência de tentativas dispersas de industrialização. (SINGER; CAMPOS; OLIVEIRA, 1981, p. 89-90).

Nesse contexto, a proclamação da República teria dado início à organização administrativa sanitária nos Estados e à formação de órgãos responsáveis pela vigilância sanitária nessas Unidades da Federação. (COSTA; ROZENFELD, 2000, p. 25).

Contrariamente à centralização das políticas de saúde do final do Império, no

\footnotetext{
${ }^{157}$ Sobre a importância da Primeira República e as contribuições de sua retomada histórica para o estudo da Saúde Pública afirmam Lima, Fonseca e Hochman (2005, p. 30): “[...] Deve-se acentuar que os estudos históricos voltados à temática da saúde vêm contribuindo para a revisão desse período, enfatizando o papel da saúde na construção da autoridade estatal sobre o território e na conformação de uma ideologia de nacionalidade, capaz de superar a imagem negativa referida às teses de inferioridade climática do país e racial da população brasileira. Um dos temas centrais nesses trabalhos é o movimento sanitarista da Primeira República, expressão das mais importantes dos projetos nacionalistas e de reforma social que se intensificaram no contexto da Primeira Guerra Mundial”.
} 
início do Período Republicano observa-se a opção pela descentralização administrativa.

Embora não haja menção expressa no texto da Constituição Federal de 1891 à saúde nem as questões relacionadas a doenças, é possível depreender das competências orçamentárias relacionadas em seus artigos $5^{\circ}, 6^{\circ}$ e 34 que os assuntos de saúde restaram delegados aos Estados e Municípios, reservando-se à União a responsabilidade pelos serviços de higiene, a fiscalização do exercício da medicina e farmácia, a análise das substâncias importadas e o serviço sanitário marítimo dos portos. (BRASIL, 1891; SINGER; CAMPOS; OLIVEIRA, 1981, p. 107).

Posteriormente, com o Decreto n. 2.449 , de $1^{\circ}$ de fevereiro de 1897 , foi criada no âmbito Federal a Diretoria Geral de Saúde Pública, com sede na Capital Federal e subordinada ao Ministério da Justiça e Negócios Interiores, fruto da unificação dos serviços de higiene da União executados pelo Instituto Sanitário Federal e pela Inspetoria Geral de Saúde dos Portos.

Dentre suas atribuições, além dos serviços sanitários federais já citados anteriormente, passou para a competência da União a pesquisa da natureza, etiologia, do tratamento e da profilaxia das doenças transmissíveis presentes nas localidades carentes de recursos materiais. Nesse mesmo sentido, competia à sua Diretoria Geral de Saúde Pública planejar os socorros sanitários necessários que deveriam ser oferecidos a qualquer Estado, mediante sua solicitação e a constatação de seu caso de calamidade pública; preparar soros antitóxicos e curativos para as autoridades que os solicitassem; organizar as estatísticas demográfico-sanitárias; elaborar o Código Farmacêutico Brasileiro, e assessorar o governo, prestando-lhe as informações exigidas. (FIOCRUZ, 2006).

Contudo, em resposta às crises sanitárias que se seguiram a partir de 1904, modificou-se a legislação sanitária com a edição do Decreto n. 1151, de 05 de janeiro de 1904, que reorganizou os serviços de higiene administrativa da União, transferindo-se para esse ente a responsabilidade sobre todos os demais serviços de higiene no Distrito Federal. (BRASIL, 1904a).

No que diz respeito à regulamentação geral dos serviços de saúde no país, o Governo Federal foi autorizado a promulgar o Código Sanitário, com vigência em todo o território nacional, que deveria tratar: (i) de todas as questões relativas à higiene urbana e domiciliar; (ii) da profilaxia das moléstias infecciosas; (iii) do serviço sanitário dos portos e da profilaxia sanitária internacional; (iv) da regulamentação do exercício da medicina e da 
farmácia; (v) do Código Farmacêutico; (vi) das penalidades às infrações sanitárias que poderiam ser convertidas em prisão de no máximo três meses e cumuladas com outras sanções como a perda de direitos; (vii) da apreensão e destruição dos gêneros nocivos à saúde, bem como o seqüestro e venda de animais ou objetos cuja existência nas habitações fosse proibida; (viii) o fechamento e interdição de prédios, obras e construções. (BRASIL, 1904a).

Por sua vez, para a resolução dos conflitos decorrentes dessa atuação estatal foi instituído pelo citado decreto de 1904 a Justiça Sanitária no Distrito Federal, sendo composta de um juiz, um procurador, um sub-procurador, um escrivão e oficiais de justiça sanitária.

A competência desse foro relacionava-se aos feitos da Saúde Pública e a todas as ações e processos civis e criminais em matéria de higiene e salubridade pública, relacionados à execução das leis e dos regulamentos sanitários e à observância e efetividade dos mandados e ordens das autoridades sanitárias ou relativos aos atos de ofício destas. ${ }^{158}$

Contudo, o próprio Decreto n. 1.151/1904, em seu art. $1^{\circ} \S 20$, restringia o poder dessa Justiça Sanitária e de suas autoridades judiciais, federais e locais, as quais não poderiam conceder interditos possessórios contra os atos da autoridade sanitária exercidos ratione imperii, nem modificar ou revogar os atos administrativos ou medidas de higiene e salubridade por ela determinadas nesta mesma qualidade. (BRASIL, 1904a).

Dessa forma, intensificaram-se as intervenções de polícia médica sanitária com uma maior produção normativa e o esquadrinhamento do espaço urbano, com destacado valor para o saber médico, sendo que as ações de combate às doenças infectocontagiosas passaram a contar com os avanços das pesquisas bacteriológicas beneficiadas pela criação dos Institutos de Pesquisa. (COSTA; ROZENFELD, 2000, p. 25). ${ }^{159}$

\footnotetext{
${ }^{158} \mathrm{O}$ regulamento processual da Justiça Sanitária foi estabelecido pelo Decreto n. 5.224 , de 30 de maio de 1904. (BRASIL, 1904c).

${ }^{159}$ Nesse contexto, pode ser citado o Decreto n. 5.157, de 08 de março de 1904, que aprovou o regulamento do serviço de profilaxia da febre amarela, como exemplo marcante dessa regulamentação sanitária de forte intervenção sobre o corpo social e os espaços público e privado urbanos, aliando o saber médico aos interesses de Estado, na linha da Medicina Social alemã e francesa, tratadas por Foucault (1979). O referido decreto atribuiu à Diretoria Geral de Saúde Pública a competência exclusiva para o gerenciamento das medidas necessárias à profilaxia da febre amarela na cidade do Rio de Janeiro, criando para a sua execução a
} 
Essas medidas inserem-se na reforma sanitária comandada por Oswaldo Cruz, que dirigiu a Diretoria Geral de Saúde Pública dos anos de 1903 a 1909.

Tal reforma reposicionou os limites da ação do Poder Público frente aos direitos individuais, inclusive em face do direito de propriedade, haja vista a grande reforma urbana empreendida na cidade do Rio de Janeiro e a campanha de vacinação obrigatória contra a varíola em todo o país.

O movimento pela reforma da Saúde Pública nas duas últimas décadas da Primeira República é identificado como um dos elementos mais importantes no processo de construção de uma ideologia da nacionalidade, com impacto na formação do Estado brasileiro, podendo ser divido em dois períodos fundamentais. (HOCHMAN, 1998, p. 59).

$\mathrm{O}$ primeiro deles, situado na primeira década do século $\mathrm{XX}$, teria forte influência da gestão de Oswaldo Cruz à frente dos serviços federais de saúde, de 1903 a 1909, sendo a maior parte de suas ações restritas ao saneamento urbano do Distrito Federal e à vigilância sanitária dos portos. Destaca-se, ainda, nessa fase inicial o combate às epidemias de febre amarela, peste e varíola. (HOCHMAN, 1998, p. 60).

O segundo período do movimento sanitarista, entre as décadas de 1910 e 1920, seria voltado para o saneamento rural, com especial atenção para o combate de três endemias rurais: ancilostomíase, malária e mal de chagas. Estaria, portanto, relacionado à “descoberta dos sertões" e de "seus habitantes abandonados e doentes" e à possibilidade de sua cura e integração à comunidade nacional. (HOCHMAN, 1998, p. 60-61).

O termo sertões teria sido empregado inicialmente pelo movimento sanitário como sinônimo de abandono, ausência de identificação nacional e difusão de doenças endêmicas. Nesse sentido, afirma Hochman (1998, p. 68):

[...] O movimento sanitarista classificou o isolamento do sertanejo,

brigada contra o mosquito. Dentre seus poderes destacam-se (i) o isolamento domiciliar dos amarelentos; (ii) a política sanitária dos focos constituídos e zonas suspeitas; (iii) a polícia médica sanitária dos domicílios, dos lugares e logradouros públicos; (iv) a vigilância médica, além outras medidas. Dessa forma, uma vez notificado qualquer caso de febre amarela, era realizado o inicial isolamento do doente por meio de cortinado e, de acordo com o julgamento do médico inspetor sanitário ou auxiliar, determinava-se o isolamento domiciliar do enfermo, sendo possível, ainda, ser feita a sua remoção para os hospitais de isolamento. Poderia ainda ser realizado o isolamento das pessoas que residiam nos focos da doença e outras medidas restritivas da propriedade e liberdade privadas em nome da preservação da saúde pública. (BRASIL, 1904b). 
destacado por Euclides da Cunha em 1902, como um estado de abandono da população rural pelas autoridades governamentais. Esse diagnóstico não só embasava demandas por ações positivas do governo em matéria de saneamento e saúde pública e pelo aumento da presença do Poder Público em vastas áreas desassistidas do país, como, também, apresentava a possibilidade de conformar uma identidade de ser brasileiro distinta daquela fornecida pela doença. Nesse diagnóstico, os sertões continham um grande hospital: eram ao mesmo tempo abandono e doença.

O movimento sanitarista da Primeira República seria, então, marcado por um ideário que relacionava a superação das precárias condições sanitárias do Brasil, sobretudo no interior do país, à noção de salvação nacional e à formação de uma consciência cívica. A esse respeito, Giovanni Gurgel Aciole (2006, p. 126) destaca as correntes nacionalistas que se poderia depreender do pensamento higienista de Oswaldo Cruz, da descrição dos sertões por Euclides da Cunha e da defesa do serviço militar obrigatório por Olavo Bilac. $^{160}$

O enfrentamento desse diagnóstico do país como um grande hospital e de sua população profundamente doente seria a chave para a superação do atraso nacional. Para tanto, teria sido desenvolvida uma proposta nacional-reformadora "possível mediante ações de higiene e saneamento, fundadas no conhecimento médico e implementadas pelas autoridades públicas; ações em que a medicina, aliada ao poder público, era instrumento fundamental dessa transformação". (ACIOLE, 2006, p. 126).

Em tais considerações é possível identificar a interpretação do movimento pela reforma da saúde pública no início do século XX como um processo de construção de uma ideologia da nacionalidade, com impactos relevantes na formação do Estado brasileiro, que, segundo Hochman (1998, p. 61) permitiria tratar o movimento sanitarista da Primeira República como “a expressão de uma lenta, porém crescente, identificação, pela sociedade

\footnotetext{
${ }^{160}$ Nesse mesmo sentido, Lima, Fonseca e Hochman (2005, p. 35) destacam a influência das idéias sanitárias e a criação da Liga Pró-Saneamento de 1918, que mobilizou crescentes setores das elites intelectuais e política brasileira em torno do saneamento rural, na mudança do modo de pensar o país e os problemas da população rural, levando à revisão das teses relacionadas à inferioridade racial brasileira e à centralidade do abandono do poder público como principal obstáculo aos projetos civilizatórios da nação. O símbolo dessa ruptura à personagem Jeca Tatu de Monteiro Lobato, caricatura dos pobres interioranos na literatura brasileira, que, de inicial "parasita da terra, marcado pela preguiça e inferioridade racial", passou a ser um brasileiro redimido pela higiene após seu criador entrar em contato com as teses do movimento sanitarista da década de 1910 e assumir o saneamento como "idéia força" para a superação dos entraves da doença ao desenvolvimento nacional.
} 
brasileira, dos problemas sanitários como problemas de interdependência”.

Por sua vez, sem negar esse caráter nacionalista do sanitarismo republicano, ainda de acordo com o citado autor, existiriam outras correntes interpretativas da história da saúde pública que identificam as políticas de saúde na Primeira República como o produto estratégico das classes dominantes. O desenvolvimento do movimento sanitário é, dessa forma, associado à dinâmica do capitalismo nacional e internacional e, por conseguinte, os principais atores públicos desse período, especialmente os sanitaristas e dirigentes da saúde pública, seriam tidos como intelectuais subordinados aos interesses dos grupos dominantes nacionais e estrangeiros. (HOCHMAN, 1998, p. 59-60).

Em que pese o reducionismo de ambas as vertentes, a sobreposição de seus pontos de vista permite problematizar a dinâmica sistêmica e os diversos conflitos presentes na composição das políticas de saúde no Brasil, deixando de lado explicações meramente deterministas ou monocausais.

Mais próxima dessa segunda linha interpretativa, posiciona-se Rodolpho Telarolli Júnior (1996) ao estabelecer as relações entre o conhecimento disponível no final do século XIX, o padrão de organização tecnológico das ações sanitárias e o papel do modelo político do Estado republicano na forma de gestão desses serviços sanitários, caracterizado pelo "predomínio absoluto do modelo campanhista/policial". (TELAROLLI JUNIOR, 1996, p. 09).

Em seu estudo sobre a evolução das práticas sanitárias no Estado de São Paulo entre 1889 e 1911, o citado autor destaca a grande atenção do poder público à febre amarela que caracterizaria a formação dos serviços sanitários no Estado, na medida em que esta doença transmissível era identificada como a fonte dos maiores prejuízos à produtividade agrícola, centro da atividade econômica nacional, causadora de grande mortalidade entre os imigrantes estrangeiros e demais trabalhadores livres que substituíam a mão-de-obra escrava na cafeicultura.

Nesse sentido, ao menos no Estado de São Paulo, as prioridades sanitárias teriam sido guiadas inicialmente não por interesses humanistas, mas sim econômicos, de modo a priorizar o combate às epidemias de grande mortalidade como a malária, a varíola, o cólera e, principalmente, a febre amarela disseminadas na década de 1890 pela zona cafeicultora paulista "que desestabilizava toda a vida política e administrativa ameaçando as atividades da cafeicultura em diferentes etapas da produção à exportação e demais 
atividades econômicas urbanas, como a incipiente indústria”. (TELAROLLI JUNIOR, 1996, p. 237).

Para fundamentar essa tese, o autor expõe o "paradoxo da tuberculose", que, a partir de 1898, "se tornou a doença de maior peso individual entre as causas de morte no Estado de São Paulo, mas mesmo assim, antes de 1930, não se encontram ações estatais voltadas especificamente para o controle da doença”. Dessa forma, chama a atenção para o fato de que "mesmo matando entre duas e três vezes mais que a malária nos primeiros 20 anos do século XX, a tuberculose foi uma doença praticamente ignorada pelos serviços sanitários, ao contrário da febre amarela, na década de 1890, e da malária, a partir da década de 1910" (TELAROLLI JUNIOR, 1996, p.52). ${ }^{161}$

A maior atenção dispensada à febre amarela e à malária seria uma exceção a essa desídia para com as demais doenças infecciosas e estaria relacionada ao fato dos picos epidêmicos de grande mortalidade dessas duas doenças coincidirem com a expansão da lavoura cafeeira mata adentro e a construção de ferrovias no interior do Estado de São Paulo, incidindo entre os homens em idade produtiva e estrangeiros. Nesse contexto, tais questões sanitárias foram, muitas vezes, motivo de impasse e obstruções diplomáticas no processo de exportação agrícola e imigração de mão-de-obra estrangeira, essencial ao desenvolvimento econômico e produtivo do período. ${ }^{162}$

Por conseguinte, empreendidos os esforços necessários à contenção dessas

\footnotetext{
${ }^{161}$ A explicação desse "paradoxo" estaria relacionada à condição social das principais vítimas dessa doença e ao seu impacto indireto na econômica da época. Nesse sentido, afirma Telarorlli Junior (1996, p. 53): “A tuberculose incidia com grande freqüência apenas entre a população mais pobre. Em 1920, na cidade de São Paulo, entre os 639 óbitos registrados pela doença não se encontra o de nenhum médico, farmacêutico, dentista, juiz, advogado, engenheiro ou clérigo. Foram apenas 2 professores, 10 funcionários públicos e 16 militares, contra 88 operários e 33 lavradores. Consumindo lentamente as forças do trabalhador sem impedilo de exercer suas funções durante algum tempo, não afetando significativamente o desenvolvimento dos processos produtivos do complexo cafeeiro no campo ou na cidade a tuberculose não foi prioridade na Primeira República".

${ }^{162}$ A esse respeito complementa Telarolli Junior (1996, p. 28): “A preocupação dos governos estrangeiros com os problemas de seus cidadãos no Brasil levou à proibição da imigração para o país em alguns períodos. [...] As queixas dos imigrantes, apresentadas nos relatos de viajantes e autoridades consulares italianas [...] As doenças epidêmicas de grande mortalidade, como a febre amarela, o cólera, a malária, a febre tifóide e outras, monopolizaram as atenções na década de 1890 [...]”. Ademais, conforme o referido autor, observa-se que "as dificuldades e os receios eram recíprocos e a introdução de doenças epidêmicas pelos imigrantes era um forte motivo de preocupação para o governo paulista. Em 1893 uma epidemia de cólera na capital paulista causou pânico. Com 53 óbitos, a doença foi introduzida por imigrantes italianos cujos navios haviam feito escala em Gênova e Marselha, portos então contaminados". (TELAROLLI JUNIOR, 1996, p.29).
} 
epidemias, foi possível garantir no início do século XX um grande excedente de mão-deobra disponível para a agricultura, a despeito da ausência de ações sanitárias efetivas de combate às demais doenças endêmicas debilitantes como a tuberculose, a lepra, a ancilostomose e o tracoma, bem como de um discurso político que as valorizava. ${ }^{163}$

A Medicina Social que se delineava no Brasil nesse período poderia ainda ser relacionada à fraqueza dos municípios nesse inicial sistema político republicano e ao modelo sanitário "tecno-assistencial" campanhista-policial, marcado pelo centralismo autoritário de suas decisões.

Tem-se, dessa maneira, que fora do Distrito Federal, os serviços e ações sanitárias, sobretudo no Estado de São Paulo, restringiam-se, nos moldes da "política médica e campanha sanitária", às referidas medidas voltadas ao controle das epidemias que afetavam as atividades do complexo cafeeiro praticamente em todo o conjunto de etapas de seu processo produtivo (TELAROLLI JUNIOR, 1996, p.67).

Essa submissão das ações sanitárias aos interesses dos setores agrários, especialmente o setor cafeicultor, poderiam ser entendidas a partir das distorções do liberalismo praticado no Brasil durante a Primeira Republica que, diferentemente do discurso teórico liberal, contava com mecanismos de proteção estatal para a sobrevivência econômica das oligarquias cafeeiras. ${ }^{164}$

A estrutura político-econômica dominante na Primeira República é fundamental para a compreensão do desenvolvimento das políticas sanitárias paulista voltado à defesa de interesses econômicos e concentrador das iniciativas sanitárias no âmbito da organização estadual a despeito da estrutura formal federalista da Constituição

\footnotetext{
${ }^{163}$ Essa contradição teria, portanto, uma base econômica relacionada ao "fato de essas doenças não trazerem prejuízos substanciais à produtividade agrícola, pela possibilidade de fácil reposição dos trabalhadores doentes e debilitados". Tal quadro de imobilismo teria persistido ainda por muitos anos, sendo que só mais tarde, "quando entraram em cena outros fatores, como as mudanças políticas que se acentuaram na década de 1920, o crescimento do movimento nacionalista e uma conjuntura internacional favorável ao combate às doenças debilitantes em toda a América Latina, houve uma mudança efetiva na linha de ação estadual, identificável no código Sanitário Rural de 1977. (São Paulo Lei no 1696, de 20.12.1917)". (TELAROLLI JUNIOR, 1996, p.55).

${ }^{164}$ O domínio político das oligarquias cafeeiras na Primeira República foi possível através do Partido Republicano Paulista (PRP) que se perpetuava no poder graças ao pacto coronelista, no plano das relações entre Estado e municípios, e da política dos governadores, em nível nacional. (TELAROLLI JUNIOR, 1996, p.68).
} 
Federal de 1891 propugnar o princípio da autonomia municipal. ${ }^{165}$

Ressalta-se, nesse contexto, a influência que a oligarquia cafeeira, personificada na figura dos "coronéis", exercia sobre o sistema político-eleitoral republicano implantado, marcado pelas relações de troca de favores entre os poderes estaduais e locais - relação estado/município, base do Pacto Coronelista - possível graças à fragilidade econômica dos municípios e à já citada oligarquização do Poder decorrente da Política dos Governadores, no plano nacional. (FAORO, 1979). ${ }^{166}$

Em relação à assistência médica, como o discurso político da República caracterizava-se pelo "liberalismo à brasileira, limitado ao campo econômico e a oligarquização do poder", as ações e cuidados em saúde foram transferidos para a esfera

${ }^{165}$ No que diz respeito ao impacto desse sistema político na conformação das políticas de saúde do período,
destaca-se a gradual concentração das atividades sanitárias no âmbito estadual. Nesse sentido, afirma
Rodolpho Telarolli Junior (1996, p. 238): "A Constituição Federal de 1891 manteve a tradição brasileira de
municípios financeiramente frágeis, dependendo do auxílio dos recursos do Tesouro estadual - Mesmo as
pequenas obras e benfeitorias eram realizadas com recursos estaduais e intermediadas pela liderança local,
que se tornava credora dos chefes estaduais, correspondendo com apoio político. A ação sanitária estadual
fossem comissões sanitárias ou obras de saneamento, não fugia à regra, sendo objeto de barganha com as
oligarquias locais. Nessa intrincada relação de poder, unindo estado e municípios, encontra-se a chave do
modelo administrativo progressivamente estadualizante dos serviços sanitários na Primeira República". ${ }^{166}$ De acordo com Raymundo Faoro (1979), a política dos governadores pode ser entendida como um "comércio de favores", através da qual, do ponto de vista regional, é possível entender como esses coronéis utilizavam seus poderes públicos para fins particulares, misturando a organização estatal e seus erários com os seus próprios bens. Através desse comércio de favores eram firmados os compromissos bilaterais, entre governadores e presidente, abrangendo os parlamentares, envolvendo regionalmente o apoio dos coronéis que, durante a da República Velha, tinham por objetivo garantir a estabilidade do grupo dirigente estadual, oligarquizado nos partidos locais e em seus grupos familiares, bem como assegurar a permanência dos deputados e senadores representantes da elite republicana no poder central do país. (FAORO, 1979, p. 582). Essa estrutura de poder estabeleceu-se com a transição gradual do comando político, que desde o Império já contava com a nomeação dos presidentes de província. Com a República, mesmo com o Exército na chefia do governo, tal estrutura não sofre alterações sendo, na dinâmica do regime republicano com os novos cargos políticos como o de governador, deslocado o eixo decisório para os grandes Estados que se fortaleceram com o aliciamento dos pequenos, num movimento que culmina na política dos governadores. Nesse contexto, ainda segundo Faoro (1979, p. 621), "é que se afirma o coronelismo, num casamento, cujo regime de bens e relações pessoais será necessário determinar, com as oligarquias estaduais". Embora não seja um fenômeno exclusivamente republicano brasileiro, mas que tem suas origens no patrimonialismo central do Império, na nova conformação federativa de 1891, o coronelismo integra-se ao poder estadual, no qual o governador representa a espinha dorsal da vida política. Dessa forma, segundo a síntese proposta pelo referido autor, o coronelismo "se manifesta num 'compromisso', uma 'troca de proveitos' entre o chefe político e o governo estadual, com o atendimento, por parte daquele, dos interesses e reivindicações do eleitorado rural. As despesas eleitorais cabem, em regra, ao coronel, por conta de seu patrimônio. Em troca, os empregos públicos, sejam os municipais ou os estaduais sediados na comuna, obedecem às suas indicações. Certas funções públicas, não constitucionalizadas, estão enfeixadas em suas mãos. Daí que o coronel embora possa ser oposicionista no âmbito municipal - coronel contra coronel - há de ser governista no campo estadual e federal". (FAORO, 1979, p.631). 
individual e, dessa forma, se inviabilizou o acesso de grande parte da população e suas benfeitorias e serviços. (TELAROLLI JUNIOR, 1996, p. 67).

Esse quadro geral dos serviços médicos pouco se diferencia do delineado no Império e assim permanece até as primeiras décadas do século $\mathrm{XX}$, sendo caracterizado por uma prática de acesso restrito, seja pelo pequeno número de médicos e de escolas médicas, seja pela ausência de seus cuidados pelo poder público, restando à população socorrer-se das entidades assistenciais de caridade ou dos serviços não oficiais dos práticos, como os cirurgiões, barbeiros, boticários, além dos curandeiros em geral.

A manutenção dessa omissão estatal é relacionada, de acordo com Aciole (2006, p. 128), à influência das elites políticas e dos círculos profissionais e científicos da medicina e saúde pública na definição do conteúdo das políticas de saúde.

Desse modo, enquanto o movimento sanitarista convergia com outros sistemas sociais, como na citada articulação pelas reformas sanitárias descritas, no que diz respeito à assistência médica, têm-se, no final da República Velha, várias disputas internas e externas associadas aos interesses profissionais dos médicos, de acordo com as suas diferentes concepções higienistas, generalistas ou especialistas acerca do papel do Estado na saúde. (ACIOLE, 2006, p. 128).

No que diz respeito ao ponto de convergência desses profissionais sobre a responsabilidade do Estado e da natureza de suas ações a serem desenvolvidas na área de saúde, afirma Aciole (2006, p. 129):

\begin{abstract}
Apesar dessa disputa, emergirá [na década de 1920] um movimento em torno da configuração dos interesses da profissão, entre os quais a afirmação do perfil determinado da prática profissional e a hegemonia de condutas desejáveis, domínio de conhecimento científico, obtenção e manutenção do monopólio de trabalho e formalização de normas de conduta. Esta 'defesa' profissional, delineará, por conseguinte, a luta contra os 'práticos' e os 'boticários' elevados à categoria de charlatões, e contra os 'alternativos' - homeopatas e espíritas - o que constituirá, a princípio, inegável ruptura com os padrões e assistência a que a maioria da população então recorria.
\end{abstract}

Os conflitos internos entre médicos generalistas, especialistas e higienistas em torno do que deveria ser a saúde coletiva foram expressos e debatidos pelos integrantes da elite profissional médica no Congresso Nacional de Práticos de 1922 e, após a formação da Sociedade Brasileira de Higiene, em 1923, nos cinco congressos por ela realizados até 
1930. (MERHY, 2006, p. 80-81).

Delineavam-se, assim, três perfis da prática médica:

(i) generalista, para o qual, mais importante do que curar, a prática médica deveria centrar-se no alívio da dor, no consolo, conforto e apoio ao doente, sendo este perfil centrado na idéia do médico como um produtor individual de serviços de saúde, sob a lógica da clínica individualizada e direta sendo que na relação médico-paciente não deveria haver nenhuma mediação burocrática ou qualquer ingerência estatal;

(ii) especialista, caracterizado pela defesa, frente ao crescente conhecimento científico, da divisão da prática médica de acordo com determinada doença ou parte do corpo, sendo sua conduta profissional determinada pela busca da precisão do diagnóstico e da cura, diferentemente do apregoado pelo generalista;

(iii) higienista, entendido por sua vez, como uma especialidade do conhecimento médico, opunha-se à visão tradicional e paliativa do grupo generalista, distinguindo-se, contudo dos demais especialistas, por ressaltar o caráter científico e a dimensão coletiva de sua prática médica. (ACIOLE, 2006, p. 130-131). ${ }^{167}$

Já nos debates do Congresso de 1922, seria possível depreender as duas lógicas opostas em torno da presença do Estado na saúde e no mercado de trabalho desses profissionais. Enquanto, de um lado, os higienistas eram favoráveis ao aumento da presença estatal, os generalistas e especialistas, de outro, postulavam exatamente o oposto, ou seja, uma limitação dessa presença em razão dos reflexos da atuação do Estado na oferta de trabalho para o médico.

\footnotetext{
${ }^{167}$ A grupo dos higienistas, por sua vez, não seria em si uniforme, sendo, segundo Aciole (2006, p. 130-131), "um tanto mais heterodoxo, pois [tais higienistas] apresentavam uma identidade profissional composta de três elementos distintos: um cunho normatizador de hábitos e costumes, um caráter mais preventistas e uma lógica eugenista". A despeito dessas diferenças, o referido autor enfatiza, como traço comum entre eles, o fato de que todos os seus representantes no Congresso de 1992 "atuavam profissionalmente em alguma instância do poder público, vinculada à gestão de serviços de profilaxia, educação ou ação higiênica. (ACIOLE, 2006, p. 131).
} 
A respeito dos debates do Congresso Nacional de Práticos de 1992 entre os generalistas, especialistas e higienistas, e de suas lógicas distintas em torno da política sanitária a ser adotada pelo Estado, afirma Aciole (2006, p. 131-132):

[...] Seguindo a lógica amplamente difundida no interior do pensamento médico generalista/especialista se ampliava a oferta de trabalho ao criar postos com prestígio e poder medicalizador sobre a sociedade. Por outro lado, seguindo a lógica higienista, se reduziam os postos de trabalho, em conseqüência da eficácia e eficiência das medidas higiênicas e preventivas na diminuição da incidência de doenças. Isto é, quanto mais estas medidas fossem implementadas poderiam provocar a redução dos clientes capazes e necessitados de consumir serviços médicos. Outra razão, contra a qual se ergueram argumentos no Congresso, era decorrente da idéia de que a ampliação e difusão da rede de serviços de assistência médica, oferecida pelo Estado, poderiam atrair uma clientela com alto poder aquisitivo, freqüentadora, até então, dos estabelecimentos privados.

Dessa forma, resultou uma posição ambígua desses profissionais, com forte influência na formulação das políticas de saúde da época, no sentido da defesa de um poder normatizador bio-político do Estado, capaz de disciplinar os hábitos e costumes da população, ao mesmo tempo em que se questionava a organização de serviços públicos, assistenciais e preventivos de saúde, por esse mesmo Estado. ${ }^{168}$

A importância desse levantamento histórico consiste na relação que se pode estabelecer entre essa lógica inicial que irá conformar o sistema sanitário brasileiro, os Modelos de Medicina Social descritos por Foucault $(1974,1979)$ e a formulação do modelo biomédico, base do paradigma flexneriano de assistência à saúde desenvolvida no Brasil nas décadas seguintes, que contra o qual se insurgiu o novo movimento sanitarista brasileiro do final do século XX. ${ }^{169}$

\footnotetext{
${ }^{168}$ De acordo com Aciole (2006, p. 132-133): "Esta ambigüidade significa, estabelecer um escopo restritivo sob o qual a ação do Estado pudesse, pela sua eficiência e eficácia, nunca exercer efeito competitivo com a clientela potencial consumidora de assistência individual médica para a obtenção de saúde. Tendência sempre presente na agenda dos médicos até os dia de hoje - defensores inarredáveis da livre escolha no mercado - variando somente o grau com que defendem, ou aceitam a presença do Estado e o leque de ações que deve executar desde que preserve esse núcleo sagrado que é o consumo individual".

${ }^{169}$ A discussão do modelo biomédico será empreendida no item "3.4 O movimento pela reforma sanitária e as tensões bio-políticas com o modelo biomédico hegemônico no final do século XX". Cumpre aqui introduzir que, de acordo com Jairnilson Silva Paim (1997, p. 20), o paradigma flexneriano corresponde ao modelo biomédico hegemônico, combatido pela reforma sanitária da década de 1980, que, em linhas gerais, reduz o sistema de saúde ao conjunto de estabelecimentos de assistência médico-hospitalar, centrados no diagnóstico e na terapia alopática. Nele se insere o modelo biomédico como uma prática de intervenção soberana, na qual princípios mecanicistas, biologizantes, individualistas, de especialização e tecnifícação são
} 
Percebe-se, em certa medida, a despeito das peculiaridades de cada época e da fase de diferenciação funcional desses sistemas, as tensões e as diferentes expectativas em torno da saúde e do sentido que deve ser dado às políticas públicas a ela relacionadas. ${ }^{170}$

Sendo assim, a partir dessa ótica "liberal", de reduzida intervenção estatal na prestação direta desses serviços médicos à população, uma "clientela representada pelo doente pobre" restou desassistida e marginalizada, não apenas pela ausência de serviços de assistência pública como pelo combate estatal aos praticantes não oficiais da medicina, curandeiros, parteiras, boticários, enfermeiras-visitadoras, espíritas e homeopatas, desautorizados pelo estatuto científico que presidia a prática médica. (ACIOLE, 2006, p.132).

Nesse contexto, restava a essa população carente socorrer-se das práticas filantrópicas de assistência aos pobres citadas ao tratarmos das instituições hospitalares de caridade herdadas do tempo colonial.

Com as transformações sociais e econômicas que se seguiram às primeiras décadas do século XX, sobretudo o início da industrialização e a decorrente urbanização, a essas iniciativas caritativas somaram-se as primeiras organizações de auxílio mútuo estabelecidas entre os trabalhadores, especialmente por meio de associações de bairro. (ACIOLE, 2006, p.135). ${ }^{171}$

hegemônicos. Segundo Amauri Moraes dos Santos (2005, p. 73), os "profissionais de saúde envoltos nesta dimensão seguem reproduzindo o modelo capitalista ortodoxo, onde a saúde e o medicamento são considerados produtos de troca, mercadorias de intensa exploração mercantill”.

${ }^{170}$ Dentre os vários exemplos que se poderia citar dessa relação histórica e das diferentes inter-relações sistêmicas em torno da saúde, cumpre desde já destacar o impacto da intervenção estatal na oferta de serviços médicos e no mercado de produtos de saúde e os conflitos de interesse entre as organizações profissionais, sistemas econômicos, científicos e políticos na linha das preocupações "médicas", similares àquelas do referido Congresso de 1922 que se fazem presentes, mutatis mutandis, até hoje. Nesse sentido, afirma Aciole (2006, p. 131) sobre a dualidade do poder estatal em ampliar e reduzir a oferta de trabalho para o médico: “[...] Apesar de a ação estatal, desde então, ter transformado o Estado em principal comprador de mão-deobra, e difundido a criação de demandas profissionais. É o que se verifica, por exemplo, também na implantação do Programa Médico da Família, que, desde 1994, gerou um movimento significativo de cursos de especialização voltados para a resposta a este nicho de mercado de trabalho que se abriu. Parece também um efeito que a ação do SUS, como organização estatal, quanto mais aumente a sua eficiência e eficácia em garantir o direito a saúde e todo brasileiro resulte num claro limite à possibilidade de expansão do modelo liberal de prestação de assistência, que tem no médico o seu principal produtor direto".

${ }^{171} \mathrm{O}$ papel desempenhado por essas associações mutualistas na mediação entre as necessidades crescentes de assistência médica é descrito da seguinte forma por Aciole (2006, p. 138-139): “O sistema de ajuda mútua, implantado e financiado graças à iniciativa e às concepções cooperativistas, sindicais e anarquistas dos operários imigrantes, pode ser caracterizado pela prodigalidade nos gastos com serviços e benefícios; pela liberalidade na concessão desses mesmos benefícios; e pelo fato de que tinha na prestação de serviços de 
Seguiu-se a elas a formação das Caixas de Aposentadoria e Pecúlios (CAPs), inicialmente para os trabalhadores ferroviários, sendo seu marco histórico atribuído à Lei Eloy Chaves de 1923 que criou em cada uma das empresas de estradas de ferro existentes no país, uma caixa de aposentadoria e pensões para os respectivos empregados. A extensão da regulamentação dessas CAPs para os trabalhadores de outras empresas públicas e privadas ocorreu a partir de 1926 com a promulgação do Decreto Legislativo n. 5.109, de 20 de dezembro de 1926. (BRASIL, 1923; 1926). ${ }^{172}$

A importância dessas instituições para a conformação do sistema de saúde nacional decorre do fato de as mesmas não se restringiram à concessão de benefícios previdenciários, mas também de serviços médicos privados que passaram, gradativamente, a ser ofertado aos trabalhadores urbanos e seus familiares, expandindo a clientela e as bases restritivas da assistência médica brasileira. ${ }^{173}$

assistência médica uma atribuição ainda mais fundamental que a previdência estrita".

172 Ressalte-se, contudo, que a criação dessas Caixas não era automática, mas relacionada ao poder de mobilização e organização dos trabalhadores de determinada empresa para reivindicar a sua criação. De acordo com Silvia Helena Zanirato (2003), a instituição dessas primeiras instituições previdenciárias, mais do que simplesmente atender a uma reivindicação trabalhista, relaciona-se a contra-ofensiva do patronato da época às grandes greves de 1907 e 1919, no sentido de garantir uma mão-de-obra disponível e disciplinada, o que não estava sendo mais garantido pelas obras assistencialistas e beneficentes até então mantidas por essa elite urbana. (ZANIRATO, 2003, p. 122-123). A referida autora, a partir da reconstituição dos debates e dos interesses econômicos a que estava associado o deputado paulista Eloy Chaves, aponta para a tentativa do patronato de se eximir das indenizações acidentárias, que desde 1904 vinha sendo obrigada a arcar, com a transferência para o trabalhador desse custo, na medida em que com as caixas haveria a sua contribuição compulsória para o novo sistema. Superava-se, ademais, o problema do déficit das entidades assistenciais patronais e, sob o discurso da pacificação social, buscava-se disciplinar trabalhadores compelindo-os a aceitarem as condições e os riscos de trabalho em troca dos benefícios futuros. A partir do discurso feito por Eloy Chaves quando da apresentação de seu projeto de lei, alerta Zanirato (2003, p. 128): “O projeto foi apresentado como sendo um prêmio à vida futura do empregado, de modo que a este competia trabalhar visando ao descanso e à tranqüilidade na velhice e reconhecendo como parte natural da trajetória os espinhos do trabalho, que deveriam ser suportados com a esperança do prêmio futuro. Depreende-se dessa passagem a idéia de que havia uma outra intenção na promulgação da lei, ou seja, a de que os trabalhadores deveriam ser dóceis e disciplinados, não arrancando os espinhos do trabalho, mas suportando-os com a certeza do descanso em uma velhice assegurada".

${ }^{173}$ Conforme os artigos $9^{\circ}$ da Lei Eloy Chaves, Decreto Legislativo 4.682/1923, e 14 do Decreto Legislativo 5.109/1926, além das aposentadorias e pensões, as Caixas de Aposentadoria e Pensões proveriam os “a soccorros medicos em casos de doença em sua pessoa, ou pessoa de sua familia, que habite sob o mesmo tecto e viva sob a mesma economia, bem como internação hospitalar, em caso de intervenção cirurgica" e a oferta de "medicamentos obtidos por preços especiaes, determinados pelo Conselho de Administração". (BRASIL, 1923; 1926). Sobre o impacto desse modelo de previdência social no contexto das relações entre as esferas públicas e privadas na saúde, afirma Aciole (2006, p. 140): “O aparecimento das Caixas, ainda que não se tenha constituído numa contraposição evidente à medicina liberal, representará o elemento precursor das possibilidades de abertura de um mercado de trabalho assalariado para os médicos do setor público ou privado, por meio de serviços próprios das empresas ou do seguro social que sucederá àquelas”. 
Nas décadas que se seguiram a essa reforma sanitária não se teria atingido um estágio maior de compromisso do Estado com políticas sociais relacionadas à efetiva garantia da proteção da saúde, ao passo em que as políticas públicas restaram vinculadas a uma perspectiva desenvolvimentista voltada à superação da dependência econômica do país. (AUGUSTO, 1989, p. 106).

Mesmo com a posterior substituição do sistema de CAPS pelos IAPs Institutos de Aposentadorias e Pensões -, tem-se que o sistema previdenciário permaneceu como comprador direto dos serviços de assistência médico-hospitalar, mantendo-se inalterada a dependência da estrutura privada de saúde. (ACIOLE, 2006, p. 144).

Portanto, com a Primeira República são estabelecidas as bases para a criação de um sistema nacional de saúde de concentração e verticalização das ações sanitárias no Governo Federal com a expansão da autoridade estatal sobre o território ao mesmo tempo em que se delineava a formação da burocracia em saúde pública, como se depreende da criação, em 1920, do Departamento Nacional de Saúde Pública (DNSP), dirigido por Carlos Chagas até $1926 .{ }^{174}$

As preocupações iniciais em saúde são, dessa maneira, marcadas pela prevalência de uma visão higienista, restrita ao campanhismo sanitarista de ações autoritárias centradas na educação sanitária, na higiene e no saneamento rural, sendo as

\footnotetext{
174 Tem-se, nesse contexto, a "Reforma Carlos Chagas" que na direção do DNPS "estendeu a sua ação ao saneamento urbano e, formalmente, ao rural; aos serviços de higiene infantil; à higiene industrial e profissional; à supervisão dos hospitais públicos e federais, e a à fiscalização dos demais; à propaganda sanitária e ao combate às endemias e epidemias rurais". (COSTA; ROZENFELD, 2000, p. 27). Destaca-se, ainda, tal reforma pelo grau de autoritarismo de suas ações com uma interferência direta e ampla na vida da população, como se depreende do extenso Decreto n. 15.003, de 15 de setembro de 1921, e de seus 1.199 artigos, que deram nova regulamentação ao DNSP. (BRASIL, 1921). Além das medidas restritivas e compulsórias nela previstas, essa reforma de Carlos Chagas regulamentou a licença à gestante e à puérpera com duração de 30 dias e proibiu a admissão de menores de 12 anos como operários nas fábricas. (SINGER; CAMPOS; OLIVEIRA, 1981, p. 126-127). Apesar do pouco alcance de suas ações em razão das limitações do país, segundo Lima, Fonseca e Hochman (2005), a criação desse departamento é importante, pois teria resultado de um intenso processo de negociação política entre sanitaristas, Governo Federal, estados e poder legislativo, sendo que os primeiros defendiam inicialmente a formação de um ministério autônomo para a saúde, centralizador das ações em saúde nos moldes de outros movimentos sanitaristas de países latinoamericanos, sendo esse ideário contrário aos interesses oligárquicos da época. Dessa forma, para os referidos autores, a nova estrutura estatal em saúde seria um indicativo contrário às teses que defendem a total dominação oligárquica do período sobre as políticas de saúde, senão vejamos: "As mudanças políticas implementadas com a criação do DNSP e dos postos de profilaxia rural, que acompanharam a centralização das políticas de saúde federais, remetem ao debate sobre as tendências antioligárquicas e os conflitos intraoligárquicos que se manifestaram na década de 1920 e culminaram com a Revolução de 1930". (LIMA; FONSECA; HOCHMAN, 2005, p. 36).
} 
políticas estatais de prestação de serviços de saúde incipientes e influenciadas por uma organização médica que defende a segmentação do mercado e a reserva para suas bases profissionais de um "território livre e a salvo de qualquer interferência externa, em que a medicina se afirmará com sua cientificidade e ética próprias”. (ACIOLE, 2006, p. 135).

\subsection{O sistema de saúde e sua relação com a previdência entre 1930 e 1964}

A partir de 1930, tem-se o fim da Primeira República e a ascensão de Getúlio Vargas ao centro do poder político nacional, onde permanece inicialmente até 1945 , primeiro como chefe de um governo provisório, depois como presidente eleito pelo voto indireto e, ao final, como líder de um governo ditatorial. (FAUSTO, 2002, p. 185).

Essa primeira fase, conhecida como Era Vargas, é marcada pela emergência de um Estado forte, autoritário e centralizador em resposta à crise econômica mundial, à quebra das bolsas de 1929 e à decorrente perda de hegemonia das oligarquias regionais com a fragilização do modelo econômico agro-exportador. (ACIOLE, 2006, p. 141).

Não obstante, o país passa por um surto industrial entre 1929 e 1939 em função dessa crise de 1929 e de seu impacto nas economias dependentes da exportação de produtos primários como a brasileira, levando a um "relativo deslocamento da produção do setor exportador para o setor de produção voltado para o mercado interno, incluindo a atividade industrial". (LIMA; FONSECA; HOCHMAN, 2005, p. 39).

De acordo com Costa e Rozenfeld (2000, p. 28), destaca-se nesse período o favorecimento da industrialização como alternativa viável ao crescimento econômico com um considerável desenvolvimento da indústria químico-farmacêutica e de agrotóxicos, impulsionadas, especialmente, pelos acontecimentos que se seguiram ligados ao início da Segunda Guerra Mundial.

Embora esse primeiro governo de Getúlio Vargas seja reconhecido como "um marco na configuração de políticas públicas no Brasil", a sua fase inicial com o Governo Provisório (1930-1934) foi caracterizada por uma grande instabilidade política decorrente, dentre outras razões, da heterogeneidade de forças que se aliaram durante o "processo 
revolucionário" e que se refletiam na diversidade de interesses na disputa por maior influência no Governo Federal. (LIMA; FONSECA; HOCHMAN, 2005, p. 38). ${ }^{175}$

Tal instabilidade inicial teria se refletido na conformação do sistema sanitário nacional. Nesse sentido, afirmam Lima, Fonseca e Hochman (2005, p. 38):

As políticas de saúde, então implementadas, corresponderam a alterações nos campos político, ideológico e institucional, bem como à recomposição no formato de interação entre eles. Na esfera política, observa-se o aguçamento das diferenças intra-oligárquicas, com $o$ redesenho dos poderes federativos e de seu papel na dinâmica política nacional. $\mathrm{Na}$ esfera ideológica, assistiu-se a um gradativo fortalecimento do projeto político-ideológico de construção nacional, acompanhado de medidas que favoreceram sua implementação. E na esfera institucional, a principal mudança consistiu na criação do Ministério da Educação e Saúde Pública (Mesp), o que passou por sucessivas reformulações.

Apesar da criação desse Ministério conjunto para a Educação e Saúde Pública ter sido uma das primeiras medidas do Governo Provisório, prevista no Decreto n. 19.402 de 14 de novembro de 1930, as mudanças mais significativas na área da saúde foram efetivadas apenas com a nomeação de Gustavo Capanema para ministro do Mesp, após a promulgação da Constituição Federal de 1934, e a realização de uma ampla reforma nas instituições que compunham essa agência estatal por ele implementada. (BRASIL, 1930; LIMA; FONSECA; HOCHMAN, 2005, p. 41).

Dessa forma, tiveram início uma intensa produção normativa e a implementação de várias reformas estruturais da saúde pública tanto com a criação de

\footnotetext{
${ }^{175}$ A esse respeito, afirmam Lima, Fonseca e Hochman (2005, p. 39): "Com a diversificação da economia, novos interesses surgiram, pressionando a antiga ordem e sua estrutura de poder. Questionava-se a forma de organização política em vigor que inviabilizaria a participação das forças sociais emergentes. [...] Entretanto, nenhum dos grupos em confronto logrou impor-se aos demais, o que levou a uma reformulação no esquema de alianças entre os grupos dominantes. Isso talvez explique por que não houve uniformidade na política econômica implementada, coexistindo medidas favoráveis à industrialização com outras que visavam a amparar os interesses agrários tradicionais". Apenas para exemplificar essas tensões, cumpre ainda destacar o impacto da questão do tenentismo e a luta entre o poder central e os grupos regionais na conformação do processo político desse período, assim descrita por Boris Fausto (2002, p. 189): "Com a vitória da Revolução de 1930, os 'tenentes' passaram a fazer parte do governo e formularam um programa mais claro. Propunham maior uniformização no atendimento as necessidades das várias regiões do país, alguns planos econômicos, a instalação de uma indústria de base (especialmente siderúrgica) e um programa de nacionalizações que incluía as minas, os meios de transporte e comunicação e a navegação de cabotagem. Para a realização dessas reformas era necessário contar com um Governo Federal centralizado e estável. Dissociando-se claramente dos pontos de vista liberais, os tenentes defendiam o prolongamento da ditadura e a elaboração de uma Constituição que estabelecesse a representação por classe, ao lado da representação individual”.
} 
novos órgãos quanto pela especialização e ampliação das suas funções dos já existentes. ${ }^{176}$

Nesse mesmo sentido, ainda em 1934, ocorre uma nova reformulação do Departamento Nacional de Saúde Pública (DNSP) e a criação de serviços especializados, como a assistência a doentes mentais, sob a responsabilidade da Diretoria Nacional de Saúde e Assistência Médico Social do Governo Federal. (SINGER; CAMPOS; OLIVEIRA, 1981, p. 129).

Com a Lei n. 378, de 13 de janeiro de 1937, o Ministério da Educação e Saúde Pública é reformulado. Passa, então, a se denominar apenas Ministério da Educação e Saúde, sendo competente na esfera federal, de acordo com o art. $2^{\circ}$ da referida lei, pela administração das atividades relativas (i) à educação escolar e extra-escolar, e (ii) à saúde publica e assistência médico-social. (BRASIL, 1937).

A partir dessas modificações, o DNSP teve as suas funções ampliadas, não mais restritas à esfera federal, somando-se a elas a intervenção direta e indireta sobre os departamentos estaduais de saúde, característica do centralismo decisório dessa época. ${ }^{177}$

Assim, as organizações estaduais de saúde foram reformuladas e as ações sanitárias do Governo Federal no combate às epidemias e grandes endemias, intensificadas, destinando-se novos recursos à assistência materno-infantil. (SINGER; CAMPOS; OLIVEIRA, 1981, p. 130). ${ }^{178}$

\footnotetext{
${ }^{176}$ No que diz respeito à vigilância sanitária, Costa e Rozenfeld (2000), destacam a criação do Serviço Nacional de Fiscalização da Medicina, por meio do Decreto n. 3.171/41; a manutenção da divisão entre os Serviços de Saúde dos Portos e o Serviço Federal de Águas e Esgotos; a extensão dos serviços do Instituto Oswaldo Cruz que além da pesquisa e fabricação de produtos farmacêuticos passou a realizar exames laboratoriais, inclusive os relacionados ao controle sanitário de produtos químico-farmacêuticos, e, juntamente com o Serviço Nacional de Fiscalização da Medicina, a instituição das Comissões de Revisão da Farmacopéia e de Biofarmácia sendo esta última responsável pela elaboração de "um grande número de normas, editadas em portarias, restringindo a produção e a comercialização de produtos, em benefício da saúde pública". (COSTA; REZENFELD, 2000, p. 28).

177 Segundo Lima, Fonseca e Hochman (2005), têm-se nesse período uma centralização normativa juntamente com certa descentralização executiva das políticas de saúde, voltadas ao fortalecimento da presença federal nos Estados e à contraposição da União ao jogo de interesses privados regionais. Nesse sentido, o "desenho institucional acompanhou o projeto político ideológico do governo de constituição do Estado Nacional brasileiro, estabelecendo mecanismos burocráticos que viabilizassem a integração das três esferas administrativas - federal, estadual e municipal". (LIMA; FONSECA; HOCHMAN, 2005, p. 43). Tem-se, assim, a padronização nos mínimos detalhes, por meio de novas leis, regulamentos e códigos sanitários, das atividades e dos serviços de saúde estaduais, e a intensificação do processo burocrático do Estado.

${ }^{178}$ A partir dessas reformas e da centralização do comando verificou-se, conforme Singer, Campos e Oliveira
} 
Contra essa organização oficial dos serviços sanitários nacionais, destacaramse dois movimentos sanitaristas adeptos do discurso desenvolvimentista da década de 1930 - o modelo "vertical permanente especializado", e o projeto de uma "rede local permanente" - que se alternaram nas discussões dos modelos de organização de serviços de atenção em saúde coletiva, sem romper com a dimensão assistencial-preventista até então vigente.

Ambos os movimentos tinham por foro de debate o Estado de São Paulo, constituindo os dois principais projetos de políticas de Saúde Pública da década de 1930, a despeito da existência de outras correntes no campo da saúde coletiva como o “campanhista/policial" campanhista/vertical permanente", este diluído no interior do movimento "vertical permanente especializado". (MERHY, 2006, p. 125-127).

O movimento "vertical permanente especializado" caracterizava-se pela importância dada à clínica médica na organização do conjunto de ações sanitárias, no interior dos programas de saúde pública, sendo seus adeptos, médicos especializados em diferentes áreas da medicina que tinham em comum uma posição higienista.

Sua proposta de organização sanitária-assistencial da saúde tinha como ponto central a formação de Centros de Saúde que cumpririam a função de unidades diferenciadas por ações de higiene e educação sanitária, complementadas pela montagem e funcionamento de serviços especializados. A estruturação desses centros deveria ser vertical, permanente e especializada em torno de problemas de saúde específicos, contando, ainda, com autonomia administrativa e técnica capaz de realizar diversas atividades sanitárias. (MERHY, 2006, p. 126).

Por sua vez, os defensores da "rede local permanente" consideravam o exercício conjunto da medicina e da saúde pública como práticas incompatíveis e, por tal razão, postulavam a formação de uma rede única de ações sanitárias claramente distintas das ações médicas, na qual os Centros de Saúde compreenderiam unidades integrais de

(1981, p. 130), "uma maior ingerência do Governo da união no preparo do pessoal de saúde pública, tanto nas áreas mais especializadas de formação de médicos especialistas nas áreas de saúde pública e puericultura, quanto no preparo de pessoal auxiliar, do tipo visitadora sanitária, por meio de cursos realizados em vários estados. Até então o preparo de certos tipos de pessoa de saúde pública era feito de maneira sistemática apenas pelo Instituo de Higiene de São Paulo e, esporadicamente, por alguns estados do Governo Federal". 
ações sanitárias, distintas das ações médicas, com o papel de difundir diversas práticas sanitárias. Para esse fim, tais centros deveriam ser implementados de forma integrada nos municípios, de acordo com os princípios da regionalização, hierarquização e descentralização. (MERHY, 2006, p. 126).

Apesar dessas propostas, o que se observou no período citado foi a ampliação da interferência estatal sobre o corpo social, caracterizada pelas questões de higiene, pela atuação do DNSP, voltada para o saneamento urbano e rural, a higiene industrial e materno-infantil, e, no que diz respeito às endemias rurais, através dos trabalhos desenvolvidos posteriormente pelo Departamento Nacional de Endemias Rurais (DNERu). (ACIOLE, 2006, p. 146).

Paralelamente, desenvolveu-se entre 1930 e 1950 uma rede permanente de unidades de saúde denominadas Unidades Sanitárias relacionadas às políticas de industrialização e à dependência de capital financeiro norte-americano. (ACIOLE, 2006, p. 145-146).

Nesse contexto, durante a Segunda Guerra Mundial, foi criado o Serviço Especial de Saúde Pública (SESP) a partir dos convênios firmados entre os governos brasileiro e norte-americano, e com a ajuda técnica e financeira da Fundação Rockefeller. (LIMA; PINTO, 2003, p. 1045).

As ações do SESP centraram-se inicialmente nas regiões Norte e Nordeste do país, por razões de ordem estratégica, relacionadas à produção da borracha na Amazônia, e do manganês no Vale do Rio Doce e por supostas questões geopolíticas de defesa, sendo Natal escolhida para sediar a base militar norte-americana. Tais medidas seriam justificadas para garantir o esforço de guerra e o combate às endemias e moléstias tropicais que obstaculizavam o desenvolvimento da nação. (BRAGA; PAULA, 2006, p. 56).

Com a organização dessas Unidades Sanitárias difundiram-se pelo país as questões relacionadas à saúde materno-infantil e às práticas preventivas, destacando-se a atuação do visitador sanitário, como mais novo profissional de saúde. (SINGER; CAMPOS; OLIVEIRA, 1981, p. 130).

Contudo, de acordo com Lima, Fonseca e Hochman (2005, p. 41), tais políticas públicas seguiram a lógica da divisão de competências estabelecida entre o Ministério da Saúde e o Ministério do Trabalho e Indústria e Comércio (MTIC). 
Nesse sentido, segundo os autores citados, as ações sanitárias desse período relacionam-se à forma adotada pelo governo de Getúlio Vargas de reestruturar e consolidar as políticas sociais até então desenvolvidas, na medida em que correspondem a "um formato diferenciado de reconhecimento de direitos sociais" ao invés de uma "simples divisão e especificação de funções em razão da área de atuação de cada órgão". (LIMA; FONSECA; HOCHMAN, 2005, p. 41).

Acentua-se, portanto, a dualidade do sistema de proteção social de saúde no Brasil na linha da segmentação de mercado para o exercício da medicina privada e da passagem da cidadania tutelada da Primeira República para o início de uma cidadania assistida, nos moldes descritos por Pedro Demo (1995), a despeito da previsão da "assistência médicosocial" dentre as competências do Ministério da Educação e da Saúde, conforme se depreende dos artigos $2^{\circ}, 51$ e 58 da citada Lei n. 378/1937. (BRASIL, 1937).

A esse respeito, posicionam-se Lima, Fonseca e Hochman (2005, p. 41-42):

De um lado, estabeleceu-se o arcabouço jurídico e material da assistência médica individual previdenciária, desenvolvida no MTIC, que com o passar dos anos se tornaria uma das principais referências para a prestação de serviços públicos de saúde. Era destinada aos inseridos no mercado formal de trabalho e amparada por princípios corporativos [...]. Do outro lado, no Mesp, atrelada à educação, ficou a saúde pública. Ou melhor, tudo o que dissesse respeito à saúde da população e que não se encontrava na área de abrangência da medicina previdenciária. Ao Mesp cabia a prestação de serviços para aqueles identificados como précidadãos: os pobres, os desempregados, os que exerciam atividades informais, ou seja, todos aqueles que não se encontravam habilitados a usufruir os serviços oferecidos pelas caixas e pelos institutos previdenciários.

Essa forma inicial de reconhecimento de direitos sociais teria levado à dicotomia entre a assistência médica (previdenciária), associada aos trabalhadores urbanos, e a delimitação das ações de saúde pública como políticas e serviços destinados, em sua grande parte, à população rural. (LIMA; FONSECA; HOCHMAN, 2005, p. 42).

Nesse contexto, a saúde pública teria assumido um papel cada vez mais subalterno nas políticas de Estado. De acordo com Emerson Elias Merhy (2006, p. 148), enquanto as novas políticas sindicais e previdenciárias apresentavam-se como respostas da 
nova forma de Estado para os setores urbanos, por sua vez, "para o conjunto indiscriminado da população", o "papel de 'protetor social das massas' foi cumprido por um conjunto de políticas sociais complementares àquela". ${ }^{179}$

A Saúde Pública restaria entre essas políticas complementares, que “dificilmente se abriria para uma estratégia muito ampla e de expansão dos serviços", frente ao problema central de incorporação das massas trabalhadoras à nova relação entre o Estado e os setores sociais. (MERHY, 2006, p. 148).

Conclui-se, assim, que as políticas de saúde brasileiras da primeira metade do século XX acentuaram a divisão entre ações sanitárias e ações médicas, com serviços assistenciais públicos residuais ao lado de medidas campanhistas autoritárias de saneamento e vigilância sanitária.

Com o fim da Era Vargas e o início da experiência democrática a partir de 1945, essa organização burocrática, campanhista e de limitada assistência médica teria sido confrontada e os rumos da saúde pública rediscutidos, segundo Lima, Fonseca e Hochman (2005, p. 46), “em ambiente mais democrático, caracterizado por disputas políticopartidárias, eleições livres, funcionamento dos poderes republicanos, liberdade de imprensa e organização e demandas por direitos e incorporação". (LIMA; FONSECA; HOCHMAN, 2005, p. 46).

Os autores citados destacam, ainda, os novos sentidos atribuídos à saúde na construção do Estado e da Nação em meio ao "otimismo sanitário" presente no cenário internacional do pós-guerra, na linha das expectativas da melhoria do nível da saúde proporcionais ao aumento do consumo dos avanços da medicina descritas por Foucault (1974, p. 19). Com base nesse otimismo, difunde-se a crença no "poder da ciência e da medicina em combater e mesmo erradicar, mediante novos recursos tecnológicos e

\footnotetext{
${ }^{179}$ Para se ter uma noção aproximada da limitada abrangência desse sistema previdenciário, que passou a ser o principal comprador de serviços médicos e hospitalares nesse período e nas décadas que se seguiram, cumpre destacar que o mesmo não alcançou a cobertura de mais de $23 \%$ da população economicamente ativa nem sequer nas décadas de 1950 e 1960, deixando desassistidos de seus serviços e benefícios o setor rural, os trabalhadores domésticos, autônomos e desempregados, mesmo após a substituição do modelo de Caixas de Aposentadorias e Pensões (CAPs), então em declínio dada as crises econômicas do café e à sua submissão à gestão centralizadora do Governo Federal, pelos Institutos de Aposentadorias e Pensões (IAPs), na transição do modelo agroexportador pela industrialização substitutiva das importações. (ACIOLE, 2006, p. 143).
} 
terapêuticos [...] as doenças infectocontagiosas em todo o mundo". (LIMA; FONSECA; HOCHMAN, 2005, p. 47).

Os debates sobre as formas de atenção médico-sanitária são retomados, tendo por foco duas questões centrais: o alcance e dimensões da Saúde Pública e sua estrutura administrativa. (BRAGA; PAULA, 2006, p. 58).

No que diz respeito à Saúde Pública o otimismo sanitário descrito é associado às diferentes ideologias desenvolvimentistas, que embora não mais restritas ao discurso civilizador da Primeira República, restringiam ainda sua abordagem ao "círculo vicioso da pobreza e doença”, ou seja, à relação causal entre doença e pobreza. A esse respeito, afirmam Braga e Paula (2006, p. 59):

[...] Entretanto, numa visão equivocada da realidade, os sanitaristas da época viam a relação causal no sentido doença-pobreza: para eles, solucionado o problema da doença, a pobreza estaria automaticamente resolvida. Isto levava a um outro equívoco, o método de combate à doença: comparando os níveis de doença e as ações sanitárias dos "países pobres" aos dos "países ricos", concluíram que para alcançar o mesmo nível de saúde bastava gastar os mesmos recursos e montar a mesma estrutura. A impossibilidade de tal procedimento não lhes era evidente e por muitos anos perseguiu-se tal objetivo, jamais alcançado ou sequer alcançável. Observe-se que tal posição era defendida pelos norteamericanos, como se pode depreender da atuação da SESP, patrocinada pela Fundação Rockefeller e que disseminou pelo Brasil, ao longo de quase 30 anos, unidades sanitárias-modelo, inadequadas à estrutura brasileira e às nossas possibilidades financeiras.

Em relação à questão administrativa, esse debate estendeu-se até a década 1960 em torno da centralização ou descentralização organizacional que as estruturas sanitárias deveriam assumir, alternando-se propostas de serviços municipalizados com a participação da comunidade e outras de manutenção de um modelo único, centralizado. Essa discussão foi, porém, inicialmente suspensa com o regime militar. (BRAGA; PAULA, 2006, p. 59).

Esse discurso em torno do desenvolvimento, característico do pós-guerra, levou ao questionamento do custo econômico das doenças e dos entraves dela decorrentes ao desenvolvimento nacional, com especial atenção para as endemias rurais como a malária e seus obstáculos para expansão agrícola e produtividade do trabalho.

Nesse contexto, novos significados foram atribuídos à relação entre saúde e desenvolvimento, sendo a saúde considerada um bem de valor econômico e os investimentos em "capital humano" um fator imprescindível para o desenvolvimento e a 
ordem, sobretudo, nos países mais pobres. (LIMA; FONSECA; HOCHMAN, 2005, p. 47).

Inserem-se nesse ideário os programas de controle e erradicação das doenças tropicais e os diversos planos de desenvolvimento associados à saúde, fomentados não apenas por instituições brasileiras como também por Estados de países desenvolvidos e agências internacionais criadas para coordenar, em diversas frentes, tais planos globais de desenvolvimento como se depreende dos diversos programas da Organização Mundial da Saúde (OMS), da Organização Pan-Americana de Saúde (OPAS), além do Fundo das Nações Unidas para a Infância (Unicef) e a Organização das Nações Unidas para Agricultura e Alimentação (FAO), dentre outras. (LIMA; FONSECA; HOCHMAN, 2005, p. 47). ${ }^{180}$

A Saúde Pública passa a ser sistematicamente alvo dos pronunciamentos oficiais do governo brasileiro entre 1945 e 1964 e de disputas políticas, sendo a citada relação entre doença, pobreza e subdesenvolvimento questionada no interior do movimento sanitarista, a partir da década de 1950. (BRAGA, PAULA, 2006, p. 61).

Destaca-se a reação do "sanitarismo desenvolvimentista" ao modelo campanhista e centralizador até então desenvolvido que implicava na fragilidade dos governos locais e no baixo conhecimento do estado sanitário do país pela falta de informações e dados vitais. Em oposição ao modelo vigente, propunha-se a "compreensão das relações entre pobreza e doença e sua importância para a transformação social e política do país". (LIMA; FONSECA; HOCHMAN, 2005, p. 49). ${ }^{181}$

Tais divergências em torno das relações causais entre pobreza e doença eram observadas no interior desse próprio movimento sanitarista que congregava tanto os partidários da vertente que identificava a doença como um obstáculo ao desenvolvimento e, por conseguinte, a saúde como um "pré-requisito essencial para os avanços sociais e econômicos no mundo em desenvolvimento", quanto os sanitaristas "desenvolvimentistas,

\footnotetext{
${ }^{180}$ A respeito de tais questões, desenvolveram-se no Brasil novos debates sobre diversos temas relacionados ao desenvolvimento do país, como as estratégias de superar o atraso industrial nacional, a necessidade de um maior esforço para acelerar a industrialização e uma maior intervenção do Estado na economia com o emprego de novas técnicas de planejamento. (FAUSTO, 2002, p. 235).

${ }^{181}$ De acordo com Lima, Fonseca e Hochman (2005, p. 49): “[...] Ainda que heterogêneo internamente, esse 'novo sanitarismo' integrava a corrente nacional-desenvolvimentista e se expressaria com mais vigor no processo de radicalização política que marcou o início da década de 1960”.
} 
que compreendiam não ser suficiente o combate às doenças para a superação da pobreza". (LIMA; FONSECA; HOCHMAN, 2005, p. 49).

Em linhas gerais, essas tensões internas ao movimento sanitarista estariam associadas a três diferentes dimensões das relações entre melhoria das condições sanitárias e bem-estar econômico estabelecidas nessa época. A partir do estudo feito por John Farley (2004) a respeito dos debates sanitários internacionais da década de 1950, Lima, Fonseca e Hochman (2005) propõe a seguinte síntese dos argumentos comumente contrapostos nessas diferentes dimensões:

[i] O controle ou a erradicação das doenças comunicáveis como prérequisito para o desenvolvimento econômico-social versus a convicção de que, embora o controle das doenças seja necessário, o desenvolvimento socioeconômico é um pré-requisito para a melhoria da saúde.

[ii] A crença de que as campanhas contra as doenças deveriam ser dirigidas verticalmente contra cada doença específica e "impostas de fora" versus a compreensão de que as campanhas contra as doenças deveriam ser dirigidas horizontalmente em relação a um conjunto de doenças e envolver a promoção de condições básicas de infra-estrutura sanitária.

[iii] Defensores da ideologia do desenvolvimento como valor universal versus a crença de que o sistema internacional cria e perpetua o subdesenvolvimento de maneira que os países pobres fiquem presos num permanente sistema de desigualdades. (LIMA; FONSECA; HOCHMAN, p. 49-50).

Essas tensões seriam aplicáveis à realidade brasileira, ao menos no que diz respeito à força retórica da ideologia desenvolvimentista a partir da segunda posição que priorizaria o desenvolvimento econômico e a melhoria das condições de vida da população. Contudo, segundo Braga e Paula (2006, p. 61), apesar da amplitude desse debate durante toda a década de 50 , as condições sociais e o sistema sanitário nacional teriam sofrido poucas alterações.

Dentre as pequenas mudanças institucionais do período, destacam-se a criação do Ministério da Saúde em 1953, a reorganização dos serviços nacionais de controle das endemias rurais com a criação do Departamento Nacional de Endemias Rurais (DNERu), em 1956, além das campanhas nacionais contra a lepra e pelo controle e erradicação de outras doenças como a malária entre 1958 e 1964 que teriam reforçado a dicotomia entre saúde pública e assistência médica, com a centralização da primeira nas ações voltadas às populações rurais e o direcionamento das ações ao combate de doenças específicas. (BRASIL, 1953, 1956). 
Nesse mesmo sentido, a $3^{\text {a }}$ Conferencia Nacional de Saúde de 1963 representaria o "deslocamento do processo decisório para arenas fora da burocracia pública com a politização dos congressos de higiene e conferências nacionais de saúde". (LIMA; FONSECA; HOCHMAN, 2005, p. 50).

Embora o país tenha continuado a ser predominantemente rural até a década de 1960, observa-se nesse contexto, ao lado do combate às endemias rurais e às doenças transmissíveis, a emergência de novas questões relacionadas à inclusão da assistência médica na saúde pública que passam a ser incorporadas à agenda sanitarista, através dessas dissidências desenvolvimentistas e da inicial politização dos referidos encontros nacionais de saúde. (LIMA; FONSECA; HOCHMAN, 2005, p. 50).

Por sua vez, na outra margem da dualidade das políticas públicas que caracterizou o sistema brasileiro de saúde nesse período, a assistência médica continuou marcada pela segmentação de mercado através dos incipientes serviços médicos ofertados pelo Estado, restando-lhe intervir ativamente nos Institutos de Aposentadorias e Pensões.

Essa forma de controle estatal seria, portanto, a expressão do dirigismo trabalhista da época e das exigências de racionalização e contenção financeira previdenciárias dado o aumento do custo de assistência médica-previdenciária desses Institutos. (ACIOLE, 2006, p. 143).

Em função dessa orientação contencionista, produziu-se gradativamente uma considerável redução no volume e na qualidade dos serviços médicos ofertados por esse sistema. Ademais, a partir da década de 1940, com o advento da concepção capitalizadora própria desse esboço inicial de previdência, tais Institutos passaram a construir e gerir seus próprios hospitais e serviços ambulatoriais, sendo essa postura mantida até 1964. Mesmo com essa iniciativa, permaneceram como principal comprador de serviços médicos e hospitalares privados. (ACIOLE, 2006, p. 144).

Não obstante, segundo Braga e Paula (2006, p. 71), esse setor teria passado por duas mudanças entre o final da década de 1950 e o ano de 1966: o crescimento da prestação de assistência médica-previdenciária e a superveniência de uma profunda crise econômico-financeira desses institutos de previdência.

A esse respeito, ao tratar das relações entre saúde e previdência os citados autores traçam o seguinte panorama do impacto da assistência médica nas finanças desse 
sistema previdenciário:

Se em 1949 o gasto com Assistência Médica compunha 7,3 \% da despesa total, em 1960 já estava em 19,3\%; ou seja, num patamar em que havia estado na década de 20, mas agora com um significado qualitativo diferente. Este índice refletia pressões crescentes da demanda por cuidado médico, decorrentes do intenso processo de urbanização das décadas de 40 e 50, que colocou nas cidades uma grande massa assalariada, em condições de trabalho geralmente más e remuneração baixa e que encontrava no esquema previdenciário um complemento indispensável às suas rendas e seu consumo básico, do qual faziam parte os atos médicos destinados a recuperar sua saúde, isto é, sua própria capacidade de trabalho. Refletia também a tecnificação e elevação de custos dos atos médicos, cuja inflexão em seu trajeto ascendente principia neste período. (BRAGA; PAULA, 2006, p. 71). ${ }^{182}$

Em termos gerais, a partir do estudo citado, é possível perceber que em 1966 o crescimento da assistência médica assume tamanha magnitude que o dispêndio necessário para sua manutenção chegava a $24,7 \%$ do total das despesas consolidadas dos institutos previdenciários, passando, no ano seguinte, para 29,6\% desse montante. (BRAGA; PAULA, 2006, p. 72).

No mesmo sentido descrito por Foucault (1974) ao tratar da crise atual da medicina, sobretudo, a partir da inserção da saúde no mercado, essa diferenciação dos serviços de assistência médica teriam resultado, segundo Braga e Paula (2006, p. 74), "numa integração ampliada entre Estado, empresas de serviços médicos (clínicas e hospitais particulares) e empresas industriais (farmacêutica, de equipamentos e aparatos médicos) que [corresponderia] a uma avançada organização capitalista no setor”.

Por conseguinte, como em outros países, também no Brasil, o impacto econômico da atenção médica teria passado por um acelerado crescimento nas últimas décadas do século XX com a mobilização de "um volume cada vez maior de recursos, permitindo uma crescente acumulação de capital em seu interior”. (BRAGA; PAULA, 2006, p. 74).

\footnotetext{
${ }^{182}$ Ressalte-se, ainda, que neste mesmo período, segundo o minucioso estudo econômico desenvolvido por Braga e Paula (2006, p. 71-72), "ao mesmo tempo em que se processava a expansão da medicina previdenciária, montava-se uma estrutura de atendimento hospitalar já basicamente de natureza privada e apontando na direção da formação de empresas médicas. Em 1950, 53,9\% dos leitos totais do país eram de propriedade particular; em 1960 esse percentual havia subido para 62,1\%, dos quais 14,4\% tinham finalidade puramente lucrativa. Ademais, ocorre a partir de então o avanço da indústria farmacêutica e uma expansão substancial das importações brasileiras de equipamentos médicos".
} 
A lógica dessas inter-relações sistêmicas seria permeada por uma associação entre o Estado, alguns setores da econômica nacional, como o empresarial, e das indústrias estrangeiras da área de saúde, de modo que a função do Estado, além do desenvolvimento de suas próprias ações sanitárias, cobriria o financiamento do consumo geral de saúde desse setor privado via arrecadação previdenciária. (BRAGA; PAULA, 2006, p. 76).

Contudo, essa forma dicotômica do sistema de saúde brasileiro seria insustentável demonstrando, já no início da década de 60, os sinais de sua crise.

No que diz respeito à limitada assistência médica-previdenciária citada, os Institutos de Aposentadorias e Pensões revelaram-se incapazes de atender à crescente demanda e pressão do contingente assalariado urbano em torno da ampliação e melhoria de seus serviços na medida em que não dispunham de bases financeiras sólidas.

Esse quadro era agravado, pois, do ponto de vista institucional, não era possível uma uniformização das expectativas acerca de suas prestações em função da diferenciação existente entre os institutos nesse quesito.

Por sua vez, em relação às demais políticas de saúde, a ampliação do atendimento dos serviços preventivos e assistências da saúde pública era obstaculizada pelas limitações financeiras estatais nessa área. (BRAGA; PAULA, 2006, p. 87).

Do até aqui exposto, pode ser destacado o desenvolvimento neste curto período democrático de uma clara disputa entre os diversos projetos políticos sanitários que, ao final, teriam levado à radicalização das lutas por reformas sociais no Brasil.

Nesse sentido, os debates da $3^{\text {a }}$ Conferência Nacional de Saúde, de dezembro de 1963, sinalizariam essas tensões posto que, entre os seus principais temas, encontrava a rediscussão da distribuição de responsabilidades entre os entes federativos com a proposição da municipalização dos serviços de saúde, dentre outras ações voltadas à efetivação de serviços médico-sanitários mais igualitários e acessíveis à população a partir de uma rede básica municipal. (LIMA; FONSECA; HOCHMAN, 2005, p. 54).

Contudo, "esse movimento inovador na direção da descentralização, da horizontalidade, da integração das ações de saúde, da ampliação dos serviços e da articulação da saúde com as reformas sociais" teria sido, em princípio, obstado pelo golpe militar de 31 de março de 1964. (LIMA; FONSECA; HOCHMAN, 2005, p. 55).

Desde então, as ações governamentais e o planejamento estatal no Brasil foram 
redirecionados para o estabelecimento de metas a serem atingidas, tendo como eixo central o desenvolvimento econômico em detrimento do efetivo desenvolvimento social, no qual as políticas sociais de saúde seriam efetivadas.

Sob essa nova perspectiva desenvolvimentista do regime militar, durante as décadas seguintes, o processo de secundarização das políticas sociais foi agravado, sendo as mesmas, especialmente aquelas relacionadas à saúde, sujeitadas aos interesses econômicos, pondo à margem qualquer comprometimento governamental com uma maior eqüidade social. (AUGUSTO, 1989, p. 113).

Essa apertada síntese histórica permite contextualizar o desenvolvimento do Estado brasileiro e a função por ele desempenhada na articulação inicial das inter-relações sistêmicas desenvolvidas durante o século XX entre política, economia, ciência e demais sistemas sociais em matéria de saúde da população.

A evolução do sistema sanitário nacional revela-se marcada pela dualidade das políticas públicas de saúde e pela diferenciação dos sistemas econômicos e científicos em torno desse emergente sistema, cada qual buscando influir, a partir de sua peculiar lógica interna, na definição de sentidos contrapostos de saúde, que se reflete na cisão entre saúde pública e assistência médica segmentada.

Os modelos europeus de Medicina Social teriam sido adaptados às peculiaridades da nova sociedade em formação, sendo identificados alguns traços da Medicina de Estado alemã na estruturação dos serviços estatais, com destaque para o autoritarismo e a centralidade administrativa da polícia médica brasileira implementada desde o Império, passando pelo Sanitarismo Campanhista da Primeira República e seus desdobramentos no saneamento urbano e rural, que incorporam parte da tecnologia de intervenção sobre o espaço, aperfeiçoada pela descrita Medicina Urbana francesa.

No que diz respeito aos cuidados médicos e assistenciais de saúde, observa-se mais do que uma simples e gradual conquista de sua coletivização e nacionalização com a ampliação de atividades estatais nessa área, como, aparentemente, se depreende das leituras de Sueli Gandolfi Dallari (1987) e Gilberto Hochman (1998).

O Estado brasileiro cumpre, já no início do século passado, um papel decisivo na manutenção e no desenvolvimento da própria medicina privada, seja em sua vertente individualista e liberal, como sinalizam as discussões coorporativas do Congresso 
Nacional de Práticos de 1922 sobre o estratégico abstencionismo do Estado na oferta desses serviços, seja no posterior fomento do mercado de assistência médica em sua vertente coletiva e igualmente privada através das Caixas de Aposentadorias e Pensões e dos Institutos de Aposentadorias e Pensões, cujo consumo de saúde era financiado através da contribuição obrigatória dos trabalhadores, sujeitos ao rígido controle estatal.

Nesse último sentido, consolida-se, sobretudo a partir da década de 1940, uma perene aproximação entre os sistemas político e econômico, resultando, daí, uma nova estratégia bio-política, em termos foucaultianos, voltada ao fortalecimento do Estado e à viabilização das práticas econômicas na linha da Medicina Social inglesa dos Pobres e da Força de Trabalho, que permite a coexistência de uma propositadamente incipiente assistência médica aos pobres ao lado do esquadrinhamento geral da saúde pública e do controle sanitário da força de trabalho, ou seja, a concretização de um sistema sanitário simultaneamente assistencial, privado e administrativo.

Assim, a coletivização do bem-estar em saúde no Brasil não poderia ser explicada pelas supostas três etapas descritas por Hochman (1998, p. 23) - de (i) cuidados individuais para (ii) coletivos, voluntários e assistenciais, chegando, ao final, aos (iii) cuidados estatais e à compreensão da saúde como um bem público.

De modo contrário, como se verá a seguir, essa redefinição do papel do Estado em relação à saúde da população decorreria da tentativa de ruptura e total reformulação do sistema sanitário brasileiro que vinha se consolidando até a década de 1970, quando seus sinais de esgotamento e sua incapacidade de atender às expectativas dos demais sistemas sociais propiciaram sua contraposição, com uma profunda reformulação de seus objetivos e de sua lógica organizacional, reforçada pela institucionalização das novas expectativas normativas em torno da saúde através da Constituição Federal de 1988 e de sua afirmação entre os direitos sociais fundamentais.

Contudo, a complexidade social que teria estimulado essas mudanças sistêmicas não se assemelha àquela presente na Europa no Pós Segunda Guerra Mundial, que levou à formação do Welfare State europeu e a uma nova compreensão da saúde como um direito universal de todos, declarada já em 1948 pela Organização das Nações Unidas.

Dessa forma, a remissão àquele contexto social não seria apropriada para a compreensão dos sentidos do sistema sanitário e do direito à saúde na sociedade brasileira atual, como a realizada por respeitáveis juristas dessa área. (DALLARI; FORTES, 1997). 
As peculiaridades do desenvolvimento histórico nacional e a mobilização dos sistemas sociais no Brasil, sobretudo, em torno do Movimento pela Reforma Sanitária a partir do final do século XX, demonstrariam que a Segunda Guerra, em que pese a sua importância para a história mundial e o seu valor simbólico para a afirmação dos Direitos Humanos, não teve o mesmo impacto transformador na realidade brasileira, nem as respostas de seus sistemas sociais às expectativas decorrentes da introdução do modelo de Bem-Estar Social e das políticas keynesianas e do desenrolar do Plano Beveridge nos Estados desenvolvidos a partir da década de 1950.

\subsection{O Movimento pela Reforma Sanitária e as tensões bio-políticas com o modelo biomédico hegemônico no final do século $\mathrm{XX}$}

A redefinição das funções do Estado brasileiro em matéria de saúde, tal como pactuada na Constituição Federal de 1988 e na regulamentação do Sistema Único de Saúde que se seguiu, resulta, do ponto de vista sistêmico, de um longo período de reordenação dos processos comunicacionais e das inter-relações de diversos sistemas sociais, marcado pela generalização de expectativas em torno da redemocratização e redução das desigualdades sociais do país, tendo um impacto concreto nas novas interações entre diversos atores sociais na luta pela concretização de uma sociedade mais justa e solidária.

Ainda que sob uma perspectiva sistêmica, tal evolução social não deve ser interpretada como um processo linear e harmônico de configuração de novos sentidos, valores e interesses para as diversas relações que compõem a complexidade de uma sociedade cada vez mais desigual, plural e diferenciada funcionalmente como a brasileira.

O pensamento sistêmico, embora tente lidar com tal complexidade, assume a limitação dos sistemas sociais, enquanto sistemas de sentido, e a necessidade de reduzi-la, ao menos em seus processos cognitivos e comunicacionais internos de dotação e sentido.

Nem por isso, como foi explicado inicialmente neste trabalho, a redução de complexidade, como infinitude de sentidos e de relações possíveis, permitiria supor complexidade ignorada, pelo contrário.

Admitindo-se essa dinâmica sistêmica e suas limitações cognitivas e comunicacionais, busca-se nesse tópico selecionar os aspectos relevantes para a compreensão dos processos recursivos que reordenaram o sistema sanitário brasileiro, a 
partir do conflito de expectativas em torno da saúde e de sua efetivação pelo aparelho estatal, em contraposição ao anterior sistema sanitário que se estruturava de maneira dicotômica e desvirtuada de fins sociais e humanísticos durante a maior parte do século passado.

\subsubsection{Configuração e crise do modelo biomédico brasileiro}

A descrita dualidade da organização da saúde no Estado brasileiro, dividida entre o sanitarismo campanhista e a restrita assistência médica previdenciária, relegou a saúde pública a um papel cada vez mais coadjuvante no âmbito das políticas públicas brasileira até a década de 1970.

Tal situação teria se agravado durante o regime militar brasileiro, no pós-1964, com "o predomínio financeiro das instituições previdenciárias e pela hegemonia de uma burocracia técnica que atuava no sentido da mercantilização crescente da saúde". (ESCOREL; NASCIMENTO; EDLER, 2005, p. 60).

As disputas políticas, econômicas e programáticas em relação à reorganização desse sistema, no sentido de uma descentralização das competências e da municipalização da saúde com o fim de reorganizar os serviços médico-sanitários de modo mais equânime e acessível à população, manifestas nas $3^{\text {a }}$ Conferência Nacional de Saúde de 1963, sofreram uma abrupta interrupção com a nova ordem política que pôs fim ao curto período democrático que vigorou de 1945 a 1964. (LIMA; FONSECA; HOCHMAN, 2005, p. 54).

Esse foi o mesmo destino dos movimentos sociais formados em resposta às mudanças estruturais brasileiras das décadas de 1950 e 1960, forte crescimento urbano pela rápida industrialização. Esses movimentos destacavam-se pela pressão sobre as reformas de base propostas pelo presidente João Goulart, como a exercida pelas Ligas Camponesas, pelos movimento operários, estudantis e por integrantes da própria esquerda católica como da Juventude Universitária Católica (JUC). Como as demais lutas sociais do período, estes movimentos acabaram fortemente reprimidos a partir de 31 de março de 1964. (FAUSTO, 2002, p. 244-268).

Em nome da "restauração da ordem social e política" e através dessa forte repressão social, o espaço para o debate de idéias e alternativas políticas foi suprimido, permitindo ao governo militar implantar reformas institucionais de grande impacto nos 
rumos da saúde pública e da medicina previdenciária. (ESCOREL; NASCIMENTO; EDLER, 2005, p. 60).

Os antigos Institutos de Aposentadorias e Pensões (IAPs), cujos benefícios haviam sido uniformizados pela edição da Lei Orgânica da Previdência Social, n. 3.807 de 26 de agosto de 1960, passaram por uma nova inflexão com a instauração do regime militar, formando um novo modelo pautado pelo aumento do papel regulador do Estado e a expulsão dos trabalhadores da gestão desses regimes de previdência. (BRASIL, 1960; ALMEIDA; CHIORO; ZIONI, 2001, p. 24).

Tais seguros foram então unificados com a criação do Instituto Nacional de Previdência Social (INPS) pelo Decreto-Lei n. 72 de novembro de 1966 e suas contribuições previdenciárias, centralizadas nesse novo órgão responsável pela gestão das aposentadorias, pensões e da assistência médica dos trabalhadores urbanos formais com a inicial exclusão dos rurais e demais trabalhadores urbanos. (BRASIL, 1966).

Por sua vez, segundo Sarah Escorel, Dilene Raimundo do Nascimento e Flávio Coelho Edler (2005, p. 61), com "a unificação dos IAPs quando da criação do INPS, em 1966, o Estado tornou-se o maior empregador de serviços de saúde”.

A criação desse órgão centralizador acabou por favorecer ainda mais a prática médica curativa, individual e assistencialista em detrimento da saúde pública. Isto porque, de acordo com Erivaldo Sampaio de Almeida, Arthur Chioro e Fabiola Zioni (2001, p. 24), o INPS passou a fomentar o desenvolvimento de um complexo médico-industrial, além da “organização do sistema de saúde orientado pela lucratividade e realização de privilégios para o produtor privado de saúde".

As distorções mercadológicas desse sistema continuaram a se agravar, mesmo com a posterior extensão, pela Lei n. 6.260, de 06 novembro de 1975, de parte dos benefícios da previdência e assistência social aos trabalhos rurais, que desde 1963 estavam sob a responsabilidade do Instituto de Aposentadoria e Pensões dos Industriários (LAPI) com o financiamento do FUNRURAL, conforme a Lei n. 4.214, de 02 de março de 1963. (BRASIL, 1975; Brasil, 1963). Sendo assim:

Ao mesmo tempo em que se ampliava a cobertura, desnudava-se o caráter discriminatório da política de saúde, pois eram cada vez mais nítidas as desigualdades quanto ao acesso, à qualidade e à quantidade de serviços destinados às populações urbanas e rurais e entre as diferentes clientelas dentro de cada uma delas. Surgiram também diferentes formas de 
contratação do setor privado. (ALMEIDA; CHIORO; ZIONI, 2001, p. 24-25).

Com a formação do Sistema Nacional de Previdência e Assistência Social (SNPAS), atribuí-se ao recém criado Instituto Nacional de Assistência Médica da Previdência Social (INAMPS), nos termos dos art. $6^{\circ}$ da pela Lei n. 6.439 , de $1^{\circ}$ de setembro de 1977, a competência pelos programas de assistência médica aos trabalhadores urbanos, rurais e funcionários públicos civis da União, de suas autarquias e do Distrito Federal. Por sua vez, ao INPS restaram as questões relacionadas à previdência própria dita com a implementação desse novo sistema a partir de março de 1978. (BRASIL, 1977).

Embora a criação do INAMPS representasse um discurso racional-organizador, dado o caráter autoritário das medidas em que se inseriu, com esse órgão as políticas de assistência médica continuaram sob o comando do Ministério da Previdência e Assistência Social, perpetuando o vínculo intenso entre previdência e saúde. A assistência médica continuou, assim, custeada pela previdência, seja pelo financiamento direto do setor público, seja pelos mecanismos de renúncia fiscal concedidos ao setor privado. (ACIOLE, 2006, p. 175-176).

Nesse contexto, enquanto, de um lado, a saúde pública era relegada a segundo plano, tornando-se "uma máquina ineficiente e conservadora, cuja atuação restringia-se a campanhas de baixa eficácia", de outro, a assistência médica passou, através desse financiamento previdenciário, por sua fase de maior expansão, tanto pelo aumento do número de leitos disponíveis, quanto pela ampliação de sua cobertura e do volume de recursos arrecadados, alcançando o maior orçamento de sua história. (ESCOREL; NASCIMENTO; EDLER, 2005, p. 61). ${ }^{183}$

\footnotetext{
${ }^{183}$ De acordo com o extenso levantamento econômico da saúde e previdência realizado por Braga e Paula (2006, p. 91), o descaso com a atenção à saúde coletiva restou evidente pela redução dos gastos nessa área de saúde pública não acompanhados de uma substituição de suas políticas sanitárias tradicionais por meios mais eficazes e eficientes, como se depreende do agravamento das condições de saúde da população nesse período. Assim, os referidos autores destacam, por exemplo, a decrescente participação do orçamento do Ministério da Saúde no orçamento geral da União, que passou de 2,21\% em 1968 para apenas 1,4\% em 1972. Por sua vez, no que diz respeito aos gastos públicos com esse sistema privatista de assistência médica previdenciária, tem-se que em "1970 o nível real dos gastos do INPS com Saúde - despesas correntes em assistência médica - já era superior ao de 1967 em 95,3\%, conseqüência das taxas elevadas e sustentadas de crescimento desde sua criação [...] Em 1967, a relação entre as despesas com saúde e o total das despesas do INPS era $22,4 \%$, enquanto em 1970 já havia crescido para $26,7 \%$. A partir de 1970 prossegue a elevação
} 
Não obstante esse quadro aparentemente progressista, sua organização tornouse uma fonte incontrolável de corrupção na medida em que o Estado delegava a prestação de boa parte de seus serviços previdenciários na área de saúde às empresas privadas e adotava, como forma de remuneração por tais serviços médicos, o pagamento por Unidade de Serviço (US) em seus convênios com tais entidades, sem contar com uma política de controle e fiscalização desses serviços. (ACIOLE, 2006, p. 179).

Para atender as estratégias e desenvolvimento social do II Plano Nacional de Desenvolvimento (PND) do governo militar, foi instituído o Fundo de Apoio ao Desenvolvimento Social (FAS), pela Lei n. 6.168, de 09 de dezembro de 1974, financiado com os recursos provenientes das loterias esportivas e federal, do orçamento da própria Caixa Econômica Federal e da União, em proporcionalidade direta com os arrecadados pelas receitas dessas loterias, nos termos do art. $2^{\circ}$ do referido diploma legal. (BRASIL, 1974).

No que diz respeito à área da saúde, a administração desse fundo agravou a má aplicação do financiamento público da saúde que, além do emprego dos recursos da Previdência Social, passou a contar com essa fonte para a construção e a reforma de inúmeras clínicas e hospitais privados, através de empréstimos públicos a fundo perdido.

Em relação a essa lógica privatista do direcionamento dos recursos do FAS através do Ministério da Previdência e Assistência Social (MPAS), no sentido do desenvolvimento do setor privado de saúde no Brasil, como "opção modernizadora dos governos autoritários", afirma Aciole (2006, p. 166-167):

[Durante o regime militar], o financiamento a hospitais privados, estrutura-se na forma de uma linha de crédito ao setor Saúde, sob a gestão do Conselho de Desenvolvimento Social do recém criado MPAS. [...] A legislação de criação do FAS previa ainda a distribuição dos recursos numa proporcionalidade que até $60 \%$ deveria ir para o setor público, $30 \%$ para o setor privado, e $10 \%$ para pessoas físicas, proporção que somente foi alcançada na área da educação. $\mathrm{Na}$ saúde, e muito diretamente em razão do modelo assistencial adotado pela previdência, essa relação praticamente se inverte, [...], $62 \%$ do total de propostas beneficiaram os hospitais privados lucrativos. Do total de recursos transferidos para a

sistemática da parcela gasta pelo sistema previdenciário no atendimento à saúde de seus segurados. Em 1976, já 31,3\% das despesas globais da Previdência Social destinavam-se à assistência médica”. (BRAGA; PAULA, 2006, p. 99). 
área, no período entre 1975 e 1977, 73,8\% foram utilizados para a construção de hospitais, sobretudo de tamanho médico e de propriedade privada; $4,9 \%$ para unidades básicas de saúde; $0,8 \%$ para pronto-socorros e $20,5 \%$ em outros serviços, provavelmente de apoio diagnóstico e terapêutico. Esses números representaram incremento de 26.552 novos leitos no País, dos quais $47 \%$ concentrados na região Sudeste.

Concluí-se, portanto, conforme Braga e Paula (2006, p. 131), que com “o FAS, fecha-se o ciclo de apoio financeiro governamental ao setor privado de assistência à saúde e com os recursos das contribuições à previdência, paga-se a parte mais substancial do custeio dos serviços de saúde".

A partir desse levantamento, resta demonstrado o direcionamento dos cuidados com a saúde para a medicina curativa, contribuindo ainda mais para a ineficiência desse sistema de saúde. (ESCOREL; NASCIMENTO; EDLER, 2005, p. 61-62). ${ }^{184}$

Desse modo, durante os anos de 1970, a articulação entre o público e o privado, que segundo Braga e Paula (2006) vinha desde o governo de Getúlio Vargas, é acentuada e passa a contar com o Estado, através da Previdência social, como grande financiador da saúde, e com o setor privado como prestador de serviços de atenção médica além do fornecimento de medicamentos, produtos e equipamentos biomédicos pela indústria internacional.

Consolida-se a partir daí, para utilizar a conceituação corrente entre os sanitaristas e estudiosos desse tema, o modelo biomédico que, aliado ao paradigma flexneriano de medicina, reduz o sistema de saúde ao conjunto de estabelecimentos de assistência médico-hospitalar, centrados no diagnóstico e na terapia alopática. ${ }^{185}$

\footnotetext{
${ }^{184}$ Sobre a prevalência da atuação estatal no atendimento médico individualizado no Brasil do final do século XX, afirma Maria Helena Oliva Augusto (1989, p. 115): “À medida que propicia a universalização do atendimento, a ampliação da assistência médica individualizada é apresentada como indicador de maior justiça social, numa argumentação que oculta a rentabilidade nela presente. Fica também obscurecido o fato dessa universalização realizar-se em detrimento de um outro tipo de intervenção sem a mesma rentabilidade, o das ações médico-sanitárias, que é da mesma forma, e indiscutivelmente, universalizante - ainda que atinja a população de maneira distinta. [...] Como resultado, os domínios referidos tanto à saúde coletiva quanto à saúde individual acabam recebendo, por parte do Estado brasileiro, um tratamento muitas vezes precário, que se manifesta tanto no processo de acentuada extensão dos limites da ação estatal (percebida como estatização indevida das práticas médico-assistenciais), quanto no processo de conquista, pelos interesses particulares, de espaços sempre mais amplos nos organismos oficiais (entendida como privatização progressiva do Estado, no que diz respeito à organização dos serviços de saúde)".

${ }^{185}$ Nesse sentido são os trabalhos de Donnangelo (1975, 1976), Augusto (1989), Paim (1997, 2005), Barros
} 
Dessa lógica sistêmica resulta uma prática de intervenção sobre o corpo social, caracterizada pela hegemonia dos princípios mecanicistas, biologizantes, individualistas, de especialização e tecnifícação que propiciam a medicalização indefinida da sociedade descrita nessa mesma época por Foucault (1974). ${ }^{186}$

Por conseguinte, ao final do governo Médici, que estendeu-se de 1970 a 1974, chega ao fim o curto e ilusório "milagre econômico" brasileiro, não sendo mais possível disfarçar o desgaste desse modelo político e suas conseqüências sociais, sobretudo com a piora dos níveis de saúde, fruto desse modelo concentrador de renda resultante do direcionamento econômico-desenvolvimentista estatal e da subordinação do país ao mercado mundial durante esse período. (FAUSTO, 2002, p. 268-269).

A partir de então, ganharam maior visibilidade diversos estudos e pesquisas sobre os efeitos nefastos do modelo de desenvolvimento adotado para a qualidade da vida de amplos grupos populacionais e sobre o caráter irracional e perdulário do descrito sistema de saúde. (ESCOREL; NASCIMENTO; EDLER, 2005, p. 62).

Ademais, com a rearticulação gradual dos movimentos sociais, foi possível o surgimento de algumas denúncias sobre a grave situação da saúde pública e dos serviços previdenciários de atenção médica, aumentando-se as reivindicações pela resolução mais efetiva desses problemas decorrentes do modelo de saúde implantado.

Nesse contexto, destaca-se o importante papel desempenhado pelos sindicatos

(2002, 2004), Santos (2005), Braga e Paula (2006), Aciole (2006), dentre outros estudiosos da saúde pública brasileira. Por sua vez, no que diz respeito mais especificamente às origens do citado paradigma flexneriano, de acordo com Scherer, Marino e Ramos (2005, p. 56-57), este "consolidou-se em virtude das recomendações apontadas por Abraham Flexner (1866-1959) em relatório encomendado pela Fundação Carnegie dos EstadosUnidos, em 1910 [...], cujas conclusões tiveram amplo impacto na formação médica em quase todo continente americano".

186 Sobre o impacto do modelo biomédico/flexneriano nesse processo bio-político descrito por Foucault (1974), afirmam Scherer, Marino e Ramos (2005, p. 57): "baseado num paradigma fundamentalmente biológico e quase mecanicista para a interpretação dos fenômenos vitais, [o modelo flexneriano]gerou, entre outras coisas, o culto à doença e não à saúde, e a devoção à tecnologia, sob a presunção ilusória de que seria o centro de atividade científica e de assistência à saúde. A evolução do conceito de saúde influenciou e continua influenciando a forma como a comunidade científica incorpora o paradigma da saúde, num processo de reconstrução, tanto por força das inovações científicas, quanto dos métodos e das práticas sanitárias". Nessa mesma linha, segundo Amauri Moraes dos Santos (2005, p. 73), "[essa lógica medicalizante faz com que] os profissionais de saúde envoltos nesta dimensão sigam reproduzindo o modelo capitalista ortodoxo, onde a saúde e o medicamento são considerados produtos de troca, mercadorias de intensa exploração mercantil”. 
das diversas categorias profissionais da saúde e pelos meios acadêmicos e cientistas dessa área, na medida em que os mesmos passaram a discutir a superação desse sistema em seminários e congressos sobre as epidemias, endemias e a degradação da qualidade de vida da população brasileira nesse período.

Teria surgido, assim, um movimento pela transformação das políticas públicas de saúde que unido a outros movimentos sociais passaram a lutar pela efetivação dos direitos civis e sociais, no sentido da redemocrazação do país. (ESCOREL; NASCIMENTO; EDLER, 2005, p. 62).

\subsubsection{O Movimento pela Reforma Sanitária e as tensões entre os sistemas sociais brasileiros em torno de um novo sentido para a saúde pública}

Ao final da década de 1970, durante o governo do general Ernesto Geisel, teve início uma lenta e conservadora abertura política com a distensão do regime em direção ao começo de sua liberalização, ainda que não linear, com pequenos avanços e recuos e a ameaça de retrocesso à linha dura da repressão militar até o final do governo do também general João Batista Figueiredo em 1985. (FAUSTO, 2002, p. 270).

Essa nova conjuntura, em certa medida decorrente da crise social relacionada ao esgotamento do modelo desenvolvimentista até então adotado e, segundo Boris Fausto (2002, p. 271), dos próprios conflitos internos às Forças Armadas, estimulou o rearranjo das interações sistêmicas com o surgimento de novos atores sociais, a diferenciação dos sistemas sociais e a organização dos processos comunicacionais acerca de novos projetos coletivos de interesse público.

Nesse sentido, mesmo não adotando uma abordagem propriamente sistêmica, em sua interpretação desse novo contexto social ainda em formação no início da década de 1980, afirma Aciole (2006, p. 183):

O grau e a profundidade de mudança substantiva nos padrões societários vigentes na sociedade brasileira será marcada pela emergência de um conjunto de novos atores sociais, articulados em torno de demandas sociais e políticas reprimidas, tecendo uma nova teia em torno das questões sociais politicamente problemáticas. Ou seja, essa etapa assistirá à formação e emergência de novas identidades coletivas e pela construção de projetos sociais de mudança, entre os quais podemos mencionar o movimento dos aposentados, o movimento popular em saúde, o movimento sanitário e o movimento dos médicos. 
Embora este trabalho não tenha por objeto estudar a fundo cada um desses movimentos, deve-se destacar a sua importância para a redefinição das expectativas cognitivas e normativas presentes na sociedade brasileira a partir da reestruturação de suas inter-relações sociais tendo como ponto de convergência a Constituição Federal brasileira de $1988 .{ }^{187}$

O movimento pela Reforma Sanitária tem suas origens nessa gradual aproximação entre esses movimentos e diversas outras organizações sociais que resultou na redefinição dos programas finalísticos do Estado e dos processos comunicacionais dos diversos sistemas sociais, que compõe a sociedade brasileira, em relação à saúde.

A conformação do sistema sanitário que se delineia a partir de então decorre, portanto, do embate de expectativas, dos conflitos, e outras tensões sistêmicas e, por que não dizer, materiais, uma vez que, segundo Alain Touraine (1989), a dinâmica histórica da América Latina seria marcada não só pela palavra como pelo sangue.

Assim, em que pesem a característica "desarticulação da ação coletiva", "a fragilidade da mobilização social e política" e o caráter "parcialmente moderno" do Continente Latino-Americano descritos pelo próprio Touraine (1989, p.480, 529-530), a sua redemocratização ganhou força justamente no vazio político, na crise econômica e no esgotamento dos regimes militares, propiciando o fortalecimento dos movimentos sociais e a conformação de um novo projeto de sociedade.

Em face da grave crise do modelo biomédico brasileiro em curso nesse período, diversas mudanças foram se consolidando, inicialmente, em relação a uma outra conceituação do processo saúde-doença, voltada para as suas determinações estruturais e, gradativamente, na própria organização do sistema de saúde, enquanto aparto burocrático estatal, formando as bases teóricas e práticas de uma proposta alternativa defendida pelo Movimento pela Reforma Sanitária.

\footnotetext{
${ }^{187}$ Cumpre ressaltar que as funções da referida Constituição Cidadã de 1988 e Direito em si na articulação dos processos comunicativos dos sistemas que compõe a sociedade brasileira, especialmente sob o prisma do sistema jurídico sanitário, serão discutidas no capítulo seguinte.
} 
No que diz respeito à base teórica desse movimento de reformulação do sistema sanitário nacional, destaca-se a contribuição dos sistemas científicos, sobretudo a partir das organizações universitárias, cujos Departamentos de Medicina Preventiva (DMP), criados na década de 1950, passaram a constituir um importante espaço de produção de conhecimento sobre a saúde da população e o modo de organizar as práticas sanitárias. (ESCOREL; NASCIMENTO; EDLER, 2005, p. 63). ${ }^{188}$

A partir dos estudos desses centros universitários, desenvolveu-se o questionamento, especialmente, das práticas médicas com a revisão crítica da teoria preventista que dominava a abordagem dos problemas de Saúde. Em contraposição teórica a essa forma de análise, foram, assim, delimitadas as dimensões da saúde coletiva com o deslocamento do foco do estudo do processo saúde-doença do indivíduo e de seu quadro somático para a coletividade e a distribuição demográfica da saúde e da doença.

Essa base teórica tem grande impacto no movimento sanitário da época, na medida em que este, segundo Escorel, Nascimento e Edler (2005, p. 64), “constitui-se a partir dos DMP num confronto teórico com o movimento preventista liberal de matriz americana e com sua versão racionalizadora proposta pela burocracia estatal". ${ }^{189}$

Além desse espaço universitário, a difusão de novos meios de comunicação simbolicamente generalizados em torno da saúde pública e a redefinição de sentidos do processo saúde-doença contaram também com a criação de outras organizações como o Centro Brasileiro de Estudos de Saúde (CEBES) em 1976, formado por um grupo de médicos do Curso de Formação em Saúde Pública da Universidade de São Paulo, que, por meio de sua revista Saúde em Debate, passou a divulgar a concepção democrática da saúde

\footnotetext{
${ }^{188}$ Sobre o papel dos Departamentos de Medicina Preventiva (DMP) na formação dos profissionais de saúde, afirmam Escorel, Nascimento e Edler (2005, p. 63): "Os primeiros DMP no Brasil foram criados na década de 1950, na Faculdade Paulista de Medicina e na de Ribeirão Preto. A Lei da Reforma Universitária de 1968, que incorporou a medicina preventiva no currículo das faculdades, tornou obrigatórios os DMP. Este novo campo da especialidade médica foi o locus a partir do qual começou a se organizar o movimento sanitário, que buscava conciliar a produção do conhecimento e a prática política, ao mesmo tempo em que ampliava seu campo de ação, envolvendo-se com organizações da sociedade civil nas suas demandas pela democratização do país".

${ }^{189}$ Nesse sentido, os referidos autores complementam: "O pensamento reformista, que iria construir uma nova agenda no campo da saúde, desenvolveu sua base conceitual a partir de um diálogo estreito com as correntes marxistas e estruturalistas em voga. A reformulação do objeto saúde, na perspectiva do materialismo histórico, e a construção da abordagem médico-social da saúde pretendia superar as visões biológica e ecológica do antigo preventismo". (ESCOREL; NASCIMENTO; EDLER, 2005, p. 64)
} 
como valor, articulando as posições político-ideológicas presente no movimento sanitário. (ACIOLE, 2006, p. 187).

Nessa mesma linha, podem ainda ser citados os simpósios e as publicações da Associação Brasileira de Pós-Graduação em Saúde Coletiva (ABRASCO), instituída em 1979, e sua contribuição para a sistematização das propostas e alternativas ao modelo sanitário vigente. (ALMEIDA; CHIORO; ZIONI, 2001, p. 27).

Nesses foros, os atores sociais encontravam espaço para desenvolver novas interações, emergindo daí processos cognitivos e comunicativos que, por conseguinte, se refletiram na interpenetração desses agentes com os diversos sistemas sociais a eles relacionados.

Em outros termos, da confluência dessas relações sociais nesses espaços públicos foram se consolidando novos sentidos para a saúde entre os sanitaristas e demais atores dos movimentos sociais que lutavam pela Reforma Sanitária, tomados como sistemas psíquicos, refletindo tal mudança nas organizações públicas e sociais, sistemas comunicacionais, com os quais interagiam. ${ }^{190}$

Foi possível com isso o estímulo à reformulação dos processos comunicacionais no interior dos sistemas sociais voltados ao tema saúde na medida em que, paralelamente, ocorria uma mudança do perfil profissional de importantes cargos políticos e técnicos da saúde. Estes postos, com a reabertura política e a derrota dos militares nas eleições estaduais a partir de 1982, passaram a ser ocupados por sanitaristas associados às organizações sociais citadas, formados, em sua grande parte, nos Departamentos de Medicina Social. (ALMEIDA; CHIORO; ZIONI, 2001, p. 29).

\footnotetext{
${ }^{190}$ Dentre os fatores determinantes dessas novas inter-relações, Aciole (2006) destaca ainda a influência da Reforma Sanitária italiana da década de 1970 e das idéias democráticas encampadas pelo "Eurocomunismo" (que defendia a democracia e o papel central do Estado na execução de políticas públicas voltadas ao desenvolvimento social dentre outras coisas e do qual fazia parte o Partido Comunista Italiano) no Movimento pela Reforma Sanitária brasileira. Nesse sentido, afirma o referido autor: "Neste cenário de atores em ação, é imperativo reconhecer o alinhamento ideológico predominante nos setores estratégicos do movimento sanitário com o congênere movimento italiano, que também propunha uma reforma sanitária na Itália. A Reforma Sanitária Italiana ocorrida na década de 1970 exerceu influência na Reforma Sanitária Brasileira [...]. Naquela reforma, o papel desempenhado pelo PCI (Partido Comunista Italiano), alinhado ao chamado Eurocomunismo, tinha como central a tese da democracia com valor universal, como um patrimônio universal da humanidade e, portanto, situada além e acima das classes sociais, [tal tese] vai chegar ao Brasil, especialmente pelos intelectuais ligados ao Partido Comunista Brasileiro e ao Movimento
} 
Essa interpenetração levou a novos projetos e experiências democratizantes na área de saúde como, por exemplo, a implementação das Ações Integradas de Saúde (AIS), de caráter multidisciplinar como tentativa de reorganização da assistência médico-sanitária a partir do INAMPS contando com a participação conjunta das esferas federal, municipais e estaduais e saúde.

Graças a essas Ações Integradas de Saúde, teria sido viabilizada, em 1985, a criação do Sistema Unificado e Descentralizado de Saúde (SUDS) rumo a transitória "estadualização" das unidades do sistema sanitário brasileiro entre a consolidação das propostas da $8^{\mathrm{a}}$ Conferência Nacional de Saúde e a sua incorporação no texto constitucional de 1988. (ACIOLE, 2006, p. 194-195).

Ainda como reflexo desses novos projetos e do envolvimento dos gestores de saúde com o Movimento pela Reforma Sanitária, podem ser citadas as experiências bem sucedidas de implantação de sistemas municipais de saúde como os de Piracicaba, Campinas, Bauru, Londrina, Niterói, dentre outros, a partir do movimento municipalista que tinha por expoente os Encontros das Associações de Secretários Municipais de Saúde e Entidades Estaduais e Nacional de Secretários (COSEMS e CONASEMS). (ALMEIDA; CHIORO; ZIONI, 2001, p. 27).

De modo geral, esses novos processos sociais resultaram numa prática de transição da organização do Estado na saúde em contraposição ao modelo biomédico hegemônico.

Esse rearranjo sistêmico expressou-se de forma marcante na $8^{\mathrm{a}}$ Conferência Nacional de Saúde (CNS) realizada entre 17 e 21 de março de 1986, inaugurando "um processo de participação da sociedade civil nas deliberações sobre a política de saúde" sem precedentes de acordo com Sarah Escorel e Renata Arruda de Bloch (2005, p. 97). ${ }^{191}$

Tal encontro histórico contou com um extenso processo de preparação do qual

de Reforma Sanitária”. (ACIOLE, 2006, p. 186-187).

191 Sobre a importância dessa Conferência para a reformulação do sistema sanitário brasileiro, as referidas autoras afirmam que "o Relatório Final da $8^{\text {a }} \mathrm{CNS}$ constituiu o pilar fundamental da proposta da Reforma Sanitária e do SUS, debatido e aperfeiçoado pela Comissão Nacional da Reforma Sanitária que elaborou o texto que seria incorporado como o capítulo da Saúde na Constituição Federal de 1988". (ESCOREL; BLOCH, 2005, p. 97). 
fizeram parte diversas pré-conferências estaduais e municipais e um extenso trabalho de divulgação de sua temática para a discussão da sociedade como um todo. (ALMEIDA; CHIORO; ZIONI, 2001, p. 31).

A sua abertura para a participação de representantes de entidades não restritas ao meio acadêmico e técnico de saúde resultou na adesão de diversos movimentos sociais, organizações de usuários e trabalhadores do sistema de saúde, partidos políticos, além de parlamentares e delegados de diferentes níveis de governo que se articulavam em torno da democratização do país e, por conseguinte da própria saúde. ${ }^{192}$

Tal espírito democrático refletiu-se na organização da própria Conferência, sendo seus trabalhos divididos em dois grandes grupos, um com os delegados das instituições e organizações da área de saúde e outro formado pelos demais participantes que em princípio poderiam apenas assistir ao encontro.

Dessa forma, em razão das reivindicações dos movimentos sociais participantes, a Conferência teve seus trabalhos reorganizados de modo que seu Relatório Final pudesse contar com as propostas discutidas por todos os presentes, fossem eles delegados ou não. (ESCOREL; BLOCH, 2005, p. 98).

Segundo a síntese proposta por Almeida, Chioro e Zioni (2001, p. 31), essa $8^{\text {a }}$ CNS teria como resultado "o estabelecimento de um consenso político que permitiu a formatação do projeto de Reforma Sanitária” a partir de suas discussões acerca do conceito abrangente de saúde, da compreensão da saúde como um direito de cidadania e dever do Estado, da reformulação do Sistema Nacional de Saúde com a instituição de um Sistema Único de Saúde, além de questões relacionadas ao seu financiamento setorial.

Poderia ainda ser destacada entre as discussões desses conferencistas a questão em torno da natureza do novo sistema de saúde, se este seria totalmente estatizado ou não,

\footnotetext{
${ }^{192}$ De acordo com o quadro de participantes organizado por Escorel e Bloch (2005, p. 118), a $8^{\text {a }}$ CNS contou com mais de quatro mil participantes, dos quais apenas mil considerados formalmente delegados. Os quinhentos representantes institucionais, segundo as referidas autoras, poderiam assim ser divididos: " $50 \%$ nível federal (16\% Ministério da Saúde; 16\% MPAS; 8\% Ministério da Educação; 10\% outros ministérios e órgãos); $22 \%$ nível estadual; $18 \%$ nível municipal; e $10 \%$ parlamento". Por sua vez, quanto aos outros quinhentos delegados tem-se: “ $15 \%$ produtores privados de serviços de saúde; $20 \%$ entidades de categorias de profissionais da saúde; $30 \%$ sindicatos e associações de trabalhadores urbanos e rurais; $10 \%$ associações de moradores; $20 \%$ entidades comunitárias e outras entidades civis; $5 \%$ partidos políticos".
} 
e a opção por sua imediata ou progressiva implementação. Por fim, a idéia de sua completa estatização restou recusada optando-se pelo fortalecimento e pela expansão do setor público de saúde. (ESCOREL; NASCIMENTO; EDLER, 2005, p. 78). ${ }^{193}$

Embora esse encontro não tenha contado com uma participação significativa do setor privado da saúde, beneficiário do combatido modelo privatista, essa ausência foi superada nos trabalhos da Comissão Nacional da Reforma Sanitária (CNRS), que, de acordo com Paim (2005, p. 114), representou um "marco do processo de reconstrução de alianças e de repactuação, também dentro do Movimento Sanitário".

Assim, de sua adesão aos trabalhos da CNRS, resultou a defesa de interesses privados na saúde levando à sua consideração no projeto do novo sistema sanitário. Nesse sentido, segundo Paim (2005, p. 115):

No relatório final da CNRS, encaminhado posteriormente para a Assembléia Nacional Constituinte e que tinha o aval desses atores, apesar dos "destaques", consta que "é assegurado o livre exercício da atividade liberal em saúde e a organização de serviços privados, obedecidos os preceitos éticos e técnicos determinados pela lei e os princípios que norteiam a política nacional de saúde".

Conclui-se, portanto, que esse processo de transformação do sistema sanitário, ao menos na discussão de seus pressupostos organizacionais, lógicos e finalísticos, não foi, como dito, linear, muito menos pacífico.

De modo contrário, decorreu de vários conflitos de interesses entre os sistemas econômico, político, científico, médico como se depreende da referida síntese proposta por Paim (2005), bem como dos entraves à implementação de diversos projetos como o Programa Nacional de Serviços Básicos de Saúde (Prev-Saúde), o fracasso da unificação do INAMPS ao Ministério da Saúde e das tentativas frustradas da proposta do "Plano Conasp" de substituição da forma de remuneração dos convênios com o setor privado, de

\footnotetext{
${ }^{193}$ Sobre a nova organização administrativa do Estado na área de saúde, Escorel, Nascimento e Edler (2005) chamam ainda a atenção para outro tema bastante debatido referente à unificação ou não do INAMPS com o Ministério da Saúde. Segundo o estudo histórico dos citados autores: "Para os conferencistas, a Previdência Social deveria ater-se às ações próprias do seguro social, enquanto a saúde deveria ser entregue a um órgão federal com novas características. O setor saúde receberia recursos vindos de diferentes receitas, sendo que o seu orçamento contaria com recursos provenientes do Inamps. Estes seriam progressivamente retidos, na medida em que seu órgão gestor se tornasse possuidor de financiamento próprio". (ESCOREL, NASCIMENTO, EDLER, 2005, p. 78).
} 
unidades de serviço por procedimentos, dentre tantos outros reversos do movimento sanitário no início dos anos 1980. (ACIOLE, 2006, p. 188; ESCOREL; NASCIMENTO; EDLER, 2005, p. 75).

Tem-se, assim, o panorama geral das tensões sistêmicas que conformaram os processos comunicacionais em relação à mudança nos rumos da saúde brasileira e de sua relação com o Estado.

\subsection{Aspectos gerais da nova organização constitucional do sistema sanitário brasileiro}

As tensões entre o Movimento pela Reforma Sanitária e os sistemas econômico e político acerca da redefinição de uma forma de organização do sistema sanitário brasileiro que fosse capaz de se contrapor ao modelo biomédico até então vigente levaram à generalização e institucionalização de novas expectativas normativas em relação à saúde na Constituição da República Federativa do Brasil de 1988.

Tem-se, assim, o surgimento de novos processos comunicacionais no interior do sistema sanitário decorrentes da organização do sistema de saúde prevista nessa inovadora Constituição brasileira.

De acordo com Schwartz (2004, p. 78), embora sejam relacionados, um "sistema de saúde não é sinônimo de sistema social sanitário". Segundo o referido autor, o sistema de saúde, em si, poderia ser entendido como o modo pelo qual o sistema sanitário se organiza. Nesse sentido, afirma:

[...] O sistema social se auto-reproduz por intermédio de seus elementos, enquanto as organizações decidem por intermédio das premissas de decisões. Um sistema organizacional de saúde é o meio em que há a prestação sanitária mediante processos decisórios tendentes à prestação da função sistêmico-sanitária (saúde). É a estrutura que permite processo comunicacional da observação da distinção Saúde/Enfermidade. Suas decisões, baseadas no referido código, dão a unidade do sistema sanitário e possibilitam-lhe sua contínua auto-reprodução. (SCHWARTZ, 2004, p. 78).

Como foi especificado no primeiro capítulo, as organizações juntamente com as interações constituem sistemas sociais parciais, formados por relações inter-sistêmicas, sociais e psíquicas, com processos comunicacionais próprios.

Ademais, tais processos não se restringem apenas à seleção de sentidos por 
meio de códigos de pertencimento, sendo observada a sua diferenciação através de diferentes vias de comunicação, dentre as quais se destaca a formação de estruturas hierárquicas internas que têm por função determinar as posições e a diferenciação funcional desse sistema organizacional. (NEVES, 2005, p. 60).

Em razão dessa forma de estruturação de suas operações internas, tais sistemas organizacionais trabalham com programas referentes aos seus objetivos e às condições sob as quais tais objetivos devem ser alcançados.

Por conseguinte, as organizações devem ser entendidas como espécies peculiares e parciais de sistemas sociais resultantes de acoplamentos estruturais entre sistemas sociais complexos. (LUHMANN, 1993, p. 187).

Nesse contexto, o Sistema Único de Saúde (SUS) apresenta-se como o sistema organizacional da saúde adotado pela Constituição de 1988 que promove, enquanto sistema parcial, o acoplamento estrutural de diversos outros sistemas consolidados e de maior complexidade.

Daí resulta que, como espécie de sistema organizacional, em sua estruturação repercute as operações próprias daqueles outros sistemas, não sendo, portanto, compostos de processos comunicacionais de um único sistema social.

O SUS cumpre, assim, a articulação entre os diversos sistemas sociais relacionados à saúde, tanto daqueles que se apresentavam a favor da reforma sanitária quanto dos que a ela se opunham, a fim de administrar a seleção de sentidos e os conflitos decorrentes das expectativas desses diversos sistemas sociais em relação à atuação do Estado e da sociedade como um todo na área de saúde.

Nos limites deste trabalho e em razão de seus objetivos inicialmente propostos, a conformação em si desse novo sistema organizacional deve ser aqui traçada apenas em suas linhas gerais de modo a dimensionar a discussão derradeira relativa à força normativa constitucional do sistema jurídico sanitário, que se segue no capítulo final.

A Constituição de 1988 determina, assim, a conformação desse sistema organizacional brasileiro de saúde. As expectativas normativas em relação à saúde são 
garantidas em diversas normas constitucionais podendo-se aqui destacar, em princípio, os seus artigos $6^{\circ}, 194,196$ e seguintes. ${ }^{194}$

A inserção da saúde em nível constitucional entre os direitos sociais que compõem os Direitos e Garantias Fundamentais da República Federativa do Brasil (Título II, Capítulo II, art. $6^{\circ}$ ), bem como no "conjunto integrado de ações de iniciativa dos Poderes Públicos e da sociedade" que compõe a Seguridade Social (Título VIII, Capítulo II, art. 194) é de suma importância para a interpretação da força normativa do sistema jurídico sanitário, razão porque sua discussão será empreendida na parte final deste trabalho.

No que diz respeito ao artigo 196 da Constituição Federal de 1988, cumpre ainda algumas considerações a seu respeito. De acordo com o referido dispositivo constitucional, tem-se que:

Art. 196. A saúde é direito de todos e dever do Estado, garantido mediante políticas sociais e econômicas que visem à redução do risco de doença e de outros agravos e ao acesso universal e igualitário às ações e serviços para sua promoção, proteção e recuperação. (BRASIL, 1988).

Nesses termos, o sistema sanitário e os demais sistemas sociais que compõem a sociedade brasileira redefinem sua responsabilidade e a do próprio Estado na organização do sistema sanitário nacional. ${ }^{195}$

\footnotetext{
${ }^{194}$ Poderiam ainda ser citados, de modo complementar, os seguintes dispositivos: art. 23 que trata dos entes públicos encarregados de cuidar da saúde pública; art. 24, acerca da competência legislativa em saúde; art. 30 , sobre o dever de prestar atendimento na área da saúde; art. 34 que dispõe sobre o poder-dever da União em intervir nos Estados e Distrito Federal para assegurar a "aplicação do mínimo exigido da receita resultante de impostos estaduais, compreendida a proveniente de transferências, na manutenção e desenvolvimento do ensino e nas ações e serviços públicos de saúde" (prevista na alínea "e" de seu inciso VII, acrescido pela Emenda Constitucional n. 29 de 2000); art. 35, sobre o poder do Estado em intervir nos Municípios quando "não tiver sido aplicado o mínimo exigido da receita municipal na manutenção e desenvolvimento do ensino e nas ações e serviços públicos de saúde" (inciso III, alterado pela referida EC 29/2000).

${ }^{195}$ No que diz respeito aos poderes públicos do Estado, a distribuição de competências em matéria de saúde na Constituição Federal de 1988 se fez entre todos os entes da Federação, sendo todos competentes em matéria de defesa da saúde (art. 196). Dessa forma, nos termos do artigo 24 da Constituição de 1988, a maior parte das matérias sobre a proteção e defesa da saúde são de competência comum e legislação concorrente . Possibilitou-se, assim, a normatização da matéria nos três planos, Federal, Estadual e Municipal, respeitada a integração de suas políticas no SUS. Nesse sentido, afirma Sueli Dallari (1995, p. 42): "a conclusão inevitável em matéria sanitária é que a Constituição Federal vigente não isentou qualquer esfera de poder político da obrigação de proteger, defender e cuidar da saúde".
} 
A sociedade compromete-se a viabilizar políticas sociais e econômicas com o objetivo de reduzir "os riscos de doença e de outros agravos" numa dimensão preventiva, que não pode mais ser satisfeita simplesmente pela manutenção de um sistema assistencial médico-curativo, privatista e discriminador, como aquele desenvolvido até 1988.

Nesse intento, "o acesso universal e igualitário às ações e serviços para a sua promoção, proteção e recuperação" deve garantir a todos, cidadãos brasileiros ou não, o direito de não apenas serem atendidos pelos serviços assistenciais curativos do SUS, como também de serem alcançados pelas ações e demais políticas públicas voltadas à prevenção e à promoção de sua saúde de maneira geral. ${ }^{196}$

A promoção da saúde deve ser entendida não apenas como a cura e a prevenção de doenças, mas de forma mais abrangente e interdisciplinar relacionada à garantia da qualidade de vida enquanto questão intrinsecamente ligada à saúde. Apresentase, assim, como "um processo que se constrói e que se modifica, sofrendo influência de todos os demais sistemas sociais". (SCHWARTZ, 2004, p. 102). ${ }^{197}$

\footnotetext{
${ }^{196}$ De acordo com diversos autores, dentre os quais Dallari (1995), Rocha (1999), Castro (2003) e Schwartz (2004), a Constituição Federal de 1988 teria, assim, recepcionado o conceito de saúde proposto pela Constituição da Organização Mundial da Saúde de 1946 no sentido de entender a saúde como "o estado de completo bem-estar físico, mental e social e não somente a ausência de doenças ou enfermidades". (WHO, 1989). Embora não seja possível adentrar a essa questão polêmica referente ao conceito de saúde, cumpre destacar à critica de Dejours (1986) a essa abrangente definição e sua contra-proposta por um novo conceito de saúde. A partir do desenvolvimento científico da fisiologia, da psicossomática e da psicodinâmica do trabalho, o referido autor francês chama a atenção para o aspecto dinâmico e social da saúde que não seria um estágio atingível, nem sequer passível de ser mantido, mas sim um processo relacionado a diversos fatores não apenas fisiológicos como também psíquicos, psicossomáticos e laborais. Neste último aspecto ressalta os agravos à saúde decorrentes não apenas das condições do ambiente de trabalho como de sua própria forma de organização moderna, que, em última instância, leva à banalização da injustiça social, descrita por Dejours (1999), como subterfúgio ao enfrentamento do mal estar psíquico decorrentes de suas relações sócio-laborais.
}

${ }^{197}$ No que diz respeito as tensões em torno dos sentidos de promoção da saúde, Stotz e Araújo (2004), destacam a divergência entre as distintas concepções desse termo e sua definição em diferentes documentos internacionais da Organização Mundial da Saúde. Segundo os referidos autores tem-se, basicamente, duas propostas de promoção em saúde: uma para o centro do capitalismo e outra para os países que compõem a sua periferia. Nesse sentido, enquanto que em documentos europeus, como na Carta de Ottawa de 1986, a promoção é vista como um programa de "redução das diferenças no estado de saúde da população sob o enfoque da equidade em saúde", por sua vez, para os países pobres ou "em desenvolvimento" como o Brasil passa-se cada vez mais a se propugnar, no que diz respeito a essa mesma promoção em saúde uma "responsabilização das pessoas pelas suas condições sanitárias" na medida em que procuram "impulsionar a cultura da saúde modificando valores, atitudes e relações" e não as condições estruturais de vida a que essas pessoas são submetidas, como se depreende da Carta de Bogotá de 1992 promovida pela Organização PanAmericana de saúde (OPAS), e das políticas de ajustes estruturais impostas aos países devedores pelo Banco Mundial a partir de 1990. Nesse sentido, advertem os referidos autores: "De fato, consideramos que uma das 
A proteção da saúde, por sua vez, requer o trabalho da vigilância sanitária voltado à redução dos riscos à saúde, atuando no momento anterior ao da doença e contra a sua difusão. (COSTA; ROZENFELD, 2000, p. 17).

Tem-se, de maneira geral, que essas ações e serviços de saúde são considerados de relevância pública, sejam eles desempenhados pelos poderes públicos ou de maneira autônoma pela iniciativa privada (art. 198), conforme se depreende do art. 197 da Constituição Federal brasileira.

Por conseguinte, além conferir uma atribuição funcional ao Ministério Público no sentido da proteção do direito à saúde, esse destaque do interesse público sobre as ações e os serviços de saúde denota a sua importância global para a existência e os processos comunicacionais de todos os sistemas que compõe a sociedade brasileira.

Em outros termos, como será discutido a seguir, as operações sistêmicas relacionadas à saúde, independentemente de sua origem e extensão, devem partir de uma conformação mínima às normas constitucionais, enquanto expectativas normativas garantidas pela Constituição e, assim, compartilhadas por todos os sistemas sociais.

Nesse mesmo sentido, acerca da relevância pública da saúde, afirma Schwartz (2004, p. 102-103):

[...] a Constituição conferiu à saúde e à dignidade humana um caráter fundamental e primário, no sentido de antecedente aos demais. Essa é uma premissa decisória básica do sistema organizacional brasileiro de saúde, irradiando-se a todas as suas escalas de decisão de forma cíclicorecursiva, de tal forma que decisões dela derivadas vinculam o Poder Público, tornando seu dever dispor sobre sua regulamentação, fiscalização e controle.

No que diz respeito à estruturação e hierarquia desse sistema organizacional representado pelo SUS, tem-se claramente a incorporação no novo sistema regulado pela Constituição Federal de 1988 de boa parte das reivindicações que desde a $8^{\text {a }}$ Conferência Nacional de Saúde de 1986 passaram a fazer parte do ideário de redemocratização do

mudanças relevantes na prática da saúde pública no Brasil, desde o advento da promoção, tenha sido a sofisticação das estratégias de culpabilização das próprias vítimas da incúria sanitária, além da creditação oficial do condicionamento comportamental (behaviorismo), absolutamente avessas a qualquer pedagogia da problematização". (STOTZ; ARAÚJO, 2004, p. 13). 
sistema de saúde brasileiro. (ESCOREL; BLOCH, 2005, p. 99).

Conforme se depreende do artigo 198 do texto constitucional em questão, as "ações e serviços públicos de saúde integram uma rede regionalizada e hierarquizada e constituem um sistema único".

De acordo com seus incisos, essa regionalização hierarquizada em torno de um único sistema tem por diretrizes a sua (i) descentralização "com direção única em cada esfera de governo"; a garantia do (ii) atendimento integral, "com prioridade para as atividades preventivas, sem prejuízo dos serviços assistenciais", e em todo o processo decisório que envolve a estruturação e o funcionamento desse sistema a previsão da (iii) participação da comunidade.

A descentralização apresenta-se como uma importante forma de regionalização das ações e serviços do sistema de saúde brasileiro que pode ser situada no contexto do Federalismo e da descentralização das políticas públicas promovida pela Constituição Federal de $1988 .^{198}$

De acordo com Sílvia Gerschmann e Ana Luíza D’Ávila Viana (2005), a descentralização institucional das políticas e serviços de saúde era vista pelo Movimento pela Reforma Sanitária como uma forma de desconcentração efetiva do poder político que "outorgaria um status democrático aos serviços de assistência à saúde" na medida em que se acreditava que sua efetiva realização "levaria ao fato de que os próprios cidadãos passariam a exercer o controle social, a participação efetiva na direção dos serviços de saúde e a implementação das ações de saúde”. (GERSCHMANN; VIANA, 2005, p. 309).

Nesse sentido, aliada à descentralização, consta a previsão de participação da comunidade na gestão do SUS como medida imprescindível para a democratização e eficácia de suas ações e seus serviços de saúde.

Por sua vez, no que diz respeito à integralidade do atendimento, tal diretriz

\footnotetext{
198 A esse respeito, posiciona-se Bercovici (2002, p. 23-24): “A elaboração de políticas deliberadas de descentralização, em âmbito nacional, é essencial no Brasil, onde a transferência das políticas sociais não é um processo espontâneo. O Brasil, sob a Constituição de 1988, é uma Federação. Portanto, os entes federados são dotados de autonomia, não sendo obrigados a aderir a nenhuma política federal de descentralização de políticas sociais, salvo determinação constitucional. [...] A decisão de descentralizar está, irremediavelmente, ligada à questão das desigualdades regionais, que nunca foram encaradas como
} 
implica na compreensão de que "todas as ações e os serviços de saúde (promoção, proteção e recuperação) são uma realidade una e, portanto, inseparável, constituindo-se em um todo que atua de modo harmonioso e contínuo". (SCHWARTZ, 2004, p. 106). ${ }^{199}$

Foi possível, assim, explicitar os aspectos mais gerais relacionados à organização do SUS pertinentes a discussão do sistema jurídico sanitário sob o seu enfoque normativo constitucional.

Em relação à gama de outras questões relacionadas à saúde e à organização da saúde, deve-se aqui explicar a opção por uma abordagem mais geral do sistema sanitário que fosse capaz de fornecer uma compreensão aproximada da dinâmica global de seus processos comunicacionais e de suas inter-relações como os demais sistemas sociais, com especial atenção para o sistema jurídico sanitário.

prioridades máximas".

${ }^{199}$ Cumpre apenas ressaltar que nos termos do art. 200 da Constituição Federal de 1988, dentre as demais atribuições sob a competência do SUS apresentam-se: (i) o controle e a fiscalização dos procedimentos, produtos e substâncias de interesse para a saúde e a participação na produção de medicamentos, equipamentos, imunobiológicos, hemoderivados e outros insumos; (ii) a execução das ações de vigilância sanitária e epidemiológica, bem como as de saúde do trabalhador; (iii) a ordenação e a formação de recursos humanos na área de saúde; (iv) a participação na formulação da política e na execução das ações de saneamento básico; (v) o incremento, em sua área de atuação, do desenvolvimento científico e tecnológico; (vi) a fiscalização e inspeção de alimentos, compreendendo nessas atividades o controle de seu teor nutricional, bem como de bebidas e águas para consumo humano; (vii) a participação no controle e na fiscalização da produção, transporte, guarda e utilização de substâncias e produtos psicoativos, tóxicos e radioativos; (viii) a colaboração na proteção do meio ambiente, nele compreendido o do trabalho, dentre outras atividades a serem previstas em lei. 
Por essa razão, foge aos objetivos desse trabalho discutir as disposições relacionadas diretamente à liberdade conferida à iniciativa privada em prestar por conta própria os serviços de assistência à saúde, garantida nos termos do artigo 199 da Constituição Federal de 1988, bem como os pontos que dizem respeito ao financiamento da Saúde, prevista nos três primeiros parágrafos do artigo 198 da referida Constituição.

Em que pese a importância desses temas, a discussão em curso se volta para a compreensão do sistema jurídico sanitário a partir da interpretação dos direitos sociais inscritos na Constituição Federal brasileira e da definição de sua força normativa em generalizar as expectativas normativas relacionadas à saúde, garantindo-se, ainda que contrafactualmente, a sua manutenção na sociedade brasileira. 


\section{A FORÇA NORMATIVA CONSTITUCIONAL DO SISTEMA JURÍDICO SANITÁRIO}

Neste último capítulo pretende-se, inicialmente, situar a Constituição da República Federativa do Brasil de 1988 como o ponto de convergência dos processos comunicacionais da sociedade brasileira no sentido da mais abrangente forma de institucionalização de expectativas normativas.

Essa função constitucional é fundamental para a formação de meios de comunicação simbolicamente generalizados a partir dos quais as complexões de expectativas da sociedade, normatizadas em seus princípios e regras constitucionais, se autonomizam nos casos concretos permitindo a estabilidade e o funcionamento autopoiético dos sistemas sociais.

Dessa forma, será discutido como a Constituição, enquanto "unidade política de um povo" (BERCOVICI, 2005, p. 09), não se restringe, de forma alguma, a um "mecanismo de acoplamento estrutural [apenas] entre direito e política" (CAMPILONGO, 2002, p. 98).

Cumpre adiantar que essa subestimação de sua função sistêmica decorreria de um descompasso entre os sentidos atribuídos ao termo "política" e os equívocos interpretativos daí decorrentes, na medida em que, de um lado, em Direito Constitucional o mesmo é empregado numa dimensão mais ampla do todo social e, de outro, alguns teóricos sistêmicos interpretam equivocadamente o sentido político da Constituição a partir de uma acepção mais restrita em que o referido termo é utilizado na teoria luhmanniana para especificar o subsistema social em que seriam tomadas as decisões vinculantes, ou seja, o sistema politico. (HESPANHA, 1999).

Uma vez empreendida essa importante revisão teórica, será possível delinear a força normativa do sistema jurídico sanitário a partir de sua interpretação constitucional e de seus processos auto-referenciais relacionados à dinâmica interna da Seguridade Social de que faz parte. 


\subsection{A força normativa da Constituição e a teoria dos sistemas}

Tendo em vista os limites e os objetivos deste trabalho, faz-se necessário especificar que a problematização da Constituição será restrita ao enfoque sistêmico no sentido de sua controversa função em relação às inter-relações entre os sistemas sociais.

Dessa forma, não cabe aqui esmiuçar questões “jurídico-dogmáticas”, próprias do campo científico do Direito Constitucional e da Filosofia Política, centradas na discussão do "tipo de Constituição", por exemplo, se no Brasil vige uma Constituiçãoquadro, uma Constituição programa, dirigente ou uma Constituição-processo etc.

Nessa linha, poderia ainda ser citado o problema referente à natureza de suas normas, ou seja, se a Constituição de 1988 contém simplesmente regras ou também princípios, sendo ou não consagradora e garantidora de direitos fundamentais, ou, ainda, se está limitada a uma Constituição do poder, dentre tantos outros levantamentos possíveis nessa área. (Canotilho, 1997, 2004).

De acordo com José Joaquim Gomes Canotilho (2004, p. 04), a pertinência de tais questionamentos não apresentaria em si grande relevância, ao menos em termos de sua alternatividade, pois, em seu entender, "em todas as Constituições há princípios, regras, programas, normas de direito, normas de organização e de competência”.

Sendo assim, a especificidade da Constituição Federal de 1988 quanto à preponderância de uma dessas características em detrimento de outras será tratada apenas de maneira incidental nos tópicos seguintes.

A fim de situar a Constituição e sua força normativa em relação aos acoplamentos estruturais e processos comunicacionais que compõem a sociedade brasileira, deve ser retomada a discussão introduzida nos dois primeiros capítulos acerca da dupla contingência e de como os sistemas sociais dependem do sistema jurídico para generalizar e reafirmar expectativas mínimas que cada sistema pode, em princípio, considerar em relação aos demais em seus processos internos de dotação de sentido. 


\subsubsection{Dupla contingência e função sistêmica do direito}

Como exposto inicialmente, os sistemas sociais são dotados de um fechamento operacional a partir do qual desenvolvem processos de criação e reprodução de seus elementos de funcionamento.

Daí decorre a impossibilidade de se alcançar sua total compreensão por meio de observações que lhes sejam externas tanto sob o ponto de vista do ambiente quanto do interior de outros sistemas de sentido, sociais ou psíquicos.

Insere-se nesse contexto a (dupla) contingência desses processos comunicacionais em face da dificuldade de se predeterminar com exatidão e segurança as condições de existência e as operações internas de tais sistemas, passíveis de mudança a qualquer tempo dada a ampla possibilidade de decisões e de escolhas de sentido que caracteriza a própria complexidade social. (LUHMANN, 1998, p. 113).

Reconhecida pelos sistemas, essa dupla contingência é enfrentada por seus mecanismos operacionais tornando-se parte de seu repertório sistêmico voltado à proteção frente à improbabilidade de comunicação decorrente dessa imprevisão.

Ainda assim, não se supera por completo os riscos a ela relacionados. Estes se mantêm, paradoxalmente, potencializados com a formação de expectativas operacionais em relação aos demais sistemas em suas inevitáveis inter-relações, seja nos acoplamentos estruturais entre sistemas sociais, nas interpenetrações entre sistemas sociais e psíquicos ou nas simples interações entre estes últimos. ${ }^{200}$

Destaca-se nesse ponto a função desempenhada por essas expectativas, decorrentes da mútua observação entre os sistemas, e o desenvolvimento dos meios de comunicação simbolicamente generalizados que permitem aos sistemas darem continuidade às suas operações de modo circular em seus processos de dotação de sentido e de seleção de

\footnotetext{
200 Quanto à função dos acoplamentos estruturais, vale retomar, a sua importância como condição de cognição fundamental para o processo comunicacional sistêmico, sem os quais não seria percebida a perturbação decorrente da divergência de expectativas entre os sistemas levando à perda de "oportunidades de aprendizado e de transformação de suas estruturas". (LUHMANN, 1992, p. 1.433). Por essa razão é que esses acoplamentos apresentam-se como pré-condição para a construção de regularidades, ordem e redundância indispensáveis para a redução e ordenação da complexidade desorganizada do mundo. (LUHMANN, 1998, p. 169-170).
} 
informações.

Por sua vez, o sistema jurídico trabalha a redução de complexidade através da estabilização de expectativas, servindo de orientação para os demais sistemas sociais e psíquicos. Essa estabilização de expectativas objetivas tem por fim a sua "simplificação através de uma redução generalizante”. (LUHMANN, 1983, p. 52). ${ }^{201}$

Nesse sentido, podem ser recontextualizados, inicialmente, o sistema jurídico e, logo a seguir, a própria Constituição. De acordo com Luhmann (1983, p. 227):

[...] Por tornarem-se potencialmente conflitantes, eles [os sistemas sociais] devem ser regulamentados detalhadamente. Em termos gerais, a diferenciação funcional acarreta um crescimento dos problemas e dos conflitos internos na sociedade e, dessa forma, um crescimento dos encargos decisórios em todos os planos da generalização. Os sistemas parciais da sociedade tornam-se cada vez mais reciprocamente dependentes: a economia depende das garantias políticas e de decisões parametrais; a política, do sucesso econômico; a ciência, de financiamentos e da capacidade de planejamento da política; a economia, da pesquisa científica; a família, do resultado econômico dos programas políticos de pleno emprego; a política, da socialização através da família; e a assim por diante. Ao mesmo tempo os sistemas parciais, para poderem exercer sua função constante e confiavelmente, têm que ser protegidos contra flutuações em outras esferas por eles incontroláveis. As dependências e independências recíprocas dos sistemas parciais crescem simultaneamente. [...] Dessa forma, cresce a necessidade de disponibilidades e de seguranças, que tem que ser satisfeita se bem que a liberdade de um significa a insegurança do outro. [...] Os problemas em conseqüência da diferenciação funcional transparecem aqui, e também em outros casos, nos diversos institutos do direito, no fato de que noções já familiarizadas se tornam questionáveis e inseguras; surgem rachaduras nos sistemas dogmáticos.

Dessa forma, se de um lado o processo de diferenciação funcional do sistema social global implica no fato de nenhum dos sistemas emergentes poder reivindicar a supremacia sobre os demais, nem sequer pretender substituí-los em suas respectivas funções, de outro lado, não se extinguiu a interdependência entre eles e, particularmente, a função sistêmica do direito. (LUHMANN, 1992, p. 1434-1435).

\footnotetext{
${ }^{201}$ Vale lembrar o destaque feito por Luhmann (1983, p. 52) ao aspecto simbólico da estabilização de expectativas como forma de "síntese regulativa de sentido" pelos sistemas sociais, o que não seria plenamente compreendido a partir de uma visão restritiva à generalização de expectativas meramente comportamentais e à questão coercitiva da garantia do comportamento conforme essas expectativas.
} 
A generalização e institucionalização de expectativas normativas decorrem da necessidade de seu direcionamento com o propósito de reduzir a sua exposição às frustrações ou mesmo ao conflito com outras expectativas normativas não limitadas a dois, mas a três ou mais sistemas de sentidos. Promove-se, assim, uma antecipação de expectativas que serão em parte produzidas pelos sistemas de sentido para a absorção dessas frustrações. ${ }^{202}$

Essa função de difusão e manutenção de expectativas mínimas (normativas) que cada sistema pode nutrir em relação aos demais, segundo Luhmann (1983) é exercida pelo sistema jurídico, daí porque afirmar:

Não é mero acaso que esse processo da positivação do direito se dê em
paralelo ao pleno desenvolvimento da diferenciação funcional do sistema
social. Seria possível comprovar o entrelaçamento de interdependências
diretas e indiretas - basta pensar nos diversos motivos para a legislação
que surgiram da insuficiente integração entre economia e família, entre
economia e política. O decisivo é a convergência em princípio. A
diferenciação funcional especifica e abstrai as perspectivas dos sistemas
parciais da sociedade atribuindo-lhes funções e possibilidades desiguais.
Já classificamos isso como superprodução de possibilidades
estruturalmente condicionada. Essa mudança exige um direito que pode
captar mais possibilidades e ordená-las em processos seletivos e cujo
princípio satisfaça a riqueza de possibilidades e sua redução. A
diferenciação funcional do sistema social e a positividade do direito
convergem nesse traço básico de complexidade e contingência
superdimensionadas - uma sobrecarga que a sociedade se auto-impõe e
que desencadeia processos seletivos internos ao sistema (LUHMANN,
1983, p. 237).

Com a evolução da sociedade e do nível de diferenciação funcional de seus subsistemas sociais, a Constituição passa a assumir através de seus programas e princípios normativos o papel não mais restrito à positivação estritamente legal. ${ }^{203}$

\footnotetext{
${ }^{202}$ Cumpre acrescentar que a importância desse mecanismo relaciona-se à menor tolerância dos sistemas à frustração de expectativas normativas em comparação às cognitivas. Assim, através de sua institucionalização, segundo Luhmann (1983, p. 77), acaba-se por "delinear o grau em que as expectativas podem estar apoiadas sobre expectativas de expectativas supostas em terceiros".

${ }^{203}$ Nesse sentido evolutivo do direito e da própria Constituição, Luis Roberto Barroso (2005), ao tratar da força normativa da Constituição, destaca a atribuição às normas constitucionais de status de normas jurídicas, sejam elas regras ou princípios, como uma das grandes mudanças paradigmáticas ocorridas ao longo do século XX. Por conseguinte, cumpre destacar, desde já, que a noção de princípios adotada neste trabalho e sua função no sistema jurídico não se restringem, de forma alguma, à concepção tradicional depreendida do art. $4^{\circ}$ da Lei de Introdução ao Código Civil (Decreto-lei 4.657, de 4 de setembro de 1942),
} 


\subsubsection{Constituição, expectativas normativas e os sistemas sociais}

Em sua dimensão objetiva, os programas e princípios constitucionais, enquanto complexões de expectativas, permitem a formação de meios de comunicação simbolicamente generalizados, a partir dos quais essas complexões se autonomizam em casos concretos permitindo a recursividade das operações seletivas de sentido, no interior dos sistemas sociais.

Em relação ao sistema jurídico, esses programas finalísticos e os princípios interagem nos processos seletivos de informações em sua abertura cognitiva ao ambiente na medida em que delimitam os sentidos possíveis do código binário direito/não-direito.

Conferem, dessa forma, um mínimo de coerência interna à autoreferencialidade do direito, exercendo o controle interno de suas operações comunicacionais, seu direcionamento e as condições sob as quais tais processos podem e devem ocorrer.

Nesse sentido, a interpretação constitucional dos princípios, tratada a seguir,

que considera apenas os efeitos restritos do "princípios gerais de direito" em seu papel de complementação do sistema nas hipóteses em que a lei for omissa. Essa concepção supletiva dos princípios não mais se justifica em relação à diferenciação dos sistemas sociais. Sendo assim, segundo Robert Alexy (1993, p. 83): "tanto as regras como os princípios são normas porque ambos dizem o que deve ser. Ambos podem ser formulados com a ajuda das expressões deônticas básicas do mandamento, da permissão e da proibição. Os princípios, assim como as regras, são razões para juízos concretos do dever-ser, ainda quando sejam razões de um tipo muito diferente. A distinção entre regras e princípio é, portanto, uma distinção entre dois tipos de normas". Ademais, de acordo com o referido autor, além de serem considerados como verdadeiras normas jurídicas, os princípios exercem ainda uma função peculiar no sistema jurídico devendo ser entendidos como "mandamentos de otimização". Nesse sentido afirma: "o ponto decisivo para a distinção entre regras e princípios é que os princípios são normas que ordenam que algo seja realizado na maior medida possível, dentro das possibilidades jurídicas e reais existentes. Para tanto, os princípios são mandamentos de otimização, que estão caracterizados pelo fato de que podem ser cumpridos em diferentes graus e que a medida devida de seu cumprimento não só depende das possibilidades reais, senão também das jurídicas. [...] Por sua vez, as regras são normas que apenas podem ser cumpridas ou não. Se uma regra é válida, então há de fazer-se exatamente o que ela exige, nem mais nem menos. Para tanto, as regras contêm determinações no âmbito fático e juridicamente possível". Essa distinção entre regras e princípios é fundamental pois, enquanto que um "conflito entre regras só pode ser solucionado ou através da introdução numa das regras de uma cláusula de exceção que elimina o conflito ou declarando-se inválida, pelo menos, uma das regras", no que diz respeito aos princípios, quando estes "colidem", não se aplica o tudo ou nada do conflito citado entre regras, mas um equilíbrio entre eles que pode resultar em que, no caso concreto, um deles ceda ao outro. Porém, ainda conforme o renomado jurista mencionado, "isto não significa declarar inválido o princípio afastado nem que no princípio afastado tenha que se introduzir uma cláusula de exceção. O que sucede, mais exatamente, é que, sob certas circunstâncias, um dos princípios precede o outro. Sob outras circunstâncias, a questão de precedência pode ser solucionada de maneira inversa. É este o sentido que se quer dizer quando se afirma que, nos casos concretos, os princípios têm diferentes pesos e que prevalece o princípios com maior peso". (ALEXY, 1993, p. 87-89). 
permite a evolução do próprio direito na medida em que a produção legislativa se mostra incapaz de atender a essa generalização de expectativas e a uniformização parcial de sentidos atribuídos por sistemas sociais cada vez mais especializados, cujos meios de comunicação simbolicamente generalizados não seriam captados pelo processo legislativo tradicional.

Observa-se, contudo, certa subestimação dessa função constitucional e de sua força normativa em seu aspecto integrador na sociedade, mesmo sob o enfoque teórico sistêmico.

Como fora introduzido, esse equívoco, em termos luhmannianos, poderia ser entendido como um descompasso ou mesmo um conflito entre os diversos sentidos do termo "política" utilizados em diferentes sistemas comunicacionais ou mesmo psíquicos.

No que diz respeito ao tema em questão, a divergência interpretativa estaria relacionada ao emprego do termo política que pode se referir tanto ao sentido mais amplo do todo social no qual se insere a Constituição, quanto para especificar o subsistema social da política. A esse respeito, afirma Benedito Hespanha (1999, p. 60):

A amplitude da compreensão hermenêutica dos fenômenos políticos da
ordem social poderá constituir óbice epistemológico para a comunicação
normativa da realidade positiva constitucional; o político que se regula no
texto Constitucional pode significar um minus, um plus ou um nihil do
político que é regulado na experiência histórica.

Por essa razão, segundo o referido autor, apesar da "construção científica de um sistema constitucional [decorrer] da existência lógica de um sistema político", é preciso salientar que ambas as ciências, constitucional e política, são diferentes e autônomas entre si, de modo que o "político do Direito e do sistema constitucional não é idêntico ao político da ciência e do sistema político”. (HESPANHA, 1999, 59).

A esse respeito, deve-se transcrever a síntese desse desenvolvimento normativo constitucional sob a perspectiva evolutiva do direito e do papel dos Tribunais em sua interpretação e transformação feita pelo próprio Luhmann (1990a, p. 151-152):

A diferenciação de um sistema jurídico autoconstituinte encontra um respaldo organizacional na diferenciação de legislação e jurisdição. Isso acarreta numerosas conseqüências, que podemos sugerir aqui apenas em breves tópicos:

(1) - Torna-se possível incluir os fundamentos da vigência do Direito no próprio sistema jurídico na forma de uma lei constitucional, embora na forma de uma regulamentação especial, para a qual as regras jurídicas 
costumeiras (por exemplo, a regra da colisão, pela qual o Direito novo derroga em caso de contradição o Direito mais antigo), quando com este incompatível, não têm vigência. Ao mesmo tempo a legislação constitucional exige uma reorganização da referência externa, pois não podemos esperar que bons argumentos que Deus ou o monarca, que o representa, providenciem o texto no ano exato da revolução. Como é sabido, a solução chama-se "povo".

(2) - Os fundamentos da vigência podem ser ampliados. [...] No continente europeu o Direito Civil Romano, aperfeiçoado no decurso da história, é reconhecido como Direito vigente a partir da interpretação dos Tribunais e a partir da importância da experiência histórica - mas isso somente enquanto o processo de uma codificação legal ainda não está concluído.

(3) - A tradicional função administrativa local dos Tribunais como órgãos das instâncias centrais - podemos lembrar aqui que os Estados Unidos não conheciam nenhuma autoridade a nível local além dos Tribunais, na época em que a Constituição entrou em vigor sob o dogma da separação dos poderes - é limitada significativamente e finalmente delegada integralmente às autoridades administrativas especialmente criadas para tal fim. A jurisdição (Gerichtsbarkeit) é neutralizada politicamente como função nuclear do sistema jurídico. Mas isso não significa que ela estaria condenada à ineficácia em questões de transformação do Direito. O contrário é verdadeiro: justamente por não poderem ser responsabilizados politicamente pelas conseqüências das suas decisões, os Tribunais ficam excluídos da participação na ação política, mas são por isso mesmo favorecidos na sua participação na transformação do Direito, sobretudo em áreas nas quais o legislador demonstra ser relativamente inativo.

Portanto, não faz sentido reduzir a Constituição, de forma alguma, a um mero "mecanismo de acoplamento estrutural entre o sistema político e o jurídico" (CAMPILONGO, 2002, p. 98), muito menos afirmar que no "caso específico da Constituição os sistemas envolvidos são o político e o jurídico, os quais, embora possam ser observados como temas que não são reader friendly, permitem uma compreensão da Constituição como acoplamento estrutural entre eles, sistemas” (SILVA, 2006).

Hespanha (1999, 60) adverte, ainda, que a concepção "terminológica e axiológica das realidades políticas do sistema constitucional precisa ser bem interpretada no meio envolvente da comunicação social sob pena de intromissão indébita do objeto da ciência política no objeto da ciência constitucional".

A interpretação contrária a essa evolução do direito e da Constituição, parte de um pressuposto equivocado da função supostamente atribuída ao direito de empreender um controle totalizante dos processos internos dos demais sistemas com um grau de eficácia máxima. 
Seja em termos positivistas clássicos ou sob o enfoque sistêmico, a condição de validade do direito, enquanto dever-ser ou expectativa normativa, independe do grau de eficácia de suas prescrições ou da garantia do comportamento conforme as expectativas. (KELSEN, 1998, p. 235-236; LUHMANN, 1983, p. 52).

Dentro de suas possibilidades, cabe ao direito exercer a referida generalização congruente de expectativas, influindo parcialmente nos processos comunicacionais dos demais sistemas que dependem das citadas expectativas normativas para a sua estabilização e funcionamento. A correção das externalidades decorrentes dos conflitos de sentido seria, portanto, complementar e apenas uma das formas de manutenção de tais expectativas normativas na sociedade.

Ao contrário dos ideólogos da auto-regulação que fundamentam aquele controverso entendimento numa suposta interpretação da teoria dos sistemas luhmanniana, esses diversos excertos citados são elucidativos em reafirmar, pelas palavras do próprio Luhmann (1983, 1990a, 1992, 1998), a interdependência e a função desempenhada pelo direito, sobretudo a partir da Constituição, na manutenção contrafactual dessas expectativas normativas em relação a todos os sistemas sociais.

Em outros termos, a regulação do direito não perde o seu sentido e funcionalidade no contexto de sistemas sociais auto-referenciais a despeito da impossibilidade de se direcionar totalmente os processos comunicacionais internos dos demais sistemas autopoiéticos.

Por conseguinte, a Constituição, sob uma perspectiva sistêmica, não seria pertencente a um determinado sistema, assumindo sim "o lugar por excelência de ocorrência do acoplamento estrutural entre o sistema jurídico e os demais subsistemas funcionalmente diferenciados da sociedade". (SCHWARTZ, 2004, p. 117).

No caso brasileiro, esse posicionamento é reforçado se for considerada a confluência histórica da sociedade que mobilizou os diversos sistemas sociais em torno da redemocratização do país no final da década de 1980, formando assim um singular 
acoplamento estrutural entre esses sistemas do qual é fruto a Constituição Federal de $1988 .^{204}$

Como foi possível esboçar na conformação dos movimentos sociais em torno da saúde e de suas tensões com os beneficiários do sistema sanitário biomédico e privatista vigente até então, formou-se na sociedade brasileira uma rede de novos processos comunicacionais, não restritos à reforma sanitária, de modo que a Assembléia Constituinte de 1987, não pode ser reduzida, de modo algum, a uma simples manifestação do sistema político, ou de um exercício formal do Poder Constituinte Originário. ${ }^{205}$

Desse acoplamento estrutural singular dos diversos subsistemas sociais, num processo democrático histórico, reordenaram-se os processos comunicacionais comuns com a generalização de novas expectativas normativas, institucionalizadas no nível máximo constitucional.

\footnotetext{
${ }^{204}$ Sobre os bastidores da Constituinte de 1987, a articulação, os conflitos e os resultados decorrentes desses processos comunicacionais entre os diversos sistemas e atores sociais em relação à saúde, além do histórico empreendido $3^{\circ}$ capítulo deste trabalho, pode ainda ser citada a obra de Rodrigues Neto (2003), Saúde: promessas e limites da Constituição.

${ }^{205}$ Esse aspecto conflituoso entre os diversos sistemas sociais não se reduziu às discussões do novo sistema sanitário sendo identificado em relação a outros temas, sobretudo, à ordem econômica. A despeito dos interesses e das desigualdades entre os atores envolvidos, a Constituição Federal de 1988 seria, ainda assim, representativa de diversos sistemas sociais. Nesse sentido, afirma Eros Roberto Grau (2003, p. 293-295): "Os conflitos entre elites, múltiplos, que a Constituinte registrou, são, seguramente, memoráveis. [...] Isso não significa não se possa identificar, com marcante atuação nela, facções articuladoras de interesses de classe. A heterogeneidade dos interesses representados, porém, não nos permite delinear plenamente o perfil de cada uma delas. [...] Pois essa heterogeneidade, superposta à coexistência de distintos modos de produção social que caracteriza a sociedade brasileira, é que, a um tempo só, confere complexidade e riqueza à ordem econômica na Constituição de 1988. Nela, o reflexo, correto, da realidade nacional. A Constituição de 1988 é, fidedignamente, a Constituição do Brasil, do Estado brasileiro e do povo brasileiro, conformado pela hegemonia dos grupos dominantes mas, concomitantemente, em potência capacitado - o povo - a projetar a sua própria hegemonia". Poderia ainda se citada, sob o aspecto político-partidário e seu impacto nos direitos sociais, o entendimento de Ivaneti Boschetti (2003, p. 70): "A Constituição Brasileira de 1988, como sabemos, foi o resultado de um longo e conflituoso debate político na Assembléia Constitucional que pôs, de um lado, os partidos de centro esquerda, e de outro, o chamado Centrão, formado por partidos de centro direita. A versão promulgada em 05 de outubro resulta de uma combinação de proposições conservadoras do Centrão e de reivindicações dos trabalhadores e dos partidos de esquerda: 'Não é uma Constituição de esquerda nem de uma Constituição socialista' afirmou o deputado federal Eduardo Jorge. Mas é uma Constituição que, inegavelmente, avançou na garantia dos direitos sociais".
} 
Daí decorre a força normativa da Constituição no sentido do caráter vinculante e obrigatório de suas disposições na medida em que representam essa máxima normatização das expectativas com as quais operam os diversos sistemas da sociedade. ${ }^{206}$

A Constituição Federal de 1988 expressa, portanto, os novos meios de comunicação simbolicamente generalizados com os quais passam a contar os sistemas sociais, não apenas jurídico e político, mas também econômico, científico, educacional, familiar, entre outros, em seus processos comunicacionais internos, delimitando suas novas fronteiras e sua autopoiese.

Nesse contexto, de acordo com Ivanette Boschetti (2003, 71), tem-se a Seguridade Social, na qual se insere o sistema sanitário, como o resultado desse processo. Sua institucionalização em 1988 representaria para o Brasil "o que significou a sécurité sociale para os franceses ou a social security para os ingleses na década de 1940: um movimento de reorganização de políticas já existentes sob novas bases e princípios, com ampliação, mas também introdução de novos direitos”. (BOSCHETTI, 2003, p. 71-72).

\subsection{A Seguridade Social sob a perspectiva sistêmica do direito}

A compreensão da autopoiese do sistema jurídico sanitário, sob o enfoque funcional da influência dos programas normativos constitucionais na definição de seus códigos, requer a sua discussão no âmbito da Seguridade Social e na dinâmica dos processos comunicacionais circulares, auto-referenciais, internos a esse sistema mais

\footnotetext{
206 A expressão "força normativa da constituição" remonta à enfática oposição de Konrad Hesse (1991) à interpretação restritiva das questões constitucionais como questões políticas sem caráter jurídico. Tal forma de interpretação reduzia o seu poder prescritivo à simples reiteração da "Constituição real" e a "Constituição Jurídica" a um simples "pedaço de papel” (ein Stück Papier) conforme as palavras de Ferdinand Lassalle. (HESSE, 1991, p. 09). De acordo com Barroso (2005) teria sido superada essa visão, dominante até o fim do século XIX, da Constituição como um documento essencialmente político, condicionado "à liberdade de conformação do legislador ou à discricionariedade do administrador" de modo que ao Poder Judiciário "não se reconhecia qualquer papel relevante na realização do conteúdo da Constituição". No pós Segunda Guerra Mundial, com a reconstitucionalização de diversos países europeus como Alemanha, Itália, Portugal e Espanha, foi consolidado gradativamente, como premissa do estudo constitucional, o reconhecimento de sua força normativa. Essa nova característica da Constituição implica, segundo o referido autor, no reconhecimento de que suas "normas constitucionais são dotadas de imperatividade, que é atributo de todas as normas jurídicas, e sua inobservância há de deflagrar os mecanismos próprios de coação, de cumprimento forçado”. (BARROSO, 2005).
} 
abrangente de proteção social que compõe a esfera constitucional da Ordem Social e dos Direitos e Garantias Fundamentais.

\subsubsection{Seguridade Social, teoria e interpretação dos direitos sociais enquanto direitos fundamentais e sua função na autopoiese do sistema jurídico sanitário}

O sentido do termo Seguridade Social resiste a uma definição simples e inequívoca. Para Marcus Orione Gonçalves Correia e Érica Paula Barcha Correia (2002, p. 15), a dificuldade em sua delimitação decorre "do próprio conceito jurídico [de Seguridade Social], mutável pela evolução das circunstâncias e dos sistemas de organização social e, sobretudo, pela diferente perspectiva política e jurídica adotada pelos Estados que a institucionalizam".

Moacyr Velloso Cardoso de Oliveira (1987) propõe uma definição voltada para a idéia de seguro social garantido pelo Estado, para quem a Seguridade Social representa o

[...] conjunto de medidas adotadas pelo Estado, por meio de organizações próprias ou subvencionadas, destinadas a prover as necessidades vitais da população do país, nos eventos básicos previsíveis e em outras eventualidades, variáveis segundo as condições nacionais, que podem verificar-se na vida de cada um, por meio de um sistema integrado de seguro social e de prestação de serviços sociais. (OLIVEIRA, 1987, p. 21).

Depreende-se desse primeiro conceito, que o seu autor restringe tal definição basicamente ao aspecto da relação direta e prestacional entre o Estado e os beneficiários desse sistema de proteção social.

Por sua vez, Ilídio das Neves (1996) defende a abrangência desse conceito. Não obstante reconheça a sua variabilidade, ainda assim, haveria certo consenso, ao menos na Europa, em torno da existência e imprescindibilidade da Seguridade Social, referida por esse jurista português através da expressão "Segurança Social":

Um pouco por toda a Europa a Segurança Social constitui uma realidade colectivamente assumida que, nos seus aspectos essenciais, permanece indiscutível, para além de todas as controvérsias. Se é certo que ela se apresenta com formas e funções muito variadas, permanece solidamente um denominador comum de grande latitude que exprime a sua missão fundamental: assegurar de forma organizada a protecção dos cidadãos contra determinados riscos da existência, pois se considera que os seus efeitos danosos não interessam apenas individualmente às pessoas, mas 
também à sociedade como um todo. Daí a particular responsabilidade reconhecida ao Estado no conjunto das diferentes políticas sociais. (NEVES, 1996, p. 19). ${ }^{207}$

Sob essa perspectiva de proteção social, destaca-se a importância da Seguridade Social, ou Segurança Social (aqui tratadas como expressões sinônimas), para os diversos sistemas sociais, na medida em que a "segurança social mergulha as suas raízes profundamente na sociedade". (NEVES, 1996, p. 20).

Assim, em termos sistêmicos, a Seguridade Social integra os processos comunicacionais de diversos sistemas sociais, não apenas do jurídico como parte de "um sistema de garantia de direitos sociais", como, por exemplo, do próprio sistema econômico, uma vez considerada "no plano das pessoas enquanto agentes econômicos, caso em que falamos de segurança social como um sistema de garantia de rendimentos ou de transferências". (NEVES, 1996, p. 20).

Ademais, essa "grande interdisciplinaridade da Segurança Social que apresenta uma considerável variedade de articulações interactivas com outras realidades e outros sistemas" decorre, segundo Neves (1996, p. 21), da diversidade de modelos a partir dos quais pode ser implementado esse sistema de proteção social. A esse respeito, afirma:

A concretização dos objectivos da proteç̧ão, que constitui a missão fundamental da Segurança Social, apresenta um quadro muito diversificado de soluções, em natural adequação às características das sociedades concretas, aliás sujeitas a mudanças, em que se insere. Esta circunstância condiciona a concepção do próprio Direito da Segurança Social, dos regimes jurídicos das prestações, das técnicas de financiamento e das formas de gestão. (NEVES, 1996, p. 21).

Sendo assim, segundo Neves (1996, p. 20-24), seria possível demonstrar essas inter-relações entre diversos sistemas em torno da Segurança Social através de pelo

\footnotetext{
${ }^{207}$ Essa assertiva do referido autor baseia-se não apenas em sondagens de opinião elaboradas pela Comissão Européia como no próprio reconhecimento da necessidade de sistema de proteção social pelos próprios críticos da segurança social. Nesse sentido afirma: "Na realidade, verifica-se que, em geral, mesmo os mais energicamente críticos da segurança social e, desse modo, mais convictamente propugnadores de iniciativas privadas de protecção, não negam a necessidade ou, pelo menos, não recusam a conveniência de haver um conjunto de modalidades de protecção social da iniciativa e da responsabilidade do Estado, ou seja, garantidas por ele. Pode assim afirmar-se que há hoje um amplo consenso neste domínio fulcral, embora apareçam como extremamente diversificadas os pontos de vista sobre a dimensão que essas iniciativas públicas devem apresentar”. (NEVES, 1996, p. 21).
} 
menos quatro "razões" para a existência de sistemas organizados de Seguridade Social de iniciativa estatal:

(i) razão econômica: relaciona-se aos "efeitos materiais negativos (perda de rendimentos) que os vários riscos da existência (incapacidade para o trabalho, desemprego, família, velhice, invalidez, morte, bem como a doença)" apresentam na sociedade moderna, não se restringindo a um questão meramente individual de responsabilidade de cada cidadão, "mas dizem respeito a toda a sociedade, no seu conjunto". 208

(ii) razão social: justifica a existência do sistema de proteção social público e coletivo na incapacidade previdencial dos cidadãos de "tomarem pessoalmente medidas de autoprotecção contra as conseqüências dos riscos sociais". Na medida em que Estado dispõe de informações mais completas sobre os riscos e sua incidência, os poderes públicos devem suprir essa omissão ou incapacidade de agir das pessoas em face do interesse coletivo de que tais riscos não as afetem excessivamente, comprometendo a própria sociedade.

(iii) razão jurídica: diz respeito à incorporação dos "princípios orientadores do direito pessoal dos cidadãos a determinada forma de protecção pela segurança social" ao sistema jurídico em seus diversos níveis, tanto nacional (constitucional, legal e administrativo regulamentar), quanto internacionais (tratados, convenções, direito comunitário etc.). ${ }^{209}$

(iv) razão política: a implementação do sistema de proteção social, do qual

\footnotetext{
${ }^{208}$ Em função dessa dimensão coletiva, esses "riscos de existência" devem ser considerados como riscos sociais. Sendo assim, de acordo com o referido autor, a "superação dos efeitos danosos dos riscos sociais exprime, desse modo, um interesse colectivo, atinente ao bem comum, ao equilíbrio da actividade produtiva e à repartição dos rendimentos assim gerados, a que o Estado, cuja dimensão é servir a sociedade, com justiça e equidade, deve dar resposta adequada, como noutras situações (segurança, educação, justiça, etc.). Por isso mesmo, muitos dos riscos da existência passaram a se considerados riscos sociais, cuja ultrapassagem deve ser feita de forma colectiva e mediante organismos públicos adequados". (NEVES, 1996, p. 22).

209 Portanto, restringir a segurança social à sua razão econômica é um equivoco interpretativo da complexidade assumida por esse sistema. De acordo com Neves (1996, p. 23): “Constitui um erro de análise, porque distorce a realidade objectiva dos factos, a perspectiva puramente economicista da segurança social que faz tabua rasa do património jurídico existente em matéria de protecção social".
} 
faz parte a Segurança Social, através da atuação dos órgãos do poder político apresenta-se como uma espécie de diferenciação funcional desse sistema que "na garantia de direitos sociais aos cidadãos deu origem a compromissos e a expectativas, que atravessam transversalmente as sociedades modernas". (NEVES, 1996, p. 20-24).

Essa atuação do Estado torna-se o centro das discussões sobre a Seguridade Social, uma vez que esta compreende os direitos sociais à saúde, à assistência social e à previdência social, os quais por sua própria natureza demandam a ação estatal. Nesse sentido, explica Fábio Konder Comparato (2001, p. 200):

Os direitos sociais, ao contrário [das clássicas liberdades individuais], têm por objetivo não uma abstenção, mas uma atividade positiva do Estado, pois o direito à educação, à saúde, ao trabalho, à previdência social e outros do mesmo gênero só se realizam por meio de políticas públicas, isto é, programas de ação governamental. Aqui, são os grupos sociais inteiros, e não apenas indivíduos, que passam a exigir dos Poderes Públicos uma orientação determinada na política de investimentos e de distribuição de bens; o que implica uma intervenção estatal no livre jogo do mercado e uma redistribuição de renda pela via tributária.

Ainda sob essa dimensão nuclear, Correia e Correia (2002) propõem a compreensão da Seguridade Social a partir de três perspectivas:

a) Perspectiva política - Sob essa perspectiva a Seguridade Social tem em primeiro plano e como finalidade a proteção da necessidade social, ou seja, estende-se a toda a sociedade e tem como prestador o Estado, em missão fundamental.

b) Perspectiva jurídica - Quanto à perspectiva jurídica, refere-se ao meio ou instrumento com que se pretende almejar a finalidade de proteção às necessidades sociais, por meio de uma organização normativa instrumental e das relações jurídicas decorrentes.

c) Em face da sociedade atual - Dessarte, pode-se, hoje, afirmar que o conceito de Seguridade Social equivalente à Previdência Social (destinada, apenas, à prestação dos chamados seguros sociais) está ultrapassado, cedendo lugar a uma noção assistencial, que supera todas as deficiências contidas na estrutura da Previdência Social, inclusive o mecanismo clássico de seguro privado. (CORREIA; CORREIA, 2002, p. 15-16).

Cumpre ressaltar, no entanto, que essa nova "noção assistencial", da qual se extrai o sentido mais amplo de Seguridade Social, não está restrita à organização e execução de serviços sociais, mas decorre diretamente da ampliação das atribuições do Estado Democrático de Direito. 
Nesse sentido, Ivanete Boschetti (2003), destaca o redimensionamento da atuação do Estado e a ampliação das políticas públicas relacionadas a essa matéria:

A Constituição de 1988 institucionalizou o conceito de Seguridade Social para designar uma forma nova e ampliada de implementar e articular políticas já existentes no Brasil desde o início do século XX. Esta Constituição tem o mérito de introduzir um novo conceito e propor uma reestruturação e reorganização inovadoras das políticas que passam a compor esta área: previdência, saúde e assistência. Mas não é a Carta Magna que decreta o surgimento da Seguridade Social. Inexistente em língua portuguesa, este termos é utilizado desde 1935 nos Estados Unidos e desde a década de 1940 nos países capitalistas da Europa para designar um conjunto variável de programas e serviços sociais.

Em face das transformações dos sistemas sociais e do conseqüente aumento da complexidade do sistema de Seguridade Social, as suas citadas finalidades de "proteção da necessidade social" e de "organização normativa instrumental" não podem mais ser interpretadas de forma restrita às prestações do Estado no sentido tradicional do Estado Providência, embora se reconheça a persistência e a importância de seu papel na efetivação dos direitos fundamentais e na garantia da dignidade da pessoa humana.

Foram, assim, acrescidas outras funções essenciais ao Estado no que diz respeito não apenas à Ordem Social, na qual se insere a Seguridade, como à própria Ordem Econômica (Títulos VII e VIII da Constituição Federal de 1988).

Nessa linha, destaca-se a atuação estatal das atividades de caráter social e econômico, seja esta última em sentido estrito ou em sentido amplo, que tenham implicações diretas ou indiretas na efetivação e manutenção dos direitos fundamentais. (GRAU, 2003, p. 82-83).

Ressalte-se, contudo, o cuidado em não se restringir essas transformações funcionais do Estado a um juízo superficial que possa, por ventura, sugerir a adoção de um modelo interpretativo simplista e equivocado de substituição ou negação do Estado Providência por um "Estado Regulador". A esse respeito afirma Denise Cristina Vasques (2004, p. 153):

Acredita-se que esta nova maneira de agir [como controlador e fiscalizador das atividades empreendidas pela iniciativa privada] possibilita o enxugamento do Estado. Este se torna diminuído se comparado à máquina do Estado Provedor. No entanto, o que se vê é que aquela postura não leva, necessariamente, a uma diminuição do aparelho 
do Estado. O que ocorre é que, ao deixar a iniciativa privada preencher [alguns] espaços que antes eram estatais, o poder público viu-se compelido a intervir na atuação privada para possibilitar a realização de suas políticas públicas. Ou seja, o Estado pretende realizar políticas públicas por meio de agentes privados. Para isso, deve controlar suas atividades. Houve uma mudança da atuação do Estado, mas não necessariamente uma diminuição de suas tarefas e de seu aparato.

É justamente a partir dessa "mudança da atuação do Estado" que o conceito de Seguridade Social e a nova "noção assistencial" nele introduzida devem ser reinterpretados.

Portanto, ao lado de toda a estrutura pública de serviços sociais que continuam sim a serem prestados diretamente pelo Estado através do Regime Geral de Previdência Social, do Sistema Único de Saúde e de sua rede de Assistência Social, acrescenta-se às suas atribuições de um rígido controle das atividades complementares (não substitutivas) a esses serviços públicos, como as iniciativas privadas de previdência e assistência à saúde.

Neste sentido, ao tratar da "Concretização Constitucional do Princípio da Democracia Econômica e Social", em relação às novas funções do Estado, afirma Canotilho (1997, p. 326-327):

A Constituição, ao impor aos órgãos do Estado a criação de pressupostos
materiais para a realização da democracia social e económica, atribuiu
também ao Estado funções de Estado de terceira ordem. Isto significa
que o quadro das funções do Estado não se reduz à manutenção da
segurança interna e externa do Estado, à manutenção de uma ordem-
quadro para o exercício da liberdade política e económica (funções de
Estado de primeira ordem). Também as funções do Estado não se
reconduzem a uma política de <<intervenção $>>$ e $<<$ estímulos $>>$ com o
fim de criar instrumentos de <<integração $>>$ necessários à organização
capitalista da economia (funções de Estado de segunda ordem). Avançou-
se para funções de Estado de terceira ordem que pressupõem intervenções
qualitativas na ordem económica existente. Estas intervenções não se
limitam a uma função de direção (Steuerung durch Recht,
Lenkungrescht) ou de <<coordenação $>>$ de uma <<economia de
mercado $>>$. São instrumentos de transformação e modernização das
estruturas económicas e sociais [...].

Ademais, Eliane Romeiro Costa (2003, p. 38) compreende que "a Seguridade pode representar tanto política de prevenção quanto política de proteção dos riscos”, sendo assim, acrescenta tratar-se "de um conjunto de medidas gerais para a melhoria econômica do conjunto social e [não apenas] de políticas de atendimento prestacional individual”. 
Concebida como "um instrumento protetor, garantindo o bem-estar material, moral e espiritual de todos os indivíduos da população" (ALMANSA PASTOR, 1977, p. 60), a Seguridade Social estende seus princípios, sua lógica interpretativa, enfim, sua autopoiese, ao subsistema jurídico sanitário tanto em sua perspectiva política (de proteção das necessidades sociais) quanto em sua perspectiva jurídica (enquanto organização normativa instrumental).

Nesse sentido, tem-se que a Seguridade Social ocupa uma posição de destaque na Constituição Federal brasileira de 1988 entre os direitos e garantias fundamentais da República, especificados em seu Título II. No artigo $6^{\circ}$ são reafirmados os direitos sociais, dentre os quais, em linhas gerais, encontram-se "[...] a saúde, [...] a segurança, a previdência social, a proteção à maternidade e à infância, [e] a assistência aos desamparados". (BRASIL, 1988).

Por sua vez, ao ser tratada no contexto da Ordem Social no Título VIII, delineou-se a sua abrangência, sendo a Seguridade Social definida no artigo 194 como "o conjunto integrado de ações e iniciativas dos Poderes Públicos e da sociedade, destinadas a assegurar os direitos relativos à saúde, à previdência e à assistência” (BRASIL, 1988).

Observa-se, portanto, a inserção da seguridade no Constitucionalismo Social enquanto “processo de 'socialização' de algumas liberdades públicas”. (CORREIA, 2003, p. 10).

A compreensão da dimensão e da importância do Constitucionalismo Social na conformação do sistema de Seguridade Social brasileiro requer uma pequena digressão histórica relativa à ruptura proposta por esse movimento e os novos processos comunicacionais dela decorrentes que vieram a se estabelecer entre o direito, a política, a econômica e os demais sistemas sociais.

Lucyla Tellez Merino (2006, p. 89) situa o desenvolvimento do Constitucionalismo Social como forma de resistência e objeção ao movimento de 1789 que dera origem um Estado não intervencionista e liberal.

A partir do desgaste desse modelo e da crise do individualismo que o fundamentava, de acordo com a referida autora, buscou-se a redefinição da atuação estatal na sociedade daí advindo o Estado Social de Direito. Essa nova forma de organização social, embora "tivesse seu princípio no Liberalismo", buscou "promover um Estado de 
Direito privilegiando o seu cunho social, como forma de fomentar um Estado de BemEstar Social”. (MERINO, 2006, p. 89).

O Constitucionalismo Social refere-se, portanto, à evolução da sociedade no sentido de novos processos comunicacionais que, do ponto de vista histórico, tem como marco as Constituições mexicana de 1917 e alemã de Weimar de 1919. (CORREIA, 2003, p. 10).

A importância da Carta Política mexicana de 1917, segundo Comparato (2001), reside no fato de ter sido "a primeira a atribuir aos direitos trabalhistas a qualidade de direitos fundamentais, juntamente com as liberdades individuais e os direitos políticos (arts. $5^{\circ}$ e 123)", precedendo, inclusive, a consciência européia de direitos humanos, cuja “dimensão social só veio a se afirmar após a grande guerra de 1914-1918”. (COMPARATO, 2001, p. 184).

A Constituição mexicana de 1917 representou já no início do século XX uma "reação ao sistema capitalista" na medida em que estabeleceu a "desmercantilização do trabalho" deslegitimando, por conseguinte, "as práticas de exploração mercantil do trabalho, e, portanto da pessoa humana, cuja justificativa se procurava fazer, abusivamente, sob a invocação da liberdade de contratar”. Os seus avanços em relação à proteção da pessoa humana estenderam-se sob a propriedade privada, posto que "aboliu [...] o caráter absoluto e 'sagrado' da propriedade privada, submetendo-se o seu uso, incondicionalmente, ao bem público, isto é, ao interesse de todo o povo". (COMPARATO, 2001, p. 187-188).

Por sua vez, a Constituição de Weimar de 1919, instituidora da Primeira República alemã, apesar de posterior à mexicana de 1917, teve grande impacto sobre o Constitucionalismo Social.

Teria, assim, influenciado decisivamente a própria "evolução das instituições políticas em todo o Ocidente". Em sua declaração de direitos e deveres fundamentais, essa histórica Constituição não se limitou às clássicas liberdades individuais sendo a elas somadas os "novos direitos de conteúdo social”. (COMPARATO, 2001, p. 199).

Destaca-se, ainda segundo Comparato (2001, p. 201), que "[tanto na Constituição de Weimar de 1919], como na Constituição mexicana de 1917, os direitos trabalhistas e previdenciários são elevados ao nível constitucional de direitos fundamentais". 
A partir desses novos processos comunicacionais, inicia-se uma ruptura epistemológica com a inserção dos direitos sociais entre os direitos e garantias fundamentais do Estado Democrático de Direito. Por conseguinte, é possível observar uma modificação do próprio conceito de liberdade que, se antes podia ser visto "sob a lógica do indivíduo de forma isolada, hoje [entende-se que] somente há liberdade onde ela possa crescer de forma a propiciar o engrandecimento de todos os indivíduos" (CORREIA, 2003, p. 10). ${ }^{210}$

A importância dessas considerações é estabelecer as relações auto-referenciais próprias entre os processos de dotação de sentido e operacionalização do sistema jurídico sanitário e o nível sistêmico mais abrangente da Seguridade Social relacionado ao campo constitucional dos direitos sociais fundamentais.

Outro fator relevante dessa diferenciação funcional da sociedade moderna e por conseqüência do próprio sistema jurídico refere-se ao impacto que a redefinição do conceito e da abrangência dos direitos fundamentais exerce sobre a eficácia das garantias constitucionais, inclusive nas relações privadas que devem ser permeadas pela atuação do Estado, fenômeno ao qual não está imune, por exemplo, o setor referente à saúde complementar privada.

A repercussão prática dessas considerações acerca da evolução dos direitos fundamentais, de sua interpretação e aplicação sobre o sistema jurídico sanitário, inclusive sobre o complementar sistema privado de saúde, integrantes da Seguridade Social, pode ser depreendida das seguintes considerações de Gilmar Ferreira Mendes (1998, p. 237238):

Os direitos fundamentais são concebidos, originariamente, como direitos subjetivos públicos, isto é, como direitos do cidadão em face do Estado. Se considerar que os direitos fundamentais são prima facie direitos contra o Estado, então parece correto concluir que todos os Poderes exercentes de funções públicas estão diretamente vinculados aos preceitos

\footnotetext{
${ }^{210}$ A esse respeito, embora não em termos estritamente sistêmicos, conclui Dallari (1998, p. 305): “Com efeito, as doutrinas individualistas exaltaram a liberdade individual, mas concebendo cada indivíduo isoladamente. Ora, se todos reconhecem que o homem é por natureza um ser social, é evidente que se deve conceber sua liberdade tendo em vista o homem social, o homem situado, que não existe isolado da sociedade. A liberdade humana, portanto, é uma liberdade social, liberdade situada, que deve ser concebida tendo em conta o relacionamento de cada indivíduo com todos os demais, o que implica deveres e responsabilidades".
} 
consagrados pelos direitos e garantias fundamentais. [Razão pela qual] [...] os direitos fundamentais obrigam todos os Poderes do Estado, seja o Legislativo, Executivo ou o Judiciário, nos planos federal, estadual e municipal. Nesse contexto, assume relevo questão relativa ao grau dessa vinculação, especialmente à aplicação desses direitos e garantias fundamentais nas relações privadas.

A partir desse pressuposto, o referido autor acrescenta o dever de proteção atribuído ao Estado em face dessas relações privadas:

A concepção que identifica os direitos fundamentais como princípios objetivos legitima a idéia de que o Estado se obriga não apenas a observar os direitos de qualquer indivíduo em face das investidas do Poder Publico (direito fundamental enquanto direito de proteção ou de defesa Abwehrrecht), mas também a garantir os direitos fundamentais contra agressão propiciada por terceiros (Schutzpflicht des Staats). [...] Essa interpretação do Bundesverfassungsgericht empresta sem dúvida uma nova dimensão aos direitos fundamentais, fazendo com que o Estado evolua da posição de 'adversário' (Gegner) para uma função de guardião desses direitos (Grundrechtsfreund oder Grundrechtgarant). (MENDES, 1998, p. 242-243).

Some-se a essa positivação gradativa em nível constitucional dos sistemas jurídicos nacionais, o desenvolvimento no plano internacional da teoria dos direitos humanos no sentido de sua universalidade e indivisibilidade.

Segundo Flávia Piovesan (2004, p. 14), se inicialmente os direitos humanos nascem como direitos naturais universais, estes passaram gradativamente a se desenvolver como direitos positivos particulares, direitos fundamentais positivados em cada Constituição, fruto do processo de incorporação das declarações internacionais de direitos humanos, ou em termos autopoiéticos, dos acoplamentos estruturais entre os diversos sistemas sociais que compõe a sociedade global, atingindo "sua plena realização como direitos positivos universais".

A citada autora destaca ainda o caráter indivisível dos direitos humanos, sendo, para a compreensão do desenvolvimento do Constitucionalismo Social, oportuno transcrever a contextualização internacional e história por ela sintetizada:

Além do alcance universal dos direitos humanos, a Declaração Universal [de 1948] também inova ao consagrar que os direitos humanos compõem uma unidade indivisível, interdependente e inter-relacionada, na qual os direitos civis e políticos hão de ser conjugados com os direitos econômicos, sociais e culturais. Vale dizer, a Declaração rompe com as concepções anteriores decorrentes das modernas Declarações de Direitos que apenas ressaltavam ora o discurso liberal da cidadania (Declarações 
francesa e americana do final do século XVIII) ora o discurso social (Declaração do povo trabalhador e explorado da então República Soviética Russa do início do século XX). Até então os valores liberdade e igualdade vinham divorciados. A Declaração de 1948 vem a inovar prevendo, de forma inédita, que não há liberdade sem igualdade, e não há igualdade sem liberdade. (PIOVESAN, 2004, p. 15).

Tais considerações acerca da indivisibilidade e interdependência entre os direitos individuais, civis e políticos, e os direitos sociais - dentre os quais se encontram os relativos à Seguridade Social - apresentam-se como fundamentais para a defesa destes (direitos sociais) enquanto direitos fundamentais e a compreensão de sua influência nos processos de seleção de sentido do sistema jurídico como um todo.

Na mesma linha até aqui desenvolvida, afirma Correia (2004, p. 28):

Diga-se, ainda, que não há qualquer novidade neste reposicionamento dos direitos sociais, já que se trata de uma natural evolução do status conferido a estes. A verdade é que os direitos fundamentais deixaram de ser concebidos apenas a partir da perspectiva das liberdades públicas em que se buscava do Estado apenas uma postura passiva. Os direitos fundamentais da pessoa humana devem ser concebidos, portanto, não apenas a partir da perspectiva individual, mas também à luz dos direitos sociais. Aliás, não há como se conceber a consolidação destes direitos fundamentais apenas da perspectiva do indivíduo isoladamente considerado, mas também a partir de sua inserção na coletividade. Aliás, temos constantemente afirmado que esta nova visão dos direitos fundamentais, com uma perspectiva mais social, é sentida de forma mais comum a partir da idéia de que o próprio constitucionalismo teria sofrido profundo impacto das Constituições mexicana de 1917 e de Weimar de 1919. ${ }^{211}$

A partir do posicionamento estratégico dos direitos sociais no contexto

\footnotetext{
${ }^{211}$ Nesse mesmo sentido, poderia ainda ser citado Hector Gros Espiell (1986) e sua importante contribuição nesse tema, transcrita por Flávia Piovesan (2002) ao tratar da indivisibilidade e interdependência características dos direitos humanos: "Só o reconhecimento integral de todos estes direitos pode assegurar a existência real de cada um deles, já que sem a efetividade de gozo dos direitos econômicos, sociais e culturais, os direitos civis e políticos se reduzem a meras categorias formais. Inversamente, sem a realidade dos direitos civis e políticos, sem a efetividade da liberdade entendida em seu mais amplo sentido, os direitos econômicos, sociais e culturais carecem, por sua vez, de verdadeira significação. Esta idéia da necessária integralidade, interdependência e indivisibilidade quanto ao conceito e à realidade do conteúdo dos direitos humanos, que de certa forma está implícita na Carta das Nações Unidas, se compila, se amplia e se sistematiza em 1948, na Declaração Universal de Direitos Humanos, e se reafirma definitivamente nos Pactos Universais de Direitos Humanos, aprovados pela Assembléia-Geral de 1966, e em vigência desde 1976, na Proclamação de Teerã de 1968 e na Resolução da Assembléia-Geral, adotada em 16.12.1977, sobre os critérios e meios para melhorar o gozo efetivo dos direitos e das liberdades fundamentais (Resolução $n$. 32/130)". (ESPIELL, 1986, p. 16-17 apud PIOVESAN, 2002, p. 41).
} 
constitucional (no Título II do texto constitucional, que trata justamente dos "direitos e garantias fundamentais") e em razão da própria teoria dos direitos humanos, concebida a partir da inovação introduzida pela Declaração Universal de 1948, conclui-se que a Seguridade Social e, conseqüentemente, o Direito Sanitário devem ser interpretados e concretizados sob a ótica constitucional dos direitos e garantias fundamentais e da primazia da dignidade da pessoa humana, fundamento de nosso Estado Democrático de Direito, conforme o art. $1^{\circ}$, inciso III, da Constituição Federal brasileira de 1988.

\subsubsection{A incidência e os condicionantes da interpretação constitucional sobre o sistema jurídico sanitário}

Uma vez delimitado o subsistema jurídico sanitário e suas relações internas à Seguridade Social e aos direitos e garantias fundamentais, deve-se passar ao estudo de sua interpretação constitucional.

A discussão desse mecanismo auto-referencial é indispensável para se alcançar o sentido e o funcionamento desse amplo sistema de Segurança Social (CORREIA, 2005, p. 252.) e para própria a delimitação da dinâmica dos processos de seleção e dotação de sentido de seu subsistema jurídico sanitário.

De acordo com Eros Roberto Grau (2002, p. 207), “interpretar não é apenas compreender [...], consubstancia operação de mediação que consiste em transformar uma expressão em uma outra coisa".

No que diz respeito à interpretação do direito, tem-se que a "interpretação é atividade que se presta a transformar disposições (textos, enunciados) em normas; é meio de expressão dos conteúdos normativos das disposições, meio através do qual o juiz desvenda as normas contidas nas disposições”. (GRAU, 2002, p. 39).

Nesse contexto, conforme Correia (2005, p. 253): “o sistema de Segurança Social é um sistema que se encontra, a partir de 1988, originariamente em sede constitucional", sendo assim, acrescenta o referido autor, "passou a ser segurança normativa e, mais, segurança normativa-constitucional”.

Em decorrência de tais considerações, a seleção dos sentidos e a operacionalização de questões relacionadas à Seguridade Social, como aquelas pertinentes à saúde, sejam elas de ordem pública ou privada, devem ser feitas "a partir da Constituição 
e não a partir dos atos administrativos que, aparentemente, possuem efeito normativo". (CORREIA, 2005, p. 252).

Tratando-se, pois, da interpretação constitucional faz-se necessário considerar a função elementar dos princípios.

Segundo Grau (2003), a interpretação constitucional é marcada pela ponderação dos valores da sociedade que através da Constituição passam a fazer parte do sistema jurídico na forma de princípios explícitos e implícitos. Em função dessa conformação do sistema jurídico, tais princípios devem ser considerados "como conformadores da interpretação das regras constitucionais". (GRAU, 2003, 143). ${ }^{212}$

Por essa razão, o referido autor afirma que "todo intérprete estará sempre vinculado pelos textos de direito, em especial pelos que veiculam princípios". (GRAU, 2002, p. 209).

${ }^{212}$ Deve-se ainda ressaltar a classificação utilizada por Grau (2003, p. 136), para o qual "o sistema que o direito é compõe-se de: [i] princípios explícitos, recolhidos no texto da Constituição ou da lei; [ii] princípios implícitos, inferidos como resultado da análise de um ou mais preceitos constitucionais ou de uma lei ou conjunto de textos normativos da legislação infraconstitucional (exemplos: o princípio da motivação do ato administrativo, art. 93, X, da Constituição; o princípio da imparcialidade do juiz, arts. 95, parágrafo único, e $5^{\circ}$, XXXVII da Constituição); e [iii] princípios gerais de direito, também implícitos, coletados no direito pressuposto, qual o da vedação do enriquecimento sem causa". Outra importante classificação dos princípios a ser considerada é proposta por Canotilho (1983) para quem os princípios jurídicos constitucionais se dividem em: "a) principios jurídicos fundamentais, assim entendidos os "princípios historicamente objectivados e progressivamente introduzidos na consciência jurídica geral e que encontram uma recepção expressa ou implícita no texto constitucional' (aí os princípios da publicidade dos atos jurídicos; da proibição do excesso - o que importa exigibilidade, adequação e proporcionalidade dos atos dos poderes públicos; o princípio do acesso ao direito e aos tribunais; o princípio da imparcialidade da Administração); b) princípios politicos constitucionalmente conformadores, entendidos como tais os 'princípios constitucionais que explicitam as valorações políticas fundamentais do legislador constituinte' (aí os princípios definidores da forma de Estado - onde os princípios da organização econômico-social; os princípios definidores da estrutura do Estado - unitário ou federal, com descentralização local ou autonomia local; os princípios estruturantes do regime político - princípio do Estado de Direito, princípio democrático, princípio republicano, princípio pluralista etc.; e os princípios caracterizadores da forma de governo e da organização política em geral - separação e interdependência dos poderes, princípios eleitorais etc.); c) princípios constitucionais impositivos, entendidos assim os princípios constitucionais nos quais 'subsumem-se todos os princípios que no âmbito da constituição dirigente impõem aos órgãos do Estado, sobretudo ao legislador, a realização de fins e a execução de tarefas'; tais princípios [...] são muitas vezes designados por 'preceitos definidores dos fins do Estado', 'princípios diretivos fundamentais' ou 'normas programáticas, definidores de fins ou tarefas' (aí o princípio socialista, o princípio da socialização dos meios de produção etc.); d) princípios-garantia, nos quais incluídos 'outros princípios que visam instituir directa e imediatamente uma garantia dos cidadãos'; a eles é 'atribuída a densidade de autêntica norma jurídica e uma força determinante positiva e negativa'; por se traduzirem no estabelecimento direto de garantias para os cidadãos, são chamados de 'princípios em forma de norma jurídica' (aí o princípio do nullum crime sine lege e de nulla poena sine lege, o princípio do juiz natural, os princípios de non bis in idem e in dúbio pro reo)" (CANOTILHO, 1983, p. 200-203). 
Essa vinculação aos princípios estará sempre presente na operacionalização e nos processos de seleção de sentido com os quais interage o intérprete do direito em sua interpenetração com esse sistema social na concretização da norma em cada caso concreto.

Ademais, a atribuição dessa função aos princípios é possível graças ao seu sentido deontológico que obriga seu destinatário "igualmente, sem exceção, a cumprir as expectativas generalizadas de comportamento". (GRAU, 2002, p. 112). ${ }^{213}$

Nessa linha, ao tratar da interpretação constitucional da Seguridade Social, conclui Correia (2005, p. 268):

[...] que a interpretação no sistema de Segurança Social é uma interpretação essencialmente de princípios e que os princípios relevam os conceitos constitucionais dentro de um patamar de unidade político-constitucional. Obtido o conceito, a partir dos princípios, tem-se que todo subsistema infraconstitucional, e também a atuação da administração pública, deve se submeter a esse conceito constitucional. A interpretação deve se fazer à luz desta perspectiva e daquela segundo a qual os direitos sociais são direitos fundamentais: portanto, ao lado dos direitos fundamentais individuais, existem os direitos fundamentais sociais, e a estes segundos se aplica toda a metodologia de interpretação e de diç̧ão do direito que é aplicável aos primeiros, no sentido de maximização dos resultados.

A Seguridade Social como um todo e, assim, o sistema jurídico sanitário nela compreendido devem ser interpretados essencialmente a partir dos princípios normatizados, implícita ou explicitamente, nos arts. $1^{\circ}, 3^{\circ}, 194$ e seguintes da Constituição Federal de 1988, com especial destaque para a maximização da dignidade da pessoa humana. (VILLELA, 2004, p. 41).

Tais expectativas generalizadas pela Constituição Federal de 1988 resultam dos acoplamentos estruturais entre os diversos sistemas sociais que, a favor ou contra o Movimento pela Reforma Sanitária, participaram da formação desse sistema maior de

\footnotetext{
${ }^{213}$ Ao tratar da função essencial dos princípios na conformação do novo direito, frente ao processo de "desestruturação do direito formal/moderno" decorrente da "crise do Estado Moderno", afirma Grau (2002, p. 109-110): "De seu renovar-se [a idéia de direito em seu processo de contínua evolução] vamos tomando consciência, paulatinamente. A teoria jurídica volta-se aos princípios jurídicos, salientando a sua importância, seja porque o modo formal de aplicação do direito (direito formal) não satisfaz socialmente, seja porque o direito moderno (direito posto pelo Estado) não viabiliza, por si só, a fluência das relações sociais e o dinamismo da circulação mercantil, carente de formas renovadas de legitimação. E a verificação de que os princípios são normas jurídicas, ao lado das regras - o que converte norma jurídica em gênero, do qual são espécies os princípios e as regras jurídicas - abre novas vias de indagação, riquíssimas, para os que se dedicam à teoria do direito".
} 
proteção social.

A força normativa do sistema jurídico sanitário diz respeito, portanto, à manutenção pelo direito, como verdadeiras normas jurídicas cogentes e auto-aplicáveis, de tais expectativas normativas em relação ao sistema sanitário situado no sistema geral de Seguridade Social. 


\section{CONCLUSÃO}

No decorrer deste trabalho, a sua redação foi empreendida com a preocupação de, ao final de cada um de seus capítulos, serem retomadas as principais questões discutidas e as conclusões parciais depreendidas de seu desenvolvimento, promovendo-se, assim, a sua articulação com as discussões seguintes. Por essa razão, cumpre aqui abordar, em linhas gerais, os pontos chaves que levaram à compreensão da força normativa do sistema jurídico sanitário sob a sua perspectiva sistêmica e constitucional.

Por meio do detalhamento da intrincada Teoria da Sociedade de Niklas Luhmann (1988), foi possível diferenciar sua singular estrutura conceitual, imprescindível para a compreensão dos sentidos atribuídos pelo autor a termos aparentemente sedimentados nas ciências humanas.

Procurou-se discutir a visão luhmanniana dos sistemas sociais autopoiéticos através de seus conceitos e de uma aproximação dos sentidos por eles sugeridos, dentro dos limites e contingências comunicacionais descritas em sua própria teoria. ${ }^{214}$

A compreensão sistêmica do direito foi discutida a partir de sua oposição ao positivismo jurídico científico, apresentando-se como uma alternativa capaz de não apenas superar o isolamento dogmático do direito e sua descrição aparentemente a-valorativa das relações sociais, como também assumir o caráter auto-referencial e paradoxal de suas operações comunicacionais internas sem o recurso a pressuposições lógico-fictícias ou transcendentais, à negação de sua função transformadora ou sujeição ao consenso idealizado da razão e do agir comunicativos.

\footnotetext{
214 Nesse contexto, deve ser assumido o risco de uma interpretação diferenciada da teoria estudada, relacionado à aplicabilidade da descrita contingência dos sistemas de sentido, dentre os quais se insere o pesquisador, à elaboração em si desta dissertação, não se podendo eximir da dinâmica recursiva dos processos cognitivos humanos, em termos de sua auto-referencialidade descrita por Maturana e Varela (1980, 2005), muito menos da impossibilidade de separação entre "sujeito" e "objeto" de pesquisa.
} 
Dessa maneira, graças à sua abertura cognitiva e sua função relacionada à generalização e manutenção contrafactual de expectativas normativas, foi possível situar o direito em suas inter-relações com os demais sistemas sociais que compõe a sociedade.

Tal generalização de expectativas cumpre a necessária redução da exposição dos sistemas sociais às frustrações das mesmas através de sua normatização. Por sua vez, a institucionalização de tais expectativas estabiliza os conflitos diretos entre expectativas contrapostas não limitadas a dois, mas a três ou mais sistemas de sentidos. Tem-se, assim, uma antecipação de expectativas que serão em parte produzidas pelos sistemas de sentido para a absorção dessas frustrações e o enfrentamento dos riscos da dupla-contingência comunicacional a que estão sujeitos.

Propõe-se com isso uma saída ao aparente paradoxo do direito em regular os demais sistemas igualmente auto-referenciais. Portanto, em que pese o processo de diferenciação funcional do sistema social global e a impossibilidade de um controle total de suas operações a partir de uma perspectiva externa, não se afasta essa função sistêmica do direito. (LUHMANN, 1992, p. 1434-1435).

No que diz respeito ao sistema jurídico sanitário brasileiro, para se chegar à compreensão da evolução de seus acoplamentos estruturais com os demais sistemas sociais e, dessa forma, redimensionar as expectativas normativas que lhe foram conferidas pela Constituição da República Federativa do Brasil de 1988, foi preciso abordar as tensões sistêmicas relacionadas ao desenvolvimento do sistema de saúde nacional no decorrer do século XX.

Para a discussão do sistema sanitário brasileiro, além da adoção da teoria sistêmica como quadro geral explicativo, foi preciso empreender a reconstituição histórica das origens da saúde pública e das abordagens bio-políticas de Michel Foucault (1974, 1979) e George Rosen $(1979,1994)$ com o propósito de se delinear as possíveis diferenciações funcionais dos sistemas de saúde a partir das relações entre os sistemas político, econômico e científico em torno da medicina e da atuação estatal no controle dos corpos supostamente em nome da saúde, na Europa desde o século XVIII.

Demonstrou-se, com esse levantamento, a impossibilidade de se considerar a Revolução Industrial como o ponto referencial de uma nova responsabilização do Estado em matéria de saúde, uma vez que as pesquisas desenvolvidas pelos referidos autores demonstram claramente a precedência da atuação estatal em saúde, em momento anterior à 
fase do capitalismo industrial, situando-a em diferentes contextos da história contemporânea numa inter-relação política, econômica e social de poder.

Os modelos europeus de Medicina Social, tratados no terceiro capítulo, embora não sejam capazes de fornecer um panorama explicativo completo dos processos comunicacionais relacionados às políticas públicas de saúde desenvolvidos no Brasil durante o século XX, permitem a compreensão de alguns de seus traços marcantes, como do autoritarismo e da centralidade administrativa da polícia médica sanitária, mantida desde os tempos do Império, bem como do Sanitarismo Campanhista da Primeira República e de seus desdobramentos no saneamento urbano e rural, que incorporam, à sua maneira, parte da tecnologia de estruturação dos serviços estatais e da forma de intervenção sobre o espaço, características da Medicina de Estado alemã e da Medicina Urbana francesa.

Por sua vez, as relações entre os sistemas político e econômico brasileiros, delineadas desde o período imperial, não corroboram a tese de uma simples evolução dos cuidados médicos e assistenciais em saúde no sentido de sua gradual coletivização e nacionalização com a ampliação de atividades estatais nessa área, tal como, se depreende, em princípio, das leituras de Sueli Gandolfi Dallari (1987) e Gilberto Hochman (1998).

Foi possível contrastar a esse entendimento a forma como o Estado brasileiro contribuiu, já no início do século passado, de maneira decisiva para a manutenção e o desenvolvimento da própria medicina privada, seja em seu inicial aspecto individualista e liberal, passando pelo posterior fomento do mercado de assistência médica em sua restrita e igualmente privada prestação de serviços aos segurados das Caixas de Aposentadorias e Pensões e dos Institutos de Aposentadorias e Pensões controlados pelo poder estatal.

No movimento inverso à tendência dos países europeus que passaram pela revisão de suas políticas sociais no pós-guerra, no Brasil, consolida-se, a partir da década de 1940, uma duradoura articulação entre os sistemas político e econômico, resultando, daí, uma nova estratégia bio-política, em termos foucaultianos, voltada ao fortalecimento do Estado e à viabilização das práticas econômicas na linha da Medicina Social inglesa dos Pobres e da Força de Trabalho, que permitiu a coexistência de uma assistência médica aos pobres deliberadamente precária, acompanhada do esquadrinhamento geral da saúde pública e do controle sanitário da força de trabalho, conformando uma organização do sistema sanitário ao mesmo tempo assistencial, privada e administrativa. 
A evolução do sistema sanitário nacional revelou-se, assim, marcada pela dualidade das políticas públicas de saúde, divididas entre o sanitarismo campanhista e a restrita assistência médica previdenciária, e pelas disputas entre os sistemas econômico e científico em torno desse emergente sistema social, cada qual buscando influir, a partir de sua peculiar lógica interna, na definição e generalização de sentidos contrapostos para a saúde. Como resultado, à saúde pública restou desempenhar a um papel cada vez mais secundário no âmbito das políticas públicas brasileira até a década de 1970.

No que diz respeito ao direito à saúde, outra importante conclusão a que se pôde chegar no presente estudo, relaciona-se ao questionamento levantado logo no início do quarto capítulo acerca da possibilidade de se utilizar o término da Segunda Guerra Mundial e a evolução dos sistemas sociais europeus, no sentido da implementação do Estado de Bem-Estar Social e da nova compreensão da saúde como um direito universal de todos, declarada em 1948 pela Organização das Nações Unidas, como determinantes de uma suposta reformulação da atenção dos sistemas sociais brasileiros e do próprio Estado para com a saúde de sua população, em mesmo grau de importância e força transformadora capazes de superar a conformação do sistema sanitário desenvolvida até então no Brasil.

As particularidades da sociedade brasileira e a sua dinâmica evolutiva levaram ao surgimento tardio de diferentes processos comunicacionais capazes de viabilizar novas articulações entre os sistemas sociais no país, de maneira contundente, em torno do Movimento pela Reforma Sanitária apenas no final do século XX, no contexto maior da redemocratização do Brasil.

Esse intrincado processo demonstra que a Segunda Guerra, a despeito de sua importância para a história mundial e de seu valor simbólico para a afirmação dos Direitos Humanos no plano internacional, não teve, em princípio, o mesmo impacto transformador na realidade brasileira, nem as respostas de seus sistemas sociais às expectativas cognitivas decorrentes da introdução do modelo de Bem-Estar Social, das políticas keynesianas e do desenrolar do Plano Beveridge em alguns Estados europeus desde a década de 1950.

A redefinição do papel do Estado em relação à saúde da população, elevandose os cuidados à condição de direito fundamental no Brasil, está relacionada às tensões entre os diversos sistemas sociais, mobilizados a favor e contra a ruptura com o modelo biomédico de organização da saúde que vinha se consolidando até a década de 1970, quando seus sinais de esgotamento e sua incapacidade de atender às expectativas sociais 
em torno da saúde propiciaram uma profunda reformulação de seus objetivos e de sua lógica organizacional, reforçada pela institucionalização das novas expectativas normativas em torno da saúde através da Constituição Federal de 1988 e de sua afirmação entre os direitos sociais fundamentais.

A evolução da sociedade brasileira e do nível de diferenciação funcional de seus subsistemas sociais, como foi possível discutir no último capítulo, levou a Constituição a desempenhar uma função normativa mais geral, por meio de seus programas e princípios constitucionais.

A partir da teoria dos sistemas de Niklas Luhmann foi possível interpretar essa nova função, bem como identificar seus programas e princípios constitucionais como complexões de expectativas normativas, imprescindíveis para a formação de meios de comunicação simbolicamente generalizados, através dos quais essas complexões se autonomizam em casos concretos permitindo a recursividade das operações seletivas de sentido, no interior dos sistemas sociais.

No que diz respeito especificamente ao sistema jurídico sanitário, por meio de sua contextualização no sistema global de Seguridade Social, pode-se explicitar como os princípios constitucionais da Ordem Social, enquanto normas, interagem em seus processos seletivos de informações na medida em que delimitam os sentidos possíveis de seu código binário direito/não-direito.

Conferem, dessa forma, um mínimo de coerência interna à autoreferencialidade do Direito Sanitário, exercendo o controle interno de suas operações comunicacionais, seu direcionamento e as condições sob as quais tais processos podem e devem se desenvolver.

Em sentido amplo, a interpretação constitucional dos princípios, sob a perspectiva sistêmica, permite a evolução do próprio direito e o desempenho de suas funções normativas à medida que a produção legislativa se mostra incapaz de atender a essa generalização de expectativas e à uniformização parcial dos sentidos atribuídos por sistemas sociais cada vez mais especializados, cujos meios de comunicação simbolicamente generalizados não são captados pela dinâmica legislativa tradicional.

Conclui-se este trabalho, negando mais uma vez a redução interpretativa da Constituição a um simples mecanismo de acoplamento estrutural entre os sistemas político 
e jurídico. As diferentes possibilidades de sentido para o termo política, permitem redimensionar as suas atribuições em relação à sociedade como um todo.

Dentro de seus limites, cabe ao direito e às normas constitucionais, entre as quais se destacam os princípios, exercerem a generalização congruente de expectativas, influindo parcialmente nos processos comunicacionais dos demais sistemas que dependem dessas expectativas normativas para sua estabilização e seu funcionamento.

Por conseguinte, no que diz respeito mais ao tema desta dissertação, tem-se que a Seguridade Social e o sistema jurídico sanitário nela compreendido devem ser interpretados essencialmente com base nos princípios normatizados, implícita e explicitamente, nos artigos $1^{\circ}, 3^{\circ}, 194$ e seguintes da Constituição Federal de 1988, com especial destaque para a maximização da dignidade da pessoa humana.

De todo o exposto, não se pode, portanto, deixar de reafirmar a conclusiva assertiva do último capítulo.

Considerando-se, pois, as expectativas normativas generalizadas pela Constituição Federal de 1988 como o resultado dos acoplamentos estruturais entre os diversos sistemas sociais que, a favor ou contra o Movimento pela Reforma Sanitária, participaram da formulação do sistema constitucional de proteção social, outro não pode ser o entendimento da força normativa do sistema jurídico sanitário senão que esta diz respeito à manutenção pelo direito, como verdadeiras normas jurídicas cogentes e autoaplicáveis, das referidas expectativas normativas em relação ao sistema sanitário nacional a partir do sistema geral de Seguridade Social. 


\section{REFERÊNCIAS BIBLIOGRÁFICAS}

ACIOLE, Giovanni Gurgel. A saúde no Brasil: cartografias do público e do privado. São Paulo: Hucitec; Campinas, SP: Sindicato dos Médicos de Campinas e Região, 2006.

ALEXY, Robert. Teoría de los derechos fundamentales. Madrid: Centro de Estúdios Constitucionales, 1993.

ALMANSA PASTOR, José Manuel. Derecho de la seguridad social. Madrid: Tecnos, 1977.

ALMEIDA, Erivaldo Sampaio de; CHIORO, Arthur; ZIONI, Fabiola. Políticas públicas e organização do sistema de saúde: antecedentes da Reforma Sanitária e o SUS. In: WESTPHAL, Márcia faria; ALMEIDA, Erivaldo Sampaio de. (Org.). Gestão de serviços de saúde: descentralização, municipalização do SUS. São Paulo: Edusp, 2001.

ANTUNES, José Engrácia. Prefácio. In: TEUBNER, Gunther. O Direito como Sistema Autopoiético. Lisboa: Fundação Calouste Gulbenkian, 1989.

ARAGÃO, Alexandre Santos de. Agências Reguladoras e a Evolução do Direito Administrativo Econômico. Rio de Janeiro: Forense, 2002.

ARBEX JR., José. O poder da TV. São Paulo: Scipione, 1997.

. O showrnalismo - a notícia como espetáculo. São Paulo: Casa Amarela, 2001.

. O jornalismo canalha. São Paulo: Casa Amarela, 2003.

ARNAUD, André-Jean; DULCE, M.J.F. Introdução à Análise Sociológica dos Sistemas Jurídicos. Rio de Janeiro: Renovar, 2000.

ASSIS, Jesus de Paula. Kuhn e as ciências sociais. Estudos Avançados, v. 7, n. 19, p. 133164, 1993. 
AUGUSTO, Maria Helena Oliva. Políticas públicas, políticas sociais e políticas de saúde: algumas questões para reflexão e debate. Tempo Social: Revista de Sociologia da USP, São Paulo, v. 1, n. 2, p. 105-119, 1989.

BARROS, José Augusto Cabral de. Políticas farmacêuticas: a serviço dos interesses da saúde? Brasília: UNESCO, 2004.

Pensando o processo saúde doença: a que responde o modelo biomédico. Saúde e Sociedade, São Paulo, v.11, n. 1, p. 67-84, 2002.

BARROSO, Luís Roberto. Neoconstitucionalismo e constitucionalização do Direito: o triunfo tardio do Direito Constitucional no Brasil. Jus Navigandi, Teresina, ano 9, n. 851, nov. 2005. Disponível em: <http://jus2.uol.com.br/doutrina/texto.asp?id=7547>. Acesso em: 14 jan. 2007.

BBC History. Aneurin Bevan (1897 - 1960). History Figures, 2006. Disponível em $<$ http://www.bbc.co.uk/history/historic_figures/bevan_aneurin.shtml $>$. Acesso em: $13 \mathrm{dez}$. 2006.

BECHMANN, Gotthard; STEHR, Nico. Niklas Luhmann. Tempo Social, Revista de Sociologia da USP, São Paulo, v. 13, n. 2, p. 185-200, nov. 2001.

BECK, Ulrich. O que é globalização? São Paulo: Paz e Terra, 1999.

BERCOVICI, Gilberto. Soberania e Constituição: Poder Constituinte, Estado de Exceção e os limites da Teoria Constitucional. 2005. Tese (Concurso de Professor Titular junto ao Departamento de Direito do Estado) - Faculdade de Direito da Universidade de São Paulo, São Paulo.

A Descentralização de Políticas Sociais e o Federalismo Cooperativo Brasileiro. Revista de Direito Sanitário, São Paulo, v. 3, n. 1, p. 13-28, 2002.

BERTALANFFY, Ludwig von. General System Theory. New York: Braziller, 1968.

BOSCHETTI, Ivanete. Implicações da reforma da previdência na seguridade social brasileira. Psicologia \& Sociedade, Porto Alegre, v. 15, n. 1, 2003. Disponível em: $<\mathrm{http}: / /$ www.scielo.br/scielo.php?script=sci_arttext\&pid=S0102- 
$71822003000100005 \& \operatorname{lng}=$ pt\&nrm=iso $>$. Acesso em: 14 jan. 2007.

BRAGA, José Carlos de Souza; PAULA, Sergio Góes de. Saúde e previdência - estudos de política social. 2. ed., São Paulo: HUCITEC, 2006.

BRASIL. Constituição (1891). Constituição da República dos Estados Unidos do Brasil de 24 de fevereiro de 1891. D.O.U. de 25/02/1891. Brasília, DF: Senado, 1891. Disponível em: $<$ http://www6.senado.gov.br/legislacao/ListaPublicacoes.action?id=94947>. Acesso em: 26 nov. 2006.

BRASIL. Constituição (1988). Constituição da República Federativa do Brasil. D.O.U. de 05/10/1988, P. 1 (ANEXO). Brasília, DF: Senado, 1988. Disponível em: $<$ https://www.planalto.gov.br/>. Acesso em: 26 nov. 2005.

BRASIL. Decreto n ${ }^{\circ} 2.449$, de 1 de fevereiro de 1897 - Unificar os serviços de hygiene da União. CLBR: Coleção de Leis do Brasil, Brasília, DF: Senado, 1897. Disponível em: $<$ http://www6.senado.gov.br/legislacao/ListaPublicacoes.action?id=69470>. Acesso em: 27 dez. 2006.

BRASIL. Decreto $\mathrm{n}^{\circ} 1.151$, de 5 de janeiro de 1904 - Reorganiza os serviços da hygiene administrativa da União. CLBR: Coleção de Leis do Brasil, Brasília, DF: Senado, 1904a. Disponível em: $<$ http://www6.senado.gov.br/legislacao/ListaPublicacoes.action?id=56733>. Acesso em: 27 dez. 2006.

BRASIL. Decreto n ${ }^{\circ} 5.157$, de 8 de março de 1904 - Approva o regulamento do serviço de prophylaxia da febre amarella. CLBR: Coleção de Leis do Brasil, Brasília, DF: Senado, 1904b. Disponível em: $<$ http://www6.senado.gov.br/legislacao/ListaTextoIntegral.action?id=47399>. Acesso em: 27 dez. 2006.

BRASIL. Decreto $n^{\circ}$ 5.224, de 30 de maio de 1904 - Approva o regulamento processual da Justiça Sanitária. CLBR: Coleção de Leis do Brasil, Brasília, DF: Senado, 1904c. Disponível em: $\quad<$ http://www6.senado.gov.br/legislacao/ListaPublicacoes.action?id=64731>. Acesso em: 27 dez. 2006. 
BRASIL. Decreto $\mathrm{n}^{\mathrm{o}}$ 15.003, de 15 de setembro de 1921 - Faz modificações no regulamento approvado pelo Decreto n. 14.354, de 15 de setembro de 1920 (Regulamento dos serviços a cargo do Departamento Nacional de Saúde Pública). CLBR: Coleção de Leis do Brasil, Brasília, DF: Senado, 1921. Disponível em: $<\mathrm{http}$ //www6.senado.gov.br/legislacao/ListaPublicacoes.action?id=45892>. Acesso em: 03 jan. 2007.

BRASIL. Decreto n 19.402, de 14 de novembro de 1930 - Cria uma Secretária de Estado com a denonimação de Ministério dos Negócios da Educação e Saúde Publica. CLBR: Coleção de Leis do Brasil, Brasília, DF: Senado, 1930. Disponível em: $<$ http://www6.senado.gov.br/legislacao/ListaPublicacoes.action?id=37285>. Acesso em: 03 jan. 2007.

BRASIL. Decreto Legislativo $n^{\circ} 4.682$, de 24 de janeiro de 1923 - Crea, em cada uma das emprezas de estradas de ferro existentes no paiz, uma caixa de aposentadoria e pensões para os respectivos empregados. CLBR: Coleção de Leis do Brasil, Brasília, DF: Senado, 1923. Disponível em: $<$ http://www6.senado.gov.br/legislacao/ListaPublicacoes.action?id=45136>. Acesso em: 30 dez. 2006.

BRASIL. Decreto Legislativo ${ }^{0} 5.109$, de 20 de dezembro de 1926 - Estende o regimen do decreto legislativo n. 4.682, de 24 de janeiro de 1923, a outras emprezas. CLBR: Coleção de Leis do Brasil, Brasília, DF: Senado, 1926. Disponível em: $<$ http://www6.senado.gov.br/legislacao/ListaPublicacoes.action?id=43093>. Acesso em: 30 dez. 2006.

BRASIL. Decreto-Lei n ${ }^{\circ}$ 4.657, de 4 de setembro de 1942 - Lei de introdução ao Código Civil Brasileiro. Diário Oficial da União, Brasília, DF, 04 set. 1942. Disponível em: $<$ http://www.planalto.gov.br/ccivil_03/decreto-lei/Del4657.htm>. Acesso em: 07 jan. 2007.

BRASIL. Decreto-Lei $n^{0} 72$, de 21 de novembro de 1966 - Unifica os Institutos de Aposentadoria e Pensões e cria o Instituto Nacional de Previdência Social. Diário Oficial da União, Brasília, DF, 22 nov. 1966. Disponível em: 
$<$ http://www6.senado.gov.br/legislacao/ListaPublicacoes.action?id=116854>. Acesso em: 07 jan. 2007.

BRASIL. Lei no 378, de 13 de janeiro de 1937 - Dá nova, organização ao Ministério da Educação e Saúde Publica. CLBR: Coleção de Leis do Brasil, Brasília, DF: Senado, 1937. Disponível em: $<$ http://www6.senado.gov.br/legislacao/ListaPublicacoes.action?id=102716>. Acesso em: 03 jan. 2007.

BRASIL. Lei no 1.920, de 25 de julho de 1953 - Cria o Ministério da Saúde e dá outras providências. CLBR: Coleção de Leis do Brasil, Brasília, DF: Senado, 1953. Disponível em: $<$ http://www6.senado.gov.br/legislacao/ListaPublicacoes.action?id=109070>. Acesso em: 04 jan. 2007.

BRASIL. Lei $\mathrm{n}^{\circ}$ 2.743, de 06 de março de 1956 - Cria o Departamento Nacional de Endemias Rurais no Ministério da Saúde e dá outras providências. CLBR: Coleção de Leis do Brasil, Brasília, DF: Senado, 1956. Disponível em: $<$ http://www6.senado.gov.br/legislacao/ListaPublicacoes.action?id=110878>. Acesso em: 04 jan. 2007.

BRASIL. Lei $\mathrm{n}^{\circ}$ 3.807, de 26 de agosto de 1960 - Dispõe sôbre a Lei Orgânica da Previdência Social. Diário Oficial da União, Brasília, DF, 05 set. 1960. Disponível em: $<$ http://www6.senado.gov.br/legislacao/ListaPublicacoes.action?id=113037>. Acesso em: 07 jan. 2007.

BRASIL. Lei $\mathrm{n}^{\circ}$ 4.214, de 02 de março de 1963 - Dispõe sôbre o "Estatuto do Trabalhador Rural". Diário Oficial da União, Brasília, DF, 18 mar. 1963. Disponível em: $<$ http://www6.senado.gov.br/legislacao/ListaPublicacoes.action?id=183976>. Acesso em: 07 jan. 2007.

BRASIL. Lei $n^{\circ}$ 6.168, de 09 de dezembro de 1974 - Cria o Fundo de Apoio ao Desenvolvimento Social - FAS - e dá outras providências. Diário Oficial da União, Brasília, DF, 10 dez. 1974. Disponível em: $<$ http://www6.senado.gov.br/legislacao/ListaPublicacoes.action?id=122582>. Acesso em: 07 jan. 2007. 
BRASIL. Lei ${ }^{\circ}$ 6.260, de 06 de novembro de 1975 - Institui benefícios de previdência e assistência social em favor dos empregadores rurais e seus dependentes, e dá outras providências. Diário Oficial da União, Brasília, DF, 07 nov. 1975. Disponível em: $<$ http://www6.senado.gov.br/legislacao/ListaPublicacoes.action?id=123057>. Acesso em: 07 jan. 2007.

BRASIL. Lei $\mathrm{n}^{\circ}$ 6.439, de $1^{\mathrm{o}}$ de setembro de 1977 - Institui o sistema Nacional de Previdência e Assistência Social e dá outras providências. Diário Oficial da União, Brasília, DF, 02 set. 1977. Disponível em: $<$ http://www6.senado.gov.br/legislacao/ListaPublicacoes.action?id=227168>. Acesso em: 07 jan. 2007.

BRASIL. Leis Históricas: Alvará de 22 de Janeiro de 1810 - Dá Regimento ao Provedor Mór da Saúde. Revista Jurídica Virtual. Brasília, Presidência da República, v. 6, n. 70 março, 2005. Disponível em <http://www.planalto.gov.br/ccivil_03/revista/Rev_70/>. Acesso em 24 dez. 2006.

BÜLLESBACH, Alfred. Princípios de teoria dos sistemas. In: KAUFMANN, A.; HASSEMER, W. (Org.). Introdução à filosofia do direito e à teoria do direito contemporâneas. Lisboa: Fundação Calouste Gulbenkian, 2002. cap. 10, p. 409-442.

CAMPILONGO, Celso Fernandes. Política, sistema jurídico e decisão judicial. São Paulo: Max Limonad, 2002.

Direito e democracia. 2. ed. São Paulo: Max Limonad, 2000a.

O direito na sociedade complexa. São Paulo: Max Limonad, 2000b.

CANARIS, Claus-Wilhelm. Pensamento sistemático e o conceito de sistema na ciência do direito. Trad. A. Menezes Cordeiro. 2. ed. Lisboa: Fundação Calouste Gulbenkian, 1996.

CANOTILHO, José Joaquim Gomes. A Constituição Européia entre o programa e a norma. Leituras complementares - União Européia. Ministério da Fazenda, Brasília, DF. 2004. Disponível em: <http://www.esaf.fazenda.gov.br/parcerias/ue/cedoc-ue/leiturascomplementares/a4-uniao-europeia.html>. Acesso em: 10 jan. 2007.

. Direito constitucional e teria da Constituição. Coimbra: Almedina, 1997. 
. Direito Constitucional. 3. ed. Coimbra: Almedina, 1983.

CAPRA, Fritjof. A teia da vida - Uma nova compreensão científica dos sistemas vivos. São Paulo: Editora Cultrix, 1996.

CASTRO, Marcus Faro de. Dimensões Políticas e Sociais do Direito Sanitário Brasileiro. In: ARANHA, Márcio Iorio (Org.). Direito Sanitário e Saúde Pública. Brasília: Ministério da Saúde, 2003, p. 379-390.

CLAM, Jean. Questões fundamentais de uma teoria da sociedade: contingência, paradoxo, só-efetuação. Trad. Nélio Schneider. São Leopoldo, RS: Editora Unisinos, 2006.

COMPARATO, Fábio Konder. . Ética: direito, moral e religião no mundo moderno. São Paulo: Companhia das Letras, 2006.

A afirmação histórica dos direitos humanos. 2. ed. São Paulo: Saraiva, 2001

CORREIA, Marcus Orione Gonçalves. Interpretação do direito da segurança social. In: ROCHA, Daniel Machado da (Coord.). Curso de especialização em direito previdenciário. v. 1. Curitiba: Juruá, 2005, p. 249-268.

. Os direitos sociais enquanto direitos fundamentais. In: ; CORREIA, Érica

Paula Barcha. (Coord.) Direito Previdenciário e Constituição - Obra em homenagem ao professor Wladimir Novaes Martinez. São Paulo: LTr, 2004, p. 25-43.

. Uma introdução ao constitucionalismo social. Carta Brasileira, [S.1.], n. 3, p. 1011, out. 2003.

; CORREIA, Érica Paula Barcha. Curso de direito da seguridade social. 2. ed. São Paulo: Saraiva, 2002.

CORSI, G; BARALDI, C; ESPOSITO, E. Glosario sobre la Teoría Social de Niklas Luhmann. Barcelona: Anthropos; México DF: Universidad Iberoamericana; Guadalajara: Iteso, 1996.

COSTA, Ediná Alves; ROZENFELD, Suely. Constituição da vigilância sanitária no Brasil. In: ROZENFELD, Suely (Org.). Fundamentos da vigilância sanitária. Rio de Janeiro: Editora Fiocruz, 2000, p. 15-40. 
COSTA, Eliane Romeiro. Previdência complementar na seguridade social: o risco velhice e a idade para a aposentadoria. São Paulo: LTr, 2003.

CRUZ SOBRINHO, Sidinei. Direitos Humanos e Democracia em Jürgen Habermas. 2005. Dissertação (Mestrado em Filosofia) - Pontifícia Universidade Católica do Rio de Janeiro, Rio de Janeiro.

DALLARI, Dalmo de Abreu. Elementos de teoria geral do Estado. 20. ed. atual. São Paulo: Saraiva, 1998.

DALLARI, Sueli Gandolfi. Os Estados Brasileiros e o Direito à Saúde. São Paulo: Hucitec, 1995.

; A saúde do brasileiro. São Paulo: Moderna, 1987.

; FORTES, Paulo Antônio de Carvalho. Direito Sanitário: inovação teórica e novo campo de trabalho. In: FLEURY, Sonia, (org.). Saúde e democracia: a luta do CEBES. São Paulo: Lemos Editorial, 1997, p. 187-202.

DEJOURS, Christophe. A banalização da injustiça social. Trad. Luiz Alberto Monjardim. Rio de Janeiro: Editora FGV, 1999.

Por um novo conceito de saúde. Revista Brasileira de Saúde Ocupacional, n. 54, v. 14, p. 07-11, abr./jun, 1986.

DEMO, Pedro. Cidadania tutelada e cidadania assistida. Campinas, SP: Autores Associados, 1995.

DONNANGELO, Maria Cecília Ferro. Saúde e sociedade. São Paulo: Duas Cidades, 1976.

Medicina e sociedade: o médico e seu mercado de trabalho. São Paulo: Pioneira, 1975.

DWORKIN, Ronald. Levando os direitos a sério. Trad. Nelson Boeira. São Paulo: Martins Fontes, 2002.

ELIAS, Paulo Eduardo. Estado e saúde os desafios do Brasil contemporâneo. São Paulo em perspectiva, São Paulo, v. 18, n. 3, p. 41-46, 2004. 
ESCOREL, Sarah; BLOCH, Renata Arruda de. As Conferencias Nacionais de Saúde na construção do SUS. In: LIMA, Nísia Trindade; GERCHMAN, Silvia; EDLER, Flavio Coelho. (Org.). Saúde e democracia: história e perspectivas do SUS. Rio de Janeiro: Editora Fiocruz, 2005, p. 83-119.

ESCOREL, Sarah; NASCIMENTO, Dilene Raimundo do; EDLER, Flávio Coelho. As origens da Reforma Sanitária e do SUS. In: LIMA, Nísia Trindade; GERCHMAN, Silvia; EDLER, Flavio Coelho. (Org.). Saúde e democracia: história e perspectivas do SUS. Rio de Janeiro: Editora Fiocruz, 2005, p. 59-81.

ESPIELL, Hector Gros. Los derechos económicos, sociales y culturales en el sistema interamericano. San José: Libro Libre, 1986.

FAORO, Raymundo. Os donos do poder: formação do patronato político brasileiro. v.2, 5. ed., Porto Alegre: Editora Globo, 1979.

FARIA, José Eduardo. O Direito na Economia Globalizada. 1.ed. 3. tiragem. São Paulo: Malheiros, 2002.

FARLEY, John. To cast out the disease: a history of the International Health Division of the Rockefeller Foundation (1913-1951). New York: Oxford University Press, 2004.

FAUSTO, Boris. História concisa do Brasil. São Paulo: Edusp, Imprensa Oficial do Estado, 2002.

FERNANDES, Tania. Vacina antivariólica: seu primeiro século no Brasil (da vacina jenneriana à animal). História, Ciência, Saúde-Manguinhos, Rio de Janeiro, v. 6, n. 1, mar./jun., 1999. Disponível em $<$ http://www.scielo.br/scielo.php?pid=S010459701999000200002\&script=sci_arttext\#nota4>. Acesso em 24 dez. 2006.

FERRAZ JR., Tercio Sampaio. Introdução ao estudo de direito: técnica, decisão, dominação. 2. ed. São Paulo: Atlas, 1994.

FIOCRUZ. Laboratório de Higiene da Faculdade de Medicina do Rio de Janeiro.

Dicionário Histórico-Biográfico das Ciências da Saúde no Brasil (1832-1930).

2006. Online. Disponível em:

$<$ http://www.dichistoriasaude.coc.fiocruz.br/iah/P/verbetes/labhigrj.htm>. Acesso em: 26 
dez. 2006.

FOERSTER, Heinz von. Observing Systems. California: Intersystems, 1984.

On constructing a reality. In: Preiser, Wolfgang F.E. (Ed.). Enviromental design research, 1973, p. 35-46.

FOUCAULT, Michel. Arqueologia do Saber. 5. ed. Rio de Janeiro: Forense Universitária, 1997.

Microfísica do Poder. Trad. Roberto Machado. Rio de Janeiro: Edições Graal. 1979.

A crise atual da Medicina. Texto de Apoio PESESPEPPE. Rio de Janeiro: Escola de Saúde Pública, 1974.

Les mots et les choses. Une archéologie des Sciences Humaines. Paris: Gallimard, 1966.

GERSCHMAN, Sílvia; VIANA, Ana Luíza D’Ávila. Descentralização e desigualdades regionais em tempos de hegemonia liberal. In: LIMA, Nísia Trindade; GERCHMAN, Silvia; EDLER, Flavio Coelho. (Org.). Saúde e democracia: história e perspectivas do SUS. Rio de Janeiro: Editora Fiocruz, 2005, p. 307-351.

GRAU, Eros Roberto. A ordem econômica na Constituição de 1988 (interpretação e crítica). 8. ed. São Paulo: Malheiros, 2003.

O direito posto e o direito pressuposto. 4. ed. São Paulo: Malheiros, 2002.

GUILLOD, Olivier; SPRUMONT, Dominique. Le droit a la Santé: un droit en émergence. In: ZEN-RUFFINEN, P. De la Constitution: études en l'honneur de Jean-François Aubert. Berne: Helbing \& Lichtenhahn, 1996.

HABERMAS, Jürgen. Teoría de la acción comunicativa, T.1: racionalidad de la acción y racionalización social. Trad. Manuel Jiménez Redondo. Madrid: Taurus, 2001.

O discurso filosófico da modernidade. Trad. Ana Maria Bernardo et al. 2. ed. Lisboa: Dom Quixote, 1998. 
- Direito e Democracia: entre facticidade e validade. Trad. Flávio Bueno Siebeneichler. Rio de Janeiro: Tempo Brasileiro, 1997, 2v.

. Direito e Moral. Trad. Sandra Lippert, Lisboa: Instituto Piaget, 1992.

HART, Herbert Lionel Adolphus. O conceito de direito. 3. ed. Lisboa: Fundação Calouste Gulbenkian, 2001.

HERSCHMANN, Micael M.; PEREIRA, Carlos Alberto Messeder. O imaginário moderno no Brasil. In: (Org.). A invenção do Brasil Moderno: Medicina, educação e engenharia nos anos 20 - 30. Rio de Janeiro: Editora Rocco Ltda, 1994, p. 0942.

HESPANHA, Benedito. A autopoiese na construção do jurídico e do político de um sistema constitucional. Revista dos Tribunais, São Paulo, ano 7, n. 27, p. 59-78, abr.jun. 1999.

HESSE, Konrad. A força normativa da Constituição (Die normative Kraft der Verfassung). Trad. Gilmar Ferreira Mendes. Porto Alegre: Sergio Antonio Fabris Editor, 1991.

HOCHMAN, Gilberto. A era do saneamento - as bases da política de Saúde Pública no Brasil. São Paulo: Hucitec ANPOCS, 1998.

HOUAISS. Dicionário Houaiss da língua portuguesa. UOL - Universo Online. 2005. Disponível em <http://houaiss.uol.com.br/busca.jhtm>. Acesso em: 27 jan. 2006.

HUBERMAN, Leo. História da riqueza do homem. 19.ed. Rio de Janeiro: Zahar, 1983.

JAGUARIBE, Helio. Um estudo crítico da História. Trad. Sérgio Bath, 2. ed. São Paulo: Paz e Terra, 2001, 2v.

JENSEN, Carl. 20 years of censored news. Carl Jensen and Project Censored. New York: Seven stories Press, 1997.

JONES, Kathleen. The making of social policy in Britain 1830-1990. London: Athlone, 1991. 
KELSEN, Hans. Teoria Pura do Direito. Trad. João Baptista Machado. 6. ed., São Paulo: Martins Fontes, 1998.

KILLIAN, Frederich W. Gestalt, movimento da —. In: Dicionário de sociologia. 1. ed., $6^{\mathrm{a}}$ impressão. Porto Alegre: Editora Globo, 1974, p. 150-151.

KROPF, Simone Petraglia; LIMA, Nísia Trindade. Os valores e a prática institucional da ciência: as concepções de Robert Merton e Thomas Kuhn. Hist. cienc. saudeManguinhos., Rio de Janeiro, v. 5, n. 3, 1999. Disponível em: $<\mathrm{http}: / /$ www.scielo.br/scielo.php?script=sci_arttext\&pid=S010459701999000100002\&lng-pt\&nrm=iso $>$. Acesso em: 18 jan. 2007.

KÜHN, Rolf. Luhmann. In: HUISMAN, Denis (Coord.). Dicionário dos filósofos. São Paulo: Martins Fontes, 2001, p. 621-623.

KUHN, Thomas S. Estrutura das revoluções científicas. 3. ed., São Paulo: Perspectiva, 1989.

LIMA, Ana Luce Girão Soares de; PINTO, Maria Marta Saavedra. Fontes para a história dos 50 anos do Ministério da Saúde. História, Ciência, Saúde-Manguinhos, Rio de Janeiro, v. 10, n. 3, p. 1037-1051, 2003. Disponível em: $<$ http://www.scielo.br/scielo.php?script=sci_arttext\&pid=S0104$59702003000300012 \& \operatorname{lng}=$ pt\&nm=iso $>$. Acesso em: 03 jan. 2007.

LIMA, Nísia Trindade; FONSECA, Cristina M. O.; HOCHMAN, Gilberto. A saúde na construção do Estado Nacional no Brasil: Reforma Sanitária em perspectiva histórica. In: LIMA, Nísia Trindade; GERCHMAN, Silvia; EDLER, Flavio Coelho. (Org.). Saúde e democracia: história e perspectivas do SUS. Rio de Janeiro: Editora Fiocruz, 2005, p. 27-58.

LÖWY, Michael. As aventuras de Karl Marx contra o Barão de Münchhausen marxismo e positivismo na sociologia do conhecimento. 8. ed. São Paulo: Cortez, 2003.

LUHMANN, Niklas. Confianza. Trad. Amada Flores. 1. reimpresión. Rubí (Barcelona): Anthropos Editorial; México: Universidad Iberoamericana; Santiago de Chile: Instituto de Sociología. Pontificia Universidad Católica de Chile, 2005.

La Realidad de los Médios de Masas. Barcelona: Anthropos Editorial; México: 
Universidad Iberoamericana, 2000.

. Sistemas Sociales: lineamientos para una teoría general. Trad. Silvia Pappe y Brunhilde Erker; coord. Javier Torres Nafarrate. Rubí (Barcelona): Anthropos; México: Universidad Iberoamericana; Santafé de Bogotá: CEJA, Pontifícia Universidad Javeriana, 1998.

Introducción a la Teoría de Sistemas. Lecciones Publicadas por Javier Torres Nafarrate. Barcelona: Anthropos; México DF: Universidad Iberoamericana; Guadalajara: ITESO, 1996.

Social Systems. Stanford, California: Stanford University Press, 1995.

Risk: a sociological theory. Translated by Rhodes Barrett. New York: Aldine de Gruyter, 1993.

- Operational closure and structural coupling: the differentiation of the legal system. Cardozo Law Review, v. 13, n. 5, p. 1419-1441, march, 1992.

. A posição dos tribunais no sistema jurídico. Revista da Associação dos Juízes do Rio Grande do Sul. Porto Alegre, n. 49, p. 149-168, jul. 1990a.

. Essays on Self-Reference. New York: Columbia University Press, 1990 b.

. Law as a social system. Northwestern University Law Review, v. 83, n. 1-2, p. 136-150, 1989a.

. Le droit comme système social. Droit et Societ, Paris, n. 11-12. p. 53-66. 1989b.

. Sociologia do Direito II. Trad. Gustavo Bayer. Rio de Janeiro: Edições Tempo Brasileiro, 1985.

. Sociologia do Direito I. Trad. Gustavo Bayer. Rio de Janeiro: Edições Tempo Brasileiro, 1983.

; FUCHS, Stephan. Tautology and Paradox in the Self-Descriptions of Modern Society. Sociological Theory, v. 6, n. 1, p. 21-37, 1988. Disponível em: $>$ http:/links.jstor.org/sici?sici=0735-2751\%28198821\%296\%3A1\%3C21\%3ATAPITS\%3E2.0.CO\%3B2-K>. 
Acesso em: 17 nov. 2006.

MARQUES NETO, Floriano Peixoto de Azevedo. A Nova Regulação Estatal e as Agências Independentes. In: SUNDFELD, Carlos Ari (Coord.). Direito Administrativo Econômico. São Paulo: Malheiros, 2. tiragem, 2002, p. 73-98.

MATURANA, Humberto R. II. Fundamentos biológicos del conocimiento. In: La realidad: ¿Objetiva o construida? México: Anthropos/Universidad Ibero Americana/Iteso, 1996.

; VARELA, Francisco J. A árvore do conhecimento: as bases biológicas da compreensão humana. 5. ed. São Paulo: Palas Athena, 2005.

; Autopoiesis ad Cognition. Dordrecht, Holanda: D. Reidel, 1980

; __ . De Máquinas e Seres Vivos: Autopoiese - a Organização do Vivo. São Paulo: Palas Athena, 1997.

MAZUREK, Per. Teoria analítica do direito. In: KAUFMANN, A.; HASSEMER, W. (Org.). Introdução à filosofia do direito e à teoria do direito contemporâneas. Lisboa: Fundação Calouste Gulbenkian, 2002a. cap. 8, p. 369-380.

. Teoria(s) marxista e socialista do direito. In: KAUFMANN, A.; HASSEMER, W. (Org.). Introdução à filosofia do direito e à teoria do direito contemporâneas. Lisboa: Fundação Calouste Gulbenkian, 2002b. cap. 11, p. 443-459.

MEINECKE, Friedrich. Die Idee der Staatsräson. München und Berlin: Verlag R. Oldenbeurg, 1924.

MENDES, Gilmar Ferreira. Direitos fundamentais: eficácia da garantias constitucionais das relações privadas - análise da jurisprudência da corte constitucional alemão. In: ANPPREV. Introdução ao direito previdenciário. São Paulo: LTr, 1998, p. 237-253.

MERHY, Emerson Elias. A saúde pública como política: um estudo de formuladores de políticas. 2. ed. São Paulo: Hucitec, 2006.

MERINO, Lucyla Tellez. Direitos humanos e direito do trabalho: enfoques humanistas 
na proteção dos direitos sociais. 2006. Dissertação (Mestrado em Direito) — Faculdade de Direito da Universidade de São Paulo, São Paulo.

MITCHELL, Peter R.; SCHOEFFEL, John (Org.). Para entender o poder: o melhor de Noam Chomsky. Trad. Eduardo Francisco Alves. Rio de Janeiro: Bertrand Brasil, 2005.

NAVES, Márcio Bilharinho. Marxismo e direito — um estudo sobre Pachukanis. São Paulo: Boitempo, 2000.

NEVES, Ilídio das. Direito da segurança social: princípios fundamentais numa análise prospectiva. Coimbra: Coimbra Editora, 1996.

NEVES, Rômulo Figueira. Acoplamento estrutural, fechamento operacional e processos sobrecomunicativos na teoria dos sistemas sociais de Niklas Luhmann. 2005. Dissertação (Mestrado em Sociologia) — Universidade de São Paulo, São Paulo.

OLIVEIRA, Moacyr Velloso Cardoso de. Previdência social. Rio de Janeiro: Freitas Bastos, 1987.

PAIM, Jairnilson Silva. O pensamento do movimento sanitário: impasses e contradições atuais no marco da relação público-privado do SUS. In: HEIMANN, Luiza Sterman; IBANHES, Lauro César; BARBOZA, Renato. (Org.). O público e o privado na saúde. São Paulo: Hucitec, Opas, IDRC, 2005.

. Bases conceituais da Reforma Sanitária brasileira. In: FLEURY, Sonia (Org.). Saúde e democracia: a luta dos CEBES. São Paulo: Lemos Editorial, 1997, p. 11-24.

PARSONS, Talcott. O Sistema das Sociedades Modernas. Trad. de Dante Moreira Leite. São Paulo: Livraria Pioneira Editora, 1974.

.El sistema social. Madrid: Revista de Occidente, 1966.

PASUKANIS, Eugeny Bronilsanovich. A teoria geral do direito e marxismo. Trad. Paulo Bessa. Rio de Janeiro: Renovar, 1989.

PIMENTA, Tânia Salgado. Transformações no exercício das artes de curar no Rio de Janeiro durante a primeira metade do Oitocentos. História, Ciência, SaúdeManguinhos., Rio de Janeiro, v. 11, (suplemento 1): p. 67-92, 2004. 
PIOVESAN, Flávia. A proteção dos direitos sociais nos planos interno e internacional. In: CORREIA, Marcus Orione Gonçalves; CORREIA, Érica Paula Barcha. (Coord.) Direito Previdenciário e Constituição - Obra em homenagem ao professor Wladimir Novaes Martinez. São Paulo: LTr, 2004, p. 13-24.

. Globalização econômica, integração regional e direitos humanos. In:

(Coord.). Direitos humanos, globalização econômica e integração regional: desafios do direito constitucional internacional. São Paulo: Max Limonad, 2002, p. 39-75.

REVEL, Judith. Michel Foucault: conceitos essenciais. São Carlos: Claraluz, 2002

REZENDE, Joffre M. de. Os construtores da moderna medicina. In: Tópicos selecionados de história da medicina e linguagem médica - artigos, notas e comentários. Caminhos da medicina. [S.1.], 18 set. 2003. Disponível em $<$ http://usuarios.cultura.com.br/jmrezende/construtores.htm>. Acesso em: 09 jan. 2006.

A neurologia na obra de Galeno. In: Tópicos selecionados de história da medicina e linguagem médica - artigos, notas e comentários. Caminhos da medicina. [S.1.], maio 2002a. Disponível em: $<$ http://usuarios.cultura.com.br/jmrezende/neurologia3.htm>. Acesso em: 26 dez. 2005.

. A vida breve de alguns personagens famosos da história da medicina. In: Tópicos selecionados de história da medicina e linguagem médica - artigos, notas e comentários. Caminhos da medicina. [S.1.], atualizado em 01 jan. 2002b. Disponível em: $<$ http://usuarios.cultura.com.br/jmrezende/vidabreve.htm>. Acesso em: 09 jan. 2006.

ROCHA, Julio César de Sá da. Direito da saúde: direito sanitário na perspectiva dos interesses difusos e coletivos. São Paulo: LTr, 1999.

ROCHA, Leonel Severo. Teoria do Direito e Transnacionalização. Revista de Direito UNISC, n. 9-10, jan./dez. 1988.

RODRÍGUEZ, Dário Mansilla; TORRES, Javier Nafarrate. Autopoiesis, la unidad de una diferencia: Luhmann y Maturana. Sociologias, Porto Alegre, n. 9, p. 106-140, jan./jun. 2003. Disponível em: <http://www.scielo.br/scielo.php?script=sci_arttext\&pid=S1517$45222003000100005 \& \operatorname{lng}=$ pt\&nrm=iso $>$. Acesso em: 10 nov. 2006. 
RODRIGUEZ NETO, Eleutério. Saúde: promessas e limites da Constituição. Rio de Janeiro: Fiocruz, 2003.

ROSEN, George. Uma história da saúde pública. Trad. Marcos Fernando da Silva Moreira. São Paulo: Hucitec: Editora da Universidade Estadual Paulista; Rio de Janeiro: Associação Brasileira de Pós-Graduação em Saúde Coletiva, 1994.

Da polícia médica à medicina social: ensaios sobre a história da assistência médica. Trad. Ângela Loureiro de Souza. Rio de Janeiro: Edições Graal, 1979.

ROZENFELD, Suely (Org.). Fundamentos da vigilância sanitária. Rio de Janeiro: Editora Fiocruz, 2000.

SANTOS, Amauri Moraes dos. Desafios e oportunidades do farmacêutico na promoção da saúde. Infarma, v. 17, n. 5-6, p. 73-78, 2005. Disponível em: $<$ http://www.cff.org.br/revistas/49/73\%20a\%2078.pdf>. Acesso em 30 dez. 2006.

SCHERER, Magda Duarte dos Anjos; MARINO, Selma Regina Andrade; RAMOS, Flávia Regina Souza. Rupturas e resoluções no modelo de atenção à saúde: reflexões sobre a estratégia saúde da família com base nas categorias kuhnianas. Interface - Comunicação, Saúde, Educação, v. 9, n. 16, p. 53-66, set.2004/fev.2005. Disponível em $<$ http://www.scielo.br/pdf/icse/v9n16/v9n16a05.pdf>. Acesso em 07 jan. 2007.

SCHWARTZ, Germano. O Tratamento Jurídico do Risco no Direito à Saúde. Porto Alegre: Livraria do Advogado Editora, 2004.

SILVA, Paulo Thadeu Gomes da. "Constituição". In: DICIONÁRIO DE DIREITOS HUMANOS, Brasília: Escola Superior do Ministério Público da União. Disponível em: $<\mathrm{http} / / /$ www.esmpu.gov.br/dicionario/tiki-index.php?page=Constitui $\% \mathrm{C} 3 \% \mathrm{~A} 7 \% \mathrm{C} 3 \% \mathrm{~A} 3 \mathrm{o}>$. Última modificação em: 06 out. 2006. Acesso em 11 jan. 2007.

SINGER, Paul; CAMPOS, Oswaldo; OLIVEIRA, Elizabeth Machado de. Prevenir e curar: o controle social através dos serviços de saúde. Rio de Janeiro: ForenseUniversitária, 1981.

SMITH, Mapheus. Gestalt. In: Dicionário de sociologia. 1. ed., $6^{a}$ impressão. Porto Alegre: Editora Globo, 1974, p. 150-151. 
SPENCER-BROWN, George. Laws of Form. New York: Dutton, 1979.

STOTZ, Eduardo Navarro; ARAÚJO, José Wellington Gomes. Promoção da saúde e Cultura política: a reconstrução do consenso. Saúde e Sociedade. V.13, n.2, p. 05-19, maio/ago. 2004.

TELAROLli JUNIOR, Rodolpho. Poder e Saúde: as epidemias e a formação dos serviços de saúde em São Paulo. São Paulo: Editora UNESP, 1996.

TEUBNER, Gunther. Evolution of Autopoiético Law. In: (Ed.) Autopoietic Law: a new approach to law and society. Berlin: New York: Walter de Gruyter, 1988.

O direito como sistema autopoiético. Lisboa: Fundação Calouste Gulbenkian, 1989a.

. How the Law Thinks: Toward a Constructivist Epistemology of Law. Law \& Society Review, Denver, v. 23, n. 5, p. 727-757, 1989b.

TORRES, Javier Nafarrate. Nota a la versión en lengua castellana. In: LUHMANN, Niklas. Sistemas Sociales: lineamientos para una teoría general. Trad. Silvia Pappe y Brunhilde Erker; coord. Javier Torres Nafarrate. Rubí (Barcelona): Anthropos; México: Universidad Iberoamericana; Santafé de Bogotá: CEJA, Pontifícia Universidad Javeriana, 1998, p. 17-25.

TOURAINE, Alain. Palavra e sangue: política e sociedade na América Latina. Trad. Iraci D. Poleti. São Paulo: trajetória Cultural; Campinas, SP: Editora da UNICAMP, 1989.

VASQUES, Denise Cristina. Comentários ao artigo $5^{\circ}$ da Lei Complementar n. 109/01. In: CORREIA, Marcus Orione Gonçalves; VILLELA, José Corrêa. (Coord.) Previdência privada: doutrina e comentários à Lei Complementar n. 109/01. São Paulo: LTr, 2004, p. 151-159.

VILLAS BÔAS FILHO, Orlando. O direito na teoria dos sistemas de Niklas Luhmann. São Paulo: Max Limonad, 2006a.

. Uma abordagem sistêmica do direito no contexto da modernidade brasileira.

2006b. Tese (Doutorado em Direito) - Faculdade de Direito da Universidade de São Paulo, São Paulo. 
VILLELA, José Corrêa. Alguns pontos da "privatização" da previdência e da Lei Complementar n. 108/01. In: CORREIA, Marcus Orione Gonçalves; VILLELA, José Corrêa. (Coord.) Previdência privada: doutrina e comentários à Lei Complementar $n$. 109/01. São Paulo: LTr, 2004, p. 21-53.

. Conceito jurídico de pobreza na construção da Segurança Social. 2006. Tese (Doutorado em Direito) — Faculdade de Direito da Universidade de São Paulo, São Paulo. WEBER, Max. Metodologia das ciências sociais - parte 1. Trad. Augustin Wernet. 3. ed. São Paulo: Cortez; Campinas: Editora da Universidade Estadual, 1999.

WIKIPÉDIA, A Enciclopédia Livre. [S.1], modificada pela última vez em 19 dez. 2005. Disponível em <http://pt.wikipedia.org/wiki/Istambul>. Acesso em: 26 dez. 2005.

- [S.1], modificada pela última vez em 22 nov. 2006. Disponível em $<$ http://en.wikipedia.org/wiki/Aneurin_Bevan>. Acesso em 13 dez. 2006.

WHO - World Health Organization. Constitution. 1989. Disponível em <http://whqlibdoc.who.int/publications/1989/924160252X.pdf >. Acesso em 15 jan. 2007.

ZANIRATO, Silvia Helena. O Descanso do Guerreiro - Um estudo sobre a instituição da Previdência Social no Brasil. Maringá: Eduem, 2003. 